FHWA/IN/JTRP-2009/2

Final Report

MITIGATING THE EXPANSIVE BEHAVIOR OF CHEMICALLY TREATED SOILS

Sochan Jung

Maria Caterina Santagata

April 2009 
Final Report

FHWA/IN/JTRP-2009/02

\title{
MITIGATING THE EXPANSIVE BEHAVIOR OF CHEMICALLY TREATED SOILS
}

\author{
by \\ Sochan Jung \\ Graduate Research Assistant \\ and \\ Maria Caterina Santagata \\ Associate Professor \\ School of Civil Engineering \\ Purdue University \\ Joint Transportation Research Program \\ Project No. -36-36NN \\ File No. 6-14-40 \\ SPR-2636 \\ Conducted in Cooperation with the \\ Indiana Department of Transportation \\ and the U.S. Department of Transportation \\ Federal Highway Administration
}

The contents of this report reflect the views of the authors who are responsible for the facts and the accuracy of the data presented herein. The contents do not necessarily reflect the official views or policies of the Indiana Department of Transportation or the Federal Highway Administration at the time of publication. This report does not constitute a standard, specification, or regulation.

School of Civil Engineering

Purdue University

April 2009 
TECHNICAL REPORT STANDARD TITLE PAGE

\begin{tabular}{|c|c|c|c|c|}
\hline $\begin{array}{l}\text { 1. Report No. } \\
\text { FHWA/IN/JTRP-2009/2 }\end{array}$ & \multicolumn{2}{|c|}{ 2. Government Accession No. } & \multicolumn{2}{|c|}{ 3. Recipient's Catalog No. } \\
\hline \multirow{2}{*}{\multicolumn{3}{|c|}{$\begin{array}{l}\text { 4. Title and Subtitle } \\
\text { Mitigating the Expansive Behavior of Chemically Treated Soils }\end{array}$}} & \multicolumn{2}{|l|}{$\begin{array}{l}\text { 5. } \quad \text { Report Date } \\
\text { April } 2009\end{array}$} \\
\hline & & & \multicolumn{2}{|c|}{ 6. Performing Organization Code } \\
\hline \multicolumn{3}{|c|}{$\begin{array}{l}\text { 7. Author(s) } \\
\text { Sochan Jung and Maria Caterina Santagata }\end{array}$} & \multicolumn{2}{|c|}{$\begin{array}{l}\text { 8. Performing Organization Report No. } \\
\text { FHWA/IN/JTRP-2009/2 }\end{array}$} \\
\hline \multirow{2}{*}{\multicolumn{3}{|c|}{$\begin{array}{l}\text { 9. Performing Organization Name and Address } \\
\text { Joint Transportation Research Program } \\
550 \text { Stadium Mall Drive } \\
\text { Purdue University } \\
\text { West Lafayette, IN 47907-2051 }\end{array}$}} & \multicolumn{2}{|l|}{ 10. Work Unit No. } \\
\hline & & & \multicolumn{2}{|c|}{$\begin{array}{l}\text { 11. Contract or Grant No. } \\
\text { SPR-2636 }\end{array}$} \\
\hline \multicolumn{3}{|c|}{$\begin{array}{l}\text { 12. Sponsoring Agency Name and Address } \\
\text { Indiana Department of Transportation } \\
\text { State Office Building } \\
100 \text { North Senate Avenue } \\
\text { Indianapolis, IN } 46204\end{array}$} & \multicolumn{2}{|c|}{$\begin{array}{l}\text { 13. Type of Report and Period Covered } \\
\text { Final Report }\end{array}$} \\
\hline \multicolumn{5}{|c|}{$\begin{array}{l}\text { 15. Supplementary Notes } \\
\text { Prepared in cooperation with the Indiana Department of Transportation and Federal Highway Administration. }\end{array}$} \\
\hline \multicolumn{5}{|c|}{ 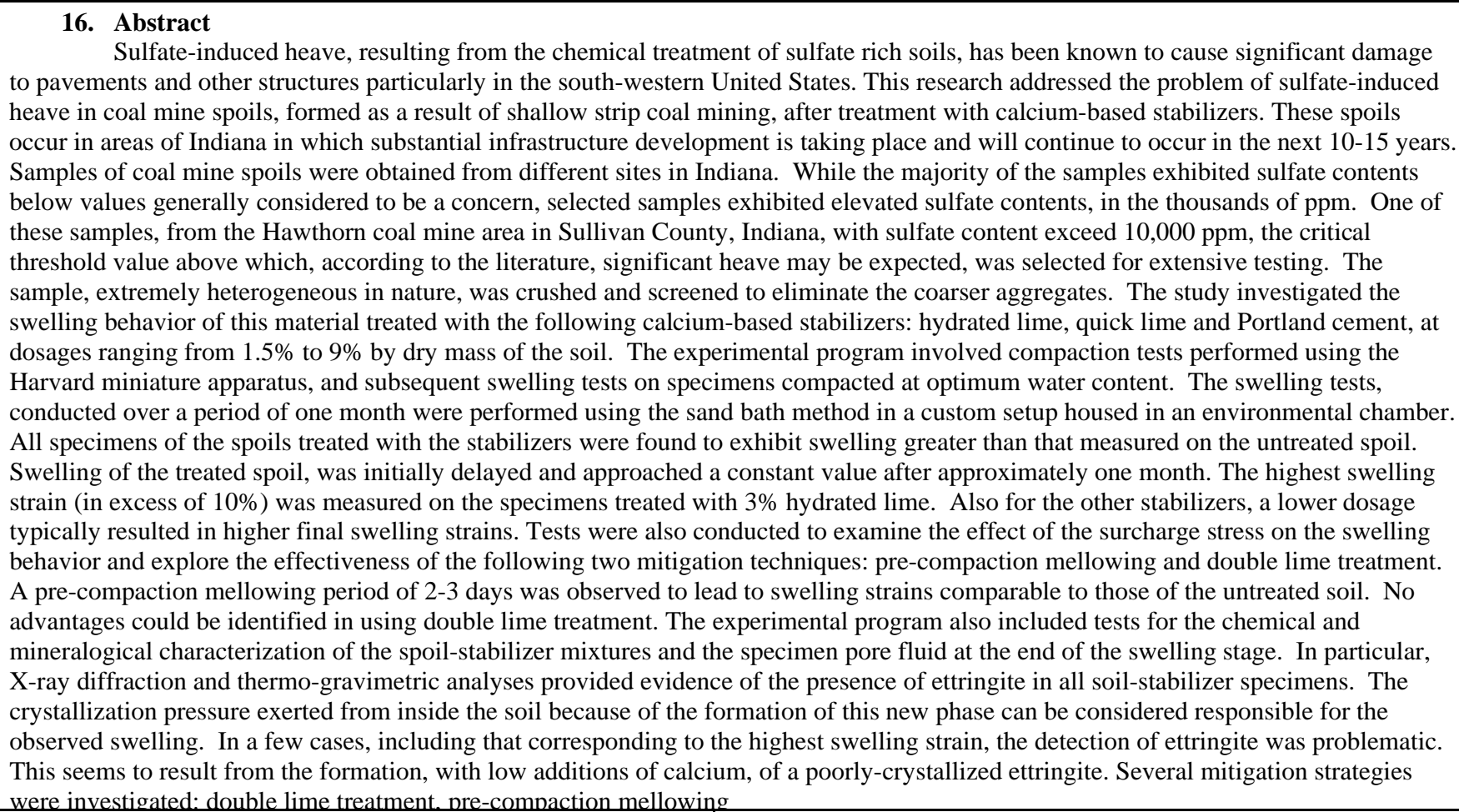 } \\
\hline \multicolumn{2}{|c|}{$\begin{array}{l}\text { 17. Key Words } \\
\text { sulfate induced heave; coal mine spoils; lime treatment; cement } \\
\text { treatment; swelling; ettringite }\end{array}$} & \multicolumn{3}{|c|}{$\begin{array}{l}\text { 18. Distribution Statement } \\
\text { No restrictions. This document is available to the public through the } \\
\text { National Technical Information Service, Springfield, VA } 22161\end{array}$} \\
\hline 19. Security Classif. (of this report) & 20. Security Classif. & is page) & 21. No. of Pages & 22. Price \\
\hline
\end{tabular}




\section{TABLE OF CONTENTS}

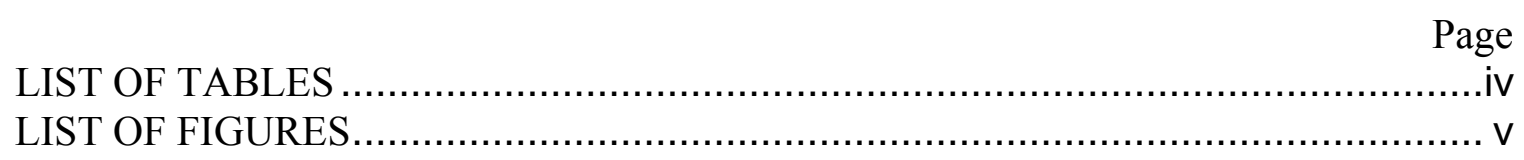

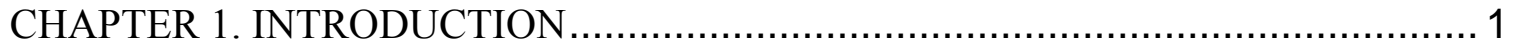

1.1. Introduction and Problem Statement .............................................................. 1

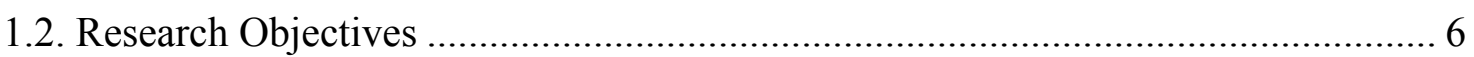

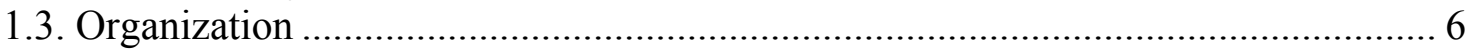

CHAPTER 2. BACKGROUND …………… 9

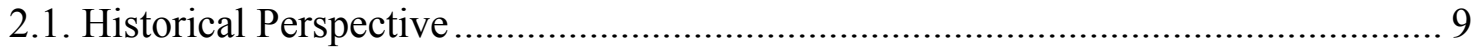

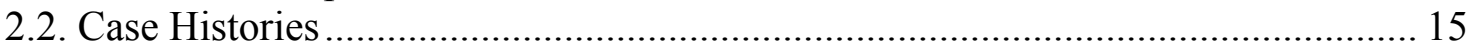

2.2.1. Stewart Avenue Projects .......................................................................... 15

2.2.2. US Army Corps of Engineers Projects......................................................... 17

2.2.3. Texas DOT Projects ……………………............................................. 18

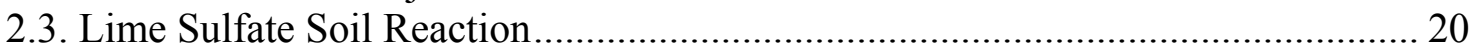

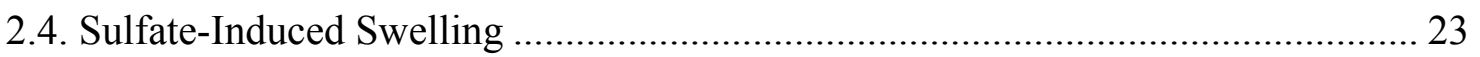

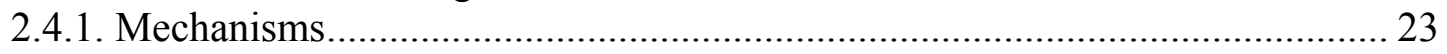

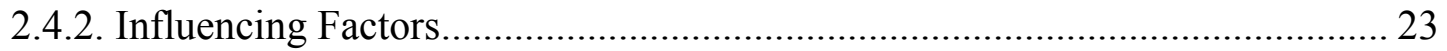

2.4.3. Geochemistry of Ettringite and Thaumasite ................................................... 25

2.5. Methods for Assessing Susceptibility to Sulfate Induced Swelling ....................... 26

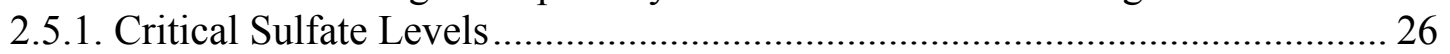

2.5.2. Thermodynamic Geochemical Model....................................................... 28

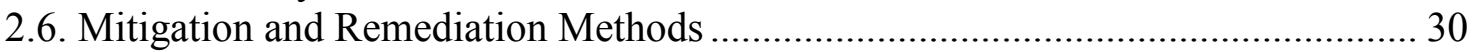

CHAPTER 3. MATERIALS AND METHODS ……........................................ 33

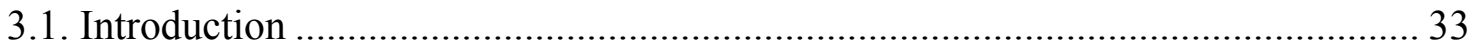

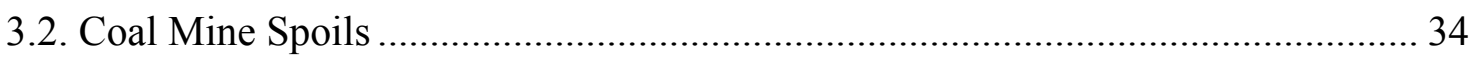

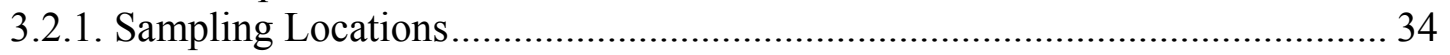

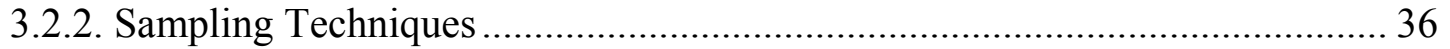

3.2.3. Characteristics (Geological Description) …………..................................... 38

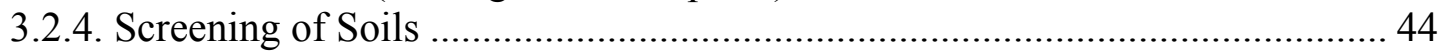

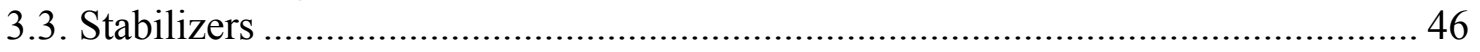

3.3.1. Hydrated Lime and Quick Lime ……………….......................................... 46

3.3.2. Portland Cement ......................................................................................... 48

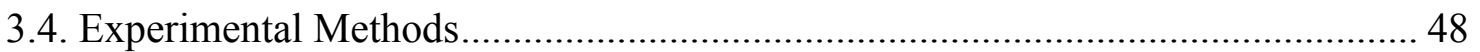

3.4.1. Existing Methods for Sulfate Content Determination..................................... 48

3.4.2. Determination of Sulfate Content of Coal Mine Spoils .................................... 51 


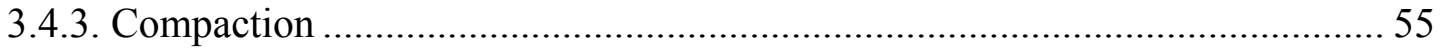

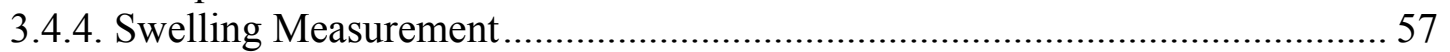

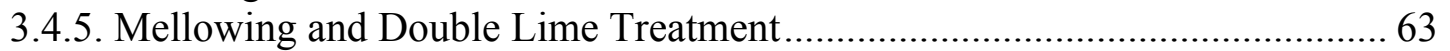

3.4.6. Chemical/Mineralogical Tests ...................................................................... 65

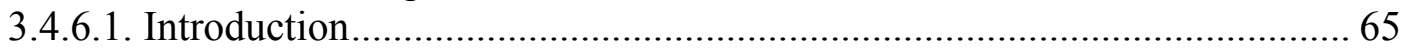

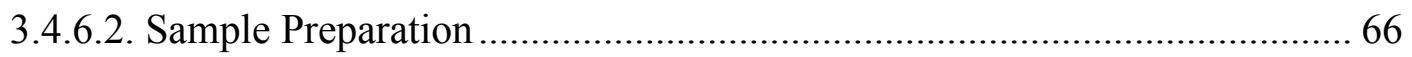

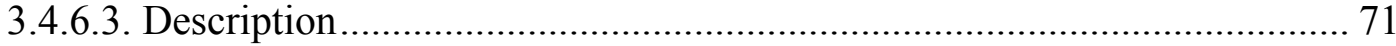

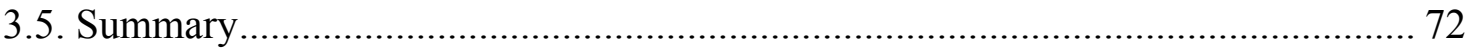

CHAPTER 4. EXPERIMENTAL RESULTS ……....................................... 74

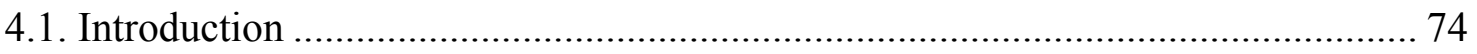

4.2. Physical and Chemical Characteristics............................................................... 76

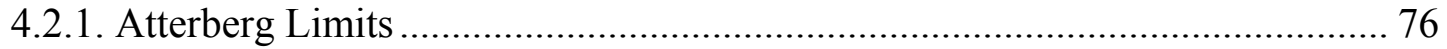

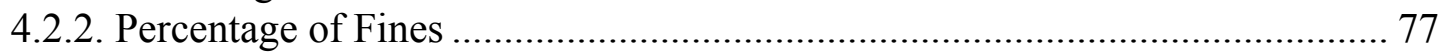

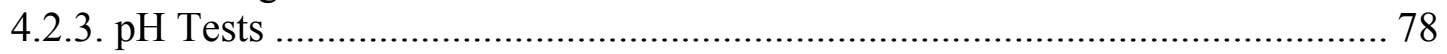

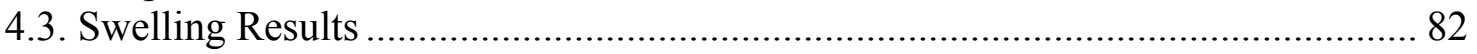

4.3.1. Reference Behavior for "Non-problematic Soil" ........................................... 82

4.3.2. Compaction Behavior of Compacted Coal Mine Spoil-Stabilizer Mixtures ... 85

4.3.3. Swelling Behavior of Spoil-Stabilizer Mixtures ............................................. 89

4.3.4. Additional Tests on Effect of Stabilizer Dosage .......................................... 102

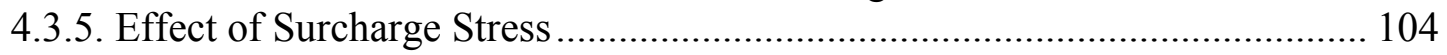

4.3.6. Comparison to Swelling Data from the Literature........................................ 105

4.3.7. Effectiveness of Pre-compaction Mellowing ................................................ 108

4.3.8. Effectiveness of Double Lime Treatment ..................................................... 114

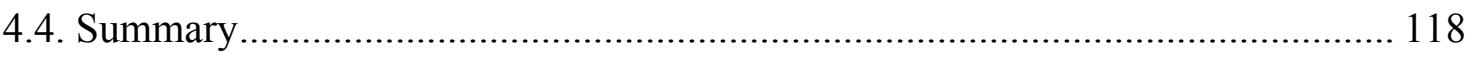

CHAPTER 5. MINERALOGICAL CHARACTERISTICS OF SOIL-STABILIZER MIXTURES AND INTERPRETATION OF SWELLING MECHANISM ................ 121

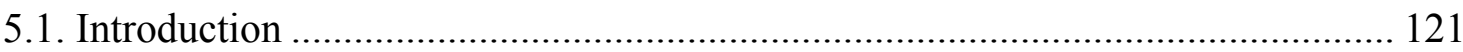

5.2. Chemical and Mineralogical Characteristics .............................................. 122

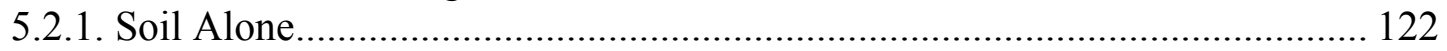

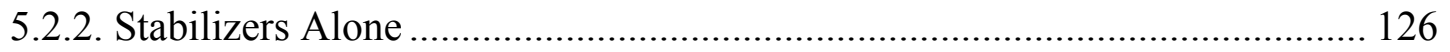

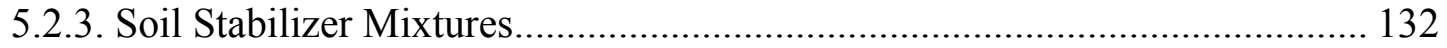

5.2.3.1. Soil mixed with hydrated lime (HL) ...................................................... 132

5.2.3.2. Soil mixed with analytical lime (AL), quick lime (QL) and Portland

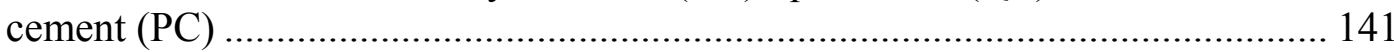

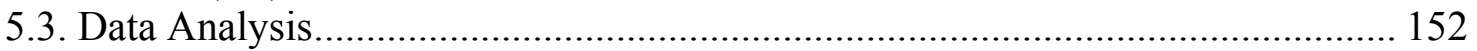

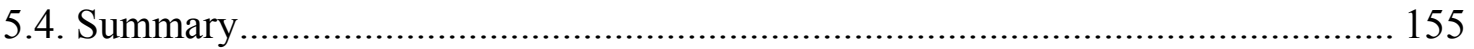

CHAPTER 6. CONCLUSIONS AND RECOMMENDATIONS …........................ 158

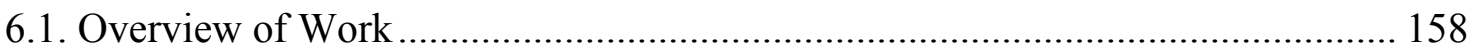

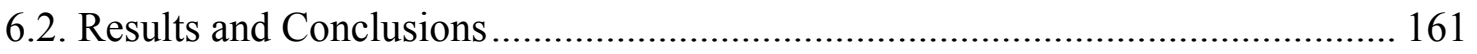

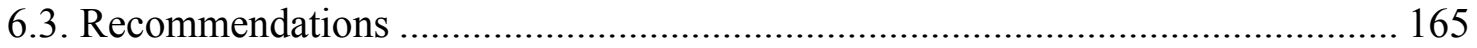

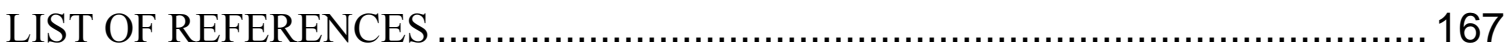

Appendix A. ION CHROMATOGRAPHY AND INDUCTIVELY COUPLED

PLASMA TESTS WITH SOIL STABILIZER MIXTURES..................................... 171 


\section{LIST OF TABLES}

Table $\quad$ Page

Table 2.1 Sulfate thresholds reported in case studies (Puppala et al. 2002) ..................... 27

Table 2.2 Guidelines for using lime in sulfate bearing soils...................................... 28

Table 3.1 Initial sampling locations and amounts collected ......................................... 35

Table 3.2 Second sampling locations and amounts collected in Sullivan County........... 35

Table 3.3 Geological descriptions for Minne A soil..................................................... 39

Table 3.4 Geological descriptions for Minne B soil .................................................... 39

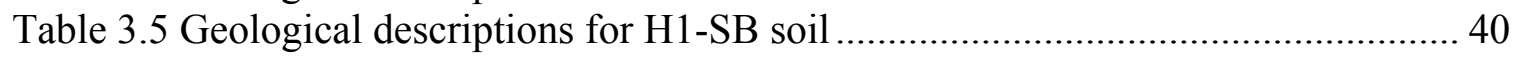

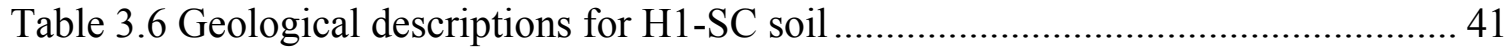

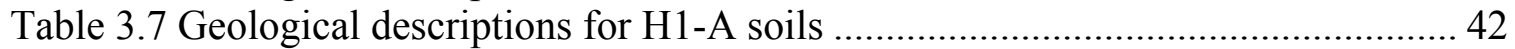

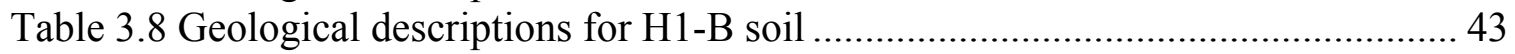

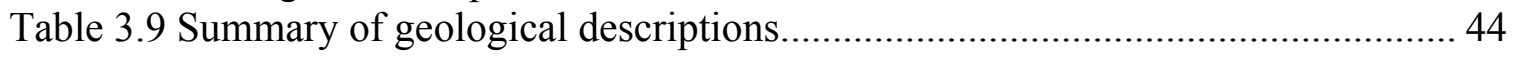

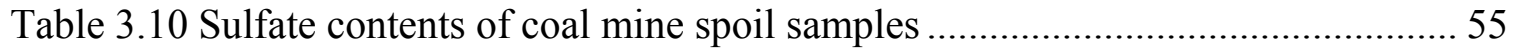

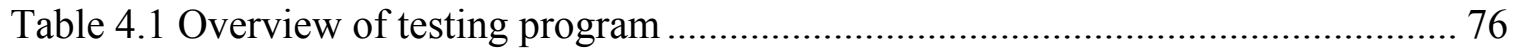

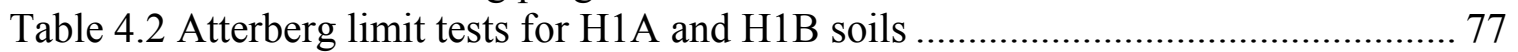

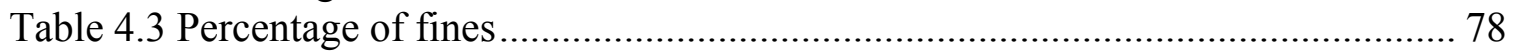

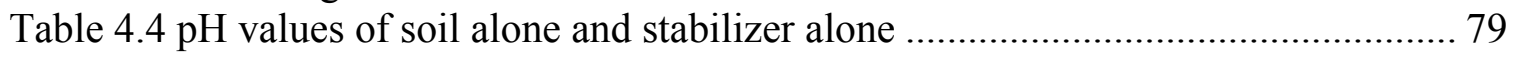

Table 4.5 Initial water content for binder treated H1A soils ....................................... 88

Table 4.6 Water content and degree of saturation of H1A specimens at OMC conditions

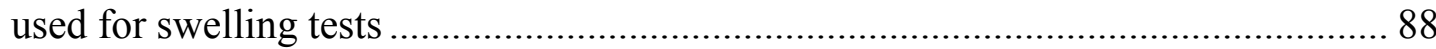

Table 4.7 Final swelling strains for untreated and treated H1A and H1B soil (data from Figures 4.7-4.8, 4.10-4.12) ........................................................................... 100

Table 4.8 Final swelling strains for H1A soil treated with hydrated lime (1.5\%-9\%) ... 103

Table 4.9 Water content at optimum for H1A soil treated with 3\% and 7\% hydrated lime

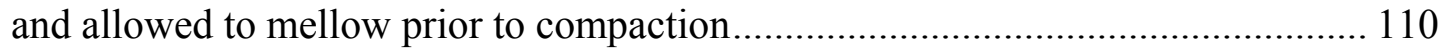

Table 4.10 Swelling strain reduction with pre-compaction mellowing ........................ 113

Table 4.11 Final swelling strains following double lime treatment and comparison to

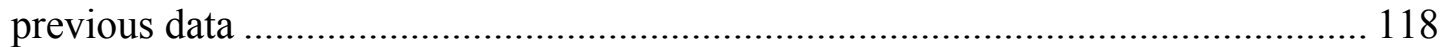

Table 5.1 Summary of soil sulfate content measurements ....................................... 125

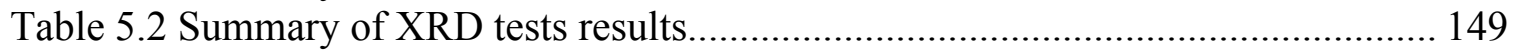

Table 5.3 Summary of TGA tests results (Continued) ............................................... 150

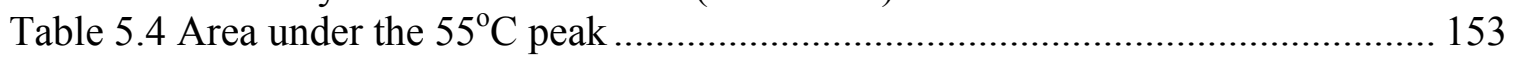

Table A.1 Charge balances from IC and ICP for hydrated lime mixtures................... 171

Table A.2 Charge balances from IC and ICP for analytical lime, quick lime and Portland

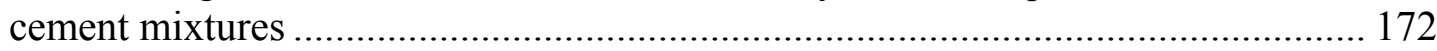




\section{LIST OF FIGURES}

Figure Page

Figure 1.1 Area of shallow coal strip mining in Sullivan County Indiana ...................... 3

Figure 1.2 Scarce vegetation of strip mine areas .................................................... 4

Figure 1.3 Map of coal mines in Indiana (Research Institute of Indiana University) ....... 5

Figure 2.1 Correlations between swelling strain and reactive alumina consumption

(Puppala et al. 2005b) ...................................................................................... 14

Figure 2.2 Thermodynamic phase diagram (a) Frisco soil (b) US 290 soil (Little et al.

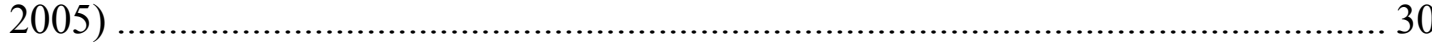

Figure 3.1 Heterogeneous nature of coal mine spoils at a) Minnehaha and b)-c) Hawthorn

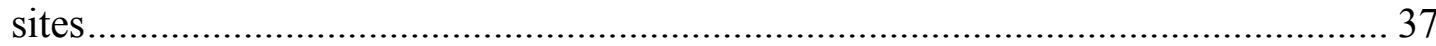

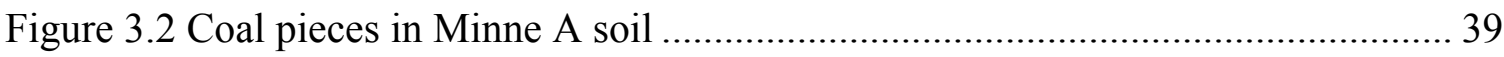

Figure 3.3 Separation of H1-SB soil into various fractions....................................... 41

Figure 3.4 Separation of H1-SC soil in various fractions ....................................... 42

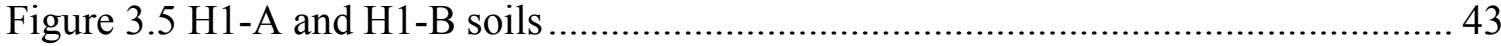

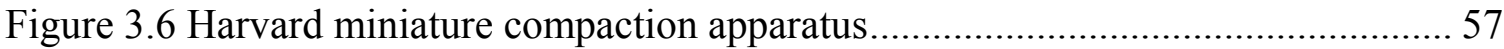

Figure 3.7 a) Specimen in sand bath b) Specimen in sand bath with surcharge............ 62

Figure 3.8 Swelling setup and additional specimens inside temperature controlled box . 63

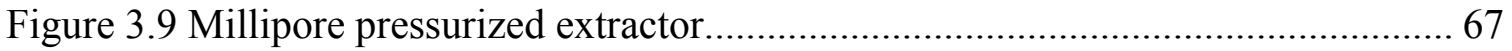

Figure 3.10 Regulator applying the pressure to the millipore pressurized extractor ........ 68

Figure 3.11 Wet sieving of the soils with methanol solution and \#325 sieve ................. 69

Figure 3.12 Aquatic vacuum pump extracting water from the soils.............................. 70

Figure $4.1 \mathrm{pH}$ fixation results of H1A soil mixed with (a) hydrated lime, (b) quick lime

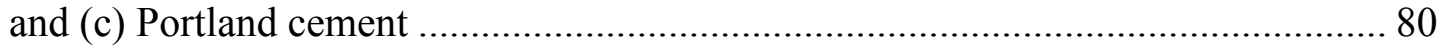

Figure 4.2 Compaction behavior of silty clay with $0 \%, 3 \%$ and $7 \%$ hydrated lime........ 83

Figure 4.3 Swelling behavior of silty clay with $0 \%, 3 \%$ and $7 \%$ lime over 1 day and 30 day periods

Figure 4.4 Compaction behavior of (a) H1B soil; and (b) H1A soil treated with hydrated

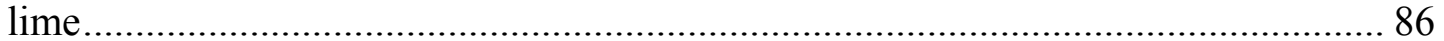

Figure 4.5 Compaction behavior of H1A soil treated with (a) analytical lime; b) quick

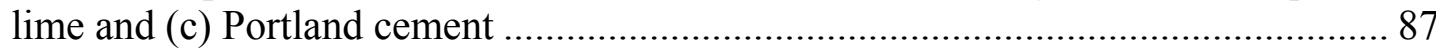

Figure 4.6 Swelling behavior of H1B soil treated with hydrated lime over a period of 130

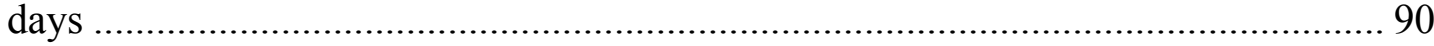

Figure 4.7 Swelling behavior of H1B soil treated with $3 \%$ and $7 \%$ hydrated lime......... 91

Figure 4.8 Swelling behavior of H1A soil treated with $3 \%$ and $7 \%$ hydrated lime ........ 95

Figure 4.9 Variability in swelling behavior of H1A soil treated with: a) $3 \%$ and b) $7 \%$

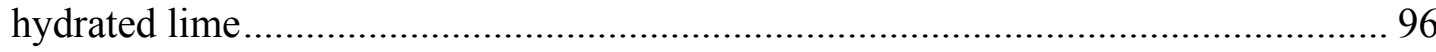


Figure 4.10 Swelling behavior of H1A soil treated with 3\% and 7\% analytical lime ..... 97

Figure 4.11 Swelling behavior of H1A soil treated with 3\% and 7\% quick lime............ 98 Figure 4.12 Swelling behavior of H1A soil treated with 3\% and 7\% Portland cement ... 99 Figure 4.13 Comparison of swelling behavior of H1A soil treated with various stabilizers

Figure 4.14 Compaction behavior of H1A soil treated with $1.5 \%-9 \%$ hydrated lime.... 102

Figure 4.15 Swelling behavior of H1 A soil treated with 1.5\%-9\% hydrated lime......... 103

Figure 4.16 Swelling behavior of H1A soil treated with 3\% hydrated lime under various surcharge stresses. 105

Figure 4.17 Swelling strains measured on two Texas soils under varying testing conditions: a) soil 1 treated with 4\% lime; b) soil 1 treated with $8 \%$ lime; c) soil 2 treated with 4\% lime; and d) soil 2 treated with $8 \%$ lime (Puppala et al. 2005b)..... Note: circles identify testing conditions close to those used in this research 107

Figure 4.18 Compaction behavior of H1A soil treated with: a) 3\% and b) 7\% hydrated lime and mellowed for 1, 2, and 3 days. 109

Figure 4.19 Swelling behavior of H1A soil treated with 3\% hydrated lime after mellowing for 1, 2 and 3 days

Figure 4.20 Swelling behavior of H1A soil treated with 7\% hydrated lime after mellowing for 1, 2 and 3 days....

Figure 4.21 UC strength of H1A soil treated with 7\% hydrated lime treated as a function of mellowing conditions and curing time (Note: $\mathrm{mw}=$ mellowing, $\mathrm{cu}=$ curing, $\mathrm{HL}=$ hydrated lime, $\mathrm{D}=$ days)

Figure 4.22 Swelling behavior for H1A soil following double treatment $(3 \%+4 \%)$ with

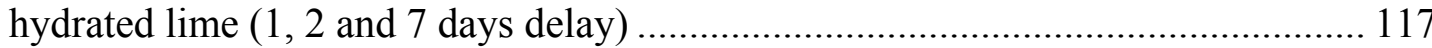

Figure 5.1 XRD pattern for soil H1A (numbers identify peaks of selected minerals) ... 123

Figure 5.2 TGA plot with DTG data for soil H1A 123

Figure 5.3 XRD pattern for hydrated lime (HL)(numbers identify peaks of selected minerals).

Figure 5.4 TGA plot with DTG data for hydrated lime (HL).

Figure 5.5 XRD pattern for analytical lime (AL) (numbers identify peaks of selected minerals)

Figure 5.6 TGA plot with DTG data for analytical lime (AL)

Figure 5.7 XRD pattern for quick lime (QL) (numbers identify peaks of selected minerals)

Figure 5.8 TGA plot with DTG data for quick lime (QL)

Figure 5.9 XRD pattern for Portland cement (PC) (numbers identify peaks of selected minerals)

Figure 5.10 XRD patterns for all stabilizers only (numbers identify peaks of selected minerals)

Figure 5.11 TGA plot illustrating the range of temperature at which calcium carbonate decomposes

Figure 5.12 XRD pattern for H1A soil treated with 1.5\% hydrated lime (numbers identify

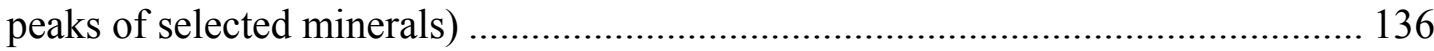

Figure 5.13 TGA plot with DTG data for H1A soil treated with 1.5\% hydrated lime... 137 
Figure 5.14 XRD pattern for H1A soil treated with 3\% hydrated lime (numbers identify peaks of selected minerals) ............................................................................ 137

Figure 5.15 TGA plot with DTG data for H1A soil treated with 3\% hydrated lime...... 138 Figure 5.16 XRD pattern for H1A soil treated with 5\% hydrated lime (numbers identify

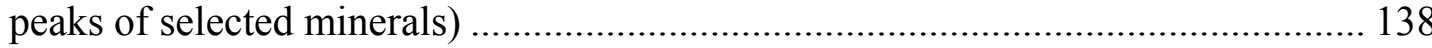

Figure 5.17 TGA plot with DTG data for H1A soil treated with 5\% hydrated lime...... 139

Figure 5.18 XRD pattern for H1A soil treated with 7\% hydrated lime (numbers identify peaks of selected minerals)

Figure 5.19 TGA plot with DTG data for H1A soil treated with 7\% hydrated lime ..... 140

Figure 5.20 XRD pattern for H1A soil treated with 9\% hydrated lime (numbers identify

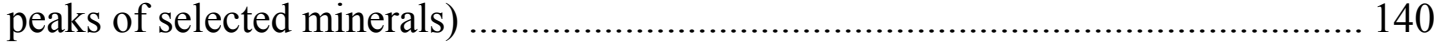

Figure 5.21 TGA plot with DTG data for H1A soil treated with 9\% hydrated lime...... 141 Figure 5.22 XRD pattern for H1A soil treated with 3\% analytical lime (numbers identify peaks of selected minerals)

Figure 5.23 TGA plot with DTG data for H1A soil treated with 3\% analytical lime .... 143

Figure 5.24 XRD pattern for H1A soil treated with 7\% analytical lime (numbers identify peaks of selected minerals) 144

Figure 5.25 TGA plot with DTG data for H1A soil treated with 7\% analytical lime .... 144

Figure 5.26 XRD pattern for H1A soil treated with 3\% quick lime (numbers identify peaks of selected minerals) 145

Figure 5.27 TGA plot with DTG data for H1A soil treated with 3\% quick lime 145

Figure 5.28 XRD pattern for H1A soil treated with 7\% quick lime (numbers identify peaks of selected minerals) .............................................................................. 146

Figure 5.29 TGA plot with DTG data for H1A soil treated with 7\% quick lime .......... 146

Figure 5.30 XRD pattern for H1A soil treated with 3\% Portland cement (numbers identify peaks of selected minerals) ................................................................... 147

Figure 5.31 TGA plot with DTG data for H1A soil treated with 3\% Portland cement .. 147 Figure 5.32 XRD pattern for H1A soil treated with 7\% Portland cement (numbers

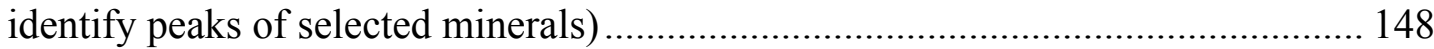

Figure 5.33 TGA plot with DTG data for H1A soil treated with 7\% Portland cement .. 148

Figure 5.34 Area under the $55^{\circ} \mathrm{C}$ peak on the DTG curve (H1A soil treated with $3 \%$ hydrated lime) 153

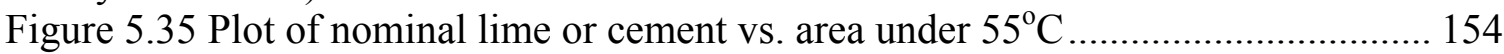

Figure 5.36 Plot of final swelling strain vs. area under $55^{\circ} \mathrm{C}$ 155 


\section{CHAPTER 1. INTRODUCTION}

\subsection{Introduction and Problem Statement}

Lime and cement, among the most common chemical admixtures, are widely used for the improvement of subgrades, in the construction of pavement bases and structural fills as well as in other civil engineering projects. Their importance lies in the fact that they improve several engineering properties of soils such as strength and durability and reduce expansion potential, enabling their better use as engineering materials. The amount of cement (typically Type I or Type II Portland cement) that is required depends on the type of soil and on the final desired properties. Generally the amount ranges from 4 to $16 \%$ by dry weight of soil. The amount of lime depends on the content of clay minerals in the soil. A rule of thumb mentioned in the literature (Wang 2002) is to allow $1 \%$ by weight of lime for each $10 \%$ of clay in the soil.

However, over the past 20 years, several cases have been reported where structures - in most cases pavements - have undergone significant amount of heave leading to failures and hazards when natural sulfate-bearing soils were treated with calcium-based stabilizers such as lime and ordinary Portland cement (Mitchell 1986;

Hunter 1988; Mitchell and Dermatas 1992; Kota et al. 1996; Puppala et al. 2004; Little et al. 2005). These failures were found to be related to sulfate reactions that cause the formation of two minerals: ettringite and thaumasite. These two minerals yield an 
expansive behavior, especially under hydration, which is responsible for heaving distress to structures - mainly pavements - built on the treated soils. This heave, referred to as sulfate-induced heave, leads to reduction of the design life of structures such as highways, street roadways, parking lot pavements and other loaded structures. The problem of heave or swelling related to the existence of sulfates in solution within the soil, generally referred to as "sulfate attack", has in some cases caused damages of millions of dollars (Mitchell 1986; Hunter 1988; Petry and Little 1992; Rollings et al. 1999).

In order to control sulfate-induced heaving damage, many researchers and engineers have considered and tried to determine threshold problematic sulfate levels, i.e. levels above which significant structural problems and distress occur. A report by the National Lime Association (2000) suggest threshold values of sulfate content within the soil material, which may provide guidelines for using lime in sulfate bearing soil. The advantage of using these threshold values is that they represent a relatively easy and quick method to assess the potential for heaving problems. However, since the sulfateinduced heaving mechanism is complicated and related to several influencing factors, according to some researchers (e.g. Puppala et al. 2004; Little et al. 2005) engineering judgment based exclusively on sulfate threshold levels can lead to poor results.

Sulfate rich soils, such as those on which the majority of the literature studies highlighted above have focused, typically occur in areas under desert and semidesert conditions of the southwestern United States. In arid climates in the absence of vegetation and presence of clay rich materials with low permeability which limit infiltration, the abundant runoff can, after high-intensity storms, sometimes lead to the formation of a 
shallow lake only for a few days or weeks. After evaporation, dissolved salts are concentrated or accumulated in adjacent areas instead of flowing to the sea, even though the geologic deposition itself has a complex history and deposited salts are a function of rock composition in the adjacent regions. Sometimes, if infiltration occurs, this salty water flows downward into the subsurface. Therefore, all of the ions from the salts such as sodium, chloride, alkalis, or sulfates (bittern salts) are available in those areas (Terry 1995).

These salts tend not to be present in deposits in the mid-western states, where, due to the wet climatic conditions they have been leached out. However, high sulfate contents can come about from other sources. In particular, in Indiana high sulfate contents are expected in coal mine spoils formed as a result of strip mining. Figure 1.1 shows a picture of a strip coal mine.

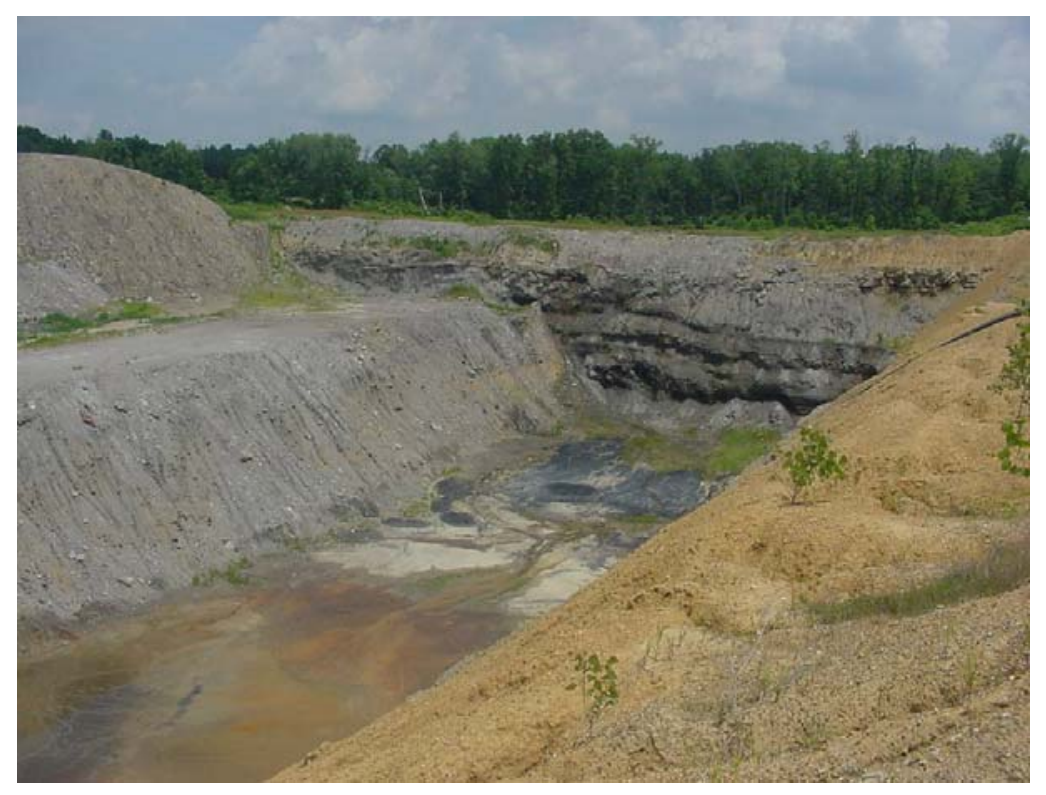

Figure 1.1 Area of shallow coal strip mining in Sullivan County Indiana 
Strip mining is "a type of mining in which soil and rock overlying the mineral deposit are removed. It is different from underground mining, in which the overlying rock is left in place, and the mineral removed through shafts or tunnels". Strip mining is "only practical when the mineral deposit to be excavated is relatively near the surface and is most commonly used to mine coal or tar sand" (Wikipedia-strip mining).

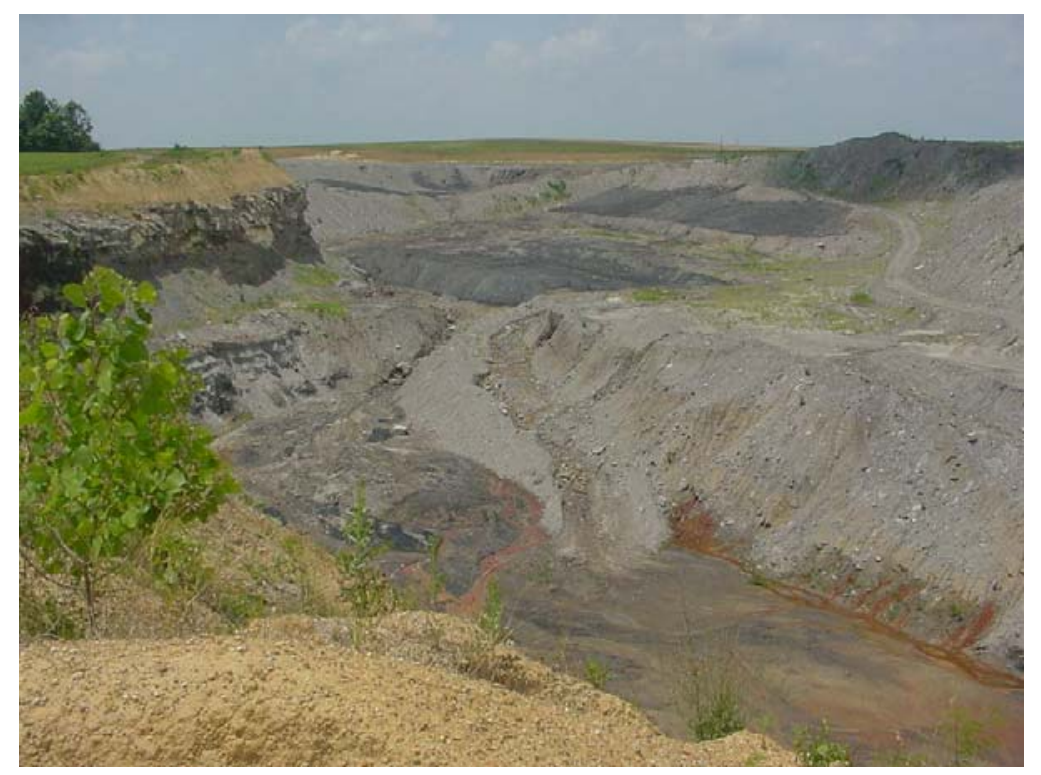

Figure 1.2 Scarce vegetation of strip mine areas

The old strip mine areas of Indiana have a landscape somewhat similar to that of the southwestern United States. Despite the enactment of state reclamation laws, vegetation is limited by the high acidity of the soil, caused by the weathering from shale units (Terry, 1995) (see Figure 1.2). In addition, as a result of coal mining, sulfur (S) is likely to be present in the spoils. 


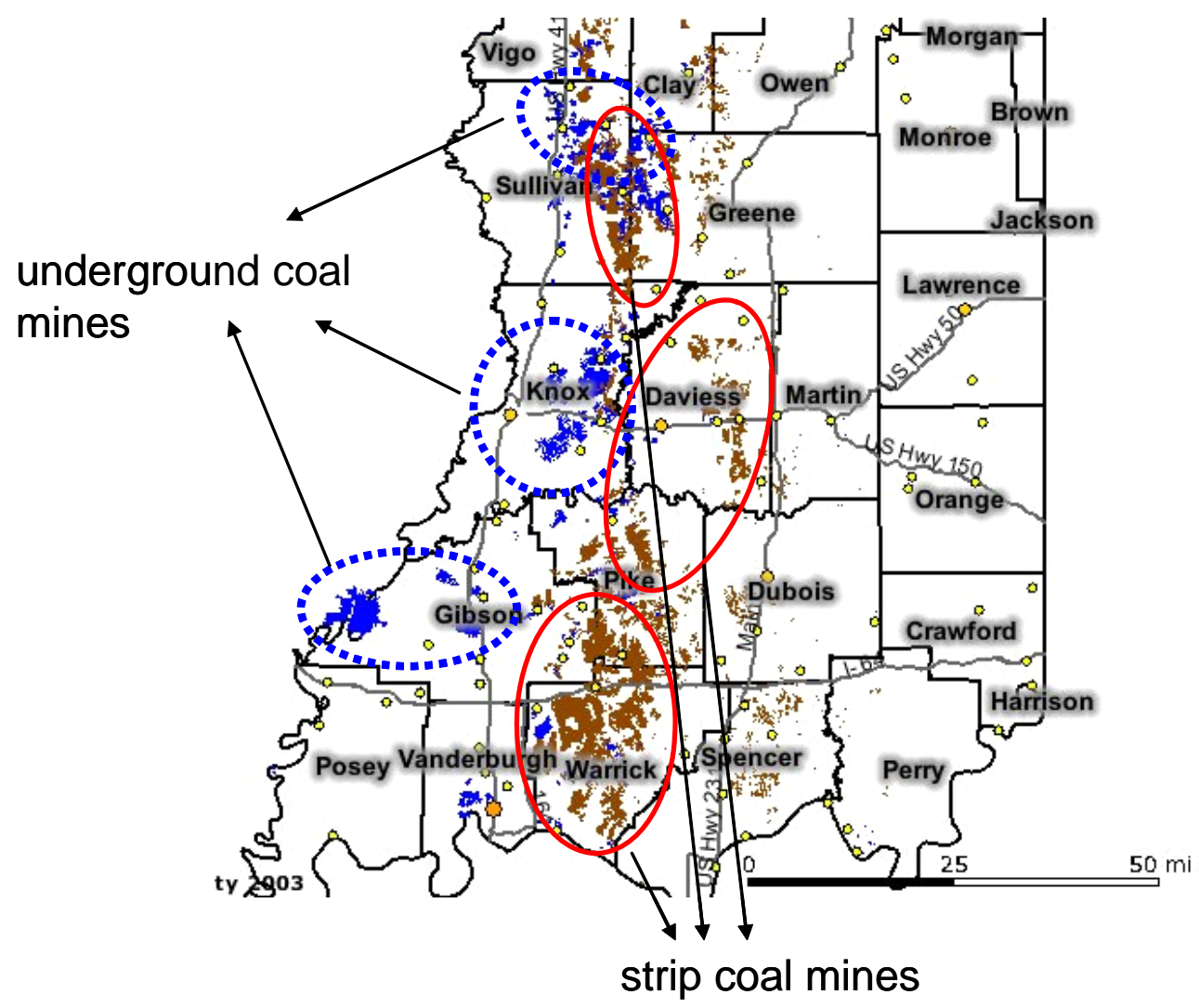

Figure 1.3 Map of coal mines in Indiana (Research Institute of Indiana University)

Figure 1.3 shows a map of Indiana highlighting the areas of underground and strip coal mining. Counties in which strip coal mining has been common include: Warrick, Clay, and Sullivan. These areas include parts of the state in which substantial infrastructure development is taking place and will continue to occur in the next 10-15 years (e.g. I-69 construction, and US 231 extension). It is possible that in these areas coal mine spoils may ultimately form the subgrade for the new infrastructure, and/or be used for embankment/subbase construction. This was the motivation for the research summarized in this report. 


\subsection{Research Objectives}

The overall goal of this research was to investigate whether sulfate induced swelling associated with chemical treatment of soils could potentially be an issue of concern in the State of Indiana. The work focused on the treatment of coal mine spoils, formed as a result of shallow strip coal mining. These soils are known to have high sulfate contents; additionally they are present in areas of the State where infrastructure development is in progress and expected to further occur. The specific objectives of the work were to:

- Assess the occurrence of sulfate induced swelling in chemically treated coal mine spoils;

- Quantify the swelling as a result of treatment with different stabilizers: hydrated lime, quick lime and Portland cement;

- Establish the mechanism by which swelling occurs;

- Evaluate currently employed mitigation options, including pre-compaction mellowing and double-lime treatment;

- Develop testing and evaluation methods for investigating the possible occurrence of sulfate induced heave at other locations.

\subsection{Organization}

This report is organized into six chapters with the goal of introducing the research problem, summarizing the relevant literature, describing the experimental methods, 
presenting and discussing the experimental results, and providing conclusions and recommendations for further study. The following paragraphs provide a brief description of each of the six chapters of this .

Chapter 1 presents the problem statement and outlines the objectives of the work. Chapter 2 provides a brief background on the topic of sulfate induced swelling. In addition to reviewing selected case histories on sulfate-induced heave documented in the literature, the chapter summarizes lime-sulfate reactions, discusses the methods currently employed for assessing the susceptibility of soils to sulfate induced swelling, and briefly reviews approaches to mitigating this problem.

Chapter 3 discusses the materials and methods. In addition to a short introduction, the chapter is organized in three main sections. The first (Section 3.2) illustrates the sampling program; provides a geological description of the samples; and describes the procedures followed to "screen" the field samples to obtain the soil used in the swelling tests. Section 3.3 presents the stabilizers employed in the research. Finally, Section 3.4 describes the experimental methods employed in this research to: determine sulfate content; to prepare compacted soils specimens; to measure swelling; to investigate the effects of mellowing and double-lime treatment; and to perform the chemical and mineralogical tests discussed in Chapter 5.

Chapter 4 presents an overview of the experimental program. Then the results of preliminary tests conducted on both the soils (Atterberg limits sulfate content) and the soil-stabilizer mixtures ( $\mathrm{pH}$ tests) are discussed. Finally, the chapter presents the results of the extensive program of one-dimensional swelling tests conducted on various soil- 
stabilizer combinations under a range of experimental conditions (different surcharge, with or without mellowing, with single or double treatment).

Chapter 5 provides an interpretation of the swelling data presented in Chapter 4 based on the results of mineralogical and chemical tests performed on the soil-stabilizer specimens at the end of the swelling stage.

Finally, Chapter 6 presents the conclusions of this research work and provides recommendations for future work. 


\section{CHAPTER 2. BACKGROUND}

\subsection{Historical Perspective}

The earliest work on the effects of the presence of sulfate ions on the behavior of cement and lime stabilized soils is that by Sherwood (1962). In this study experiments were conducted on cohesive and granular soils stabilized with cement and lime in presence of sulfate ions. While Sherwood (1962) focused on the strength of the stabilized soils (i.e. swelling was not addressed), he concluded that the presence of sulfates was detrimental when the soils contained a significant clay fraction and had sufficient access to water. Unfortunately, the work of Sherwood (1962) went mostly unnoticed, and it was not until more than 20 years later that additional studies supported his observations.

Perhaps the first discussion in the technical literature of heave caused by lime treatment of sulfate bearing soils is presented by Mitchell (1986) in his Terzaghi lecture. In this paper, Mitchell (1986) reported the unexpected swelling and pavement failure observed in Stewart Avenue in Las Vegas showing that the reason was the treatment with lime of the local sulfate rich soils. He correctly suggested that the cause of the heave was the significant growth of crystals of ettringite and thaumasite, two highly expansive crystalline minerals well known for their detrimental effect on concrete. 
The Stewart Avenue case history was investigated also by Hunter (1988) who provided a detailed description of the geology and the soil conditions at the site and presented conclusions in substantial agreement with those provided by Mitchell (1986). Hunter (1988) also addressed the issue of the mechanism responsible for the heave through extensive analysis based on soil chemistry and thermodynamic parameters of ettringite and thaumasite. He suggested that the major factors controlling lime-induced heave were temperature, percentage of clay-sized particles and availability of water. He recognized that due to the lack of experimental data and the complexity of the swelling mechanism, it was not possible to predict lime-induced heave, and that further research was needed. He also noted that soil sulfate content might not necessarily be the best or the only parameter for predicting heave in sulfate bearing soils treated with calcium based stabilizers. This observation has been validated by subsequent studies (e.g. Little et al. 2005).

Hunter's effort to use geochemical modeling to predict lime-induced heave continued in his Ph.D. thesis (Hunter 1989). The dissertation was divided into three main parts: a literature review, a discussion of the swelling mechanisms in lime-treated soils, and, finally a discussion of the geochemical modeling required to determine the stability of ettringite for a given lime treated soil. These geochemical studies were used to make phase diagrams depicting conditions that indicated whether lime-induced heave was likely to occur or not. It was proposed that such diagrams could be the basis for evaluating susceptibility of a given soil to heave induced by lime treatment

The mechanism responsible for swelling in sulfate bearing soils treated with lime was further investigated by Mitchell and Dermatas (1992). These authors proposed that 
ettringite was formed by the reactions between lime, the alumina in the clay and the sulfate present in the soil. Their conclusions were based on an extensive laboratory testing program conducted on laboratory prepared specimens compacted with a procedure using the Harvard compaction apparatus. The specimens were used to perform both unconfined compressive strength tests as well as swell tests using the sand bath method. Additionally, x-ray diffraction (XRD) and scanning electron microscopy (SEM) were used to identify the presence of ettringite crystals. This study found that important factors affecting ettringite-related heave are clay amount and type, surface area and amount of alumina in the clay, amount and type of sulfates and lime, temperature and humidity variation.

Subsequent work by Dermatas (1995) highlighted the role played by curing time, high $\mathrm{pH}$ conditions, and the availability and flow of pore water. Dermatas (1995) also first suggested pretreatment with barium salts as a means to mitigate swelling in sulfate rich soils treated with lime. Both the work by Mitchell and Dermatas (1992) and that by Dermatas (1995) emphasized that further research was needed to establish reliable general guidelines for lime stabilization projects in sulfate-bearing soils.

Concurrently with the work by Mitchell and Dermatas (1992) additional case histories documenting damage in lime treated sulfate bearing soils surfaced. For example, Perrin (1992) presented three case histories showing considerable damage by limeinduced heave at three different sites in Texas: Loyd Park, Cedar Hill State Park, and Laughlin Air Force Base. In his paper Perrin (1992) discussed the results of the investigations conducted at each of the three damaged areas and described how the damaged areas were remediated. 
Additional work done by Petry with Little (Petry and Little 1992) showed that soluble sulfate levels predicting problematic behavior depended on the method used to determine the sulfate content (in particular on the on soil/water extraction ratio). Petry and Little (1992) also advocated the use of three-dimensional laboratory swelling tests to better represent actual field conditions.

Kota et al. (1996) introduced and summarized several case histories of pavement failures. They also discussed the methods for determining soluble sulfate levels and the procedures for predicting sulfate-induced heave in soils, highlighting their limitations. In addition, Kota et al. (1996) reviewed the techniques for construction of pavements on sulfate-bearing soils, including double lime treatment, the use of low- or none-calciumbased soil stabilizers, pretreatment with barium compounds, the use of geotextiles and geogrids.

Partially in response to the concerns raised on the use of lime for treating sulfate bearing soils, in 2000 the National Lime Association produced a report which proposed critical threshold sulfate levels above which sulfate induced heave was expected to be an issue (see Section 2.5).

While the protocol proposed by the National Lime Association (2000) for determining problematic soluble sulfate levels was of easy and quick use, many cases of results inconsistent with that protocol have and continue to be documented. As a result, research on the topic of heave resulting from chemical modification of sulfate bearing soils continues to be active. In particular, researchers at the University of Texas at Arlington have worked extensively on this topic and most recently have completed a report to NSF that summarizes their most recent research (Puppala et al. 2005b). The 
report includes data from an extensive laboratory experimental program conducted on different soils doped with known amounts of sulfates and tested under a variety of conditions (different moisture content, temperature, surcharge stress, stabilizer and stabilizer dosage) as well as a comprehensive analysis of literature data.

In addition to elucidating the role played by the parameters listed above, one of the most significant recommendations contained in the report by Puppala et al. (2005b) is not to rely on soluble sulfates alone for the prediction or assessment of sulfate induced heave. Since reactive alumina plays an important role in the formation of ettringite, Puppala et al (2005b) introduce a method for quantifying the consumption of reactive alumina. They suggest a correlation between the swelling strain and reactive alumina consumption of lime treated soils (see Figure 2.1). 


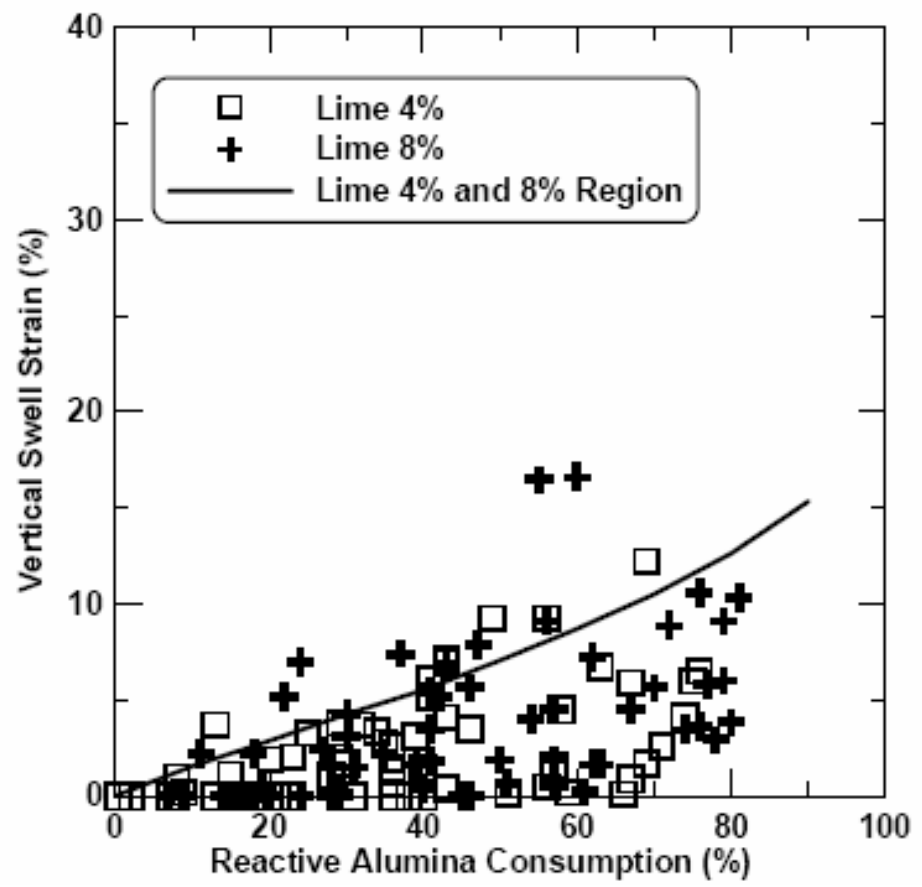

Figure 2.1 Correlations between swelling strain and reactive alumina consumption (Puppala et al. 2005b)

Puppala et al. (2005b) also emphasize that critical sulfate threshold levels depend on soil type, treatment type, as well as confining stresses, and temperature conditions. They also propose correlations to predict the swelling response of chemically treated sulfate rich soils.

Note that the group from the University of Texas in Arlington is also responsible for the development of an improved method for measuring sulfate content in fine soils (Puppala et al. 2002). This and other existing methods are reviewed in Chapter 3.

The most recent contribution of significance in the area of sulfate induced heave is that by Little et al. (2005). Their work building on that by Hunter (1989) showed that thermodynamic geochemical modeling can explain the very different susceptibility to swelling of soils having the same sulfate content and treated with the same stabilizer. 
They propose that this method can provide a more accurate and unbiased assessment of the risk of sulfate induced heave, and can be an effective means for evaluating additives used to address the problem (see more in section 2.5.1).

\subsection{Case Histories}

\subsubsection{Stewart Avenue Projects}

The Stewart Avenue case study, which was described by Mitchell (1986) in his $20^{\text {th }}$ Terzaghi Lecture, is the first well documented case of heave induced by sulfate attack. During the spring of 1975 an approximately 3 mile section of Stewart Avenue in Las Vegas, Nevada was constructed using lime stabilization, which was relatively new at the time. The street was widened from two to four $12 \mathrm{ft}$ wide lanes. $4 \%$ of quicklime $(\mathrm{CaO})$ by dry mass of the soil was mixed with the local expansive silty clay soils for subbase construction after laboratory results showed significant improvement in soil strength and stability with this treatment. The road appeared to perform successfully after completion of the construction. However, two years and six months later, distress started appearing on the road and after three years from construction severe damage in certain areas of the road with several inches of heave was observed. Several investigations were performed to determine the causes of the failure; the conclusions of these investigations are presented by Mitchell (1986), Hunter (1988), and Mitchell and Dermatas (1992).

Hunter (1988) described site conditions, geology and soil conditions, and presented with great detail field observations and laboratory test results. Field 
observations of the subbases were conducted in both damaged ad undamaged areas; it was noted that the areas with the most severe damage were in proximity of sources of water such as utility trenches and were underlain by soft plastic silty layers; hard and cemented materials were found in the undamaged areas.

Untreated and lime treated soil samples were collected from the field and brought to the laboratory. Swelling tests conducted under a $100 \mathrm{psf}$ surcharge on samples of both the untreated and treated soil showed swelling strains observed up to $12 \%$ in the lime treated samples, twice those measured on the untreated soil. Mitchell (1986), Hunter (1988) and Mitchell and Dermatas (1992) all hypothesized that the heave was caused by one or more chemical reactions. X-Ray diffraction (XRD) and scanning electron microscopy (SEM) analysis were performed in order to identify the constituents of samples from damaged and undamaged subbase, and native soils.

The results of these analyses showed that the heave was caused by chemical reactions between the lime and the sulfate rich soils. Tests identified the presence of thaumasite in the damaged subbase. Thaumasite is an expansive mineral created by the chemical reaction between the calcium present in the lime, the alumina in the clay, sulfate and water at high pH (Hunter 1988; Hunter 1989).

These studies led to conclude that there was a risk in treating sulfate bearing clay soils with lime; that problems could arise even for relatively low sulfate concentrations; that at least approximately $10 \%$ of clay was needed to provide the necessary amount of alumina; and that future studies should focus on long term performance, as immediate test results could be misleading (Mitchell 1986; Hunter 1988). 


\subsubsection{US Army Corps of Engineers Projects}

Perrin (1992) reported the investigations of heave damage on three projects of the US Army Corps of Engineers, in the Fort Worth district in Texas: several park roads in Loyd Park and Cedar Hill State Park located on the southwest of Dallas and an auxiliary airfield of Laughlin Air Force Base located southwest of Spofford. The pavements were constructed over a 6 in thick subgrade stabilized with 5 to $6 \%$ lime.

Heave was detected in both the transverse and the longitudinal directions in the Loyd Park and the Cedar Hill State Park projects. The heave varied from barely noticeable to as much as 12 in over widths of 1 to $2 \mathrm{ft}$; the spacing between these bumps ranged from 10 to $15 \mathrm{ft}$. At the Laughlin Air Force Base project, the heave was generally less than 2 in over a width of 1 to $2 \mathrm{ft}$. The common observation at all three sites was that the damage was more severe in the areas of poor drainage.

Following Hunter (1988)'s work, the damage was recognized as being caused by sulfate induced heave of the lime-treated soils. Additional investigations were performed in order to determine the amount of clay present in the soil and the soluble sulfate concentrations. Lime-treated soils throughout the Loyd Park site were found to contain large amounts of quartz $\left(\mathrm{SiO}_{2}\right)$ and minor amounts of gypsum $\left(\mathrm{CaSO}_{4} \cdot 2 \mathrm{H}_{2} \mathrm{O}\right)$ and calcite $\left(\mathrm{CaCO}_{3}\right)$. Soluble sulfate concentrations of the lime-treated soils were found to vary from 2,000 to 9,000 ppm. The soils in the Cedar Hill State Park area were moderately to highly plastic clays weathered from the underlying clay shale. Soluble sulfate concentrations in the lime-treated soils yielded mean sulfate levels of 21,200 ppm. Lastly, subgrade soil conditions at the Laughlin Air Force Base were similar to the 
previous two areas, i.e. predominantly highly plastic clays rich in gypsum. Soluble sulfate concentrations tests showed sulfate contents varying from 14,000 to $25,000 \mathrm{ppm}$.

The results of the investigations supported the finding by Hunter (1988) that the heave was caused by the formation of ettringite and thaumasite (X-ray diffraction analyses conducted demonstrated the presence of both these minerals in the lime-treated soil samples from the damaged areas), and that the conditions favorable to these chemical reactions were the presence of sufficient clay minerals, high sulfate concentrations and access to free water.

Removal and replacement of lime-treated soils at these sites were effective, but extremely costly. As a result of this experience it was recommended that additional investigations be conducted in particular to explore mitigation techniques such as double lime treatment. See Section 4.3.8 for a discussion of this mitigation approach,

\subsubsection{Texas DOT Projects}

Kota et al. (1996) summarized the findings of an investigation performed on two state highways in Texas: SH-118 and SH-161. The first was located in Brewster County near Alpine, Texas. Preconstruction investigations documented the high sulfate content of the native soil: $24,700 \mathrm{ppm}$ of soluble sulfates (based on extraction in water with a 1:10 soil-water ratio). Therefore, experimental test sections were planned using both lime and cement to stabilize the highly plastic clay. The cement stabilized sections used $4 \%$ Type II cement based on strength criteria; whereas the lime stabilized sections used $6 \%$ lime 
based on the results of $\mathrm{pH}$ tests on the soil lime mixture, as suggested by Eades and Grim (1966).

The construction was completed by the middle of 1993; a few months later heave was observed in both the lime and cement stabilized sections (the lime stabilized section had more severe damage). Damage became obvious a few days after the first rain following the end of the construction. The height of transverse ridges was $50-100 \mathrm{~mm}$ and their spacing ranged between 4.5 and $7.6 \mathrm{~m}$. Subsequent rains caused additional heave although the first heave was the most severe and significant in the lime stabilized section. Additional transverse ridges were still forming a year later, and severe longitudinal cracks with openings of 50 to $100 \mathrm{~mm}$ were observed after 1.5 years following construction. The sections without stabilizers remained in excellent condition except in the areas near the cross drainage pipes where cement stabilized soils were used.

The SH-161 project (Dallas, Texas) consisted of entrance and exit ramps. The pavement cross-section consisted of a $200 \mathrm{~mm}$ thick asphalt concrete layer over a 200 mm thick subgrade stabilized with $7 \%$ lime. The construction was completed in early 1994 and by June of the same year heave was observed. Investigations showed an increase in the level of soluble sulfates at the site; gypsum-laden water was entering the soil.

As a solution for the problem, double (or even triple) application of lime was considered. Based on laboratory tests (Petry 1994), an additional 7\% was added to the existing lime treated soil, in an attempt to minimize the swelling and maximize the strength of the treated material. Swell tests were performed on soil samples with no additional lime and samples with different percentages of additional lime; all the samples 
exhibited swelling. Six months after the addition of $7 \%$ lime to the existing lime treated subgrade, heave continued to be observed. It was concluded that either additional expansive minerals had formed after additional lime had become available to the soluble sulfates (soluble sulfate levels observed in the field were around 12,000 ppm), or that the formation of expansive minerals associated with the first treatment was continuing to occur (i.e. had taken longer than what was expected).

\subsection{Lime Sulfate Soil Reaction}

When lime is applied to a clayey soil to stabilize it and sulfate exists in the soil or groundwater, the sulfates may combine with the alumina from the clay and the calcium and hydroxide ion from the stabilizer to ultimately form the minerals such as ettringite and thaumasite (Dermatas 1995). The geochemical reactions involved in the growth of ettringite are quite complex.

According to Mitchell (1986), when quicklime ( $\mathrm{CaO})$ is used as a stabilizer, it combines with water to form calcium hydroxide as follows:

$$
\mathrm{CaO}+\mathrm{H}_{2} \mathrm{O} \rightarrow \mathrm{Ca}(\mathrm{OH})_{2}
$$

When a "non-problematic" soil (i.e. a soil with negligible sulfate content) is treated with a calcium-based stabilizer, some calcium ions exchange with sodium on the clay and the intrinsic swelling of the clay minerals can be suppressed; as a result the mixture exhibits negligible swell and higher strength. In addition, the hydration of 
quicklime may cause a water content reduction leading to further strength increase. In the presence of sodium sulfate, however, the available lime is partially depleted as follows (Mitchell 1986):

$$
\mathrm{Ca}(\mathrm{OH})_{2}+\mathrm{Na}_{2} \mathrm{SO}_{4} \rightarrow \mathrm{CaSO}_{4}+2 \mathrm{NaOH}
$$

Silica $\left(\mathrm{SiO}_{2}\right)$ and alumina $\left(\mathrm{Al}_{2} \mathrm{O}_{3}\right)$ will dissolve from the clay when the $\mathrm{pH}$ goes up to 12.4 . These materials can then combine with the calcium from the stabilizer and sulfate present in the soil to form ettringite: $\mathrm{Ca}_{6}\left[\mathrm{Al}(\mathrm{OH})_{6}\right]_{2} \cdot\left(\mathrm{SO}_{4}\right)_{3} \cdot 26 \mathrm{H}_{2} \mathrm{O}$ (see more in section $2.4 .3)$

Although the formation of ettringite is not a new phenomenon, the engineering profession does not seem to have enough knowledge of sulfate reactions with lime in stabilized soils (Perrin 1992). However the formation of ettringite and the related swelling mechanism are well established in concrete. Since the same components are responsible for ettringite formation in both materials, ettringite formation and swelling of concrete are discussed in the following paragraphs based on the work by Odler and Jawed (1991).

During cement hydration, the different constituent phases react with water to form hydration products. The volume is smaller than the combined volume of cement and water. This irreversible chemical shrinkage is on the order of 5 to $8 \%$ of the original water-cement system. However, this volume change is insignificant compared to volumetric changes resulting from expansive chemical reactions that can occur during the hydration process. 
In Portland cement, calcium sulfate is usually present in the form of gypsum $\left(\mathrm{CaSO}_{4} \cdot 2 \mathrm{H}_{2} \mathrm{O}\right)$ which is ground together with cement clinker to control the setting of cement. However, excessive amounts of calcium sulfate can result in expansion and might lead to cracking of the concrete. In an effort to prevent excessive amounts of expansion, the amount of sulfate is carefully controlled and is never to exceed upper limits varying between 2.3 and $4.5 \%$ by mass of the final cement product, depending on the cement type (ASTM C 150).

Sulfate ions, which are essential to the formation of ettringite, are generally provided by the sulfates of calcium, magnesium, sodium and potassium present in the cement or in the environment to which the concrete is exposed. Even though the sulfates cannot produce ettringite without the presence of calcium ions, calcium hydroxide in the hydrating cement usually supplies enough calcium ions to allow the reaction to take place.

$$
\mathrm{M}_{2} \mathrm{SO}_{4}+\mathrm{Ca}(\mathrm{OH})_{2}+2 \mathrm{H}_{2} \mathrm{O} \rightarrow \mathrm{CaSO}_{4} \cdot 2 \mathrm{H}_{2} \mathrm{O}+2 \mathrm{MOH} \quad \text { Eq. } 2.3
$$

where $M$ is an alkali metal ion, i.e. calcium, magnesium, sodium or potassium (Odler and Jawed 1991).

Ettringite formation starts immediately with the access of water and this reaction is completed within a few hours prior to cement setting; a moderate contraction of cement paste is monitored during this period. When the sulfates of calcium present in cement are excessive, the ettringite formation continues, leading to volume expansion and finally damage. 


\subsection{Sulfate-Induced Swelling}

\subsubsection{Mechanisms}

There are two different hypotheses for the mechanism responsible for the swelling of ettringite and thaumasite: the crystal growth mechanism and the hydration or water adsorption mechanism. The first one takes place when calcium, aluminum, and sulfate ions present in the stabilized soils combine to generate ettringite crystal growth. Significant pressures on the restraining media (soil-stabilizer mixture) can be exerted by ettringite crystal growth and interlocking between crystals. If these pressures are large enough, swelling of the media can occur. On the other side, the expansion of ettringite through hydration is difficult to explain, however it is widely regarded as a possible swelling mechanism of the mineral. Overall, sulfate induced heave may be caused by both mechanisms; however the heave due to crystal growth is a much longer process than the one due to water adsorption (Dermatas 1995).

\subsubsection{Influencing Factors}

According to many researchers, five factors affect sulfate attack in soils. These factors, in a rough order of magnitude, are the following: 


\section{A. Sulfate Content}

The level or content of sulfates in the soil is among the more important factors for the formation of ettringite. Actually, for some researchers it is the most important factor (Ferris et al. 1991).

\section{B. Clay Content}

The clay content in the soil of interest is also a very important factor for potential swelling behavior. Hunter (1988) found that for soils with less than $10 \%$ clay fraction, the swelling was insignificant even if the soil sulfate content exceeded $20,000 \mathrm{mg} / \mathrm{kg}$. This observation was supported by Mitchell and Dermatas (1992) based on experiments on sand specimens mixed with kaolinite and montmorillonite.

The alumina content of the clay also plays an important role as demonstrated by the greater swelling reported by Mitchell and Dermatas (1992) for sand-kaolinite mixtures compared to sand mixed with montmorillonite. This is due to the higher alumina content of the kaolinite.

C. $p H$ Value

According to Rollings et al. (1999), the $\mathrm{pH}$ value above 12 normally typical of soils treated with calcium-based stabilizers guarantees the conditions for solubility of silica and alumina. This factor is significant, because it produces the necessary alumina in chemical reaction so that ettringite can form.

\section{Moisture}

Moisture is another important factor for the formation of ettringite. In the Stewart Avenue project (section 2.2.1) where sulfate induced heave was observed, the magnitude of swelling and the level of moisture were correlated (Mitchell 1986: Hunter 1988). 
Generally, a high permeability of the soil encourages swelling; however it is not a required factor for expansive behavior.

\section{E. Temperature}

Mitchell and Dermatas (1992) have found that the formation of ettringite in lime treated soils depends on the temperature. The temperature that is usually found in pavements, i.e. $20-40{ }^{\circ} \mathrm{C}$ depending on the area and the site conditions, is in that range that would allow ettringite to be formed. The resulting expansion would be higher in warm weather. Opposite results have been reported by Puppala et al. (2005), who measured greater swelling strains at lower temperatures (some data from Puppala et al. (2005) is presented in Chapter 4).

\subsubsection{Geochemistry of Ettringite and Thaumasite}

The formula of hydrated calcium aluminum sulfate hydroxide, i.e. ettringite, is $\mathrm{Ca}_{6}\left(\mathrm{Al}(\mathrm{OH})_{6}\right)_{2} \cdot\left(\mathrm{SO}_{4}\right)_{3} \cdot 26 \mathrm{H}_{2} \mathrm{O}$ and that of the silicon-bearing member of the ettringite mineral group, thaumasite, is $\mathrm{Ca}_{6}\left(\mathrm{Si}(\mathrm{OH})_{6}\right)_{2} \cdot\left(\mathrm{CO}_{3}\right)_{2} \cdot\left(\mathrm{SO}_{4}\right)_{2} \cdot 24 \mathrm{H}_{2} \mathrm{O}$.

When the silica and alumina in the clay minerals are soluble, the formation of ettringite always occurs first and thaumasite can be slowly converted from ettringite only at temperatures below $15^{\circ} \mathrm{C}$. Above $15^{\circ} \mathrm{C}$ (Hunter 1988; Hunter 1989) ettringite remains stable.

The solubility of ettringite can be written as a dissolution reaction: 
$\mathrm{Ca}_{6}\left(\mathrm{Al}(\mathrm{OH})_{6}\right)_{2} \cdot\left(\mathrm{SO}_{4}\right)_{3} \cdot 26 \mathrm{H}_{2} \mathrm{O} \leftrightarrow 6 \mathrm{Ca}^{2+}+2 \mathrm{Al}(\mathrm{OH})_{4}^{-}+3 \mathrm{SO}_{4}^{2-}+4 \mathrm{OH}^{-}+26 \mathrm{j}$

Eq. 2.4

Isostructural substitution of silica for aluminum and carbonate for sulfate can lead to the transformation of ettringite into thaumasite (Hunter 1988).

$$
\begin{aligned}
& \mathrm{Ca}_{6}\left(\mathrm{Al}(\mathrm{OH})_{6}\right)_{2} \cdot\left(\mathrm{SO}_{4}\right)_{3} \cdot 26 \mathrm{H}_{2} \mathrm{O}+2 \mathrm{H}_{2} \mathrm{SiO}_{4}^{2-}+2 \mathrm{CO}_{3}^{2-}+\mathrm{O}_{2} \\
& \leftrightarrow \mathrm{Ca}_{6}\left(\mathrm{Si}(\mathrm{OH})_{6}\right)_{2} \cdot\left(\mathrm{CO}_{3}\right)_{2} \cdot\left(\mathrm{SO}_{4}\right)_{2} \cdot 24 \mathrm{H}_{2} \mathrm{O}+2 \mathrm{Al}(\mathrm{OH})_{4}^{-}+\mathrm{SO}_{4}^{2-}+4 \mathrm{OH}^{-}+2 \mathrm{H}
\end{aligned}
$$

Eq. 2.5

\subsection{Methods for Assessing Susceptibility to Sulfate Induced Swelling}

\subsubsection{Critical Sulfate Levels}

Sulfate content determination procedures often provide different sulfate measurements for the same sulfate-rich soil. Thus, critical threshold sulfate levels, i.e. levels at which significant problems in the infrastructure appear, are difficult to establish. As a result, threshold levels provided by different researchers fall in a relatively large range. From an overview of the documented case studies, the lower sulfate content limit connected to potential risk of heave of the soil and distress in the structures appears to be around 3,000 ppm. However, problems in soils with sulfate contents as low as 500 - 
1,000 ppm are also cited. Table 2.1 (Puppala et al. 2002) presents a summary of reported cases studies, indicating the differences in the amounts of sulfate contained in the soil.

Table 2.1 Sulfate thresholds reported in case studies (Puppala et al. 2002)

\begin{tabular}{|c|c|c|c|c|}
\hline Reference & Location & $\begin{array}{c}\text { Stabilizer, } \\
\text { Percentage }\end{array}$ & $\begin{array}{c}\text { Sulfate } \\
\text { Content, } \\
\text { ppm }\end{array}$ & $\begin{array}{c}\text { Heave after } \\
\text { Construction }\end{array}$ \\
\hline \hline Hunter (1988) & Nevada & Lime, 4.5 & 43,500 & 6 months \\
\hline Perrin (1992) & Texas & Lime, 5 & $2,000-9,000$ & Immediately \\
\hline Perrin (1992) & Texas & Lime, 6-9 & $\begin{array}{c}14,000- \\
25,000\end{array}$ & 2 months \\
\hline Perrin (1992) & Texas & Lime, 6 & 21,200 & 2 months \\
\hline $\begin{array}{c}\text { McCallister } \\
\text { and Tidwell } \\
(1994)\end{array}$ & Colorado & Lime, NA & 2,775 & NA \\
\hline $\begin{array}{c}\text { Kota et al. } \\
(1996)\end{array}$ & Texas & Cement, 4 & 12,000 & 6 Lime, 6-7 \\
\hline $\begin{array}{c}\text { Burkart et al. } \\
(1999)\end{array}$ & Texas & Lime, 6-9 & $233-18,000$ & Varies \\
\hline $\begin{array}{c}\text { Puppala } \\
(1999)\end{array}$ & Texas & Lime, 5 & $320-13,000$ & 3 months \\
\hline $\begin{array}{c}\text { Lawrence } \\
(2000)\end{array}$ & Texas & Lime, 6-8 & $500-5,000$ & 1 month \\
\hline
\end{tabular}

Note: $\mathrm{NA}=$ not available

In an effort to categorize the above problematic levels, the National Lime Association (2000) provides the following recommendations with respect to the sulfate levels and the equivalent risk to pavements and other structures (see Table 2.2). 
Table 2.2 Guidelines for using lime in sulfate bearing soils

\begin{tabular}{|c|c|c|}
\hline $\begin{array}{c}\text { Sulfate level } \\
\text { (ppm) }\end{array}$ & Risk & Recommendations \\
\hline$<3,000$ & $\begin{array}{c}\text { Too low to be } \\
\text { of concern }\end{array}$ & $\begin{array}{c}\text { Low potential for harmful reaction, but } \\
\text { good mix design and adequate water (at } \\
\text { least 3\% higher than OMC) } \\
\text { recommended }\end{array}$ \\
\hline $3,000-5,000$ & Moderate risk & $\begin{array}{c}\text { Moderate concern, but localized distress } \\
\text { possible. Special attention given to } \\
\text { mixing water (+ mellowing and curing) }\end{array}$ \\
\hline $5,000-8,000$ & $\begin{array}{c}\text { Moderate to } \\
\text { high risk }\end{array}$ & $\begin{array}{c}\text { Very close attention to construction } \\
\text { technique. Swelling test recommended } \\
\text { before treating soils }\end{array}$ \\
\hline$>8,000$ & $\begin{array}{c}\text { High and } \\
\text { unacceptable } \\
\text { risk }\end{array}$ & $\begin{array}{c}\text { Too high risk for routine work. } \\
\text { Generally not suitable for lime } \\
\text { stabilization }\end{array}$ \\
\hline
\end{tabular}

Note: $\mathrm{OMC}=$ optimum moisture content

\subsubsection{Thermodynamic Geochemical Model}

Little et al. (2005) presented their study on 'Ettringite formation in lime-treated soils: establishing thermodynamic foundations for engineering practice' to the Transportation Research Board at the 2005 Annual Meeting in Washington, D.C.

This paper contends that, while the simple protocol established by the National Lime Association (2000) has been used for a long time in order to determine critical threshold level of soluble sulfates, this 'rule-of-thumb' based on experience is not 
sufficient to deal with the very complex phenomenon of ettringite formation from the reaction between lime and soil. The paper presents results for two different soils (referred to in the paper as Frisco soil and US 290 soil), both having soluble sulfate content of 3,000 ppm and similar pH after treatment with lime. Despite the same sulfate content, ettringite is found to form in the lime treated Frisco soil, while no swelling or ettringite formation is observed when treating the US 290 soil.

Having conducted careful thermodynamic geochemical modeling, Little et al. (2005) find that the differences observed in the field can be explained based on the thermodynamic phase diagrams of the two soils shown in Figure 2.2. In this figure it is observed that the locus corresponding to the $\mathrm{pH}$ and the activity (on a log scale) of the sulfate falls within the ettringite stability field in the case of the Frisco soil (Figure 2.2a), while it falls well below the ettringite stability field in the case of the US 290 soil (Figure 2.2b). This means that in the second case thermodynamically ettringite cannot form.

Little et al (2005) conclude that thermodynamic geochemical modeling is a scientifically sound and unbiased approach to establish reasonable threshold sulfate levels for a given soil and an ideal tool to assess the potential impact of additives. 
(a)

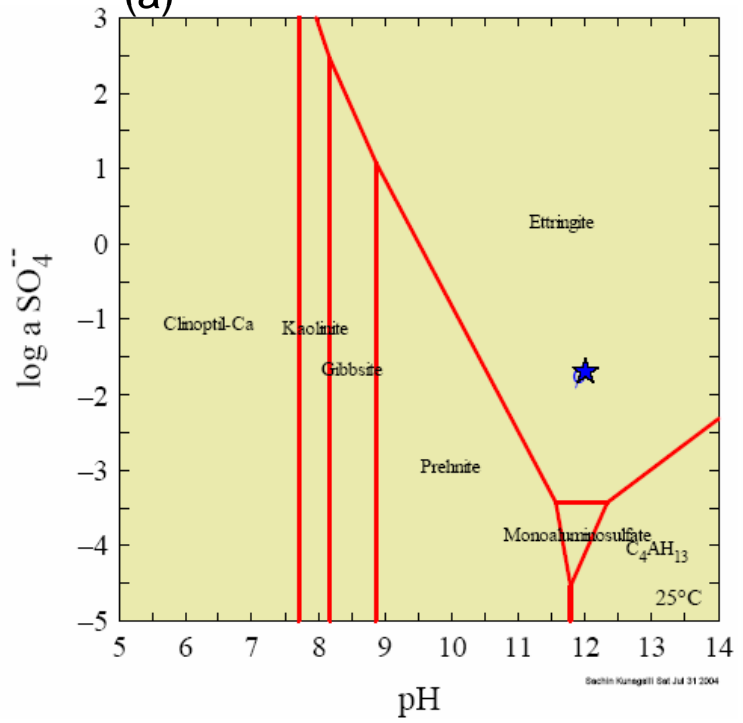

(b)

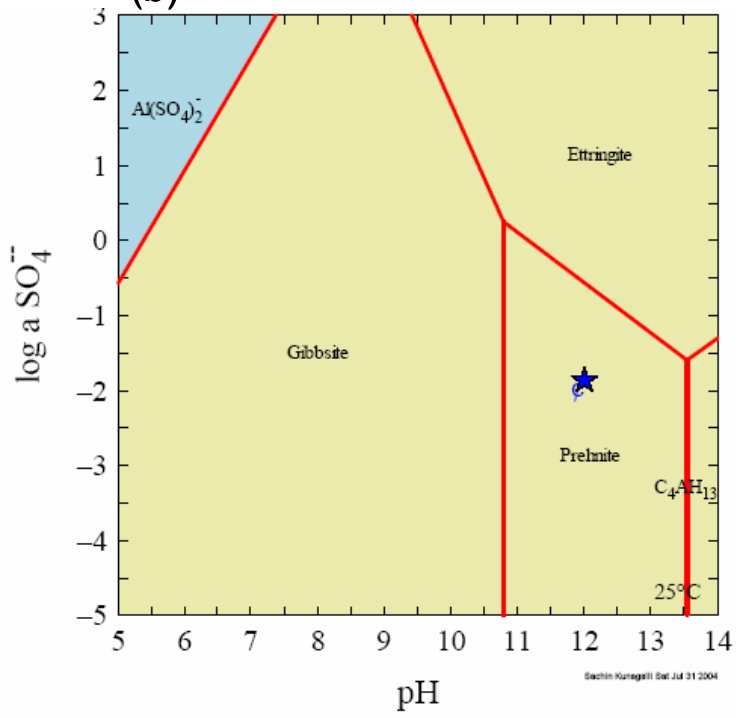

Figure 2.2 Thermodynamic phase diagram (a) Frisco soil (b) US 290 soil (Little et al. 2005)

\subsection{Mitigation and Remediation Methods}

Several methods have been proposed for mitigating sulfate induced heave in sulfate bearing soils. They include: pretreatment with barium compounds; double lime treatment; treatment with, low/non-calcium stabilizers; treatment with a combination of lime and ground granulated blast furnace slag (GGBFS); pre-compaction mellowing.

Barium compounds used to pretreat sulfate bearing soils include: barium hydroxide, barium chloride, and barium carbonate. When barium compounds react with the soluble sulfates, barium sulfate, which is not very soluble, is formed, and the availability of calcium sulfate (which can form ettringite) is reduced. The use of barium compounds, which has been applied in California, Texas and Colorado, has been shown to be successful in mitigating the expansive behavior of chemically treated soils. 
However, these compounds may have detrimental effects on the environment and are not cost-effective materials (Ferris et al. 1991; Petry and Little 1992; Dermatas 1995).

Double lime treatment, which has been suggested by many researchers (Ferris et al. 1991; Perrin 1992; Petry and Little 1992; Kota et al. 1996), involves a first application of lime to the soil with no compaction to allow the formation of the expansive minerals, and the subsequent application of additional lime prior to compaction. It appears that a critical factor affecting the effectiveness of this method is the delay period between the first and second lime treatment (Kota et al. 1996). In addition, the method appears to be effective only for soils with relatively low sulfate content (e.g. below 7000 ppm).

Low-calcium stabilizers proposed for the treatment of sulfate bearing soils include: low-alumina cement, fly ash. Non-calcium stabilizers such as polymers, resins, enzymes or acids have also been proposed. Several researchers (Kota et al. 1996; Harris et al. 2003) have been trying to prove the effectiveness of these methods in the laboratory and applying them to the field; however it is still hard to find successful well documented field case histories.

Partial substitution of lime with GGBFS has been proposed by Wild et al. (1998, 1999) as a method for mitigating sulfate-induced heave. These researchers performed laboratory swelling tests and unconfined compressive strength tests in order to find the proper combination of lime and GGBFS. However, their work was only successful with specific clays (Kimmeridge clays, U.K.) and particular sulfate levels. In addition, the long term durability of sulfate bearing soils treated with lime and GGBFS remains to be investigated. 
Pre-compaction mellowing is a method in which the soil-lime mixture is left to mellow at constant water content for several days, thus allowing the formation of expansive minerals before the soil is compacted. The method has been reported to be successful in mitigating swelling in sulfate-bearing soils. This method was applied by Harris et al. (2004) to eastern Texas soils doped with known amounts of sulfate, and treated with various percentages of hydrated lime. Mellowing periods were varied up to 3 days, in order to find the proper combination of mellowing period and sulfate content. It was concluded that 1 and 2 days of mellowing were necessary to reduce swelling of soils with sulfate contents of 5,000 and 7,000 ppm, respectively. The study also compared simple mellowing to double lime treatment and found that a single application of $6 \%$ lime led to less swelling compared to double lime treatment with $3 \%+3 \%$ lime. Having demonstrated the effectiveness of mellowing for soils typical of eastern Texas, the study cautioned against its use in soils having different characteristics without further verification. 


\section{CHAPTER 3. MATERIALS AND METHODS}

\subsection{Introduction}

The present chapter, which focuses on the materials and experimental methods employed in this research, is organized in three main sections. The first (section 3.2) describes the coal mine spoils used in this research. Specifically, it discusses how the final sampling location - on the site of the Hawthorn coal mine in Sullivan County, Indiana - was selected based on sulfate content measurements on eight different samples obtained during an exploratory stage at eight locations in six different counties in Indiana. The section provides geological descriptions of the coal mine spoil samples, emphasizing their highly heterogeneous nature, and describes the screening procedure used to homogenize the samples, break down the large clods present in the spoil and remove the coarser particles. This procedure was made necessary by the decision to employ the Harvard miniature apparatus to prepare the compacted specimens used for the swelling tests.

Section 3.3 briefly describes the four calcium based stabilizers used to treat the coal mine spoils after screening: a commercial quick lime, a research grade quick lime, a commercial hydrated lime and type I Portland cement.

Finally, section 3.4 describes the experimental procedures used to measure the sulfate content of the spoils (3.4.1 and 3.4.2), to compact the spoil samples (both alone 
and with the various stabilizers- 3.4.3), and to conduct the swelling measurements (3.4.4). The modifications to the procedures for the tests in which the following two mitigation methods - pre-compaction mellowing and double lime treatment - were investigated, are also discussed (3.4.5).

Finally, the chapter provides an overview of the sample preparation procedures and of the equipment used to perform the chemical/mineralogical tests.

\section{2. $\underline{\text { Coal Mine Spoils }}$}

\subsubsection{Sampling Locations}

Eight samples in form of five pound bags of coalmine spoils were collected by Mr. Dan Chase of the Indiana Department of Transportation between September 2002 and March 2003. Sulfate contents were determined as described in 3.4 .2 for these eight soil samples, referred to as Soil 1 through Soil 8. As discussed in more detail in Section 3.4.2, it was found that Soil 8, sampled in the area of the Hawthorn mine in Sullivan County, had the highest sulfate content. This site was selected for additional sampling, which occurred in July 2003. At that same time samples were also obtained from another site in Sullivan County located within the Minnehaha State Fish and Wildlife Area. Throughout this the symbol ' $\mathrm{H} 1$ ' is used to denote the samples from the Hawthorn mine; the Minnehaha mine spoils samples are instead denoted with the name 'Minne'. Table 3.1 summarizes the exact sampling locations, the depths of sampling, and the amount of spoil collected. 
Table 3.1 Initial sampling locations and amounts collected

\begin{tabular}{|c|c|c|c|c|}
\hline & $\begin{array}{l}\text { Sample } \\
\text { Name }\end{array}$ & Location Collected & $\begin{array}{c}\text { Date } \\
\text { Collected }\end{array}$ & $\begin{array}{l}\text { Amount } \\
\text { Collected } \\
\end{array}$ \\
\hline \multirow{8}{*}{$\begin{array}{l}\text { Sam- } \\
\text { pling } \\
\text { phase } \\
\text { I }\end{array}$} & Soil 1 & $\begin{array}{l}0.3-0.6 \mathrm{ft} \text { deep at about } 10 \mathrm{ft} \text { inside the R/W fence } \\
\text { on the north of I- } 64 \mathrm{~W} \text {, Warrick County }\end{array}$ & 09/02/02 & $5 \mathrm{lbs}$ \\
\hline & Soil 2 & $\begin{array}{l}0.2-0.5 \mathrm{ft} \text { deep on the south of CR-450 S and the } \\
\text { northwest of CR-1250 E, Gibson County }\end{array}$ & $10 / 10 / 02$ & $5 \mathrm{lbs}$ \\
\hline & Soil 3 & $\begin{array}{c}94 \mathrm{~m} \text { east of CR-275 E and 14m north of centerline } \\
\text { of SR-246, east of Clay City, Clay County }\end{array}$ & 03/03/03 & $5 \mathrm{lbs}$ \\
\hline & Soil 4 & $\begin{array}{l}\text { 19m north of centerline of CR-1100 S and } 0.65 \mathrm{mi} \\
\text { east of CR-225 E, southwest of Coal City, Clay } \\
\text { County }\end{array}$ & 03/03/03 & $5 \mathrm{lbs}$ \\
\hline & Soil 5 & $\begin{array}{l}17 \mathrm{~m} \text { north of centerline of CR-350 and } 100 \mathrm{~m} \text { east } \\
\text { of RR tracks, } 0.8 \mathrm{mi} \text { west of CR-1500 and } 0.2 \mathrm{mi} \\
\text { east of county line, Greene County }\end{array}$ & 03/04/03 & $5 \mathrm{lbs}$ \\
\hline & Soil 6 & $\begin{array}{l}25 \mathrm{~m} \text { north of CR-50 S and } 0.1 \mathrm{mi} \text { west of county } \\
\text { line Sullivan County }\end{array}$ & 03/04/03 & $5 \mathrm{lbs}$ \\
\hline & Soil 7 & $\begin{array}{c}16 \mathrm{~m} \text { west of centerline of CR-800 E and } 0.5 \mathrm{mi} \\
\text { south of Pleasantville, Sullivan County }\end{array}$ & $03 / 05 / 03$ & $5 \mathrm{lbs}$ \\
\hline & Soil 8 & $\begin{array}{l}\text { 10m west of centerline of CR- } 800 \mathrm{E} \text { and } 1 \mathrm{mi} \\
\text { southwest of Pleasantville, Sullivan County }\end{array}$ & $03 / 05 / 03$ & $5 \mathrm{lbs}$ \\
\hline
\end{tabular}

Table 3.2 Second sampling locations and amounts collected in Sullivan County

\begin{tabular}{|c|c|c|c|c|}
\hline & $\begin{array}{c}\text { Sample } \\
\text { Name }\end{array}$ & Location Collected & $\begin{array}{c}\text { Date } \\
\text { Collected } \\
\end{array}$ & $\begin{array}{l}\text { Amount } \\
\text { Collected }\end{array}$ \\
\hline \multirow{6}{*}{$\begin{array}{l}\text { Sam- } \\
\text { pling } \\
\text { phase } \\
\text { II }\end{array}$} & Minne A & $\begin{array}{c}\text { 0-2ft deep at } 0.5 \mathrm{mi} \text { east of the ranger check } \\
\text { station and } 0.75 \mathrm{mi} \text { north of SR-54, Minnehaha } \\
\text { State Fish and Wildlife Area }\end{array}$ & $07 / 07 / 03$ & $\begin{array}{l}20 \text { gal } \\
320 \mathrm{lbs}\end{array}$ \\
\hline & Minne B & $\begin{array}{c}2-4 \mathrm{ft} \text { deep at } 0.5 \mathrm{mi} \text { east of the ranger check } \\
\text { station and } 0.75 \mathrm{mi} \text { north of SR-54, Minnehaha } \\
\text { State Fish and Wildlife Area }\end{array}$ & 07/07/03 & $\begin{array}{l}20 \text { gal } \\
320 \mathrm{lbs}\end{array}$ \\
\hline & $\mathrm{H} 1-\mathrm{A}$ & $\begin{array}{l}0-2 \mathrm{ft} \text { deep at } 10 \mathrm{~m} \text { west of centerline of CR-800 E } \\
\text { and } 1 \mathrm{mi} \text { southwest of Pleasantville }\end{array}$ & 07/07/03 & $\begin{array}{l}20 \text { gal } \\
320 \mathrm{lbs}\end{array}$ \\
\hline & H1-B & $\begin{array}{l}\text { 2-4ft deep at } 10 \mathrm{~m} \text { west of centerline of CR-800 E } \\
\text { and } 1 \mathrm{mi} \text { southwest of Pleasantville }\end{array}$ & $07 / 07 / 03$ & $\begin{array}{l}30 \text { gal } \\
480 \mathrm{lbs}\end{array}$ \\
\hline & $\mathrm{H} 1-\mathrm{SC}$ & $\begin{array}{l}\text { a collection of the first scoop by backhoe, } 10 \mathrm{~m} \\
\text { west of centerline of CR-800 E and } 1 \mathrm{mi} \\
\text { southwest of Pleasantville }\end{array}$ & $07 / 07 / 03$ & $\begin{array}{l}5 \mathrm{gal} \\
80 \mathrm{lbs}\end{array}$ \\
\hline & H1-SB & $\begin{array}{l}\text { a collection of the darkest soil on the surface that } \\
\text { appeared to have the highest sulfate content, } 10 \mathrm{~m} \\
\text { west of centerline of CR- } 800 \mathrm{E} \text { and } 1 \mathrm{mi} \\
\text { southwest of Pleasantville }\end{array}$ & $07 / 07 / 03$ & $5 \mathrm{lbs}$ \\
\hline
\end{tabular}




\subsubsection{Sampling Techniques}

Samples of Soil 1 through Soil 8 were collected with a shovel, after removing the first few inches of surficial soil. While these samples were highly disturbed, this was not an issue given that the samples were intended only for chemical tests. The samples from the Minnehaha mine and Hawthorn mine were also disturbed samples. In this case, however, due to the greater amount of soil to be sampled (soil was needed not only for chemical tests, but also for the compaction and swelling tests), a backhoe was used to remove approximately the first 6 inches of soil. Then the first sample was collected up to a depth of approximately 2 feet. This soil was excavated with the backhoe and transferred to 5 gallon buckets. This sample, referred to in the following as H1A, was used for the majority of the tests presented in this report. A second sample (H1B) was collected in a similar manner by excavating up to a depth of 4 feet. As shown in Table 3.2, these two samples comprised $320 \mathrm{lbs}$ and $480 \mathrm{lbs}$ of soil, respectively. In addition two smaller samples were collected closer to the surface: one sample (H1SB) comprised very dark soil which was present at the surface; the second sample (H1SC) was part of the most superficial 6" of soil first removed by the backhoe. Care was taken to ensure that the soil sampled was representative of the field conditions; however some of the very large "aggregates" present in the spoil, including a 18" diameter piece of shale, were not collected.

Similar procedures were followed to collect two large samples (see Table 3.3and 3.4) from the Minnehaha State Fish and Wildlife Area site. 
Figure 3.1 shows pictures taken at the two sites during sampling. They highlight the highly heterogeneous nature of the spoils.
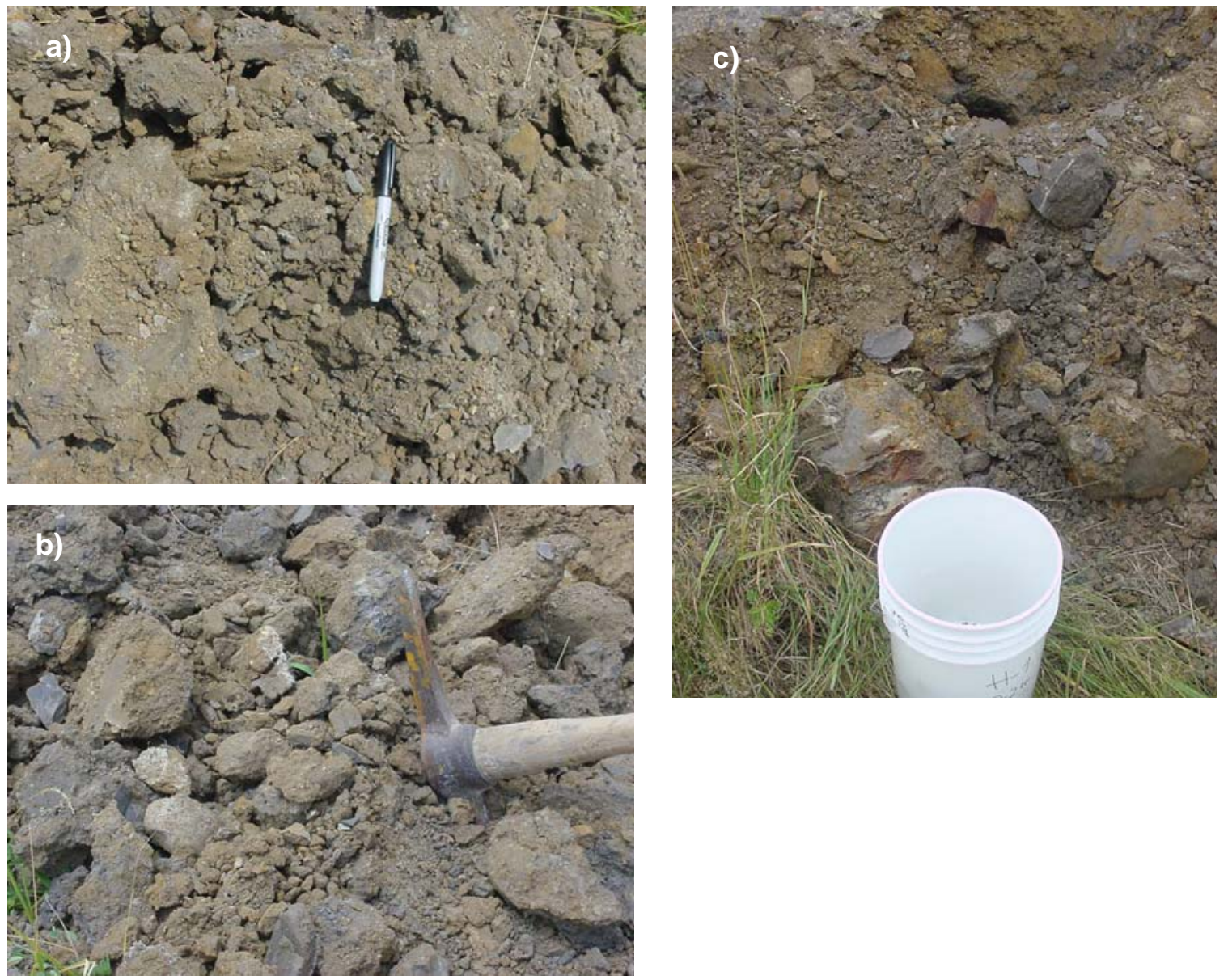

Figure 3.1 Heterogeneous nature of coal mine spoils at a) Minnehaha and b)-c) Hawthorn sites 


\subsubsection{Characteristics (Geological Description)}

The following geological descriptions are based on visual examination conducted on the spoil samples immediately following sampling by Mr. Wendell Solomon, who worked on the research project as part of a summer undergraduate research experience.

\section{A. Minnehaha Mine Spoil, 0-2 and 2-4 ft - Minne A and Minne B}

This mine spoil was largely composed of glacial till, a brown clay soil matrix containing coarser aggregates (mostly pebbles) and clods of various sizes. Till present in large clod form is believed to represent the remains of the pre-mined virgin soil. Most of the soil was in the form of loose till due to the mechanical disturbance from mining and sampling. There was a relatively small amount of coal that could be visually identified (Figure 3.1). Gray shale present was believed to be the local bedrock material that was excavated by the drag line in the mining process. These shale pieces ranged in size from $1 / 2$ in to 3 in diameter, and consisted of long plate like particles. Approximate percentages of the various components outlined above are summarized in Table 3.3 and 3.4. Small errors may derive from the fact that not all of the shale or coal was picked out from the till matrix. However the results should be within a percent or two of the actual values. 
Table 3.3 Geological descriptions for Minne A soil

\begin{tabular}{|c|c|c|}
\hline & Mass $(\mathrm{g})$ & \% of soil \\
\hline \hline (Loose) Till & 15400 & 76.2 \\
\hline Clods & 3039 & 15.0 \\
\hline Pebbles & 80 & 0.4 \\
\hline Gray Shale & 1670 & 8.2 \\
\hline Coal Pieces & 34 & 0.2 \\
\hline Total Soil & 20223 & 100.0 \\
\hline
\end{tabular}

Table 3.4 Geological descriptions for Minne B soil

\begin{tabular}{|c|c|c|}
\hline & Mass (g) & \% of soil \\
\hline (Loose) Till & 1399 & 47.5 \\
\hline Clods & 1058 & 36.0 \\
\hline Pebbles & 10 & 0.3 \\
\hline Gray Shale & 468 & 15.9 \\
\hline Coal & 10 & 0.3 \\
\hline Total Soil & 2945 & 100.0 \\
\hline
\end{tabular}

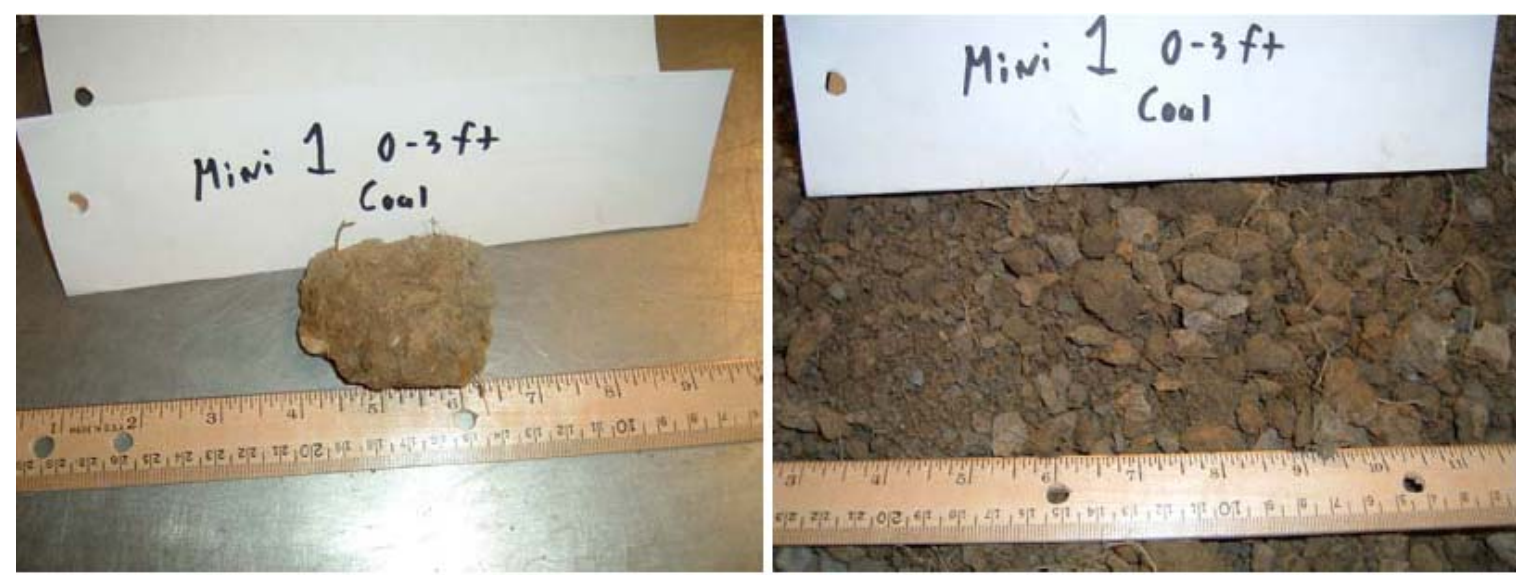

Figure 3.2 Coal pieces in Minne A soil 


\section{B. Hawthorn Mine Spoil, surface material- H1-SB}

This was a dark mine spoil with large quantities of coal and black shale; soil fines appeared to derive from the weathering of the coal and black shale. These fine soil particles ranged from clay particles up to particles $1 / 2$ in diameter. Many of the black shale pieces had red stains along fractures implying some iron concentration in these soils. Shale particles ranged in size from $1 / 2$ in to 3 in diameter. There was also a yellowish white silt stone with a range in diameter from $1 / 4$ in to $7 / 4$ in diameter. A large amount of coal was present in the form of pieces having diameter from $1 / 16$ in to 1.8 in. Table 3.5 summarizes the percentages of the various components. As above, some error may derive from the fact that some coal and shale particles were left in the matrix of loose soil. Also note that some larger pieces could not be sampled and were left at the site.

Table 3.5 Geological descriptions for H1-SB soil

\begin{tabular}{|c||c|c|}
\hline & Mass (g) & \% of soil \\
\hline \hline (Loose) Till & 1469 & 72.9 \\
\hline Silt Stone & 109 & 5.4 \\
\hline Black Shale & 330 & 16.3 \\
\hline Coal & 107 & 5.3 \\
\hline Total Soil & 2016 & 100.0 \\
\hline
\end{tabular}



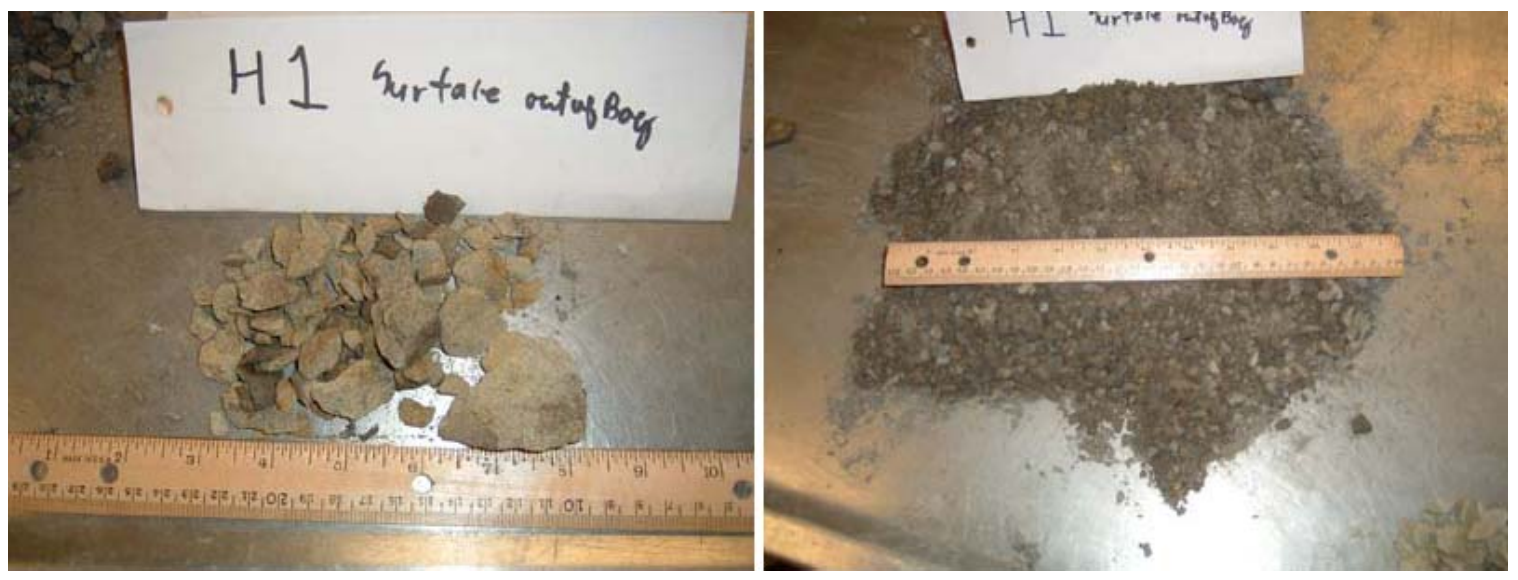

Figure 3.3 Separation of H1-SB soil into various fractions

C. Hawthorn Mine Spoil, surface material from first scoop of back hoe - H1-SC

Spoil was primarily composed of brown glacial till with gray brown flat plate like shale particles. Shale particles ranged from $1 / 4$ in to 2 in diameter. Most coal present was about to $1 / 2$ in diameter. See Table 3.6 for a summary of the various fractions present.

Table 3.6 Geological descriptions for H1-SC soil

\begin{tabular}{|c|c|c|}
\hline & Mass $(\mathrm{g})$ & \% of soil \\
\hline (Loose) Till & 2224 & 78.1 \\
\hline Gray Brown Shale & 613 & 21.5 \\
\hline Coal & 11 & 0.4 \\
\hline Total Soil & 2848 & 100.0 \\
\hline
\end{tabular}



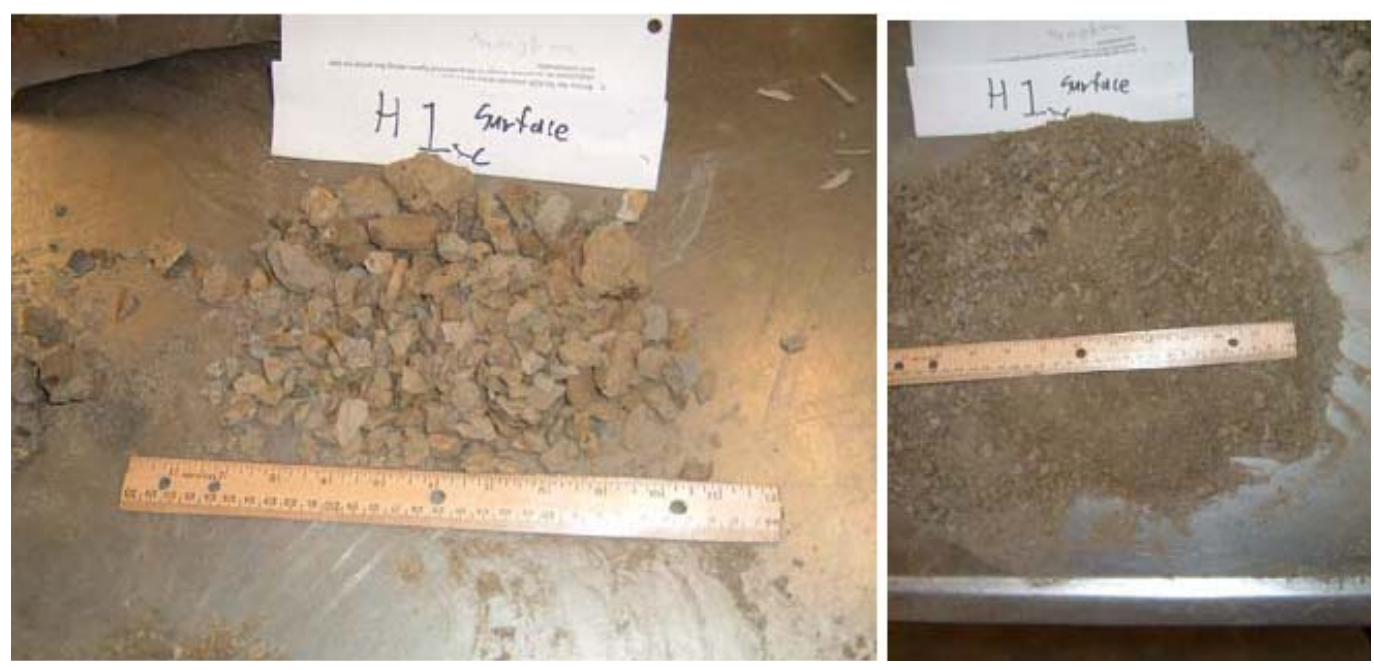

Figure 3.4 Separation of H1-SC soil in various fractions

D. Hawthorn Mine Spoil, 0-2 and 2-4 ft - H1-A and H1-B

Soil particles ranged from clay particles up to particles 1 in diameter. Like the H1-SB sample, many of the black shale pieces had red stains along fractures implying the presence of iron. Shale particles ranged in size from $1 / 2$ in to 3 in diameter. Also in this case, some larger pieces were left at the site. Table 3.7 and Table 3.8 summarize the various fractions.

Table 3.7 Geological descriptions for H1-A soils

\begin{tabular}{|c||c|c|}
\hline & Mass $(\mathrm{g})$ & \% of soil \\
\hline \hline (Loose) Till & 1033 & 48.5 \\
\hline Clods & 894 & 42.0 \\
\hline Gray Shale & 193 & 9.1 \\
\hline Coal & 8 & 0.4 \\
\hline Total Soil & 2128 & 100.0 \\
\hline
\end{tabular}


Table 3.8 Geological descriptions for H1-B soil

\begin{tabular}{|c||c|c|}
\hline & Mass $(\mathrm{g})$ & \% of soil \\
\hline (Loose) Till & 1354 & 51.0 \\
\hline Clods & 222 & 8.4 \\
\hline Gray Shale & 1043 & 39.4 \\
\hline Coal & 31 & 1.2 \\
\hline Total Soil & 2650 & 100.0 \\
\hline
\end{tabular}
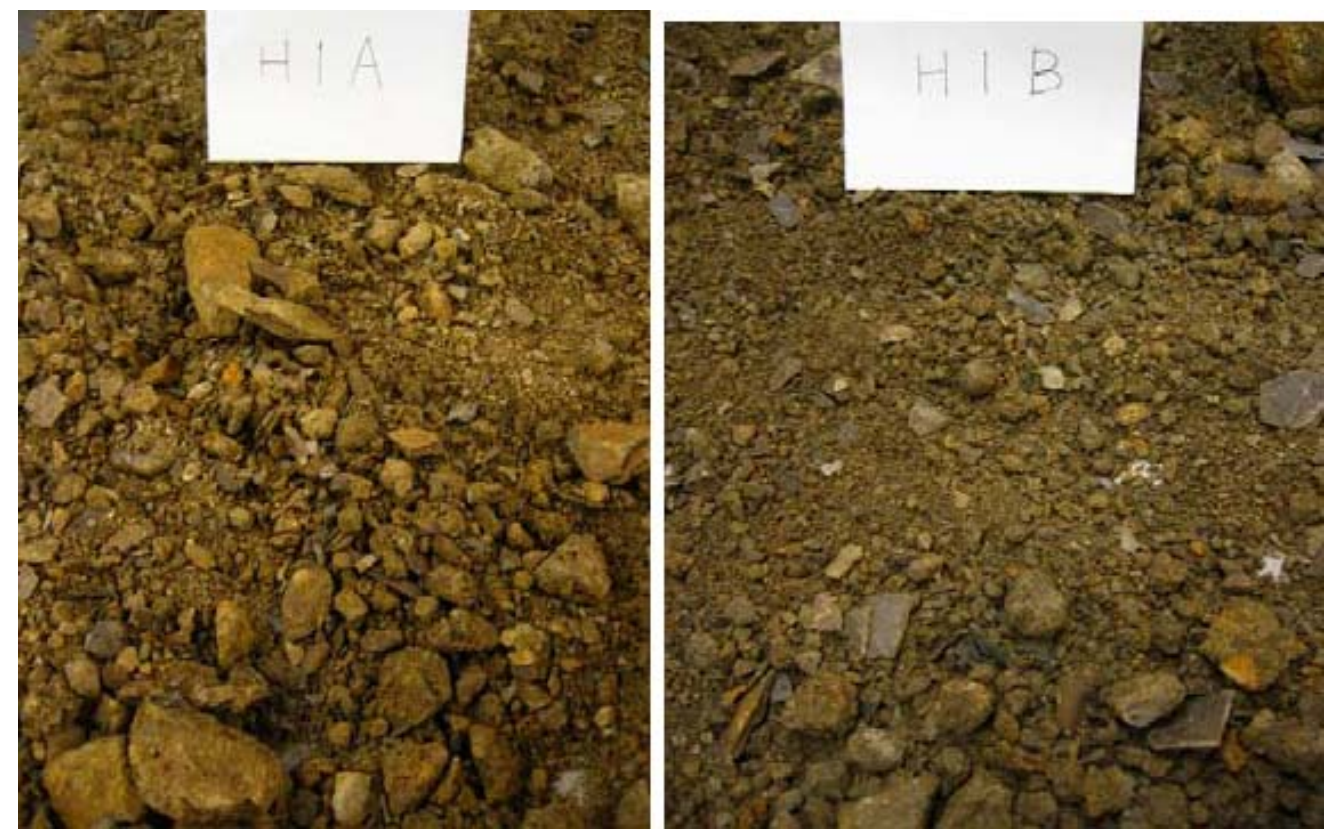

Figure 3.5 H1-A and H1-B soils

Table 3.9 summarizes the results of the geological description for the six samples collected from the Hawthorn and Minnehaha sites. The data indicate the highly variable nature of the spoils even at a given location. 
Table 3.9 Summary of geological descriptions

\begin{tabular}{|c||c|c|c|c|c|c|}
\hline & $\begin{array}{c}\text { Minne A } \\
(\%)\end{array}$ & $\begin{array}{c}\text { Minne B } \\
(\%)\end{array}$ & $\begin{array}{c}\text { H1-SB } \\
(\%)\end{array}$ & $\begin{array}{c}\text { H1-SC } \\
(\%)\end{array}$ & $\begin{array}{c}\text { H1-A } \\
(\%)\end{array}$ & $\begin{array}{c}\text { H1-B } \\
(\%)\end{array}$ \\
\hline Till & 76.2 & 47.5 & 72.9 & 78.1 & 48.5 & 51.0 \\
\hline Clods & 15.0 & 36.0 & - & - & 42.0 & 8.4 \\
\hline Pebbles & 0.4 & 0.3 & 5.4 & - & - & - \\
\hline Shale & 8.2 & 15.9 & 16.4 & 21.5 & 9.1 & 39.4 \\
\hline Coal & 0.2 & 0.3 & 5.3 & 0.4 & 0.3 & 1.2 \\
\hline Total Soil & 100.0 & 100.0 & 100.0 & 100.0 & 100.0 & 100.0 \\
\hline
\end{tabular}

\subsubsection{Screening of Soils}

As shown in Figure 3.1 and in Table 3.9, coal mine spoils are highly heterogeneous materials with a large range in particle sizes. As a result of the nature of these materials concerns arise as to the:

- Repeatability of the tests;

- Selection of the very small samples required for chemical testing (in particular sulfate content determination);

- Selection of the samples to be used for the compaction and swelling tests.

As discussed later in the report, primarily to limit the amount of soil used, the swelling tests were conducted on 1.3 in diameter by 2.8 in tall triaxial size specimens compacted using the Harvard miniature apparatus. The use of this method is limited to soils with particle size smaller than \#4 sieve (4.76 mm) (Wilson 1970).

Hence, prior to performing any test the soil was screened and crushed to remove coarser particles and aggregates. The following procedure was used to screen the coal mine spoil samples obtained from the Hawthorn coal mine site prior to compaction. The 
soil from the field was first air-dried and particles larger than approximately 1 " in diameter were removed by hand. Less than $20 \%$ of the soil was eliminated in this phase. The soil was then mixed in a $1.5 \mathrm{ft}^{3}$ concrete mixer to homogenize the samples and break down the existing clods. After mixing, the soil was broken and crushed into smaller pieces with a hammer, and sieved through a \#4 sieve (corresponding to $4.75 \mathrm{~mm}$ ). The soil finer than $4.75 \mathrm{~mm}$ was crushed further and pulverized using a mechanical crusher until it was almost all passing through a $\# 40$ sieve $(0.425 \mathrm{~mm})$. Finally, the pulverized soil was mixed again using a $1.5 \mathrm{ft}^{3}$ concrete mixer. Note that approximately $20 \%$ additional soil was screened through the two sieving operations, leading to a total amount of material eliminated through the screening process of $35-40 \%$.

It is recognized that the above described screening procedure leads to the formation of a geomaterial that differs from that present in the field. There is no doubt that the compaction behavior of the coal mine spoils investigated in this research would have been better studied employing much larger samples (and perhaps a field test). However, the mixing and crushing action applied during the screening process were intended to simulate the action of compaction equipment in the field. Additionally, as a result of the screening process which led to the "loss" of a significant amount of coarser material, the resulting swelling behavior of the soil following treatment with various calcium-based stabilizers is likely to represent a "worst case scenario".

A procedure similar to that described above was followed to treat the $\mathrm{H} 1$ and Minne soil samples used for the measurements of sulfate content conducted immediately after sampling (see data in Table 3.9). In addition to eliminating the material greater than 1 ", the soil was also sieved through the $3 / 8$ " sieve. Then it was sieved as above through 
the \#10 and \#40 sieves. Note that sulfate content determinations were conducted on both the material passing (data in Table 3.9) and the material retained on the \#40 sieve.

Note that a different procedure was used to treat the samples of Soils 1-8 (see Table 3.1) prior to determination of their sulfate content. In this case each soil sample was fed through a sample splitter until a sample of about $100 \mathrm{~g}$ was collected. This sample was used, without further crushing or sieving, for measuring the sulfate content (see procedure for this test in section 3.4.2). Note that for these samples no effort was placed to crush the material that did not fit through the sample splitter. It was simply discarded.

\subsection{Stabilizers}

\subsubsection{Hydrated Lime and Quick Lime}

Two types of lime products, both purchased from the Carmeuse lime company in Indiana, were used to investigate the effect of stabilizer on sulfate induced heave: hydrated lime and quick lime. These calcium-based stabilizers are widely used in the field of road construction in Indiana.

Quick lime is the term commonly used to refer to calcium oxide, $\mathrm{CaO}$. The commercial product used in this research has a granular appearance (larger lumps in a powder matrix) and is odorless, and white or grayish-white in color. According to the MSDS provided by the manufacturer the quick lime used in this project is comprised of $89 \%$ of calcium oxide, less than $4 \%$ of magnesium oxide and less than $1 \%$ of silica- 
crystalline quartz. Quick lime has a molecular weight of 56.08 (this number is required to determine the amount of water required to allow all the lime to react).

Hydrated lime is the term used to refer to calcium hydroxide, $\mathrm{Ca}(\mathrm{OH})_{2}$, an odorless white or grayish-white granular powder, with molecular weight of 74.08 and specific gravity of 2.24 . According to the MSDS sheet provided by the manufacturer, the hydrated lime used in this research is comprised of more than $85 \%$ calcium hydroxide and less than $1 \%$ of silica-crystalline quartz.

In addition to the two commercial lime products listed above, a research grade quick lime was also used in the experimental program. This lime product, referred to in this as "analytical lime" is comprised of over $99 \%$ calcium oxide.

In order to avoid hydration due to humidity, and carbonation from the air, the lime products were kept in their original containers, which were flushed with nitrogen gas and sealed tightly. Whenever a container was opened, the container was refilled with nitrogen gas before it was closed. Periodic XRD tests (see Chapter 5) demonstrate that these precautions were effective in avoiding carbonation and partial hydration of the lime. As discussed in Chapter 4 , dosages of the lime of $3 \%$ and $7 \%$ by mass of the dry soil were selected to treat the coal mine spoils based on the results of $\mathrm{pH}$ fixation tests (see Section 4.2.3). Note that these dosages are consistent with general field practice. In the case of hydrated lime, additional work was conducted with dosages of $1.5 \%, 5 \%$ and $9 \%$ by mass of the dry soil (see Section 4.3.4). 


\subsubsection{Portland Cement}

Type-I Portland cement, obtained from Lone Star industries, was also used in this research. Type I Portland cement is widely used for soil treatment in Indiana and is readily available. As explained in Chapter 4 , dosages of $3 \%$ and $7 \%$ by mass of the dry soil were used also for this stabilizer.

\subsection{Experimental Methods}

\subsubsection{Existing Methods for Sulfate Content Determination}

One of the major problems involving sulfate induced heave, and sulfate attack in general, is the lack of a common used methodology for determining the sulfate content of soils. As noted by Puppala et al. (2002), this may be in part responsible for the range in the sulfate threshold contents (or critical sulfate contents) reported by various researchers in the literature. Currently the following four documented methods - none standardized exist for sulfate content determination:
A. Texas Department of Transportation Method (Tex-620-J Method)
B. U.S. Army and Air Force Method (TM 5-822-14/AFJMAN 32-1019)
C. AASHTO Method (Designation T 290-95, 1999)
D. The University of Texas at Arlington (UTA) Method and the Modified UTA
Method 
Two key aspects characterize each of these methods, which are all intended for fine-grained soils: the procedure used to extract the sulfate from the soil, and the method used to determine the sulfate content of the solution extracted. Note that currently there is no standard ASTM or U.S. Army Corps of Engineers (USACE) test method. The following paragraphs provide a brief summary of methods A-D.

\section{A. Texas Department of Transportation Method}

The Texas Department of Transportation Method (Tex-620-J Method) is used by the Texas Department of Transportation (TxDOT) in highway construction projects. The method involves mixing $30 \mathrm{~g}$ of dry soil sieved through the U.S. \#4 sieve with $300 \mathrm{ml}$ of deionized water and heating this mix for 24 hours at a near-boiling temperature. After filtration through a $2.5 \mu \mathrm{m}$ filter, $\mathrm{BaCl}_{2}$ is added to the solution, which is again heated to a near boiling temperature of $100^{\circ} \mathrm{C}$ for $10 \mathrm{~min}$. The solution is then filtered through a Whatman filter No. 42. The sulfate content is determined from the weight of the barium sulfate $\left(\mathrm{BaSO}_{4}\right)$ precipitate left on the filter. For details on this method see Puppala et al. (2002).

\section{B. U.S. Army and Air Force Method}

The U.S. Army and Air Force Method (TM 5-822-14/AFJMAN 32-1019) is also based on measuring the precipitation of barium sulfate $\left(\mathrm{BaSO}_{4}\right)$, and involves a procedure similar to that described above. Compared to the Texas DOT method, procedural differences are in: the solid-water dilution factor (1:30 instead of $1: 10)$; the duration of the first heating stage ( 1.5 hours $)$ and the size of the filter used in the first filtration 
$(8 \mu \mathrm{m})$; an intermediate treatment of the filtrate with $\left(\mathrm{MgCl}_{2}\right)$ and an additional filtration stage prior to addition of the barium chloride $\left(\mathrm{BaCl}_{2}\right)$; a $12 \mathrm{~h}$ digestion stage after adding the $\mathrm{BaCl}_{2}$. For details on this method see Puppala et al. (2002).

\section{AASHTO Method}

Two procedures are included in the AASHTO (Designation T 290-95, 1999) method: a gravimetric procedure and a turbidimetric procedure. The first one is "utilized to determine the amount of water-soluble sulfate ion present in the soil". Similarly to the previous ones, the sulfate ion is precipitated and the mass determined as barium sulfate after removal of silica and other insoluble matter. The method is "applicable to samples containing approximately 20 to $100 \mathrm{mg} / \mathrm{kg}$ of sulfate ion and it can be extended to higher or lower ranges". The turbidimetric method is "intended for rapid routine or control tests for the water soluble sulfate ion in soil where extreme accuracy and precision are not necessary".

In both methods, the dried sample (in air or drying apparatus not exceeding $60^{\circ} \mathrm{C}$ ) of finer than $2 \mathrm{~mm}$ (\#10 sieve) is used for the test. The fraction retained on the sieve is pulverized and then the fraction passing \#10 sieve is mixed with previously obtained sample. $300 \mathrm{~mL}$ of distilled water is added to $100 \mathrm{~g}$ of the soil sample and thoroughly mixed for the test.

\section{The UTA and the Modified UTA Method}

The UTA Method was formulated by Petry (1994) based on the gravimetric analysis for sulfate measurements in water. Petry (1994) modified the method to take into 
consideration differences in the nature of the media (soil instead of water). While, compared to the other three methods, the UTA method is considered a refined test method, a revised method - the Modified UTA Method - was proposed by Puppala et al. (2002). The latter represents the state of the art for sulfate determination and is briefly summarized below.

The Modified UTA Method involves mixing $10 \mathrm{~g}$ of dried soil with $100 \mathrm{~mL}$ of distilled water. The solution is subjected to a shaking process and then put in a centrifuge (with $\sim 14,000 \mathrm{rpm}$ ) to extract the soluble sulfates. The solution extracted is then filtered through a $0.1 \mu \mathrm{m}$ filter (this is one of the key differences with respect to the original UTA method which used a $0.45 \mu \mathrm{m}$ filter) and the filtrate is then diluted with $200 \mathrm{ml}$ of distilled water. At this point, if necessary, the solution's $\mathrm{pH}$ value is adjusted to fall between 5 and 7 . The filtrate is then heated to the boiling point while adding $\mathrm{BaCl}_{2}$. The process stops when no more precipitation is observed. After the solution stays at least 12 hours in a $80-90{ }^{\circ} \mathrm{C}$ oven, the digested precipitate is filtered one more time through a 0.1 $\mu \mathrm{m}$ membrane. Finally, the membrane is dried, weighed, and the residual weight is used to calculate the $\mathrm{SO}_{4}{ }^{2-}$ present in the soil specimen (Puppala et al. 2002).

\subsubsection{Determination of Sulfate Content of Coal Mine Spoils}

The following procedure was used to determine the sulfate content of the coal mine spoils utilized in this research project. It is based on the modified UTA method proposed by Puppala et al. (2002) (see below for a discussion of the deviations from this method). 
1. Testing is done on a $10 \mathrm{~g}$ sample of soil that has been sieved through a $\# 4(4.75 \mathrm{~mm})$ sieve.

2. $100 \mathrm{ml}$ of de-ionized water is added to the container with the samples.

3. The samples are agitated for $60 \pm 5$ minutes with a US Stoneware rolling wheel mixer at 260 RPM.

4. The samples are then centrifuged for $60 \pm 5$ minutes using an International Equipment Corporation's model CS Centrifuge (RPM 6000)

5. The solute is filtered through a $0.1 \mu \mathrm{m}$ filter.

6. The sulfate content is determined, either using a gravimetric method or employing ion chromatography (IC).

In the first case, the filtrate is diluted to $200 \mathrm{ml}$ by adding distilled water. If necessary, the $\mathrm{pH}$ value of the solute is adjusted to fall between 5 and 7 using a few $\mathrm{ml}$ of dilute hydrochloric acid. The solute is boiled and titrated with barium chloride until no precipitation is observed. The solute is then digested in an oven kept at a controlled temperature of $85^{\circ} \mathrm{C}$ for 12 hours. Finally, the precipitate is rinsed onto a $0.1 \mu \mathrm{m}$ filter paper of known mass. This filter paper is then dried and weighed. The residual weight is used to calculate the $\mathrm{SO}_{4}{ }^{2-}$ present in the soil sample.

When using ion chromatography (in this research a Dionex Bio LC ion chromatograph was used), the following procedure is employed after filtration through the $0.1 \mu \mathrm{m}$ filter paper (step 5 above):

a) de-ionized water is added to the solute to obtain $200 \mathrm{~mL}$ of solute. 
b) the solute is diluted a number of times to place the concentration of the solute in the calibrated range $(0,10,25$ and $50 \mathrm{ppm})$ of the ion chromatograph. In this research the dilution factor was typically 100.

c) Approximately $0.5 \mathrm{ml}$ of solute is injected into the ion chromatograph. Regardless of how the sulfate contents of the soil extract is obtained, the data are then converted to ppm and expressed in terms of sulfate content of the soil solids.

There are several differences between how these sulfate contents tests were performed in this research and the procedure recommended by Puppala et al. (2002).

1. De-ionized water was used in place of distilled water. This is considered an improvement to the method as it avoids the addition of ions to the solutions.

2. While the Modified UTA method recommends using an Eberbach Shaker, a rolling wheel mixer was used in this research. To compensate for the less efficient mixing of the rolling wheel mixer, the time of agitation was extended from 30 minutes to $60 \pm 5$ minutes.

3. The Modified UTA method recommends the use of a IEC-HT Centrifuge (with14,000 rpm) for 30 minutes. This type of centrifuge was not available in the geotechnical laboratory at Purdue. Hence the locally available centrifuge was used. The centrifuging time was extended to $60 \pm 5$ minutes to compensate for the lower RPM $(\sim 6,000$ in place of 14,000$)$.

4. When using the barium titration method, the barium chloride solution was not filtered through a $0.1 \mu \mathrm{m}$ filter before each use. Instead, the $\mathrm{BaCl}_{2}$ solution was visually inspected to ensure that there were no particulates in it. 
5. The recommended silver nitrate tests were not performed to determine if residual chlorides were present in the precipitate; instead, the samples were flushed with large quantities of de-ionized water.

Note that the use of the ion chromatography for determination of the sulfate content of the filtrates is not suggested by Puppala et al. (2002). This method was utilized in this research because, once calibration of the equipment is completed, it is quite time efficient and yields data that is self consistent.

Table 3.10 summarizes the values of the sulfate contents measured on six of the eight samples collected during the first preliminary sampling stage using the two techniques summarized above (sulfate contents were determined also for soils 1 and 2; while the data are not available, there is record that for both soils they were lower than the values obtained for soils 4 and 8 [Solomon 2003]). Despite the differences between the data obtained with the gravimetric method and the IC, it is observed that only two samples - Soil 4 and Soil 8 - had sulfates contents that could represent a concern. Additionally, the sulfate content of Soil 8 greatly exceeded that of all other soils. Hence additional sampling was conducted at the location where Soil 8 had been obtained. Sulfate content determinations on these samples (all identified by the symbol H1) confirmed the elevated sulfate contents $(\sim 7,000-15,000 \mathrm{mg} / \mathrm{kg})$. Note that extraction tests, and subsequent sulfate determination tests were conducted also on subsamples of soil H1 of different fineness (finer than and passing the $\# 40$ sieve - see section 3.2.4.). These data were found to be overall consistent. 
Table 3.10 Sulfate contents of coal mine spoil samples

\begin{tabular}{|c|c|c|c|c|c|}
\hline $\begin{array}{c}\text { Sample } \\
\text { name }\end{array}$ & $\begin{array}{c}\mathrm{SO}_{4} / \mathrm{soil} \\
(\mathrm{mg} / \mathrm{kg}, \\
\mathrm{GV})\end{array}$ & $\begin{array}{c}\mathrm{SO}_{4} / \mathrm{soil} \\
(\mathrm{mg} / \mathrm{kg}, \mathrm{IC})\end{array}$ & $\begin{array}{c}\text { Sample } \\
\text { name }\end{array}$ & $\begin{array}{c}\mathrm{SO}_{4} / \mathrm{soil} \\
(\mathrm{mg} / \mathrm{kg}, \\
\mathrm{GV})\end{array}$ & $\begin{array}{c}\mathrm{SO}_{4} / \text { soil } \\
(\mathrm{mg} / \mathrm{kg}, \mathrm{IC})\end{array}$ \\
\hline \hline Soil 3 & 76.16 & 132.86 & H1-SC & - & 7364.20 \\
\hline Soil 4 & 2873.37 & 833.53 & H1-SB & - & 9428.81 \\
\hline Soil 5 & 1772.63 & - & H1-A & - & 14843.20 \\
\hline Soil 6 & 123.96 & 41.77 & H1-B & - & 10680.96 \\
\hline Soil 7 & 405.79 & 0.17 & Minne A & - & 76.15 \\
\hline Soil 8 & 12401.73 & 6354.01 & Minne B & - & 436.55 \\
\hline
\end{tabular}

Note: $\mathrm{GV}=$ gravimetric method, $\mathrm{IC}=$ ion chromatography method

Table 3.10 also shows the sulfate content of the soil sampled at the Minnehaha wildlife site. Due to the low sulfate content values $(<500 \mathrm{mg} / \mathrm{kg})$, these samples were not further employed in this research, and all further testing made use of the "H1" soil.

\subsubsection{Compaction}

The specimens, 2.8 in in height and 1.3 in diameter, used for the swelling tests were compacted using the Harvard miniature compaction apparatus (Figure 3.6). This procedure was selected to minimize the amount of soil used. Further, the size and the aspect ratio of the specimen were chosen to accelerate the swelling process and to yield higher values of the swelling strain. The maximum dry density and optimum water content were determined for the soil alone, and for the various soil-stabilizer combinations examined in this research. For each soil-stabilizer combination, the material required to yield one soil specimen at each of 5 different water content values was 
tempered for 24 hours at constant water content. After 24 hours, the appropriate amount of stabilizer and the water required to react with the stabilizer were added and mixed with the wet soil just before compaction.

A lubricant was used on the inside of the Harvard miniature mold to facilitate extrusion of the compacted specimens from the mold (and avoid shearing of the specimens while extracting the specimen from the mold). The procedure used in preparing the specimens is summarized below:

1. Weigh the compaction mold and measure its internal dimensions; clamp the mold and collar to the base.

2. Add the desired amount of loose soil in the mold (this amount is based on the use of 5 layers to fill the entire mold). Level the surface of the soil.

3. Insert the tamper in the mold until it is in contact with the soil. Press down on the tamper until the spring starts to move. Note that the tamper must be calibrated to start moving at a force of $40 \mathrm{lbs}$. Release the pressure and move the tamper to a new position. Start tamping at the edge of the mold applying one tamp in each quadrant before applying the fifth tamp at the center. Repeat this procedure 5 times for a total of 25 tamps.

4. Repeat steps 2 and 3 four more times to obtain the 5 layers.

5. Separate the collar from the mold and remove the mold from the base.

6. Using a straight edge, trim the excess soil on the top of the mold and at its bottom (if needed).

7. Weigh the mold and soil contained inside and then extrude the soil specimen. Take samples from the trimmed material for water content measurement. 


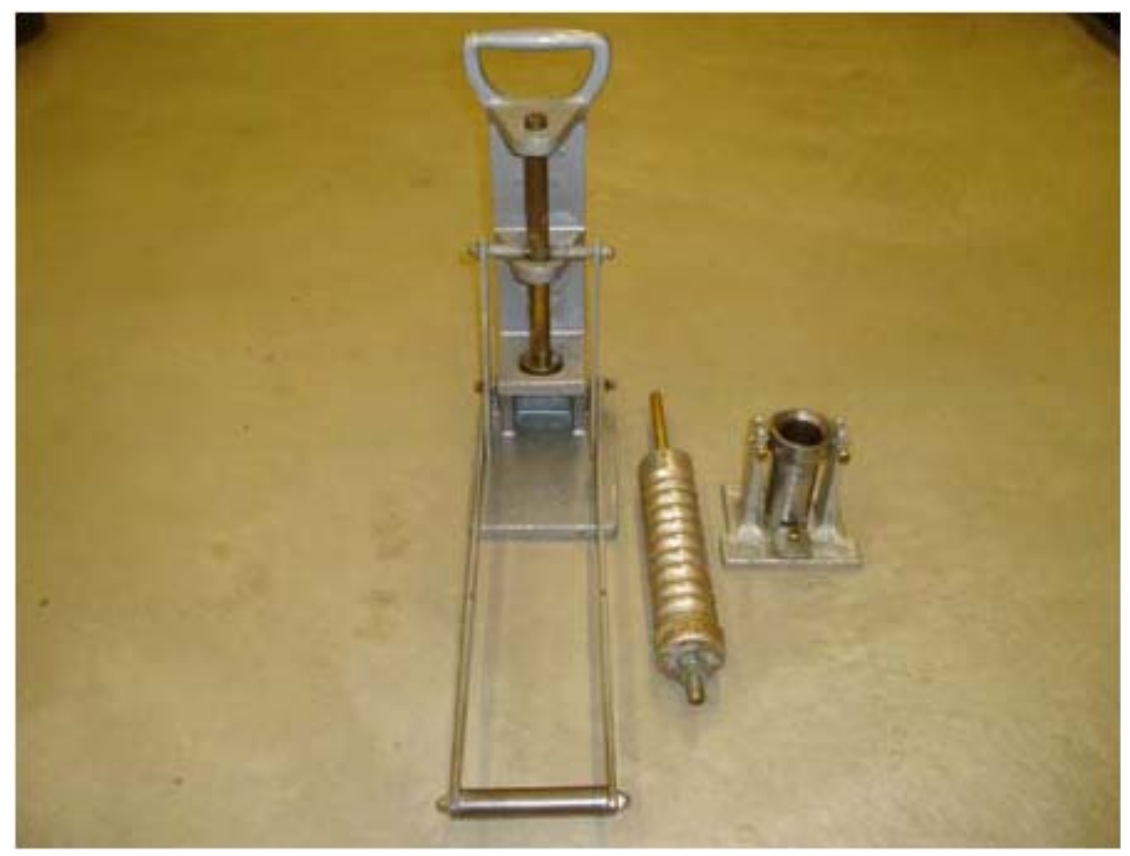

Figure 3.6 Harvard miniature compaction apparatus

\subsubsection{Swelling Measurement}

The following paragraphs summarize the procedure used for: a) preparation of the specimens used for the swelling tests; b) setup of the specimens in a sand bath and subsequent one-dimensional swelling tests.

\section{A. Specimen Preparation}

The soil samples are mixed with the required amount of water to achieve the optimum water content and are tempered for 24 hours before compaction. Before compaction, the required amount of stabilizer is added to each soil sample along with the amount of water required to react with the stabilizer. 
The specimens are compacted using the Harvard compaction apparatus (Figure 3.6) in a manner similar to that described above. Lubricant is not used on the inside of the mold to avoid contaminating the specimen and for fear that it might create an impermeable layer on the lateral surface which could prevent water from entering the specimen from the sides during the swelling stage. Therefore, an alternative procedure is required to facilitate specimen extrusion and prevent specimen shearing during extraction from the mold. The procedure used in preparing the specimens is summarized below:

1. Prepare a piece of wax paper with length equal to the height of the Harvard compaction mold (including the collar) and width equal to the internal perimeter of the mold.

2. Tape the mold and collar together. Place the wax paper inside the mold and tape it to form a cylinder inside the mold.

3. Make multiple 2-3 mm long cuts in the top part of the wax paper, and tape it to the outside of the mold.

4. Clamp the mold and collar to the base, and add the desired amount of soil in the mold.

5. Proceed as described for the compaction tests to compact 5 layers.

8. Remove the mold and collar from the base.

9. Remove the tape holding the mold and collar together. Cut the tape holding the wax paper in place. Note that the tape cannot be removed at this time since the soil inside the mold covers a portion of the tape. Remove the collar and, using a razor, cut the wax paper along the upper edge of the mold and remove the upper part of the wax paper. 
10. Using a straight edge, trim the excess soil on the top of the mold and at its bottom (if needed). Use the trimmed soil for initial water content measurements.

11. Place the mold in the sample ejector and extrude the specimen. Remove the wax paper and measure the weight, diameter and height of the specimen (three readings each for diameter and height).

\section{B. Sand Bath Preparation}

Immediately after compaction, the specimens intended for the swelling tests are placed in a sand bath and provided access to water, while monitoring the resulting swelling strains (additional specimens were tested to measure the unconfined compressive strength). The sand-bath setup used in this research is based on the set-up employed by Mitchell and Dermatas (1992). The specimen is placed in a rigid container, on a bed of sand and is surrounded by densely compacted sand, which is then saturated with water. Therefore, the sand bath allows for water access from all directions and provides some lateral confinement. In this research, plastic containers (3-in in diameter and 6-in tall), typically used to cast concrete specimens, were used to house the sand bath. This was done to: accommodate the triaxial size specimen obtained using the Harvard miniature compaction tests, and to allow placement of all swelling specimens in the same Styrofoam housing (see below). Additionally, the low cost of the setup allowed performing several concurrent swelling measurements. Figure 3.7 a shows a compacted specimen placed inside the plastic cylinder and surrounded by the sand. As shown in Figure $3.7 \mathrm{~b}$, a stainless steel cylinder was placed on top of each specimen to provide the desired surcharge (see also surcharge on sand surface). For most tests a reference 
surcharge of $0.3 \mathrm{psi}(2 \mathrm{kPa})$ (in the form of a 1" tall stainless steel cylinder) was used. This value is representative of the low end of stresses exerted by a pavement system (e.g. corresponding to a pavement with 2 in of asphaltic concrete as wearing surface, and additional 3 in of asphalt stabilized sand as base [both with $\gamma=110$ pcf], Holtz and Kovacs 1981) on the underlying subgrade. Note that higher surcharge stresses are expected with different pavement systems (e.g. in the case of 8 in of Portland cement surface $[\gamma=150$ pcf] and 10 in of sand-gravel base $[\gamma=130 \mathrm{pcf}]$ the surcharge stress would be almost five times greater). Hence tests were also performed to investigate the dependence of the swelling strain on the applied surcharge. See section of 4.3.5. for details.

Special care must be placed in preparing the sand bath, in particular for the base layer, to ensure that the specimen top is level. Details on the preparation of the sand bath can be summarized as follows:

1. Preparation of base layer of sand

a.) Place $480 \mathrm{~g}$ of sand on the bottom of the plastic cylinder to form a base layer with thickness of $2.2 \mathrm{in.} \mathrm{Level} \mathrm{the} \mathrm{surface} \mathrm{of} \mathrm{the} \mathrm{sand} \mathrm{using} \mathrm{a} \mathrm{wood} \mathrm{plunger.}$

b.) Place a circular steel plate (diameter 2.8 in) on the top of the sand and apply pressure by hand while tapping on the sides of the mold with a rubber hammer. Tap between 25 and 30 times going around the perimeter.

c.) Check the thickness of the base sand layer, measuring the height from the top of the sand to the top of the mold (this height should be 3.8 in).

d.) If the sand bath is prepared before having the final specimen: 
i) Place a dummy specimen with the metal surcharge on top of it at the center of the sand layer. The top of the surcharge should be level with the top of the mold.

ii) Use a custom stainless steel ring (similar to shown in Figure 3.7b, but with handles on top of the ring) to check horizontal alignment.

iii) Ensure vertical alignment placing a bubble level over the stainless steel surcharge.

2. Placement of specimen and completion of sand bath

a.) Place the specimen directly on the base sand layer (If necessary, perform steps i)iii) in d.) above.

b.) Slowly add sand uniformly around the specimen up to $3 / 4$ th its height. Level the sand surface using a spatula, and place the ring with handles on top of the sand. Using a rubber hammer, tap on the sides of the mold between 15 and 20 times.

c.) Remove the ring and add sand until the sand level is just over the top of the specimen. Place the ring surcharge and tap on the sides using a rubber hammer for 10-15 times.

d.) Place the surcharge over the specimen and start adding water. Make sure that the water falls on the surcharge first and not directly on the specimen or sand. 


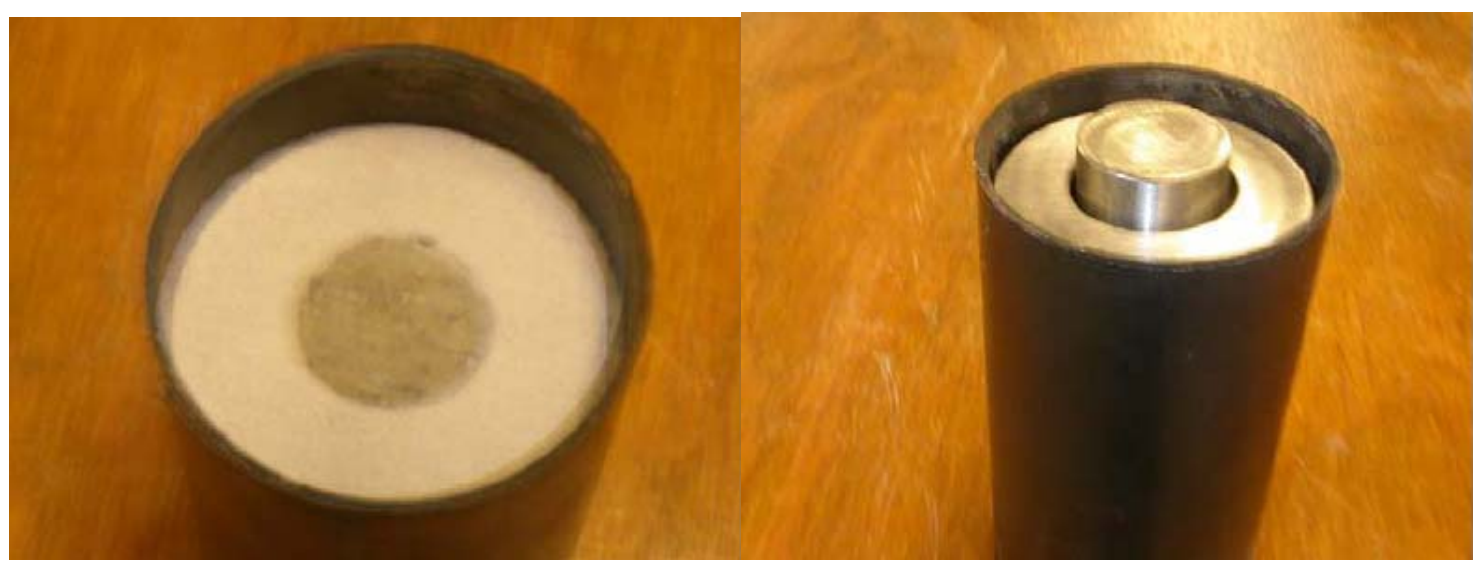

Figure 3.7 a) Specimen in sand bath b) Specimen in sand bath with surcharge

\section{One-dimensional Swelling Tests}

After placing the compacted soil specimens in the sand bath, the plastic cylinders are placed in a large Plexiglas container located in a Styrofoam box in order to minimize temperature changes and limit the effects of air flow on the swelling measurements. Vertical swelling strains are measured using Linear Variable Differential Transformers (LVDT) and recorded using an automated data acquisition system. LVDT readings are taken every hour over the first 6 hours, every 2 hours up to 12 hours, and every 12 hours after that. At each reading time, 100 readings are recorded and their average used as the measurement for that time.

Water is replenished in the sand bath over the duration of the swelling measurements. Figure 3.8 shows the swelling measurement setup, with six concurrent measurements taking place. As shown in Figure 3.8, additional specimens prepared under the same conditions as those used for the swelling measurements, and intended for chemical/mineralogical tests, are also placed in the Styrofoam box. 


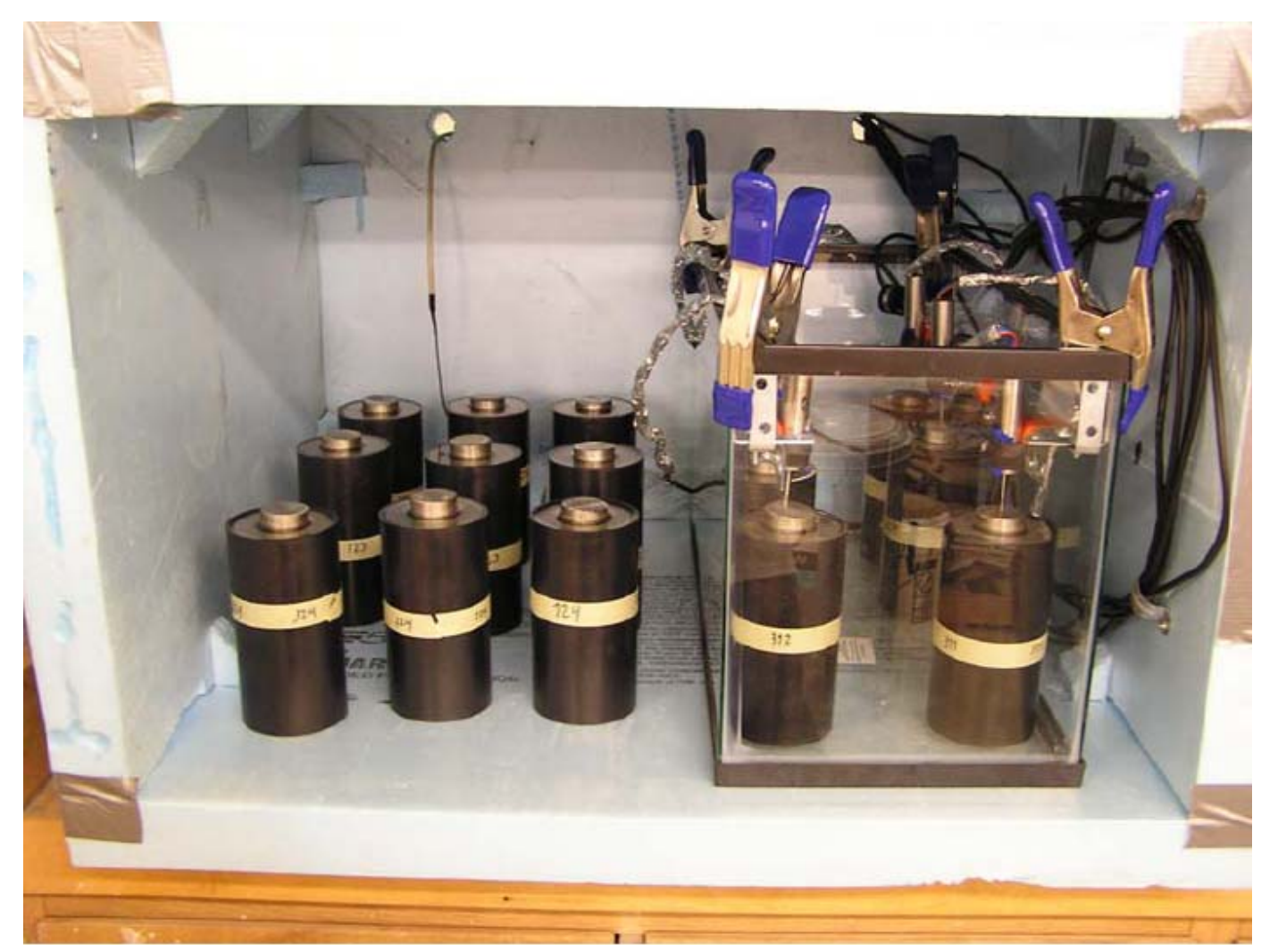

Figure 3.8 Swelling setup and additional specimens inside temperature controlled box

\subsubsection{Mellowing and Double Lime Treatment}

As discussed in more detail in Chapter 4, two methods for mitigating the effects of sulfate induced heave were evaluated in this research. These methods are: precompaction mellowing and double lime treatment. Note that both methods were evaluated only for hydrated lime, as the most serious swelling was observed with this stabilizer (see Chapter 4).

In the mellowing method the soil-stabilizer mixture is allowed to mellow (at constant water content) for one or more days before being compacted. In the tests aimed 
at evaluating this method, the procedure for mixing and compacting the soil-stabilizer mixture was modified as follows:

1. Mix the soil alone with water targeting the desired moisture content; place the soil in a sealed bag for $24 \mathrm{hrs}$ in humid room (relative humidity $>90 \%$ and temperature of $10{ }^{\circ} \mathrm{C}$ ) (this is the standard tempering stage that preceded the addition of the stabilizer in all tests).

2. Add to the tempered soil the required amount of stabilizer and the corresponding amount of water (required to react with the stabilizer); mix well. Take a sample for determination of the water content both before and after adding the stabilizer.

3. Place the stabilizer-soil mixture in a sealed bag for a period of one or more days; store the bag in a humid room (with relative humidity $>98 \%$, and temperature of about 23 $\left.{ }^{\circ} \mathrm{C}\right)$. Take a sample for determination of the water content.

4. After the desired mellowing period (1-3 days in this experimental program) compact the soil-stabilizer mixture using the Harvard miniature compaction apparatus. The resulting specimen is used to determine the compaction curve (required to identify the optimum moisture content) or for the swelling tests. In either case use the material trimmed from the top of the specimen to determine the moisture content.

Note that in this research, tests performed to explore the effectiveness of the mellowing method were performed for both $3 \%$ and $7 \%$ hydrated lime.

The double lime treatment is similar to the mellowing method in that there is a delay between the time the soil is mixed with the lime and the time the mixture is compacted. This method, however, also involves a second addition of lime after the mellowing stage. The procedure employed to mix and compact the soil-stabilizer 
mixture is identical to that described above for the mellowing method up to step 3. After the desired mellowing period (1-7 days in this experimental program), an additional amount of lime (and the corresponding amount of water required to react with the lime) is added to the soil stabilizer mixture. The soil-stabilizer mixture is then immediately compacted using the Harvard miniature compaction apparatus. Again, the material shaved from the top of the specimen is used to determine a final value of the moisture content. In this research all tests with double lime treatment involved a first addition of $3 \%$ lime and a second addition of $4 \%$ lime (by dry mass of the soil).

\subsubsection{Chemical/Mineralogical Tests}

\subsubsection{Introduction}

In addition to the swelling tests, which represented the bulk of the experimental program, a number of tests were conducted on the specimens at the end of the swelling stage. This was done to determine, through investigation of the chemistry and mineralogy of the soil-stabilizer mixture, the source of the swelling.

X-ray diffraction analysis (XRD) and thermo-gravimetric analysis (TGA) were conducted on the solids to determine the mineralogy of the soil stabilizer-mixture. Additionally, the chemical composition of the pore fluid was characterized using ion chromatography (IC) and inductively coupled plasma (ICP). 
Section 3.4.6.2 describes the procedures used to extract the pore fluid and prepare the samples for XRD and TGA; while section 3.4.6.3. briefly outlines the procedures and equipment used to perform the chemical/mineralogical tests.

\subsubsection{Sample Preparation}

The paragraphs below summarize the procedures used to extract the pore fluid from the soil-stabilizer specimens at the end of the swelling stage. The fluid was to be used for $\mathrm{pH}$ measurements and for Ion Chromatography and Inductively Coupled Plasma. Solid samples from these same specimens were used for the X-Ray diffraction (XRD) and Thermo-Gravimetric analyses.

\section{A. Pore Fluid Extraction}

1. After removing the specimen from the sand bath, clean the specimen surface in order to avoid the presence of sand particles.

2. Take $10 \mathrm{~g}$ of the specimen for measuring the water content.

3. Take a $10 \mathrm{~g}$ sample of the specimen and place it in methanol for further study (e.g. Scanning Electron Microscope analysis); note that the methanol is intended to stop hydration and prevent carbonation of the specimen.

4. Put the remaining specimen in the millipore pressurized extractor shown in Figure 3.9. The soil is placed in three layers and each layer is compacted dropping the Harvard miniature tamper dropped from a height of 3 in. 

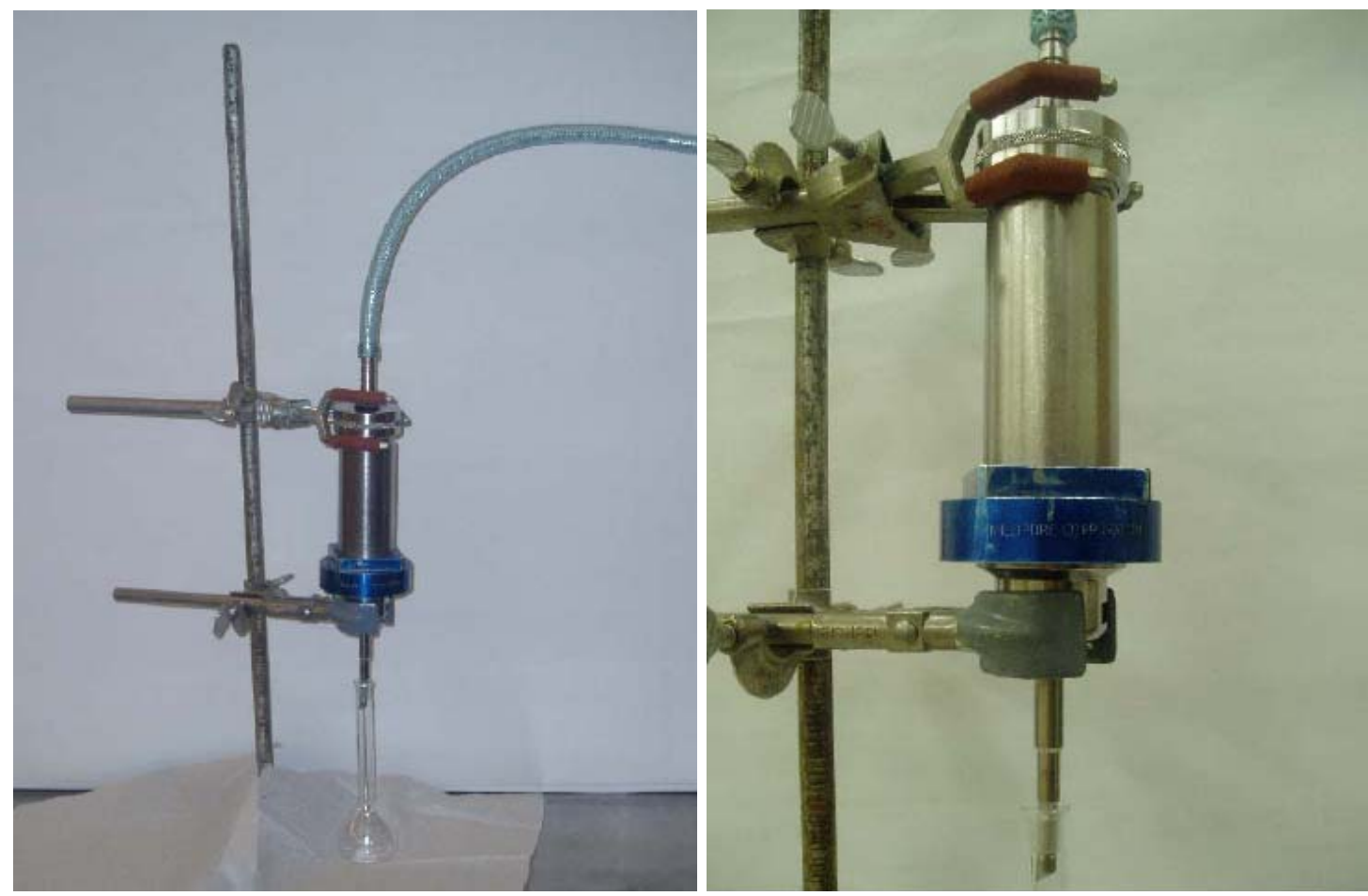

Figure 3.9 Millipore pressurized extractor

5. Gradually apply an increasing pressure to the extractor, up to 80 psi (Figure 3.10 ). 


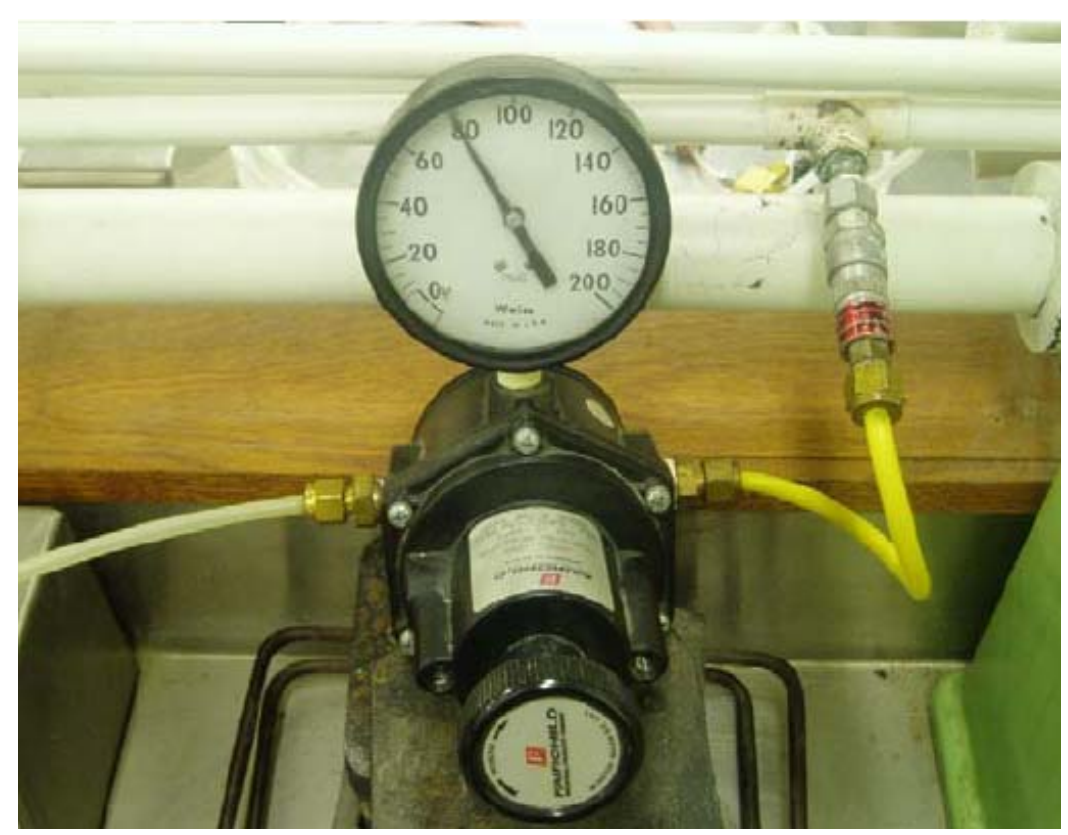

Figure 3.10 Regulator applying the pressure to the millipore pressurized extractor

6. Place a $50 \mathrm{~mL}$ flask at the outlet of the extractor to collect the pore fluid from the specimen.

7. Measure the mass of the exacted pore fluid to $0.0001 \mathrm{~g}$.

\section{B. Sample preparation for $\mathrm{pH}$ measurements and IC/ICP analysis}

1. Dilute the pore fluid with de-ionized water up to exactly $50 \mathrm{~mL}$ using a pipette.

2. Obtain the diluting factor, i.e. mass of total fluid to mass of pore fluid.

3. Set aside $10 \mathrm{~mL}$ of diluted solution in a cone shape plastic bottle for $\mathrm{pH}$ measurement.

4. Place $40 \mathrm{~mL}$ of diluted solution into a cone shape plastic bottle for IC/ICP analysis. 


\section{Sample preparation for XRD and TGA analyses}

1. Extrude the soil specimen from the millipore pressurized extractor.

2. Soak the soil specimen in methanol, in order to avoid carbonation.

3. Place $30-50 \mathrm{~g}$ of soil in a mortar and grind using a pestle.
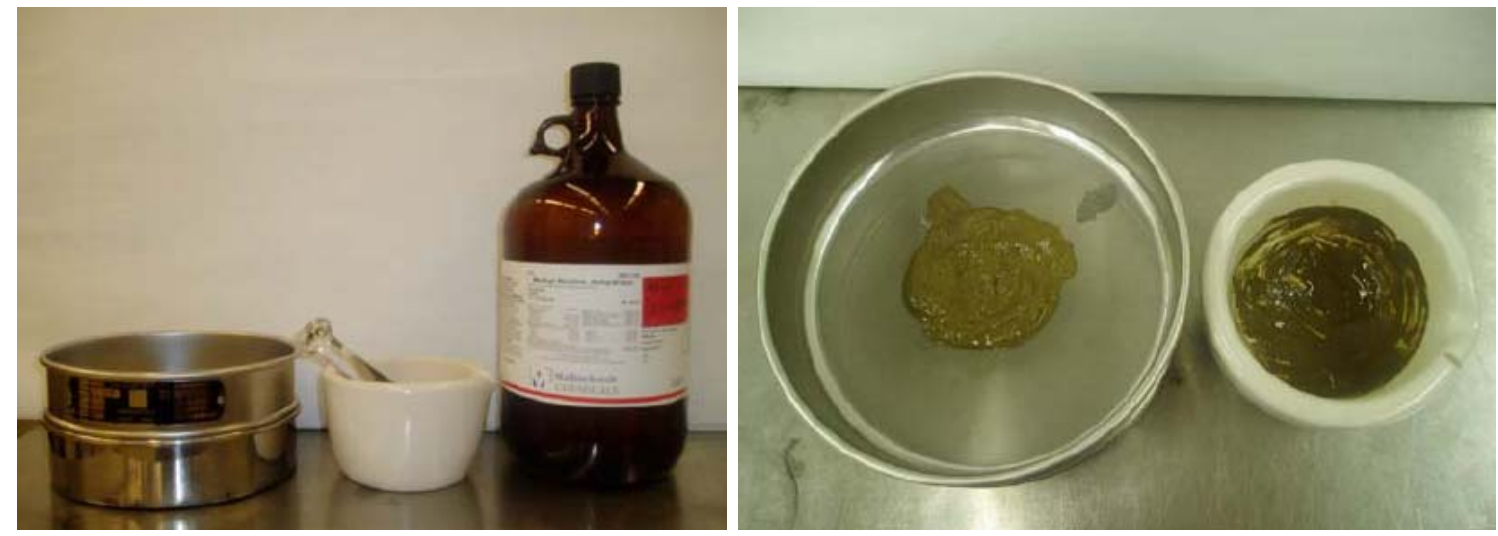

Figure 3.11 Wet sieving of the soils with methanol solution and \#325 sieve

4. Wet sieve the soil-methanol solution through a $45 \mu \mathrm{m}$ sieve (see Figure 3.11). Note that a $45 \mu m(\# 325)$ sieve is used instead of a $75 \mu m(\# 200)$ sieve in order to investigate ettringite minerals more carefully.

5. Extract the fluid out of both the passing and remaining fractions using a $0.45 \mu \mathrm{m}$ filter paper and an aquatic vacuum pump (see Figure 3.12). Note that the aquatic vacuum pump should be used since methanol is a flammable liquid. 


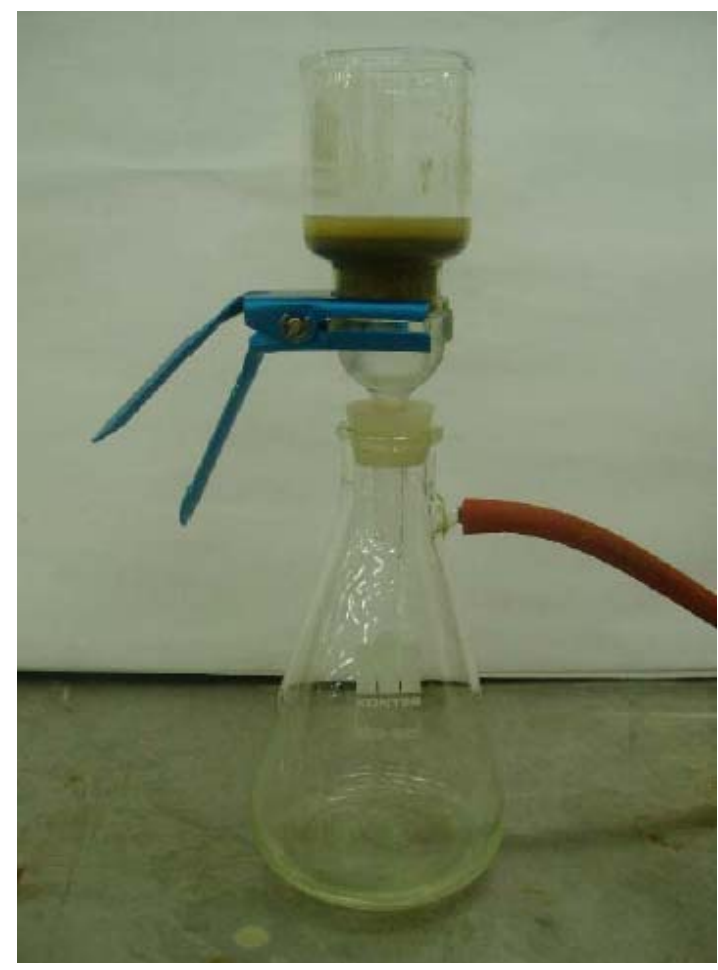

Figure 3.12 Aquatic vacuum pump extracting water from the soils

6. Allow the solids remaining on the filter paper to dry in air for $24 \mathrm{hrs}$.

7. Crush and grind the solids using pestle and mortar to allow for the air-dried soils to pass through a $45 \mu \mathrm{m}$ sieve.

8. Set aside in an air-tight plastic bottle at least $5 \mathrm{~g}$ of the passing soils for XRD/TGA analyses. 


\subsubsection{Description}

\section{A. X-Ray Diffraction $(X R D)$ analysis}

Air-dried soil samples were treated with methanol (to block hydration and prevent carbonation) and used to prepare a random powder mount. A Siemen's D-500 diffractometer was used for all XRD analyses. The sample was run using $\mathrm{CuK} \alpha$ radiation with the tube powered to $50 \mathrm{kV}$ and $30 \mathrm{~mA}$; the scan was taken between $20 \mathrm{of} 5^{\circ}$ and $2 \theta$ of $65^{\circ}$ with a 0.04 degree step size. The results of these tests are presented in Section 5.2.

\section{B. Thermo-Gravimetric Analysis (TGA)}

A $30 \pm 3 \mathrm{mg}$ sample of air-dried soil was placed in the furnace of a TA 2050 thermogravimetric analyzer (manufactured by TA Instruments, USA). Then, the sample was heated in a nitrogen environment from room temperature to $1000^{\circ} \mathrm{C}$ at a heating rate of $10^{\circ} \mathrm{C} / \mathrm{min}$. The loss of weight was monitored and plotted over the entire temperature range. In addition, the first derivative thermogravimetric (DTG) curve was obtained to aid in indentifying the decomposition of different minerals at different temperatures. Additional details are provided in Section 5.2.

\section{Ion Chromatography (IC) test}

Ion Chromatography (IC) is an analytical technique to detect the ionic solutes in water. In this research this technique was applied for determination of the concentration of soluble sulfates and chlorides of both the coal mine spoils, and the pore fluid formed in 
the soil-stabilizer specimens during the swelling period. A ion chromatograph, manufactured by Dionex and located in the Environmental Laboratory of Purdue's School of Civil Engineering, was used for all tests. Before conducting all analyses, the ion chromatograph was calibrated with standard solutions containing precisely known concentration of sulfate and chloride ions.

\section{Inductively Coupled Plasma (ICP)}

Inductively Coupled Plasma (ICP) is a quantitative analytical technique to detect the concentration of each element recognizing characteristic wavelengths through the plasma emission detector. A Thermo Jarrel Ash ATOMSCAN 25 plasma emission spectrometer located in the Environmental Laboratory of Purdue's School of Civil Engineering, was used in the present study to detect the concentration of $\mathrm{Na}^{+}, \mathrm{K}^{+}, \mathrm{Ca}^{2+}$, $\mathrm{Al}^{3+}, \mathrm{Si}^{4+}$ and $\mathrm{S}$. This spectrometer was calibrated with standard solutions.

\subsection{Summary}

This chapter presented the materials and experimental methods used in this research. Coal mine spoil samples were obtained from eight different locations in Indiana. Based on measurements of the sulfate content of these spoils the Hawthorn coal mine site in Sullivan County was selected for additional sampling. All additional testing focused on this soil which had sulfate contents in the 7,000-15,000 $\mathrm{mg} / \mathrm{kg}$ range. The chapter presents a geological description of the coal mine spoil samples, describes the procedure used to screen the heterogeneous field samples, and provides a brief 
description of the calcium-based stabilizers used to treat the screened spoils: a commercial quick lime, a commercial hydrated lime, a research grade quick lime, and type I Portland cement. In discussing the experimental methods, emphasis is placed on the method for determining the sulfate content, given that no standard exists. The chapter continues on to describe the method, based on the use of the Harvard miniature apparatus, used to compact the screened soil, both soil alone and in combination with the various stabilizers. Details are then provided on the sand-bath method and on the test setup used to perform the swelling measurements (on specimens compacted at optimum). The chapter also contains a description of the modifications to the procedures used when preparing the specimens for investigating the following mitigation techniques: mellowing and double lime treatment.

Finally, the chapter has a description of the procedures followed to extract the pore fluid from the soil-stabilizer specimens at the end of the swelling stage and to prepare the solid samples for x-ray diffraction and thermal analysis. 


\section{CHAPTER 4. EXPERIMENTAL RESULTS}

\subsection{Introduction}

Chapter 3 discussed the origin, sampling and screening procedures used for the coal mine spoils investigated this research; presented data on the sulfate content of these materials; described the stabilizers employed in this research; and provided an overview of the experimental methods used to perform the various tests (in particular sulfate content determination, compaction tests and swelling measurements).

Based on sulfate contents results, two samples - referred to as $\mathrm{H} 1 \mathrm{~A}$ and $\mathrm{H} 1 \mathrm{~B}$, characterized by the highest sulfate contents - obtained from the Hawthorn mine site, were selected for further testing. This included tests on the soils alone (index tests, compaction tests and swelling tests), as well as on various soil-stabilizer combinations ( $\mathrm{pH}$ tests to determine the optimal dosages of the stabilizers; compaction tests using the Harvard miniature apparatus; and one dimensional swelling tests conducted on soil specimens compacted at optimum using a custom made setup which provided access of water to the specimens from both the ends and the sides). The results of the experimental program are discussed in the subsequent sections. Section 4.2 presents the results of the tests conducted to establish the physical-chemical characteristics of the soils and the soilstabilizer mixtures. Section 4.3 summarizes both the compaction and the swelling data. This section is organized in eight subsections: the first (4.3.1) provides compaction and 
swelling results for a local Tippecanoe County soil (Crosby till) containing negligible amounts of sulfate. These data are intended to represent the reference behavior of a nonproblematic soil. Section 4.3.2 discusses the compaction behavior of the coal mine spoils (samples $\mathrm{H} 1 \mathrm{~A}$ and $\mathrm{H} 1 \mathrm{~B}$ ) both alone, and following treatment with $3 \%$ and $7 \%$ (by mass of the dry soil) of four different stabilizers. These include a commercial hydrated lime (HL); a commercial quick lime (QL); a analytical grade quick lime (referred to as analytical lime - AL); and type I Portland cement. Swelling data for these soil-stabilizer combinations compacted at optimum conditions are presented in 4.3.3. The remaining subsections present additional data obtained by testing soil H1A treated with hydrated lime. Data presented in Section 4.3.3 demonstrate that the most significant sulfate induced heave is measured with this stabilizer. Thus this stabilizer was used to investigate a broader range of stabilizer dosages (1.5\% to $9 \%$, section 4.3 .4$)$, the effect of the surcharge stress ( 0.3 psi to 2.4 psi, section 4.3 .5 ), and the effectiveness of two mitigation techniques - pre-compaction mellowing (4.3.7) and double lime treatment (4.3.8) - proposed in the literature. Finally, section 4.3.6 compares the swelling results collected in this research to data available in the literature.

Table 4.1 summarizes the experimental program. Note that the results of $x$-ray diffraction tests, thermal analysis and IC/ICP tests are presented in Chapter 5. 
Table 4.1 Overview of testing program

\begin{tabular}{|c|c|c|c|c|c|c|c|c|c|c|}
\hline & \multicolumn{2}{|l|}{ Index } & \multirow{2}{*}{ Compaction } & \multicolumn{3}{|c|}{ Swelling } & \multicolumn{3}{|c|}{ Mineralogy $y^{(a)}$} \\
\hline & & $\begin{array}{c}\text { Atterberg } \\
\text { limits }\end{array}$ & $\begin{array}{l}\mathrm{p} \\
\mathrm{H} \\
\end{array}$ & & $\begin{array}{c}\begin{array}{c}\text { stabilizer } \\
\text { effect }\end{array} \\
\end{array}$ & & $\begin{array}{c}\text { Atterberg } \\
\text { limits }\end{array}$ & $\mathrm{pH}$ & TGA & $\begin{array}{c}\begin{array}{c}\text { stabilizer } \\
\text { effect }\end{array} \\
\end{array}$ \\
\hline \multirow{5}{*}{$\mathrm{H} 1 \mathrm{~A}$} & $0 \%$ & $\mathrm{O}$ & $\mathrm{O}$ & $\mathrm{O}$ & H1A & $0 \%$ & $\mathrm{O}$ & $\mathrm{O}$ & $\mathrm{O}$ & H1A \\
\hline & HL & - & $\mathrm{O}$ & $\mathrm{O}$ & $\mathrm{O}$ & HL & - & $\mathrm{O}$ & $\mathrm{O}$ & $\mathrm{O}$ \\
\hline & QL & - & $\mathrm{O}$ & $\mathrm{O}$ & $\mathrm{O}$ & QL & - & $\mathrm{O}$ & $\mathrm{O}$ & $\mathrm{O}$ \\
\hline & AL & - & $\mathrm{O}$ & $\mathrm{O}$ & $\mathrm{O}$ & $\mathrm{AL}$ & - & $\mathrm{O}$ & $\mathrm{O}$ & $\mathrm{O}$ \\
\hline & PC & - & $\mathrm{O}$ & $\mathrm{O}$ & $\mathrm{O}$ & PC & - & $\mathrm{O}$ & $\mathrm{O}$ & $\mathrm{O}$ \\
\hline \multirow{2}{*}{$\mathrm{H} 1 \mathrm{~B}$} & $0 \%$ & $\mathrm{O}$ & $\mathrm{O}$ & $\mathrm{O}$ & H1B & $0 \%$ & $\mathrm{O}$ & $\mathrm{O}$ & $\mathrm{O}$ & H1B \\
\hline & HL & - & $\mathrm{O}$ & $\mathrm{O}$ & $\mathrm{O}$ & HL & - & $\mathrm{O}$ & $\mathrm{O}$ & - \\
\hline
\end{tabular}

Notes: $\mathrm{O}=$ test performed, $0 \%=$ soil only

$\mathrm{HL}=$ hydrated lime $\left(\mathrm{Ca}(\mathrm{OH})_{2}\right) ; \mathrm{PC}=$ Portland cement;

$\mathrm{QL}=$ quick lime $(\mathrm{CaO})$ from Carmeuse lime company;

$\mathrm{AL}=$ quick lime $(\mathrm{CaO})$ from Scientific company (referred to as 'analytical lime').

(a) Tests presented in Chapter 5.

\subsection{Physical and Chemical Characteristics}

\subsubsection{Atterberg Limits}

The Atterberg limits were performed in general accordance with the procedures of ASTM standard D 4318. The only deviation from this procedure was the following: while performing the liquid limit tests the soil sample was tempered at a high water content (15 blows consistency) and then dried to lower water contents as the test progressed (wet to dry procedure). This differs from the dry to the wet procedure specified in ASTM D 4318.

Atterberg limit tests were performed on both H1A and H1B soils. These tests yielded liquid limit values of 37 and 38 and plastic limit values of 19 and 20 (Table 4.2), 
respectively. The plasticity index for both cases was 18 . Both soils can be classified as low plasticity clays (CL) according to the Unified Soil Classification System. Note that this classification refers to the screened portion of the samples.

Table 4.2 Atterberg limit tests for H1A and H1B soils

\begin{tabular}{|c||c|c|}
\hline & H1A & H1B \\
\hline \hline Liquid Limit & 38 & 37 \\
\hline Plastic Limit & 20 & 19 \\
\hline Plastic Index & 18 & 18 \\
\hline
\end{tabular}

\subsubsection{Percentage of Fines}

It is well known that fine grained particles $(<\# 200$ sieve $)$ can cause swelling when they gain access to water; this is a well documented occurrence in compacted clays which typically have degree of saturation (S) less than $80 \%$. The amount of swelling depends on degree of saturation, soil structure, physico-chemical-mineralogical properties of the fines and other influencing factors (Holtz and Kovacs 1981). As shown in Table 4.3, approximately $90 \%$ of the soil used for the swelling tests (i.e. screened soil) was comprised of fines; hence some swelling was expected, independent of the occurrence of any reaction between soil and stabilizer. 
Table 4.3 Percentage of fines

\begin{tabular}{|c||c|}
\hline & $\begin{array}{c}\text { Percentage passing through } \\
\text { \#200 sieve }\end{array}$ \\
\hline \hline H1A & 86.0 \\
\hline H1B & 90.3 \\
\hline
\end{tabular}

\subsection{3. $\mathrm{pH}$ Tests}

$\mathrm{pH}$ tests were performed on the soil alone, the stabilizers, and soil-stabilizer mixtures.

\section{A. pH measurements on soil alone and stabilizer alone}

The $\mathrm{pH}$ value of the soil alone was determined following ASTM standard D 4972 which relies on mixing approximately $10 \mathrm{~g}$ of air dried soil with $10 \mathrm{~mL}$ of either water or a $0.01 \mathrm{M}$ calcium chloride solution. As shown in Table 4.4, no significant difference was observed between the measurements in water and in the calcium chloride solution. In both cases the $\mathrm{pH}$ was found to be just below 7, most likely due to the presence of sulfate ions.

$\mathrm{pH}$ measurements of the stabilizer alone were obtained in accordance with ASTM standard D 6276, which specifies that $100 \mathrm{~mL}$ of water be added to $2.0 \mathrm{~g}$ of stabilizer and mixed thoroughly by shaking, and that the $\mathrm{pH}$ be measured no later than 15 min after the end of the continuous 1 hour shaking. Table 4.4 summarizes the results. It is observed that for all three stabilizers the $\mathrm{pH}$ values are quite close: $12.49,12.89,12.96$ for Portland cement, quick lime and hydrated lime, respectively. 
Table 4.4 pH values of soil alone and stabilizer alone

\begin{tabular}{|c|c|c|c||c|c|c|}
\hline & $\begin{array}{c}\text { Temp } \\
\left({ }^{\circ} \mathrm{C}\right)\end{array}$ & $\mathrm{H}_{2} \mathrm{O}$ & $\mathrm{CaCl}_{2}$ & & $\begin{array}{c}\text { Temp } \\
\left({ }^{\circ} \mathrm{C}\right)\end{array}$ & ${ }^{\mathrm{H}_{2} \mathrm{O}}$ \\
\hline H1A & 24.5 & 6.56 & 6.54 & HL & 24.0 & 12.96 \\
\hline H1B & 24.4 & 6.93 & 6.89 & QL & 24.3 & 12.89 \\
\hline & & & & PC & 23.6 & 12.49 \\
\hline
\end{tabular}

\section{B. Determination of the amount of stabilizer mixed using $\mathrm{pH}$ tests}

In order to find the optimum amount of stabilizer to be used for soil treatment, $\mathrm{pH}$ fixation tests were performed in accordance with ASTM standard D 6276 (this method is also commonly referred to as the Eades and Grim $\mathrm{pH}$ test). Since hydrated lime, quick lime and Portland cement were selected as calcium-based stabilizers, it was necessary to find the optimum soil-lime/cement proportion for each soil-stabilizer combination. The test was performed on air-dried H1-A soil passing the $425 \mu m$ (\#40) sieve. A sample of air-dried soil equivalent to $25 \mathrm{~g}$ of oven-dried soil was prepared and each specimen was mixed with $2,3,4,5,6,7$ and $8 \%$ stabilizer, by mass of the dry soil. Then, $100 \mathrm{~mL}$ of water was added to each of the soil stabilizer mixtures, which were placed in a shaker for 1 hour. The $\mathrm{pH}$ value for each specimen was recorded within $15 \mathrm{~min}$ of the end of the continuous 1 hour shaking. Figure 4.1(a-c) present plots of the $\mathrm{pH}$ versus the percentage of stabilizer for each of the three stabilizers. Note that the $\mathrm{pH}$ fixation test was not conducted with the analytical lime. For this stabilizer, results similar to those obtained with the quick lime are expected. 

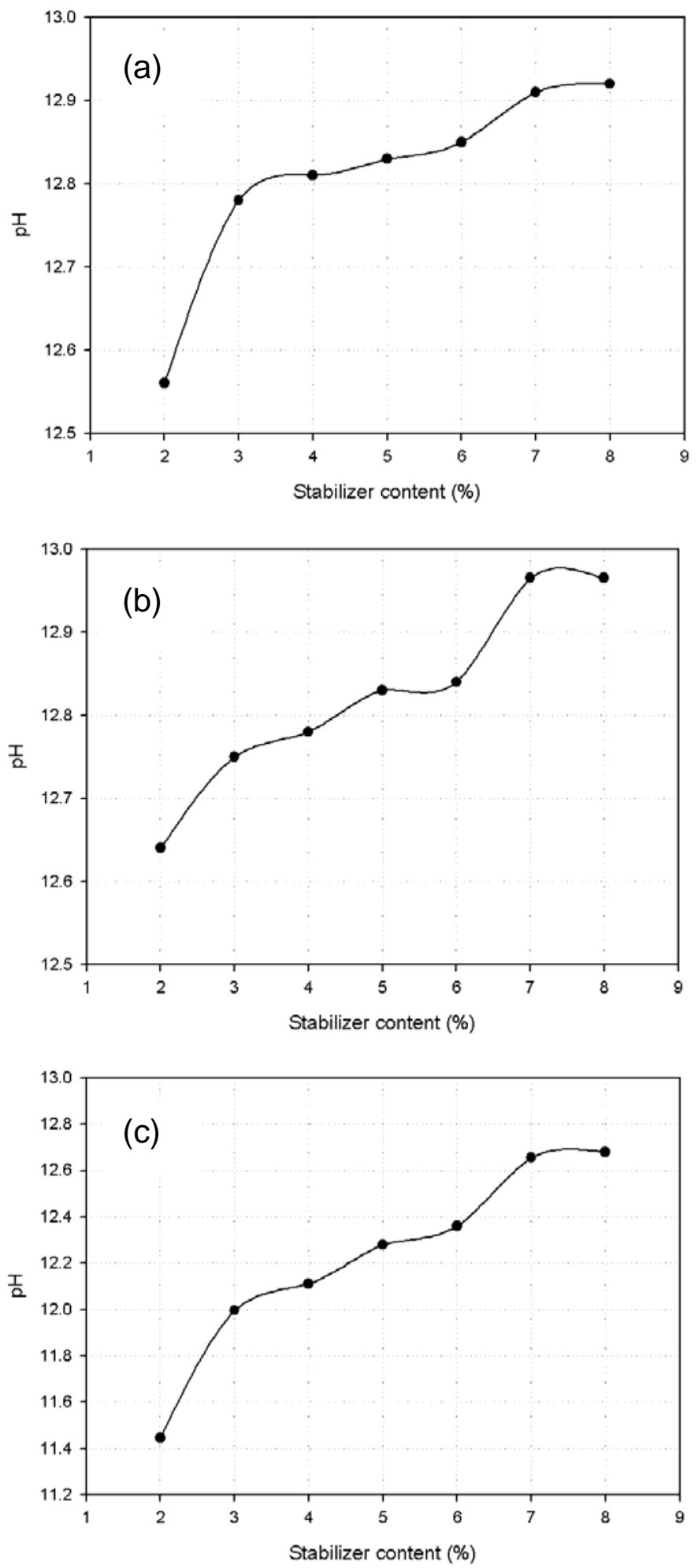

Figure 4.1 pH fixation results of H1A soil mixed with (a) hydrated lime, (b) quick lime and (c) Portland cement 
ASTM standard D 6276 recommends that the lowest percentage of stabilizer that causes a $\mathrm{pH}$ value of 12.4 be selected as the optimum percentage of lime. Note that the standard also states that: "Some soil components such as sulfates, phosphates, organics, and so forth can adversely affect soil-lime reactions and may produce erroneous results using this test method." There is, however, no other documented method to determine the optimum percentage of a stabilizer. Hence, the results of the $\mathrm{pH}$ fixation tests were used as a general guideline for selecting the stabilizer dosages.

As shown in Figure 4.1, the addition of $2 \%$ of either hydrated lime or quick lime was sufficient to yield a $\mathrm{pH}$ in excess of 12.4. For these two stabilizers a minimum dosage of $3 \%$ by mass of the soil was selected for further testing. Additionally, tests were conducted with 7\% lime (note that for the hydrated lime in subsequent stages of the experimental program tests were also performed with dosages ranging from $1.5 \%$ to $9 \%$ ). With Portland cement a $6 \%$ dosage is required for the $\mathrm{pH}$ to reach 12.4 , although the most significant increase in $\mathrm{pH}$ is observed as the dosage is increased from $2 \%$ to $3 \%$. To reflect these results, and to facilitate comparisons between the different stabilizers, also for Portland cement, tests were conducted with dosages of $3 \%$ and $7 \%$. 


\subsection{Swelling Results}

\subsubsection{Reference Behavior for "Non-problematic Soil"}

In addition to conducting swelling tests on the compacted mine spoils (soil subsamples H1A and H1B), a similar set of experiments were carried out using a local silty clay with no significant sulfate content sampled on the Purdue University campus. This silty clay, commonly referred to as Crosby till, has liquid limit $=49 \pm 1 \%$ and plasticity index $=20 \pm 1 \%$. The goal of these tests was to illustrate the swelling behavior of a soil free of sulfates in combination with the same hydrated lime used to treat the coal mine spoils (of the stabilizers investigated in this project, the hydrated lime yielded the greatest swelling).

Compaction tests were conducted on both the untreated soil and the soil treated with $3 \%$ and $7 \%$ hydrated lime. Figure 4.2 shows the compaction curves for the soil alone and for the soil treated with 3\% and 7\% hydrated lime. As shown in the figure, as a result of the addition of hydrated lime, the compaction curve shifted downwards and to the right with an increase in the optimum moisture content from $20 \%$ to $23.5 \%$, to $25 \%$, and a decrease in the maximum dry density from 1.59 , to 1.52 to $1.44 \mathrm{~g} / \mathrm{cm}^{3}$. This is typical behavior, also displayed by the coal mine spoils, which arises from the aggregation of the soil particles caused by the treatment and the partial consumption of the water by the stabilizer. 


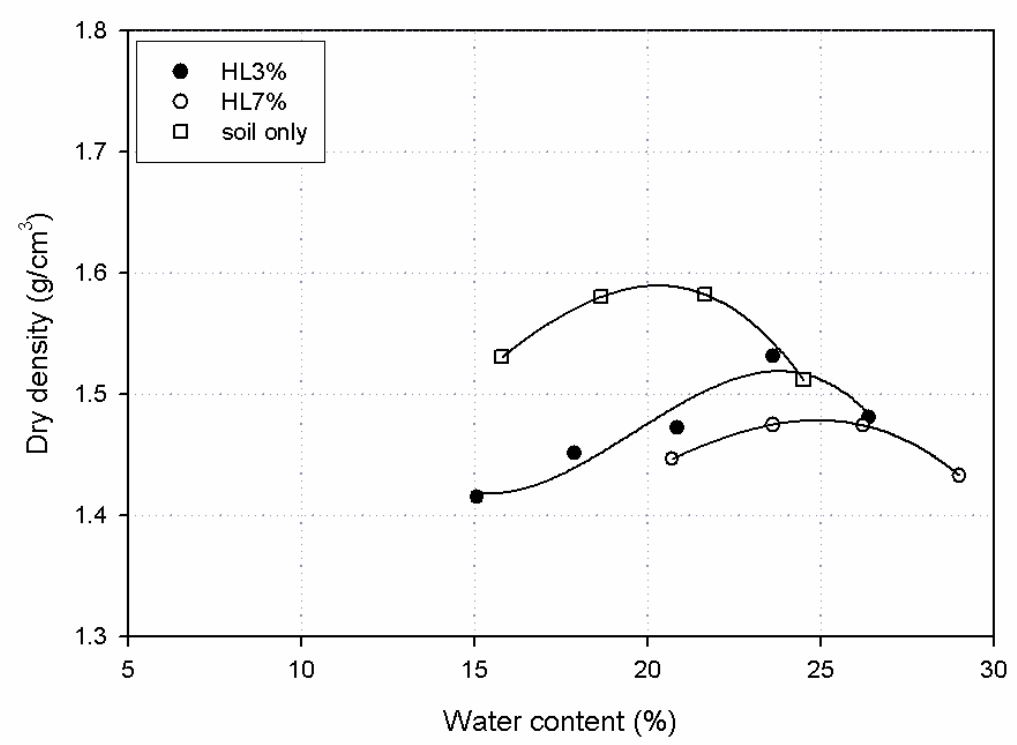

Figure 4.2 Compaction behavior of silty clay with $0 \%, 3 \%$ and $7 \%$ hydrated lime

The swelling behavior of specimens of the soil alone and the soil with $3 \%$ and $7 \%$ hydrated lime all compacted at optimum moisture content was monitored using the setup and the procedures outlined in Section 3.4.4. The resulting swelling curves are presented in Figure 4.3. The figure shows that while all specimens swelled, reduced swelling was observed in the lime treated soil. In all cases the swelling strains were much smaller than those observed for the Hawthorn mine soils which will be presented in the following section. 

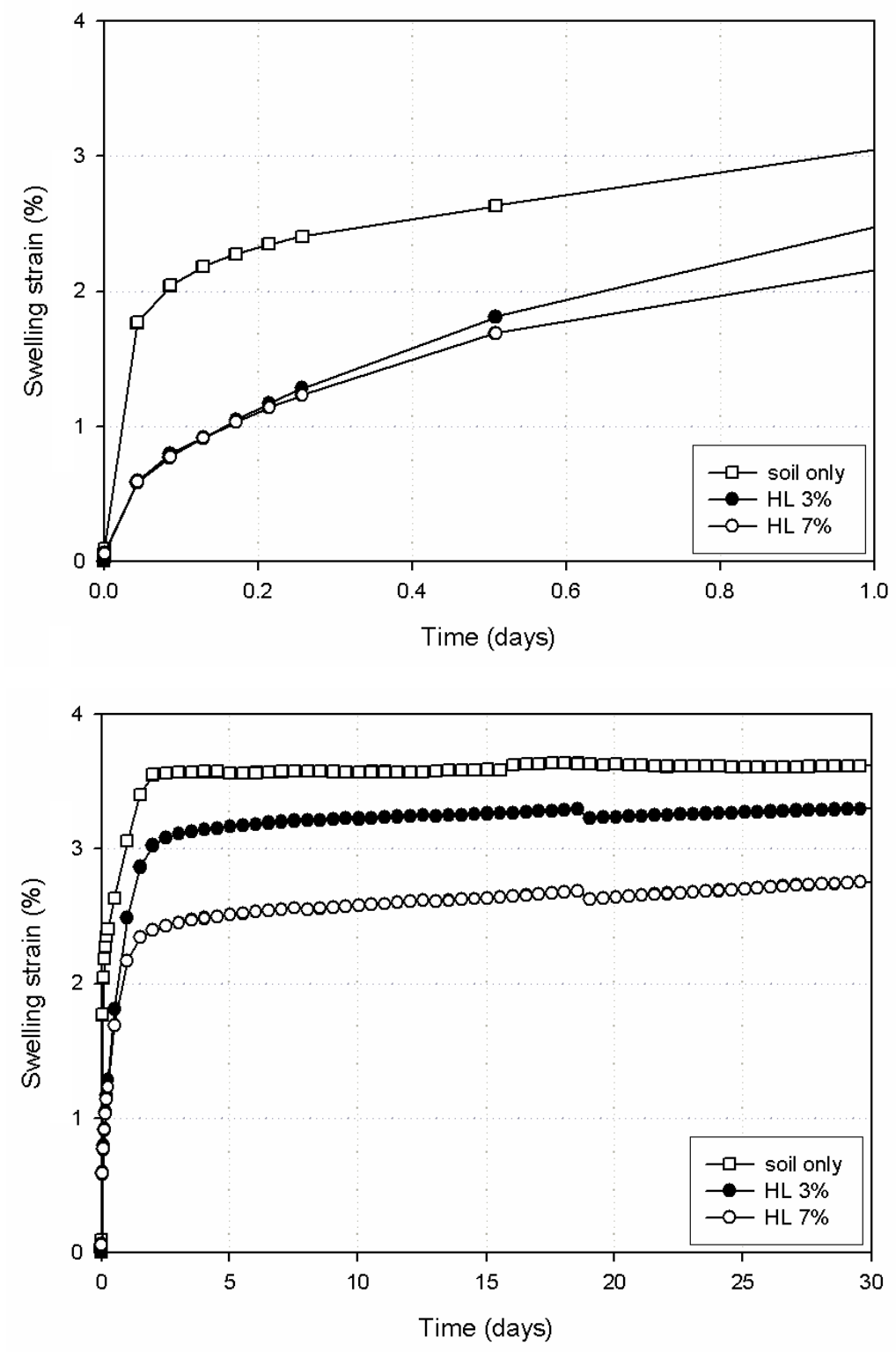

Figure 4.3 Swelling behavior of silty clay with $0 \%, 3 \%$ and $7 \%$ lime over 1 day and 30 day periods 


\subsubsection{Compaction Behavior of Compacted Coal Mine Spoil-Stabilizer Mixtures}

As discussed in the following section, the swelling behavior of the various combinations of coal mine spoil-stabilizer mixtures examined in this study was examined at the optimum moisture content. Hence, compaction tests were performed in order to determine the compaction curves and the resulting values of the optimum moisture content for each soil-stabilizer combination. As discussed in Section 3.4.3, the compaction tests were all performed using the Harvard compaction apparatus to minimize the amount of soil used.

The compaction curves are presented in Figures 4.4 (results for soil treated with hydrated lime) and 4.5 (results for analytical lime, quick lime and Portland cement). Note that Figure 4.4 reports data for both soils H1A and H1B treated with hydrated lime as with this stabilizer tests were conducted on both these subsamples obtained from the Hawthorn mine site. The data presented in Figure 4.4 shows some difference in the compaction behavior of the two subsamples. This attests to the great variability of this material (and possibly to small differences in the screening procedure). All tests with the other stabilizers instead made use of the H1A subsample, and, in general, this report will discuss the data only for this soil sample. Note that as shown in Table 3.10, the H1A sample was characterized by the highest sulfate content, and hence was expected to generate higher swelling.

For all stabilizers, as expected and as seen for the soil examined in Section 4.3.1, the addition of the stabilizer leads to a shift of the compaction curve downwards and to 
the right, (i.e. to a lower maximum dry density and a higher optimum water content). The greater the percentage of stabilizer, the greater the shift in the curve.
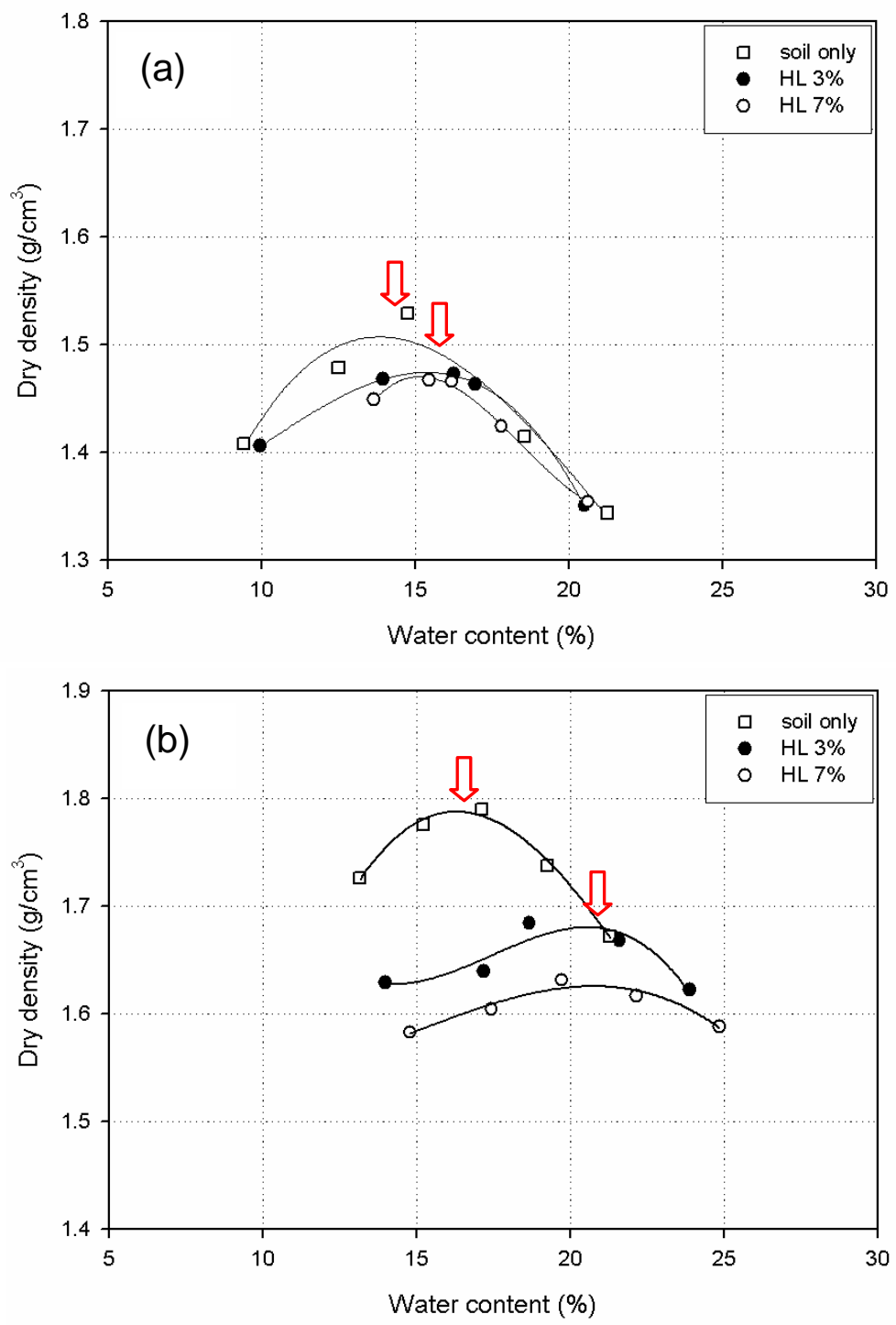

Figure 4.4 Compaction behavior of (a) H1B soil; and (b) H1A soil treated with hydrated lime 

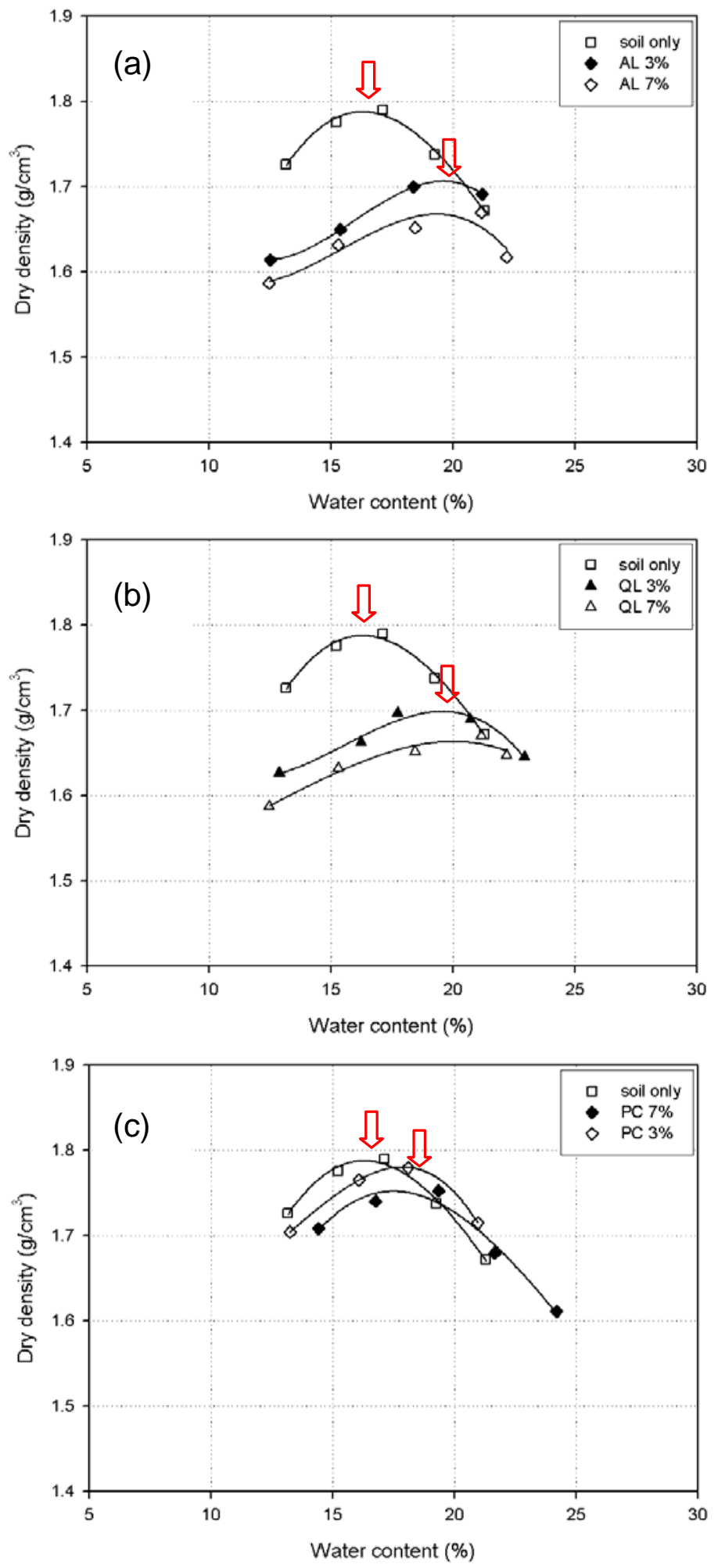

Figure 4.5 Compaction behavior of H1A soil treated with (a) analytical lime; b) quick lime and (c) Portland cement 
Table 4.5 summarizes the values of the optimum water content obtained for the various soil-stabilizer combinations. While these were the values of the water content targeted in preparing the specimens for the subsequent swelling tests, the values of water content measured on the specimens were slightly different (due to experimental errors). Table 4.6 summarizes the values of water content of the specimens used for the swelling tests conducted using soil H1A (swelling results presented in Figures 4.8, 4.10-4.12), derived from the specimen trimmings. Also included in this table are the values of the initial (post-compaction) degree of saturation. These values come from phase relation calculations. For these calculations the specific gravity of the soil alone was assumed as 2.723 and the values of the specific gravity of the stabilizers after hydration were obtained from the literature. For all specimens the values of the degree of saturation at optimum fall within $81 \%$ and $92 \%$. Note that differences in degree of saturation can affect the subsequent swelling measurements as mixtures with lower values of S (i.e. greater deficiency of water) will tend to absorb more water (Holtz and Kovacs 1981).

Table 4.5 Initial water content for binder treated H1A soils

\begin{tabular}{|c||c|c|c|c|c|c|c|c|c|}
\hline & $\begin{array}{c}\text { Soil } \\
\text { alone }\end{array}$ & $\begin{array}{c}\text { HL } \\
3 \%\end{array}$ & $\begin{array}{c}\text { HL } \\
7 \%\end{array}$ & $\begin{array}{c}\text { AL } \\
3 \%\end{array}$ & $\begin{array}{c}\text { AL } \\
7 \%\end{array}$ & $\begin{array}{c}\text { QL } \\
3 \%\end{array}$ & $\begin{array}{c}\text { QL } \\
7 \%\end{array}$ & $\begin{array}{c}\text { PC } \\
3 \%\end{array}$ & $\begin{array}{c}\text { PC } \\
7 \%\end{array}$ \\
\hline \hline H1A & $17.5 \%$ & $19.5 \%$ & $20.5 \%$ & $20 \%$ & $21 \%$ & $20 \%$ & $21 \%$ & $18 \%$ & $18.5 \%$ \\
\hline H1B & $14.5 \%$ & $15.5 \%$ & $16.5 \%$ & - & - & - & - & - & - \\
\hline
\end{tabular}

Table 4.6 Water content and degree of saturation of H1A specimens at OMC conditions used for swelling tests

\begin{tabular}{|c||c|c|c|c|c|c|c|c|c|}
\hline & $\begin{array}{c}\text { Soil } \\
\text { alone }\end{array}$ & $\begin{array}{c}\text { HL } \\
3 \%\end{array}$ & $\begin{array}{c}\text { HL } \\
7 \%\end{array}$ & $\begin{array}{c}\text { AL } \\
3 \%\end{array}$ & $\begin{array}{c}\text { AL } \\
7 \%\end{array}$ & $\begin{array}{c}\text { QL } \\
3 \%\end{array}$ & $\begin{array}{c}\text { QL } \\
7 \%\end{array}$ & $\begin{array}{c}\text { PC } \\
3 \%\end{array}$ & $\begin{array}{c}\text { PC } \\
7 \%\end{array}$ \\
\hline \hline$W_{i}(\%)$ & 16.6 & 19.2 & 20.3 & 17.8 & 18.8 & 18.5 & 18.7 & 17.2 & 17.6 \\
\hline
\end{tabular}




\begin{tabular}{|l|l|l|l|l|l|l|l|l|l|}
\hline$S_{i}(\%)$ & 85.4 & 85.2 & 87.1 & 81.0 & 81.9 & 85.1 & 81.9 & 90.5 & 90.7 \\
\hline
\end{tabular}

\subsubsection{Swelling Behavior of Spoil-Stabilizer Mixtures}

Swelling tests were performed on specimens of both the soil alone (H1A and H1B) and of various soil-stabilizer mixtures compacted at optimum conditions. These tests were conducted using the setup and the procedures described in Section 3.4.4. Special care ensured that the specimens remained continuously soaked during the test.

The results of these measurements are presented in Figures 4.6-4.12. Most of the swelling tests lasted approximately one month. More extended measurements were performed on selected specimens in the preliminary stages of the experimental work. Figure 4.6 presents the results from swelling measurements conducted on six specimens prepared with soil H1B with 0,3 and 7\% hydrated lime (duplicate specimens for each lime \%) over a period of 130 days. In addition to the effects of the presence of the stabilizer that will be discussed below, Figure 4.6 shows that in all specimens most of the swelling occurred within the first 30 days of immersion in water with no significant further change in height over the remaining testing period.

As a result of these preliminary tests, the following test termination criterion was used in all subsequent tests: the swelling test was stopped when the swelling strain changed less than $0.05 \%$ over a period of 48 hours. In all cases, 30 days were sufficient to ensure that this criterion was met. 


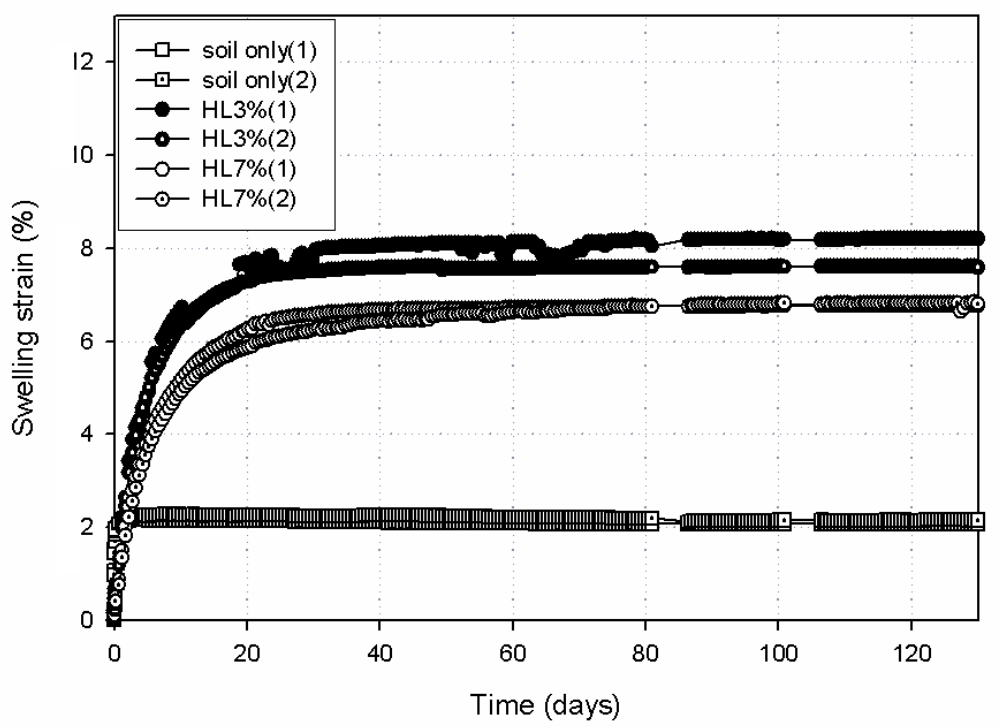

Figure 4.6 Swelling behavior of H1B soil treated with hydrated lime over a period of 130 days

Figure 4.7 presents swelling curves for the H1B soil alone and for the same soil compacted with $3 \%$ and $7 \%$ hydrated lime. As in the subsequent figures, Figure 4.7 shows the development of the strain over the first 24 hours, as well as during the entire 30 day test duration.

As shown in Figure 4.7, the untreated H1B soil exhibited very low swelling strain, while greater swelling was measured in the specimens treated with the hydrated lime. Additionally, it is observed that the soil treated with 3\% hydrated lime swelled more than the soil treated with $7 \%$ hydrated lime. Note that small differences in the values of the end of compaction degree of saturation are likely not sufficient to explain this result. This is consistent with results for other stabilizers (see below) as well as data provided by Puppala et al. (2005b), which is examined later in this chapter. Note that the final swelling strain reached by the treated soil in Figure 4.7 is lower than the values shown in 
Figure 4.6. These differences are thought to reflect the variability in sulfate content of the spoils (see also Figure 4.9 below).
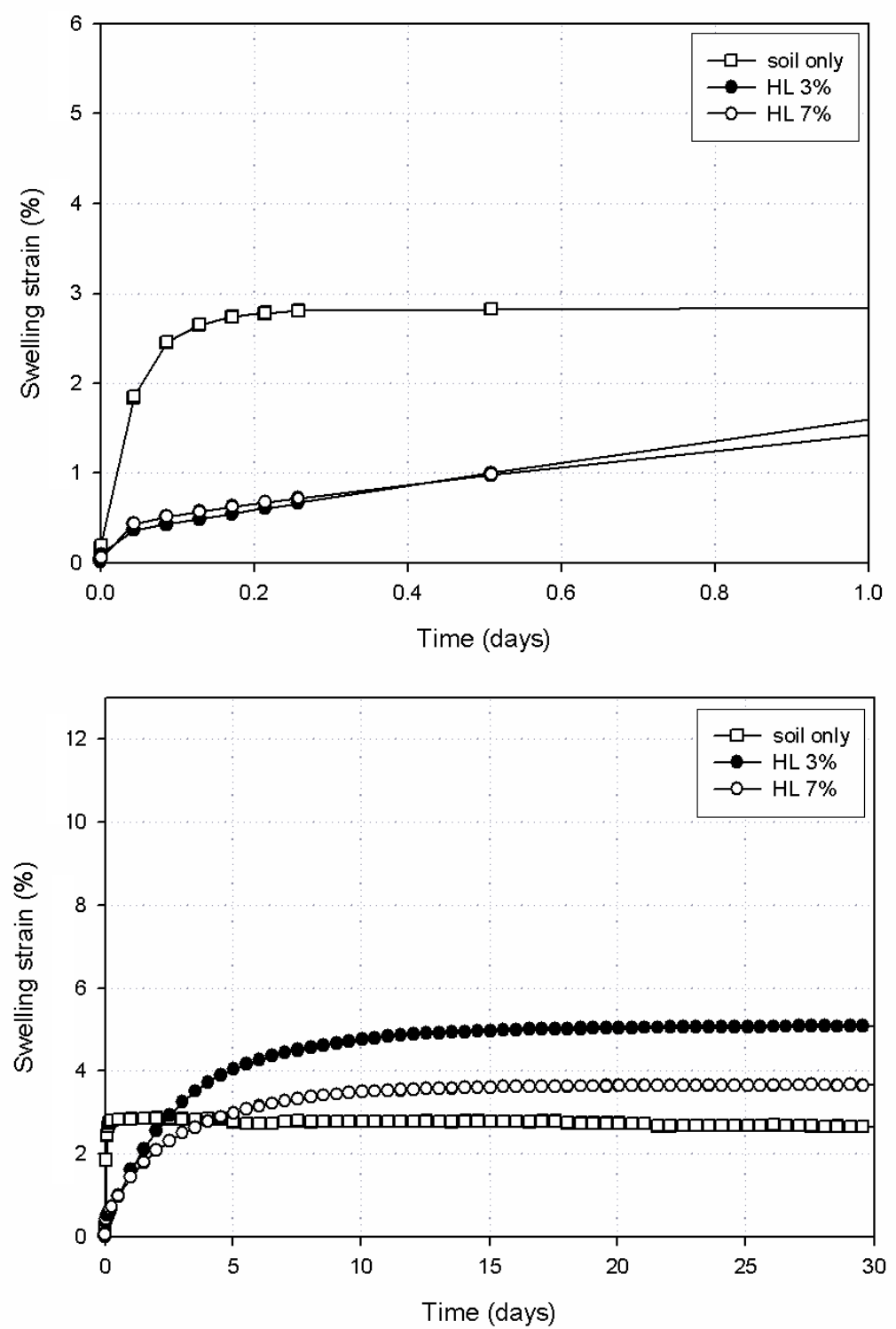

Figure 4.7 Swelling behavior of H1B soil treated with 3\% and 7\% hydrated lime 
Figure 4.7 also illustrates differences in the development of the swelling strain over time in the treated soil versus the soil alone. The soil alone shows relatively rapid swelling with the majority of the swelling strain developed over the first 6 hours of immersion in water (this value is of course dependent on the specimen size and on the drainage conditions). For the lime-treated soil, swelling is slower, with approximately 30 days required for the swelling to taper off, and one week necessary for $50 \%$ of the 30 day strain to occur. This indicates that in presence of lime the swelling mechanism is different. In particular, it suggests that it is due to the chemical reaction leading to the formation of an expansive product (as discussed in Chapter 5, and consistent with data presented in the literature, ettringite was found to form in most of the treated specimens). The delay in swelling is thought to reflect the time required for the reaction to occur; the fact that initially the expansive reaction products can be accommodated inside the soil voids; and, finally, the fact that initially the expansive behavior may be compensated by the shrinkage that characterizes the setting phase (similar observations were made by Mitchell and Dermatas 1992).

Similar plots to those presented in Figure 4.7 are shown in Figure 4.8 for H1A soil treated with $0 \%, 3 \%$ and $7 \%$ hydrated lime. As mentioned earlier, the H1A soil sample was selected for the majority of the experimental program as it exhibited the greatest sulfate content and hence was expected to lead to more significant swelling. As shown in Figure 4.8, similar trends to those described for the H1B soil apply also in this case: the swelling strain is higher in the lime treated soil compared to the untreated soil; higher swelling is observed using 3\% of lime versus $7 \%$ lime; the development of the swelling strain is delayed in the lime-treated soil compared to the untreated soil. For both 
stabilizer contents, however, the final swelling strain is observed to be greater in the case of the H1A soil. This likely is a reflection of the higher sulfate content in this soil. Indeed, with $3 \%$ lime the final swelling strain exceeds $12 \%$. As will be shown below, the swelling strain measured on the H1A soil treated with $3 \%$ hydrated lime is the greatest of the values measured on any of the spoil-stabilizer combinations examined in this research.

For H1A soil treated with 3\% and 7\% lime, several distinct measurements of the swelling behavior were conducted over the experimental program. Figure 4.9a-b show the swelling curves obtained from different tests; the data display some variability (for $3 \%$ lime the final swelling strain ranges from $8.7 \%$ to 12.1 , while for $7 \%$ lime it ranges from 8.7 to 10.2), which likely reflects differences in the sulfate content of the soil. Note, however, that for measurements conducted at the same time, and hence performed using the same soil subsample, the swelling strain for $3 \%$ lime is consistently greater than that measured with 7\% lime). The figures show that the most recent measurements (April 2007) correspond to the most significant swelling for both dosages. These are the curves selected to represent the behavior of the soil with $3 \%$ and $7 \%$ hydrated lime throughout this report . This is because the mineralogical and chemical tests presented in Chapter 5 used to analyze the mechanism responsible for swelling were performed in conjunction with these tests.

Figures 4.10-12 present the data from swelling tests conducted on the H1A soil treated with analytical lime, quick lime, and Portland cement. With all three stabilizers it is once again observed that: the treated soil exhibits greater swelling and that swelling takes place over a longer period of time. In terms of the role played by the stabilizer percentage, the data for Portland cement are consistent with those for the hydrated lime 
(i.e. greater swelling with lower binder addition). For the quick lime, no significant difference is observed between the soil treated with $3 \%$ and $7 \%$ lime; while the results for the analytical lime show a slightly higher swelling for a dosage of $7 \%$. 

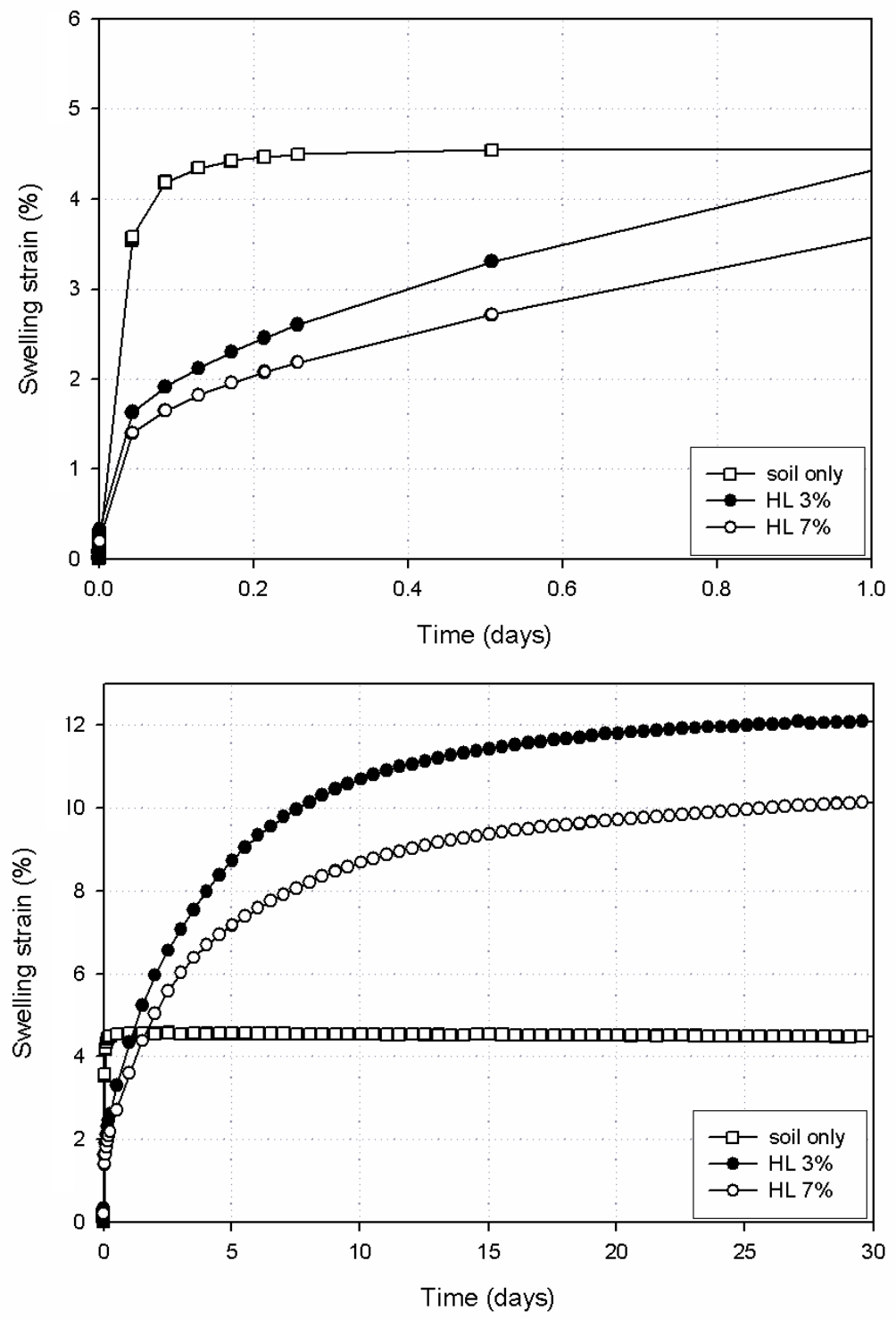

Figure 4.8 Swelling behavior of H1A soil treated with $3 \%$ and $7 \%$ hydrated lime

Table 4.7 summarizes the final values of the swelling strains measured on all the soil-stabilizer combinations examined. These data show that in all cases the treated soil exhibits higher swelling than the untreated soil. For the same soil (H1A), the highest 
swelling is measured with 3\% hydrated lime, whereas for all stabilizers, the lowest swelling is measured on the specimen treated with 7\% Portland cement.
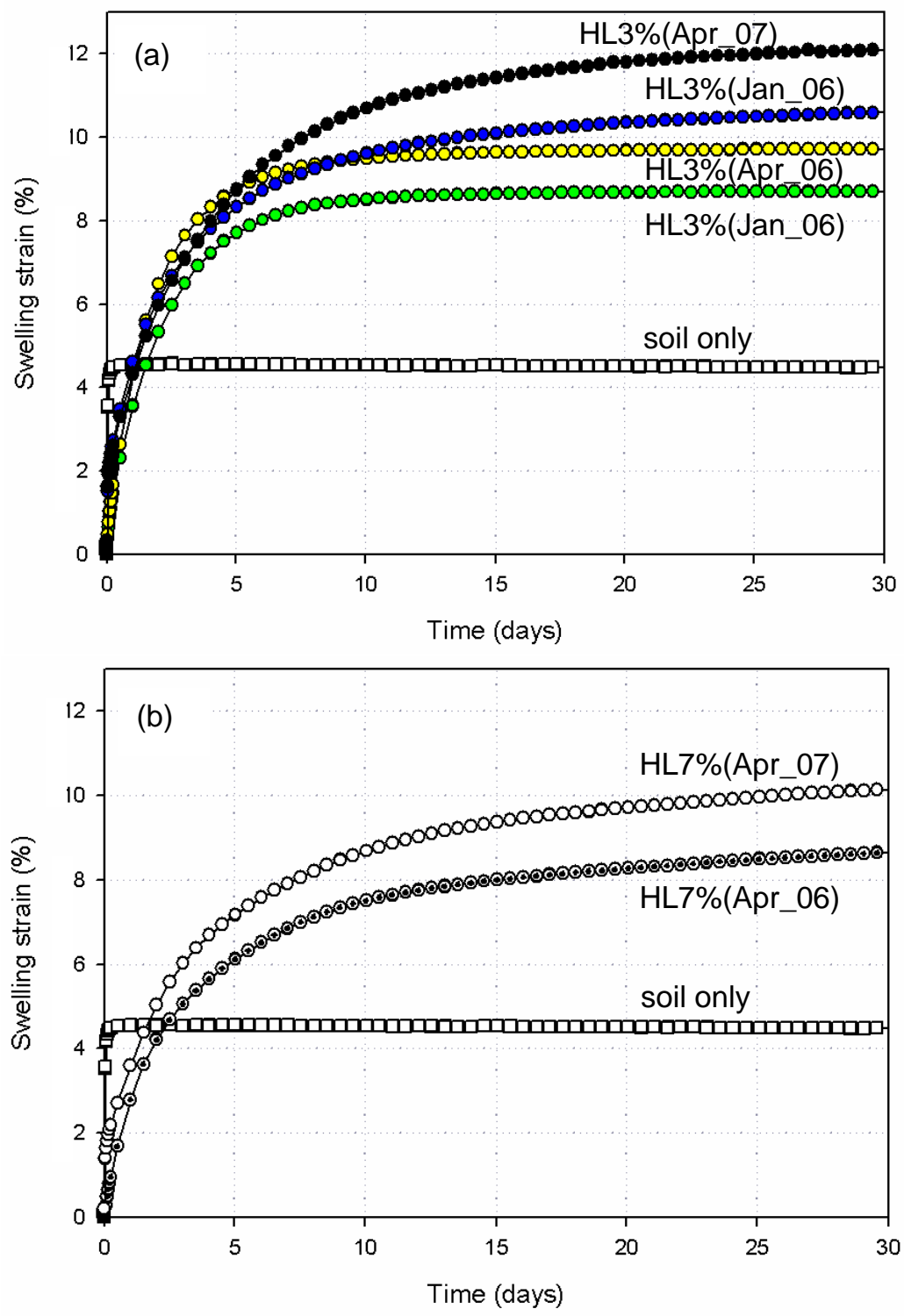

Figure 4.9 Variability in swelling behavior of H1A soil treated with: a) 3\% and b) 7\% hydrated lime 

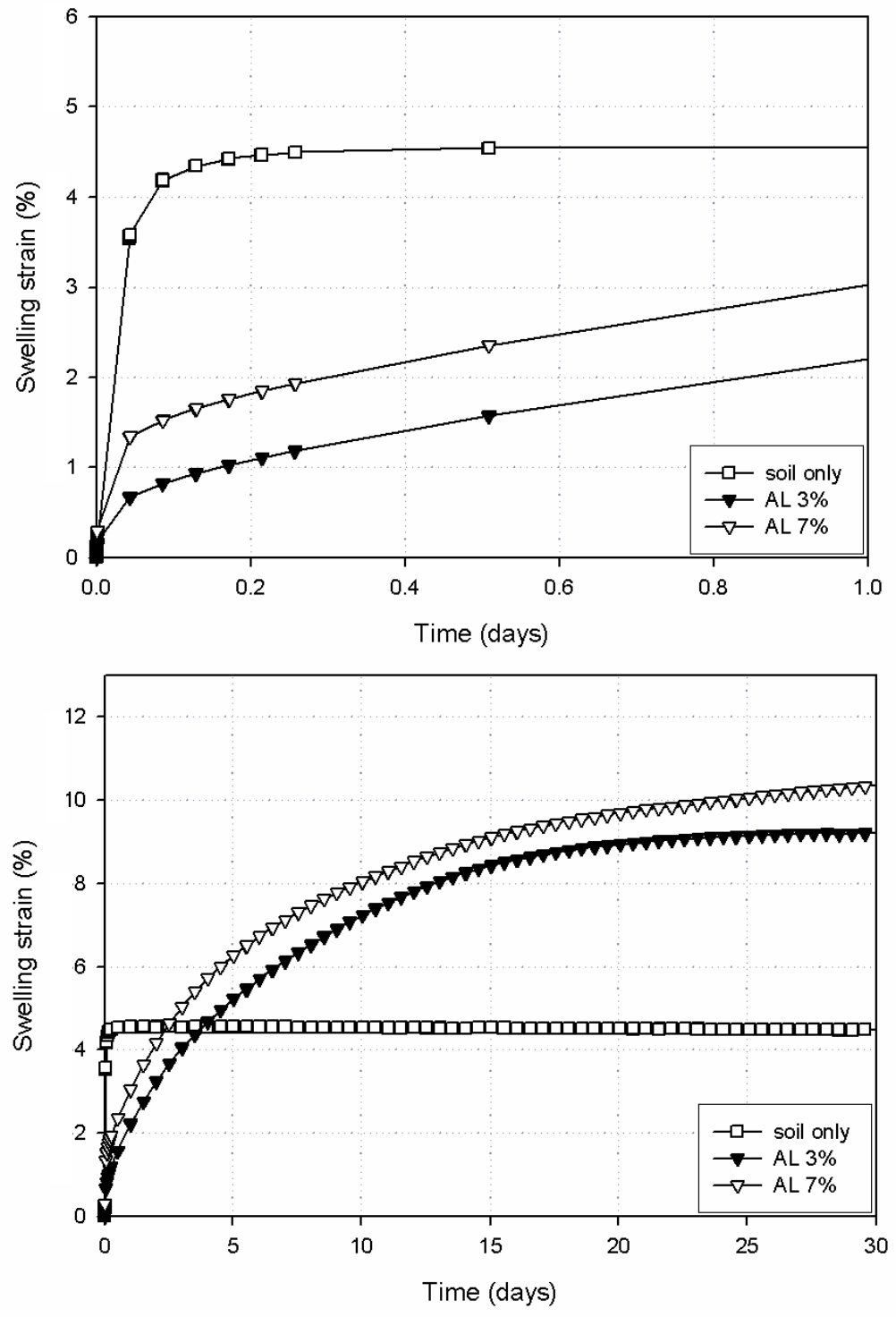

Figure 4.10 Swelling behavior of $\mathrm{H} 1 \mathrm{~A}$ soil treated with $3 \%$ and $7 \%$ analytical lime 

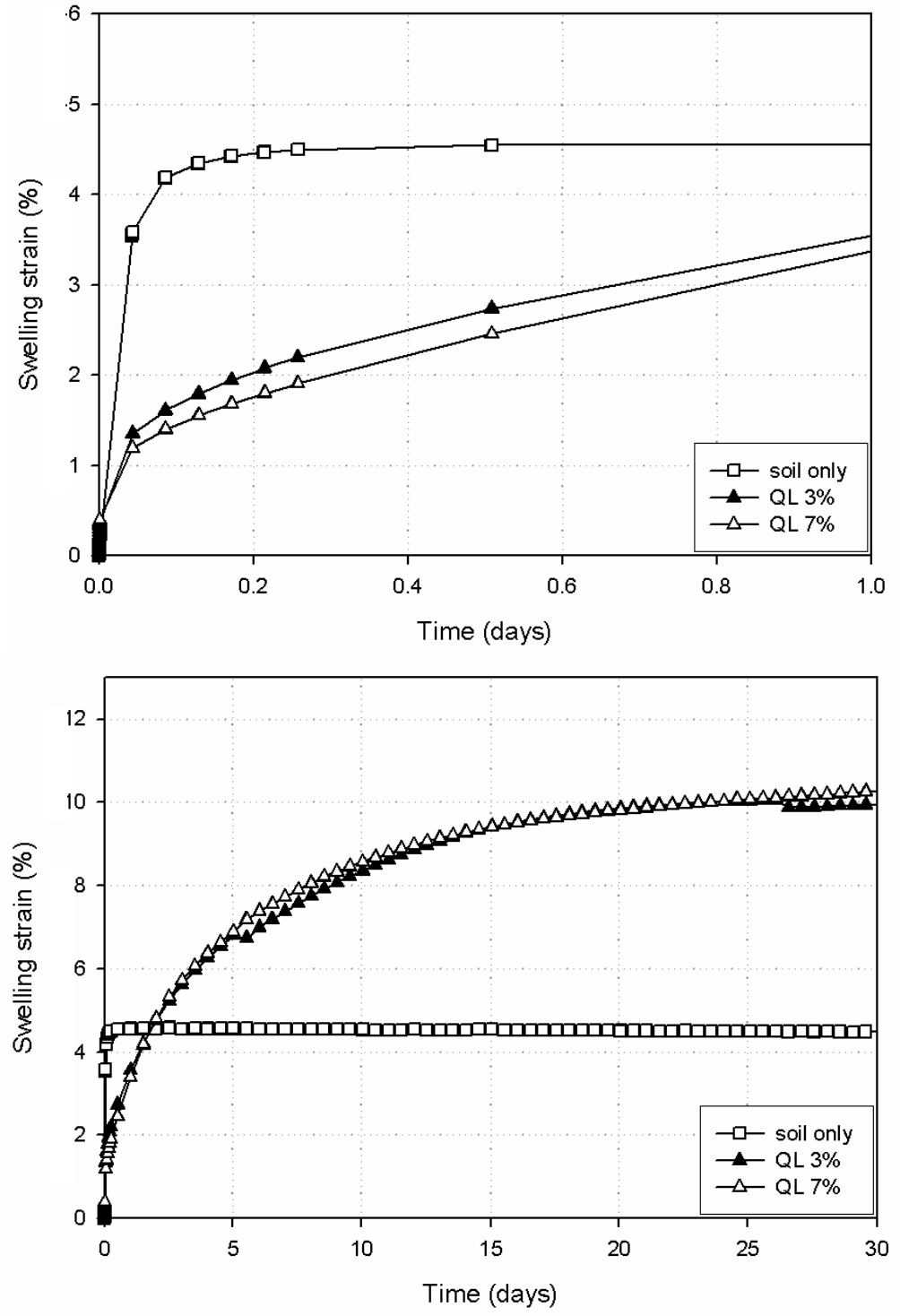

Figure 4.11 Swelling behavior of H1A soil treated with 3\% and 7\% quick lime 

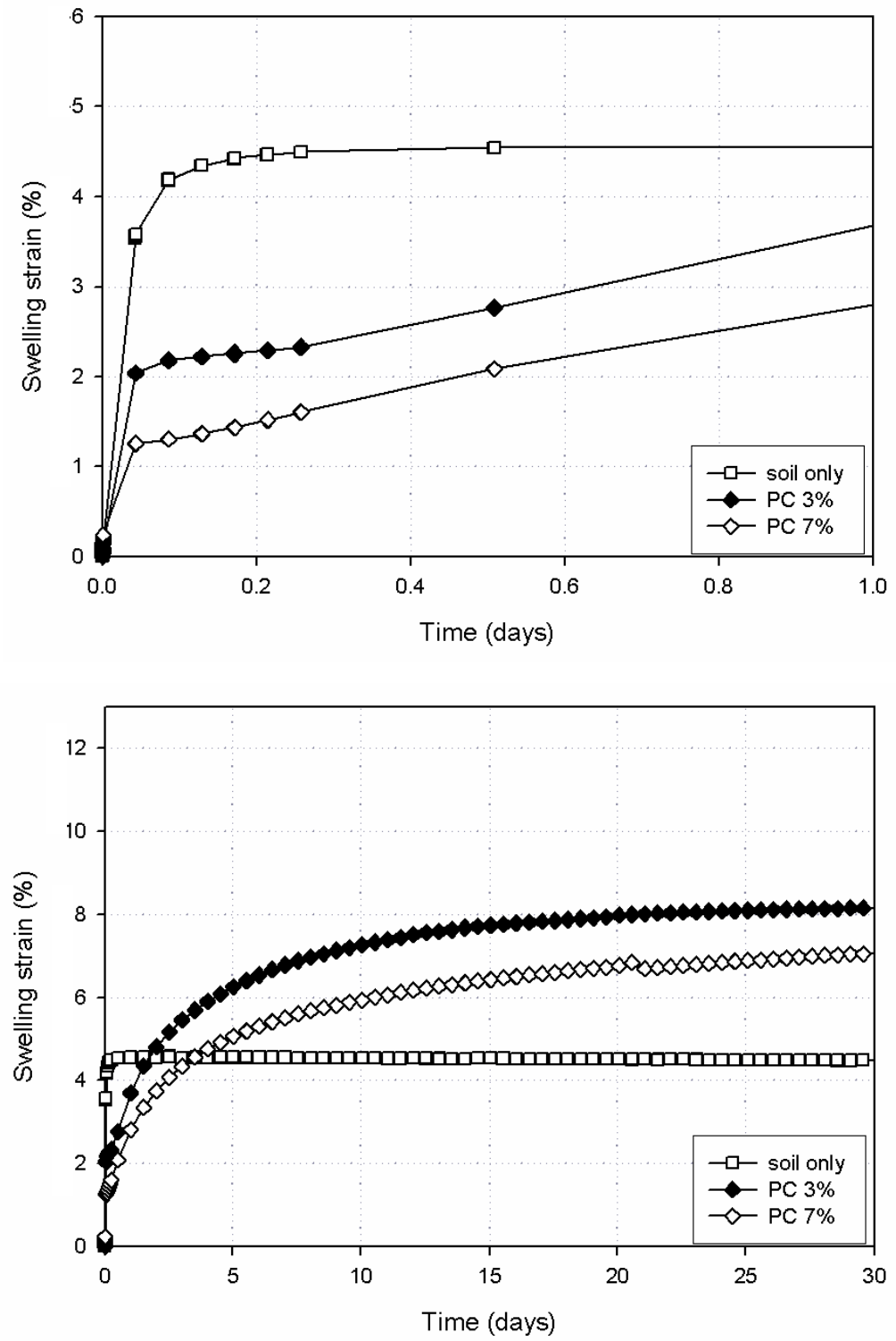

Figure 4.12 Swelling behavior of H1A soil treated with 3\% and 7\% Portland cement 
Table 4.7 Final swelling strains for untreated and treated $\mathrm{H} 1 \mathrm{~A}$ and $\mathrm{H} 1 \mathrm{~B}$ soil (data from Figures 4.7-4.8, 4.10-4.12)

\begin{tabular}{|c|c||c|c|c|c|}
\hline \multicolumn{2}{|c||}{ H1B soil } & \multicolumn{4}{c|}{ H1A soil } \\
\hline Stabilizer & $\begin{array}{c}\text { Final swell } \\
\text { strain (\%) }\end{array}$ & Stabilizer & $\begin{array}{c}\text { Final swell } \\
\text { strain (\%) }\end{array}$ & Stabilizer & $\begin{array}{c}\text { Final swell } \\
\text { strain (\%) }\end{array}$ \\
\hline Soil alone & 2.9 & Soil alone & 4.3 & & \\
\hline $3 \% \mathrm{HL}$ & 5.1 & $3 \% \mathrm{HL}$ & 12.1 & $7 \% \mathrm{HL}$ & 10.1 \\
\hline $7 \% \mathrm{HL}$ & 3.7 & $3 \% \mathrm{AL}$ & 9.2 & $7 \% \mathrm{AL}$ & 10.6 \\
\hline & & $3 \% \mathrm{QL}$ & 9.8 & $7 \% \mathrm{QL}$ & 10.2 \\
\hline & & $3 \%$ PC & 8.2 & $7 \%$ PC & 7.1 \\
\hline
\end{tabular}

Note: $\mathrm{HL}=$ hydrated lime, $\mathrm{AL}=$ analytical lime, $\mathrm{QL}=$ quick lime, $\mathrm{PC}=$ Portland cement

To better illustrate the role played by the stabilizer, Figure 4.13 presents swelling curves for H1A soil treated with 3\% of each of the stabilizers examined. As stated above, the greatest swelling is observed with hydrated lime; the curves for quick lime and analytical are relatively close, while the least amount of swelling is observed with Portland cement. As a result of this, additional testing focused primarily on soil treated with hydrated lime. Specifically, this work: examined the swelling behavior of the H1A soil sample treated with $1.5 \%, 5 \%$ and $9 \%$ hydrated lime (to complement the data obtained for 3\% and 7\% lime); investigated the effect of the surcharge stress on the swelling behavior; explored the applicability of the two following mitigation techniques: pre-compaction mellowing and double-lime treatment. These results are presented in Sections 4.3.4., 4.3.5., 4.3.7, and 4.3.8., while Section 4.3.6 compares the values of the swelling strains measured in this study to data from the literature.

Finally, note that for all soil-stabilizer combinations tests were also performed to determine the chemical and mineralogical characteristics of the mixture at the end of swelling. The results of these tests are presented in Chapter 5 . 

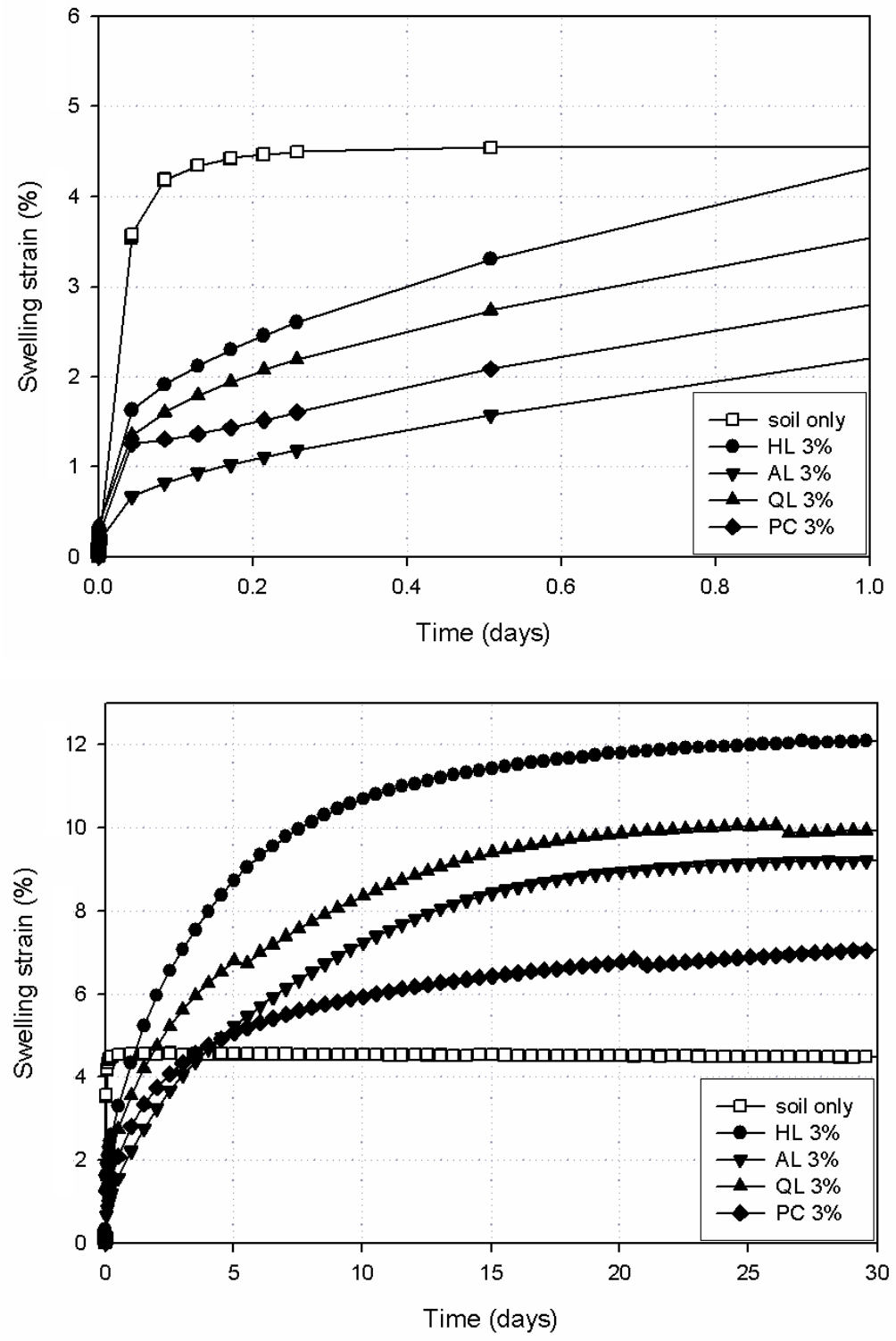

Figure 4.13 Comparison of swelling behavior of H1A soil treated with various stabilizers 


\subsubsection{Additional Tests on Effect of Stabilizer Dosage}

As stated above, tests were performed on the H1A soil treated with hydrated lime at dosages ranging between $1.5 \%$ and $9 \%$. The results of these tests are presented in Figure 4.14 and Figure 4.15, while Table 4.8 summarizes the final swelling strains. The compaction curves shown in Figure 4.14 display the expected trend of increasing optimum moisture content and decreasing maximum dry density with increasing stabilizer dosage. The swelling curves (Figure 4.15) show that all stabilizer treated specimens swell more than the soil alone. With $1.5 \%$ hydrated lime the swelling is just slightly greater than that of the soil alone $(5.2 \%$ versus $4.3 \%)$. The greatest swelling $(\sim 12 \%)$ is measured with $3 \%$ lime.

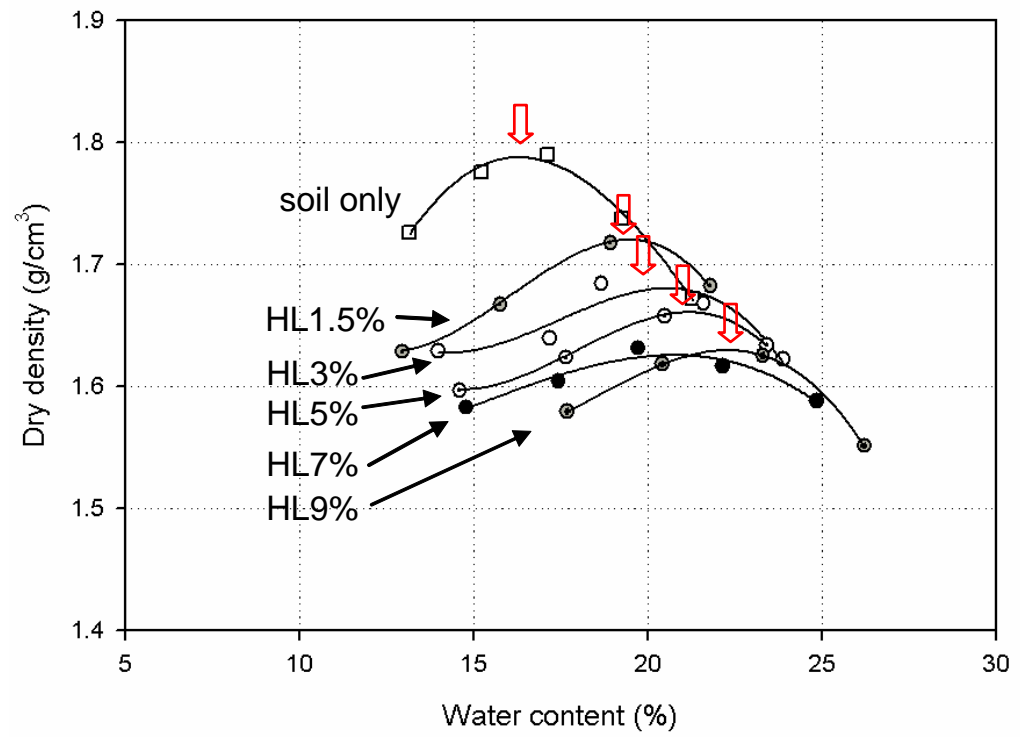

Figure 4.14 Compaction behavior of $\mathrm{H} 1 \mathrm{~A}$ soil treated with $1.5 \%-9 \%$ hydrated lime 

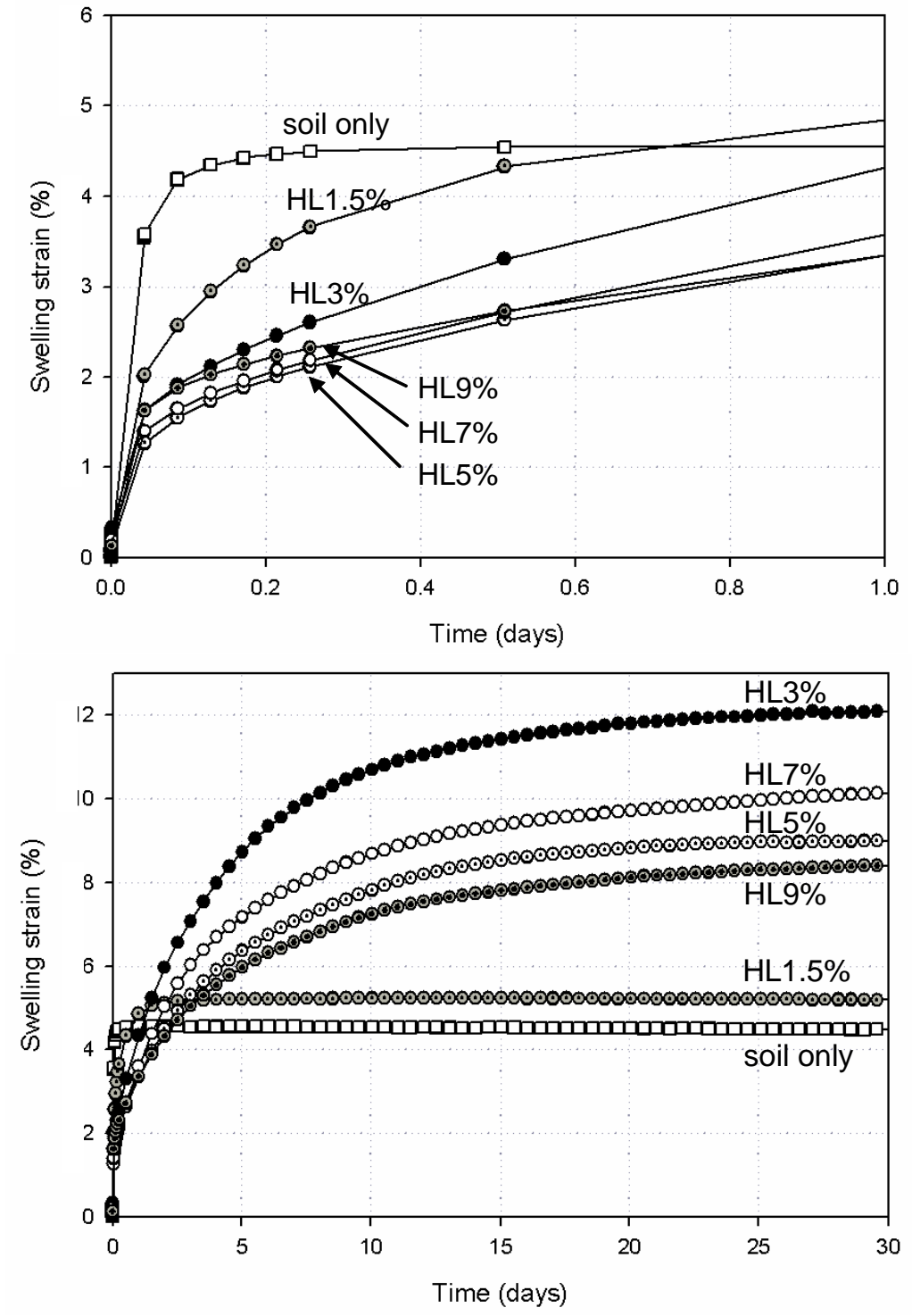

Figure 4.15 Swelling behavior of H1A soil treated with 1.5\%-9\% hydrated lime

Table 4.8 Final swelling strains for $\mathrm{H} 1 \mathrm{~A}$ soil treated with hydrated lime (1.5\%-9\%)

\begin{tabular}{|c|c|c|c|c|c|}
\hline Soil alone & HL 1.5\% & HL 3\% & HL 5\% & HL 7\% & HL 9\% \\
\hline \hline $4.3 \%$ & $5.2 \%$ & $12.1 \%$ & $9.0 \%$ & $10.1 \%$ & $8.4 \%$ \\
\hline
\end{tabular}




\subsubsection{Effect of Surcharge Stress}

Tests were conducted to examine the effect of the surcharge stress on the swelling strains. As discussed above, this investigation was limited to soil treated with $3 \%$ hydrated lime given the fact that the swelling strains were found to be the greatest with this treatment. In addition to the reference surcharge stress of 0.3 psi used for all tests described to this point, tests were conducted using the following surcharge stresses: 0.6 , 1.2 and 2.4 psi. Figure 4.16 presents the resulting swelling curves.

The curves for the lime treated soil shown in Figure 4.16 exhibit the same delayed swelling observed earlier for all specimens of treated soil. As expected, and consistent with data by Hawlader et al. (2003) and Puppala et al. (2005b), the greater the surcharge stress, the smaller the swelling strain. However, for all surcharge stresses the final swelling strain exceeds the value measured on the untreated soil with the lowest ( 0.3 psi) surcharge. The data obtained as a function of the surcharge stress can be used to develop a model capable of describing the relationship between swelling strain and surcharge stress, as done for example by Livneh and Livneh (2002). This would permit assessment of the actual impact on the road or structure of the swelling pressure from inside the base or subbase made of problematic soils. 

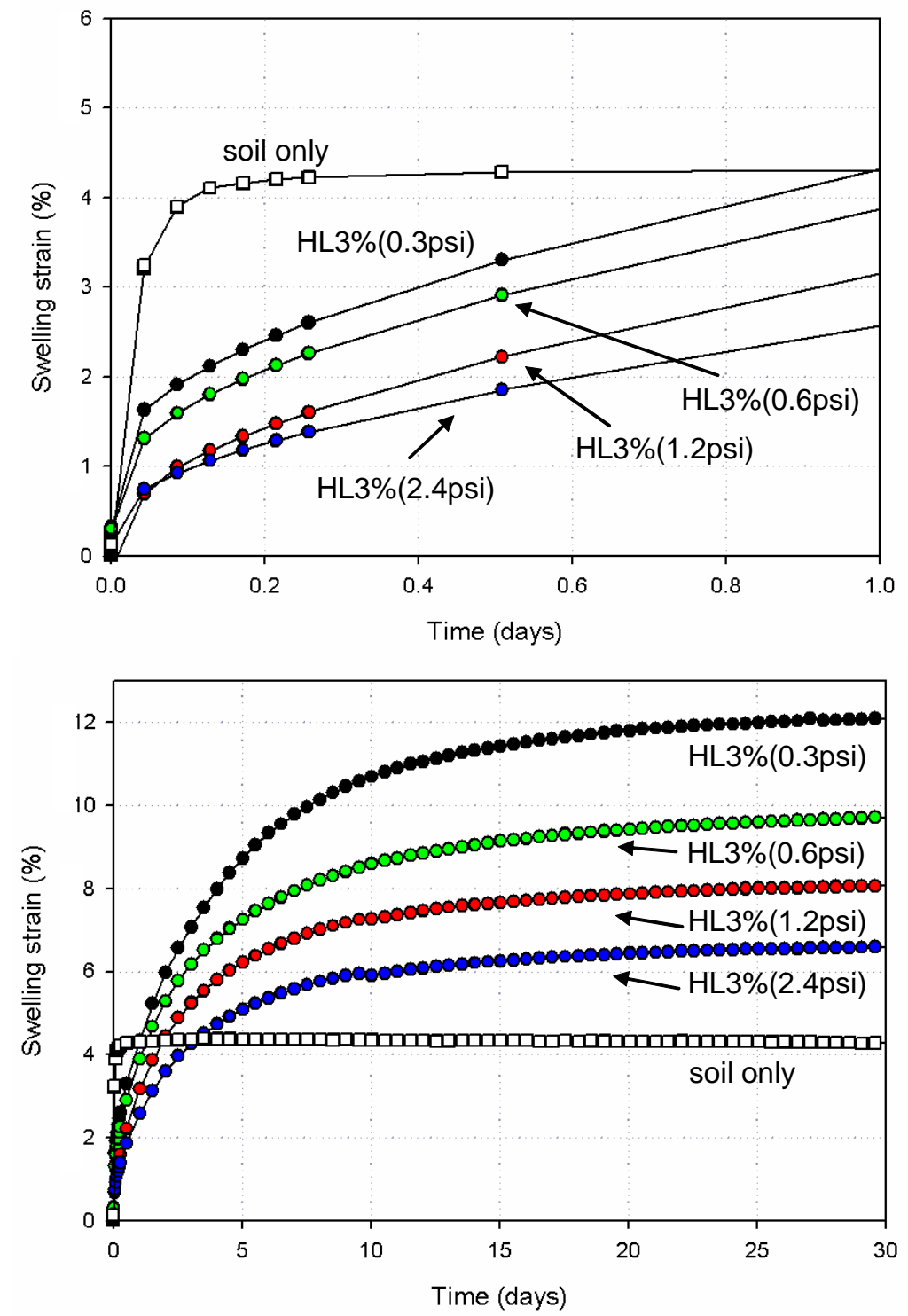

Figure 4.16 Swelling behavior of H1A soil treated with 3\% hydrated lime under various surcharge stresses

\subsubsection{Comparison to Swelling Data from the Literature}

It is of interest to compare the swelling data presented so far to results from the

literature. Here the comparison is based on data provided by Puppala et al. (2005b) from an extensive experimental program conducted on two Texas soils (both classified as low 
plasticity clays) artificially "doped" with sulfate. The swelling behavior of these soils was investigated following treatment with quick lime using a one dimensional free swell test set up (ASTM D 4546). Testing variables examined included the sulfate content (1,000 to $10,000 \mathrm{ppm})$, the lime dosage ( $4 \%$ and $8 \%$ ), the water content (optimum and wet of optimum ( $2 \%$ greater than optimum) conditions), the testing temperature $\left(4^{\circ} \mathrm{C}, 25\right.$ ${ }^{\circ} \mathrm{C}$ and $40^{\circ} \mathrm{C}$ ), and the surcharge stress ( 0 to $6 \mathrm{psi}$ ). Selected results from this work are shown in Figure 4.17. Specifically, Figure 4.17 presents data for two soils (termed S1 and S2) treated with $4 \%$ and $8 \%$ lime. In each figure the final swelling strain is plotted versus the sulfate content. The testing conditions are identified through a symbol that indicates the soil, the lime content, the water content, the surcharge stress and the temperature (e.g. 'S1-L4-Opt-P0-T25' indicates data for soil 1, mixed with 4\% quick lime at optimum water content with zero surcharge at $25^{\circ} \mathrm{C}$ ). A circle on the plots in Figure 4.17 identifies the data corresponding to measurements on soil with sulfate content of 10,000 ppm, compacted at optimum and allowed to swell under zero surcharge at $25^{\circ} \mathrm{C}$. These are the conditions closest to those used in this research. It is found that the strains reported by Puppala et al. (2005b) are of the same magnitude as those measured in this research. With increasing surcharge stress a reduction in swelling similar to that described in Section 4.3.5 is observed. Further, for soil 1 it is shown that as in this study, a higher swelling strain is measured on the soil treated with the lower lime percentage. Finally, the data by Puppala et al. (2005b) also indicate that higher swelling is measured at lower temperatures. This suggests that cold climatic conditions, such as those typical of Indiana, may exacerbate the swelling problem. 
(a)

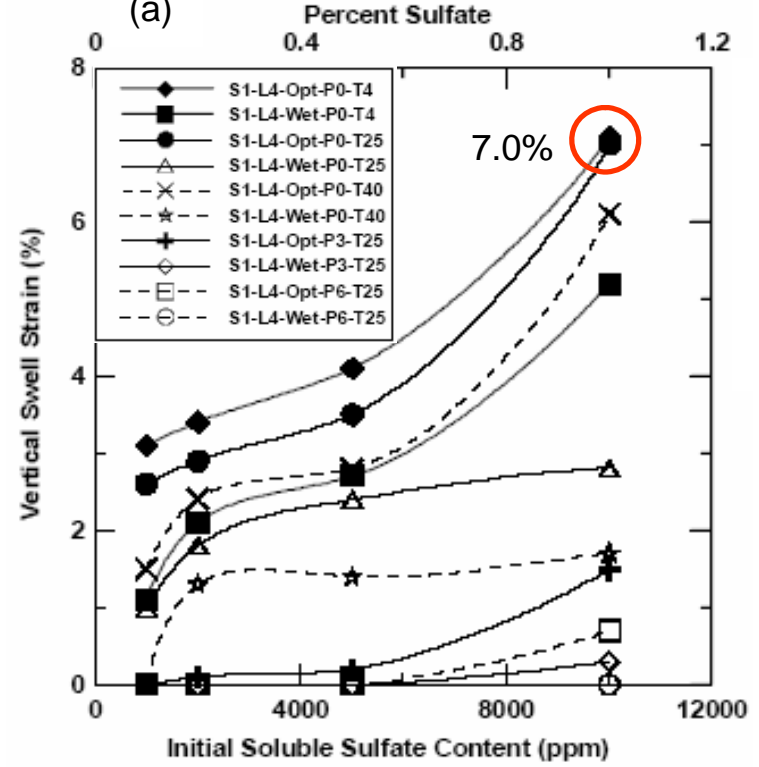

(c)

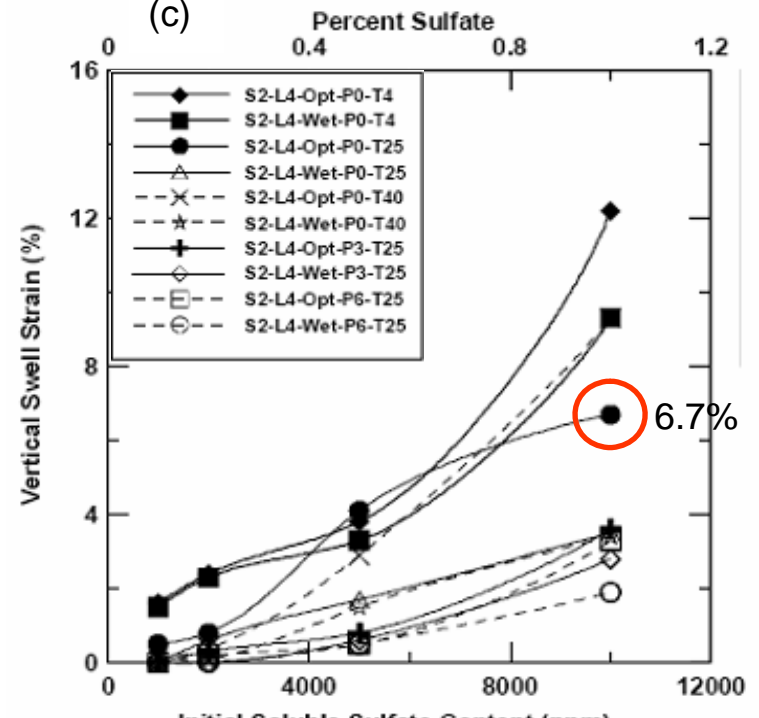

Initial Soluble Sulfate Content (ppm)

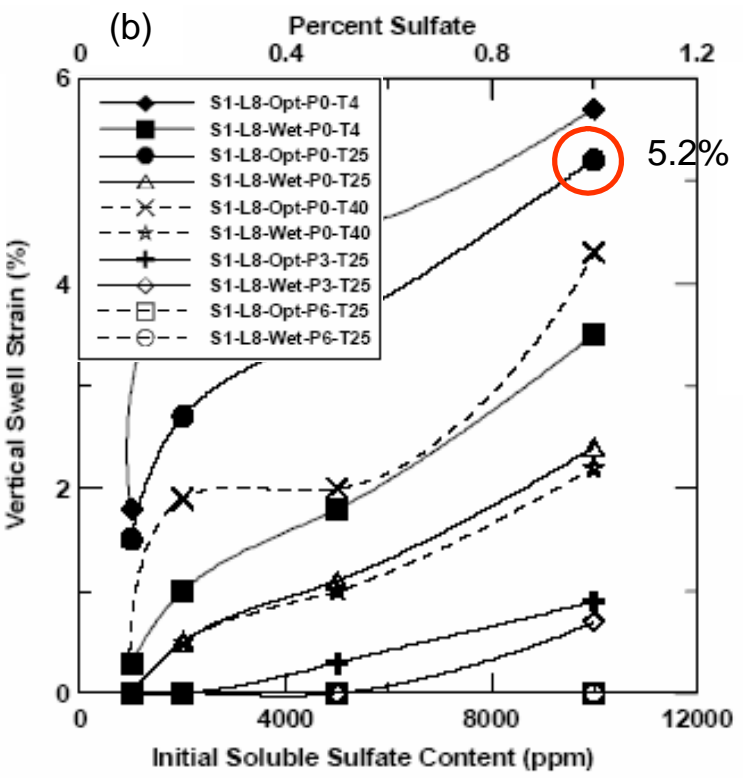

(d) Percent Sulfate

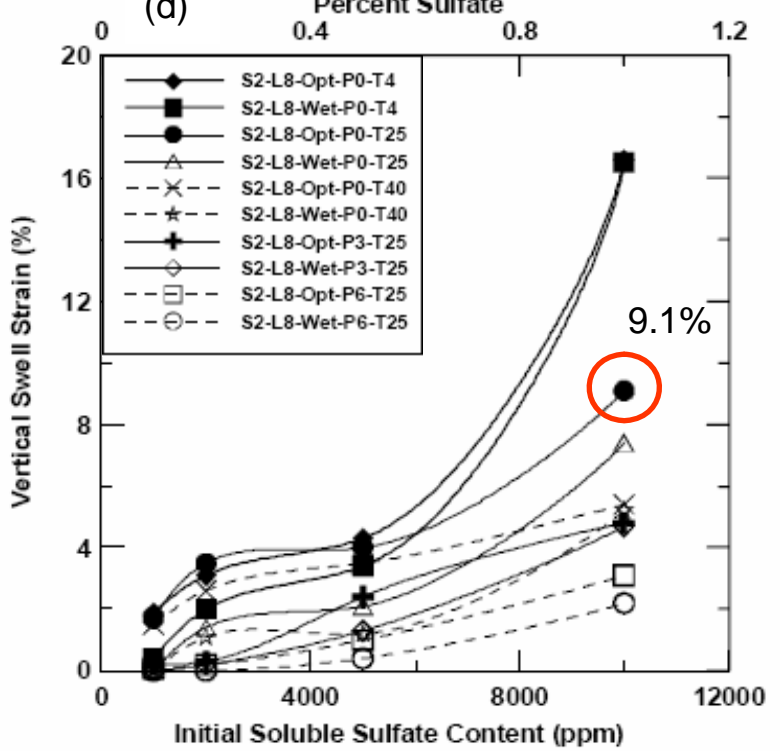

Figure 4.17 Swelling strains measured on two Texas soils under varying testing conditions: a) soil 1 treated with 4\% lime; b) soil 1 treated with $8 \%$ lime; c) soil 2 treated with 4\% lime; and d) soil 2 treated with 8\% lime (Puppala et al. 2005b)

Note: circles identify testing conditions close to those used in this research 


\subsubsection{Effectiveness of Pre-compaction Mellowing}

As reviewed in section 2.6, several methods have been proposed to mitigate the expansive behavior of chemically treated soils. One of these methods involves a mellowing period between the time the soil is mixed with the stabilizer and its compaction. The idea behind this method is to allow the reactions between soil and stabilizer that potentially can lead to the formation of expansive products to occur (at least in part) before the soil is compacted. The applicability of this method in practice comes from practical and cost considerations, which limit the duration of the mellowing stage. The method has been successfully applied to eastern Texas soils doped with sulfate compounds, and shown to be cost-effective in field applications (Harris et al. 2004). Hence it was decided to access its potential applicability to lime-treated coal mine spoils. Prior to performing swelling measurements, compaction curves for the treated soil mellowed for different periods of time had to be determined. This is because the physical and chemical properties of the soils were expected to change after mellowing.

Figure 4.18 shows the results for the compaction experiments performed as described in Section 3.4.3 for H1A soil treated with 3\% and 7\% hydrated lime and compacted after 1, 2, and 3 days of mellowing (mellowing beyond 3 days did not appear practical for field applications). For reference the figures also include the compaction curves for the soil alone and for the soil treated with lime but compacted immediately after mixing. The figures show that as the duration of mellowing increased the compaction curve shifts down and to the right, as a result of changes in the soil structure 
(aggregation of particles due to soil-stabilizer reactions). Table 4.9 summarizes the values of the optimum moisture content.
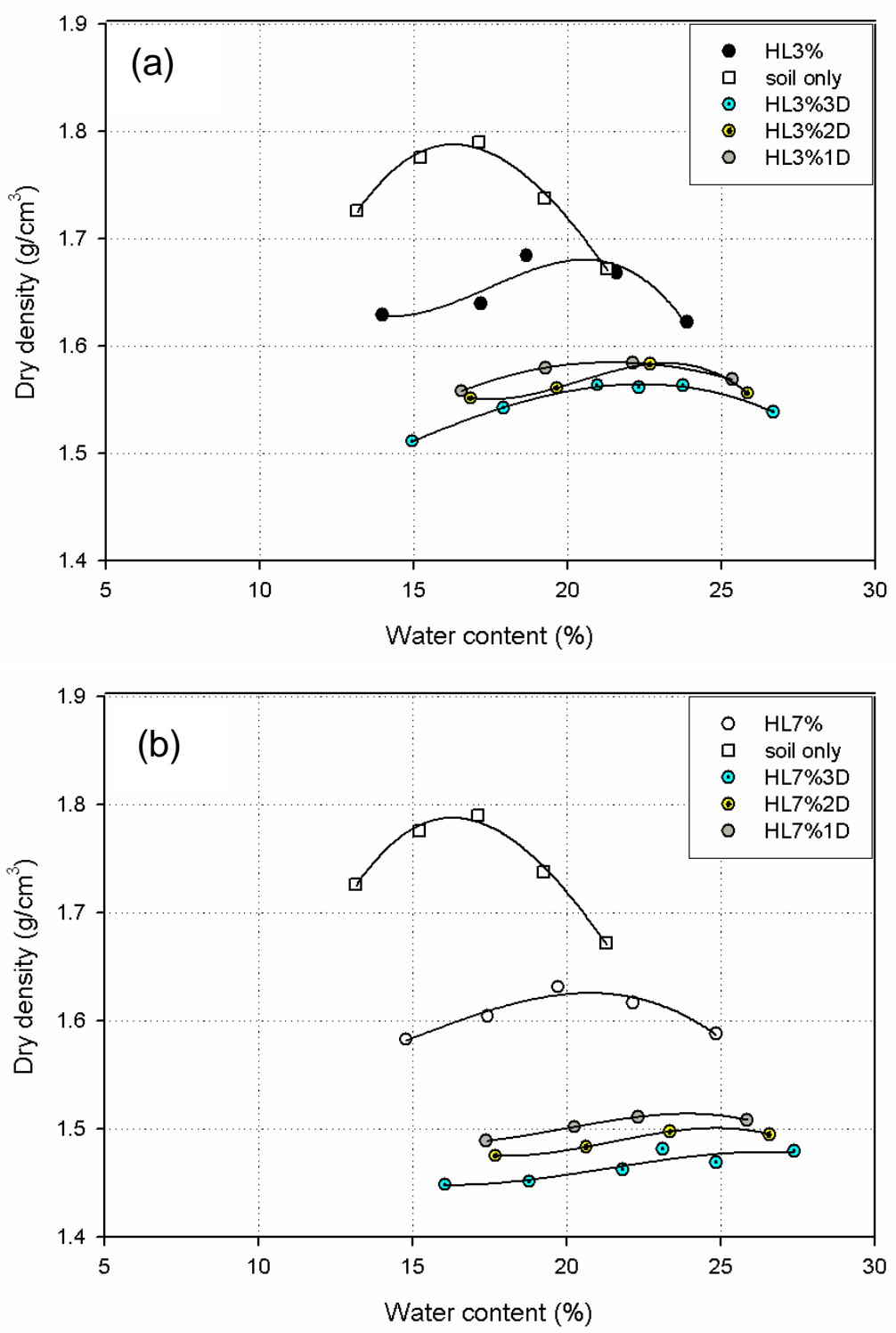

Figure 4.18 Compaction behavior of H1A soil treated with: a) 3\% and b) $7 \%$ hydrated lime and mellowed for 1,2, and 3 days. 
Table 4.9 Water content at optimum for $\mathrm{H} 1 \mathrm{~A}$ soil treated with $3 \%$ and $7 \%$ hydrated lime and allowed to mellow prior to compaction

\begin{tabular}{|c|c|c|c|c|c|c|c|}
\hline HL3\%0D & HL3\%1D & HL3\%2D & HL3\%3D & HL7\%0D & HL7\%1D & HL7\%2D & HL7\%3D \\
\hline $19.5 \%$ & $22 \%$ & $23 \%$ & $23.5 \%$ & $20.5 \%$ & $23.5 \%$ & $24 \%$ & $24.5 \%$ \\
\hline
\end{tabular}

Note: $\mathrm{HL}=$ hydrated lime, $\mathrm{D}=$ mellowing day(s)

Having determined the compaction curves, swelling measurements under the reference 0.3 psi surcharge stress were conducted on soil specimens compacted at the optimum water content. The results of these tests are plotted in Figure 4.19 (3\% lime) and Figure 4.20 (7\% lime). Also in this case the figures include the data for the soil alone and the soil treated with hydrated lime but with no mellowing. 

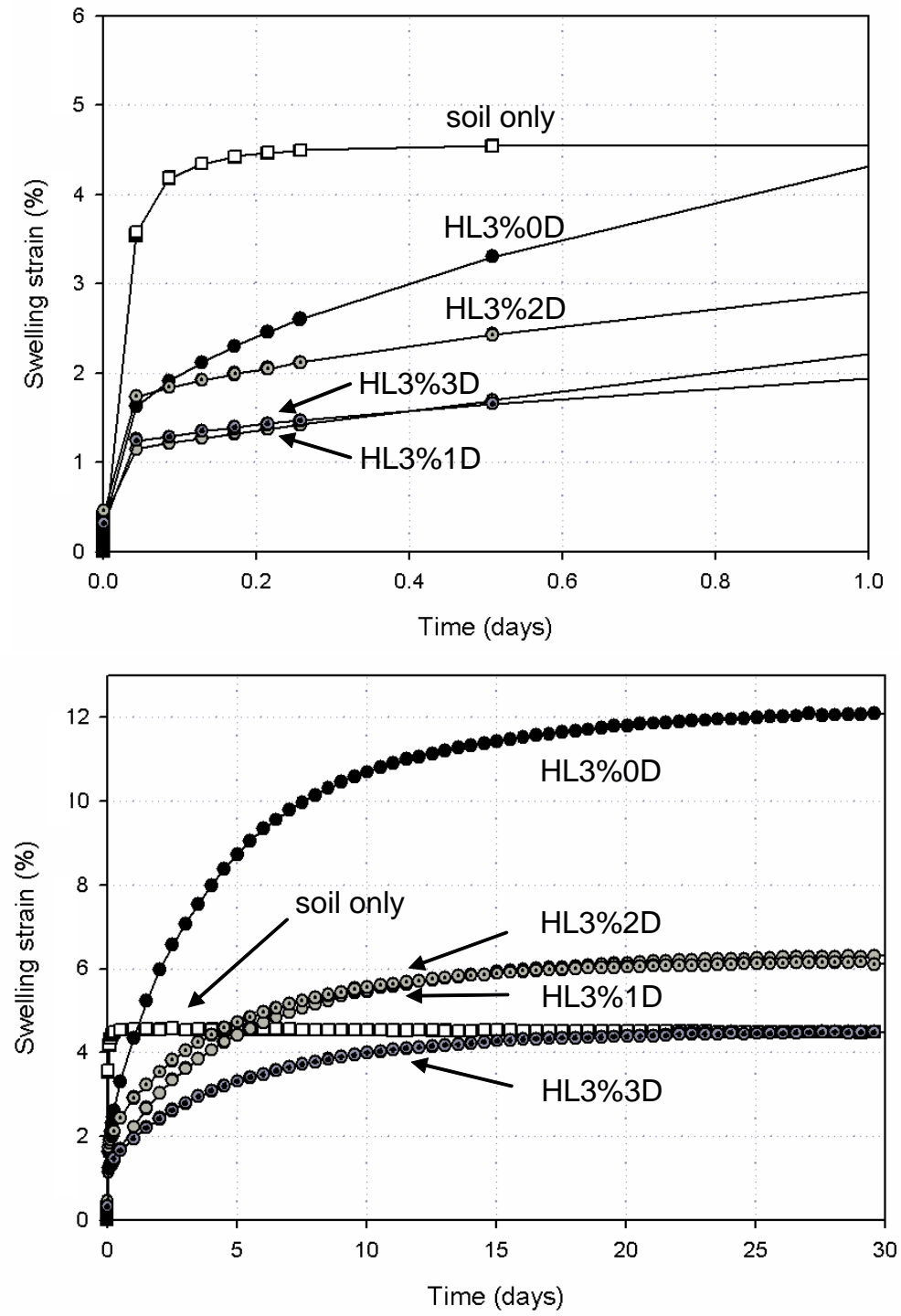

Figure 4.19 Swelling behavior of H1A soil treated with 3\% hydrated lime after mellowing for 1, 2 and 3 days 

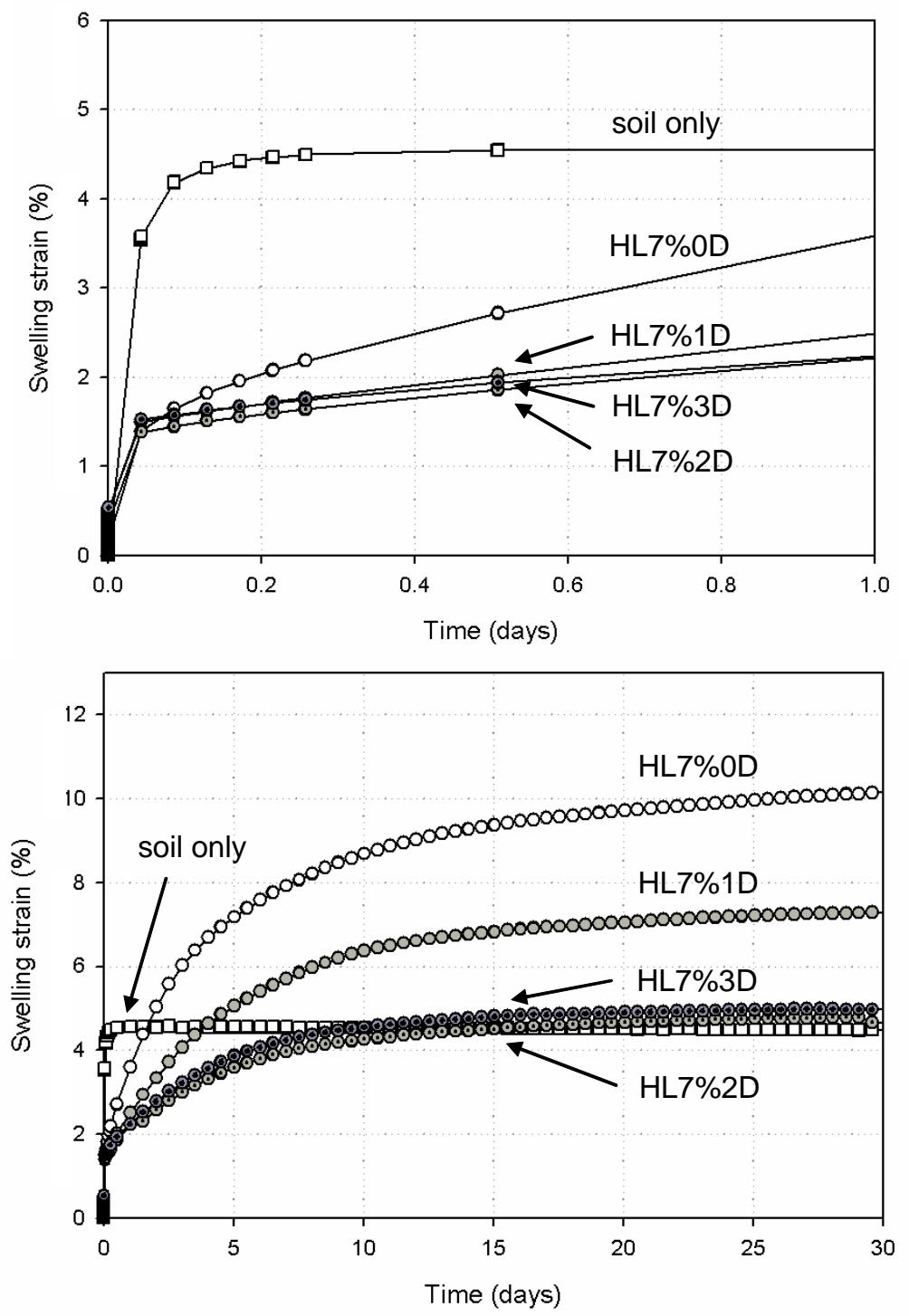

Figure 4.20 Swelling behavior of H1A soil treated with 7\% hydrated lime after mellowing for 1, 2 and 3 days

Table 4.10 summarizes the values of the final strains for all curves shown in Figures 4.19 and 4.20. This table also reports the $\%$ reduction in the final swelling strains resulting from mellowing. These data indicate that mellowing is effective in reducing the swelling strain provided that the mellowing period is long enough. For $7 \%$ hydrated lime a mellowing period of 2 or more days is sufficient to reduce the final swelling strain to 
values close to that measured on the soil alone (4.3\%). For treatment with $3 \%$ hydrated lime a mellowing period of 3 days is necessary to reach the same result. Note also that consistent with data presented earlier in the chapter the use of $3 \%$ hydrated lime leads to greater swelling than for $7 \%$ hydrated lime.

Table 4.10 Swelling strain reduction with pre-compaction mellowing

\begin{tabular}{|c|c|c||c|c|c|}
\hline $\begin{array}{c}\text { Stabilizer and } \\
\text { mellowing days }\end{array}$ & $\begin{array}{c}\text { Final } \\
\text { swell (\%) }\end{array}$ & $\begin{array}{c}\text { Strain } \\
\text { reduction } \\
(\%)\end{array}$ & $\begin{array}{c}\text { Stabilizer and } \\
\text { mellowing days }\end{array}$ & $\begin{array}{c}\text { Final } \\
\text { swell (\%) }\end{array}$ & $\begin{array}{c}\text { Strain } \\
\text { reduction } \\
(\%)\end{array}$ \\
\hline \hline HL3\%0D & 12.1 & - & HL7\%0D & 10.1 & - \\
\hline HL3\%1D & 6.3 & 48 & HL7\%1D & 7.3 & 28 \\
\hline HL3\%2D & 6.1 & 49 & HL7\%2D & 4.7 & 54 \\
\hline HL3\%3D & 4.5 & 63 & HL7\%3D & 5.0 & 51 \\
\hline
\end{tabular}

Note: $\mathrm{HL}=$ hydrated lime, $\mathrm{D}=$ mellowing $\operatorname{day}(\mathrm{s})$

Since mellowing is expected to affect the strength of the treated soil, unconfined compression tests were performed on specimens of H1A soil treated with $7 \%$ hydrated lime and compacted after 0 or 2 days of mellowing. The results of the unconfined compression tests performed after 0, 4 and 29 days of curing in a humid room with R.H. $>90 \%$ and temperature of $10{ }^{\circ} \mathrm{C}$, are shown in Figure 4.21 . It is observed that the strength of the treated soil at all curing times is partially compromised as a result of mellowing, although the strength continues to greatly exceed that of the untreated soil. 


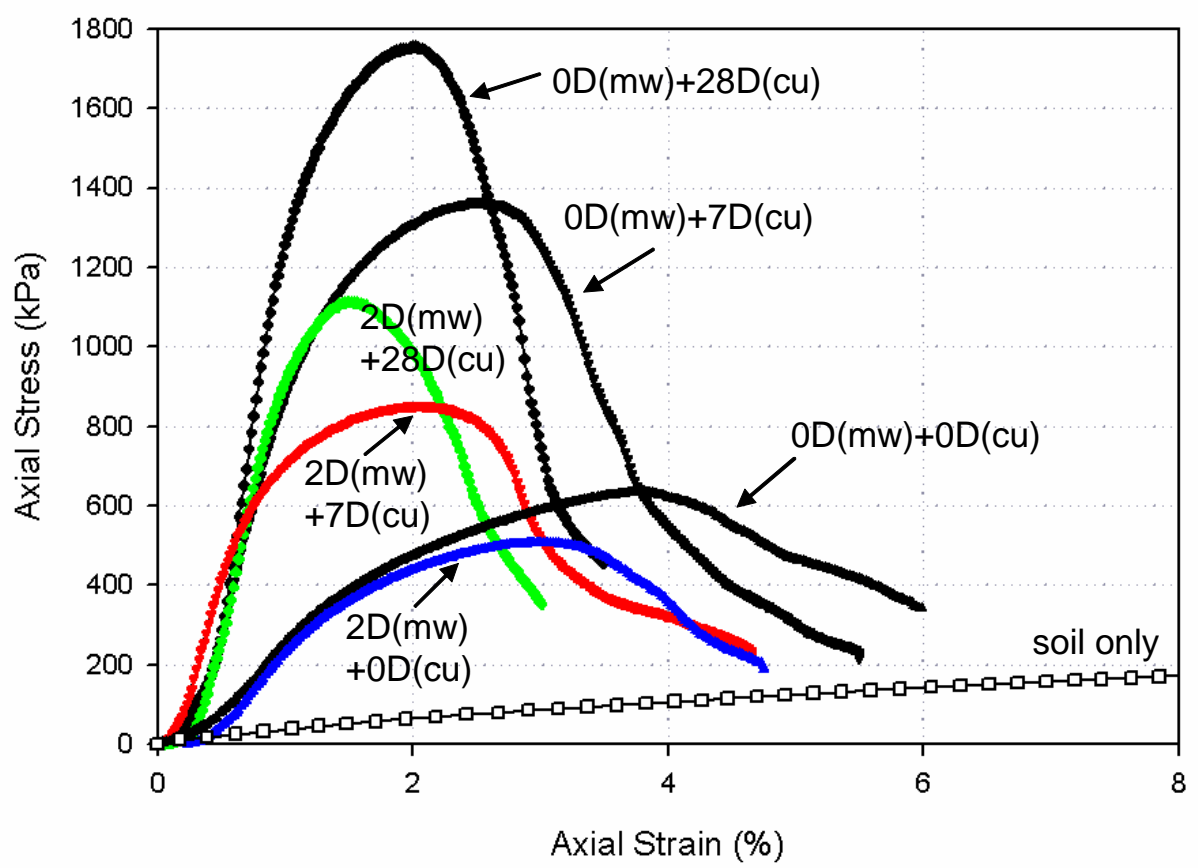

Figure 4.21 UC strength of H1A soil treated with 7\% hydrated lime treated as a function of mellowing conditions and curing time (Note: $\mathrm{mw}=$ mellowing, $\mathrm{cu}=\mathrm{curing}, \mathrm{HL}=$ hydrated lime, $\mathrm{D}=$ days)

\subsubsection{Effectiveness of Double Lime Treatment}

Double lime treatment is another mitigation approach discussed in the literature.

This method is similar to the mellowing method described above, except that after the mellowing period, additional lime is added to the mixture. The idea behind the method is that the first treatment with lime and the subsequent mellowing stage consume the sulfate present in the soil and permit formation of the potentially expansive products before the soil-stabilizer mixture is compacted; while the second lime application makes up for the reduced mechanical properties deriving from mellowing. Successful applications of this method have been reported for soil with low sulfate content $(<7000 \mathrm{ppm}$, Ferris et al. 
1991; Perrin 1992; Petry and Little 1992; Kota et al. 1996). As discussed by Kota et al. (1996), another critical factor influencing the effectiveness of this method is the delay period between the first and second lime treatment. Of course, an excessive delay limits the application of this method from both a practical and cost perspective. Although the effectiveness of this method is controversial, a small investigation of its potential suitability to treat chemically treated coal mine spoils (H1A soil) was included in this research. Again, testing was limited to H1A soil treated with hydrated lime. All tests involved a first treatment with $3 \%$ lime and the subsequent addition of $4 \%$ lime. These values of the lime dosages were selected to facilitate comparisons with the previous data for $3 \%$ and $7 \%$ lime. Tests were performed with time delay between the two treatments of 1,2 , and 7 days (while the latter value is probably not practical, as shown below, no advantage was found with delays of 1 and 2 days; hence a significantly greater delay period was examined).

In order to conserve soil, compaction tests were not performed to determine the values of the optimum water contents for the soil compacted with $3 \%+4 \%$ lime after different delay periods. Instead the values of the compaction water contents $(\mathrm{w}=22 \%$, $23 \%$ and $24 \%$ for 1,2 and 7 days delay between the two lime additions) were based on the results for the mellowed soil $(\mathrm{HL}=3 \%$ and $7 \%$ ) shown in Figure 4.22.

Figure 4.22 presents the swelling curves for the tests performed with double lime application. Data are provided for two duplicate specimens for each of the testing conditions examined. The final swelling strains for these tests are compared in Table 4.11 to the data presented earlier in this chapter. 
Overall, it is concluded that double lime treatment is not successful in mitigating the expansive behavior of the spoils examined in this research. For delays of one and two days between the two lime applications the final swelling strains continue to significantly exceed the values measured on the soil alone (7-9\% strain versus the $4.3 \%$ strain measured on the soil alone). Even with a delay time of 7 days the swelling remains slightly greater in the treated soil.

Moreover, the double lime treatment appears - at least from the perspective of the swelling behavior - to offer no advantage compared to the single lime application with pre-compaction mellowing: higher strains are measured for all mellowing durations (e.g. compare $7-9 \%$ strains measured on soil treated with $3 \%+4 \%$ lime with either 1 or 2 days of intermediate mellowing to $6 \%$ strain measured on soil treated with $3 \%$ or $7 \%$ lime and 1 or 2 days of mellowing prior to compaction). The higher strains measured in the double lime treated specimens suggest that the first addition of lime is not sufficient to consume the sulfate existing in the soil; and that sulfate is available to react with the lime added in the second stage of the treatment. These results indicate that mellowing alone appears a better mitigation approach than double lime treatment, and that the additional costs associated with the second treatment are not justified by the swelling results. It is also of interest to compare the results for the double lime treated specimens to the data for 3\% and 7\% lime with no mellowing stage. Compared to the data for $7 \%$ lime (Figure 4.8), the results for double lime treatment show marginal reductions in the final swelling strains. This is likely a result of the formation of the expansive products occurring as a result of the first addition of lime is accommodated during the pre-compaction mellowing 
stage. It appears that these improvements in swelling behavior do not justify the additional costs associated with double lime treatment.
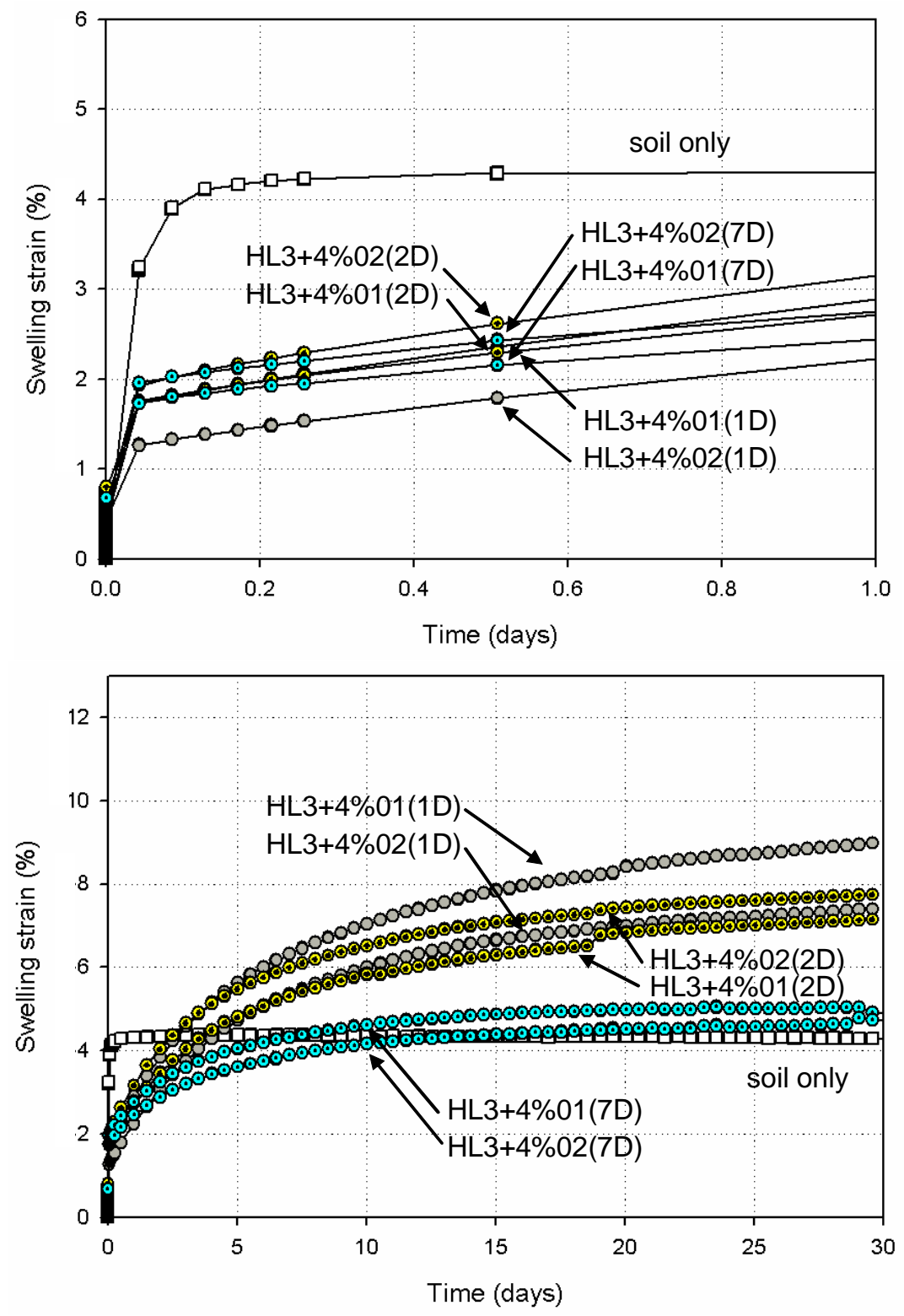

Figure 4.22 Swelling behavior for H1A soil following double treatment $(3 \%+4 \%)$ with hydrated lime (1,2 and 7 days delay) 
Table 4.11 Final swelling strains following double lime treatment and comparison to previous data

\begin{tabular}{|c|c|c|c|}
\hline $\begin{array}{c}\text { Time between first } \\
\text { lime treatment and } \\
\text { compaction }\end{array}$ & $\begin{array}{c}\text { Double Lime } \\
3+4 \% \text { H Lime }\end{array}$ & $\begin{array}{c}\text { Single Lime } \\
3 \% \text { H Lime }\end{array}$ & $\begin{array}{c}\text { Single Lime } \\
7 \% \text { H Lime }\end{array}$ \\
\hline \hline 0 days & - & $12.1 \%$ & $10.1 \%$ \\
\hline 1 day & $7.4-9.0 \%$ & $6.3 \%$ & $7.3 \%$ \\
\hline 2 days & $7.2-7.8 \%$ & $6.1 \%$ & $4.7 \%$ \\
\hline 3 days & - & $4.5 \%$ & $5.0 \%$ \\
\hline 7 days & $4.7-4.9 \%$ & - & - \\
\hline
\end{tabular}

Note also that the values of the swelling strain shown in table 4.11 for $3 \%$ and $7 \%$ lime (no mellowing) were the highest measured under these testing conditions. In other tests values of swelling closer to those measured for double lime treatment were measured (see Figure 4.9).

\subsection{Summary}

This chapter presented the results of tests conducted to investigate the swelling behavior of sulfate rich coal mine spoils treated with different calcium-based stabilizers: hydrated lime, quick lime and Portland cement. The experimental program made use of two samples of coal mine spoils (termed H1A and H1B) obtained from the Hawthorn mine site and screened as described in Chapter 3. Of the samples collected for this research, these were the ones with the highest sulfate content; and, thus, were expected to pose the greatest problems in terms of swelling induced by reactions between the sulfate and the stabilizer(s). The experimental program included tests on the soil alone (Atterberg limits, percentage of fines and $\mathrm{pH}$ ), on the stabilizers alone (to measure $\mathrm{pH}$ ), 
as well as on various soil-stabilizer combinations. Tests on the soil-stabilizer mixtures included: $\mathrm{pH}$ fixation tests (based on which stabilizer dosages of $3 \%$ and $7 \%$ by dry mass of the soil were selected), compaction tests performed using the Harvard miniature apparatus (to determine the optimum conditions) and one-dimensional swelling tests conducted on soil specimens compacted at the optimum moisture content using a custom set-up that allowed access to water also from both the ends and the sides. The treated soil specimens all displayed swelling strains greater than those measured on the untreated soil (by as much as a factor of 3), with the greatest swelling measured on specimens treated with $3 \%$ hydrated lime. In the case of the untreated specimens, the final swelling strain was reached after just a few hours. For all the treated specimens, swelling was, instead, delayed with approximately one month needed to reach the final swelling strain, and one week required for $50 \%$ of the final swelling to take place. For reference, a limited number of swelling tests were also conducted on a local soil (Crosby till) with negligible sulfate content. These tests showed that treatment with lime led to reduced swelling strains, and demonstrated that the strains measured for the lime treated spoils were due to reactions between the stabilizer and the soil.

Additional swelling tests were performed with hydrated lime (the stabilizer that led to the highest swelling strains) to investigate the effect of the surcharge stress (which was varied from 0.3 to $2.4 \mathrm{psi}$ ). These tests showed that as the surcharge loading increased, the swelling strain of the treated soils decreased. These results can be used to model the effects of swelling, and quantify the effect of surcharge loading.

Finally, the potential applicability of two mitigation approaches - pre-compaction mellowing and double lime treatment - was examined. In both cases the investigation 
focused on H1A soil treated with hydrated lime. It was found that while marginally compromising the strength of the treated soil, a pre-compaction mellowing period of 2-3 days was effective in reducing the final swelling strain of the lime treated soil $(3 \%$ and $7 \%$ hydrated lime) to values comparable to those measured on the untreated soil. Compared to the single lime treatment, the results for double lime treatment showed only a marginal reduction in the final swelling strain, unless the period between the two treatments was extended to 7 days. This is most likely due to the high sulfate content of the soil used in this experimental program, which could not be entirely "consumed" by the first lime application. A delay between the two treatments of 7 days appears unpractical for application in the field; overall, double lime treatment does not appear to offer any advantage over pre-compaction mellowing. 


\section{CHAPTER 5. MINERALOGICAL CHARACTERISTICS OF SOIL-STABILIZER MIXTURES AND INTERPRETATION OF SWELLING MECHANISM}

\subsection{Introduction}

As shown in Table 4.7, which summarizes the final swelling strains measured for all soil-stabilizer combinations investigated in this , all specimens of treated soil exhibited greater swelling than the natural soil. This indicates the formation of one or more expansive products as a result of reactions between the soil and the stabilizers.

In order to determine the mineral(s) responsible for the swelling, chemical and mineralogical studies were performed. They included: X-Ray Diffraction (XRD) and Thermo-Gravimetric Analysis (TGA) on solids samples of the specimens at the end of swelling; and Ion Chromatography (IC) and Induced Coupled Plasma (ICP) on fluid samples extracted from the specimen pore fluid solution. These tests were performed on all stabilizer-soil combinations investigated in this research (soil H1A only), on this soil alone and on the stabilizers alone (XRD analyses only). See section 3.4.6 for a description of the procedure used to prepare the samples. This chapter presents the analysis of the data, while supporting calculations are summarized in Appendix. Chemical and mineralogical analyses of the soil alone and the stabilizers alone were intended to provide baseline data for the analysis of the results obtained for the soilstabilizer mixtures. Given that previous studies on sulfate induced heave had identified 
ettringite as being responsible for the swelling, this mineral was also the focus of the chemical and mineralogical analyses investigations presented in this chapter.

\subsection{Chemical and Mineralogical Characteristics}

Results of the XRD and TGA analyses tests conducted on the soil alone, the stabilizers alone and the soil stabilizer mixtures are presented in the following subsections.

The results of the XRD tests are presented in terms of the counts measured by the detector as a function of the angle $2 \theta$; while the results of the TGA test are presented by plotting the percentage weight loss (TGA curve) as well as the first derivative thermogravimetric (DTG) as a function of temperature.

Results of selected IC tests performed on fluid extracted from the soil alone are also presented in this chapter. Data obtained from IC and ICP tests performed on pore fluid extracted from the various soil stabilizer mixtures are instead summarized in Appendix.

\subsubsection{Soil Alone}

\section{A. XRD and TGA}

The XRD spectrum and the TGA plot for soil H1A are presented in Figure 5.1 and Figure 5.2, respectively. The XRD spectrum indicates that this soil sample contains mainly quartz, kaolinite, illite and gypsum (hydrated calcium sulfate, $\mathrm{C}_{a} \mathrm{SO}_{4} \cdot 2 \mathrm{H}_{2} \mathrm{O}$ ). 

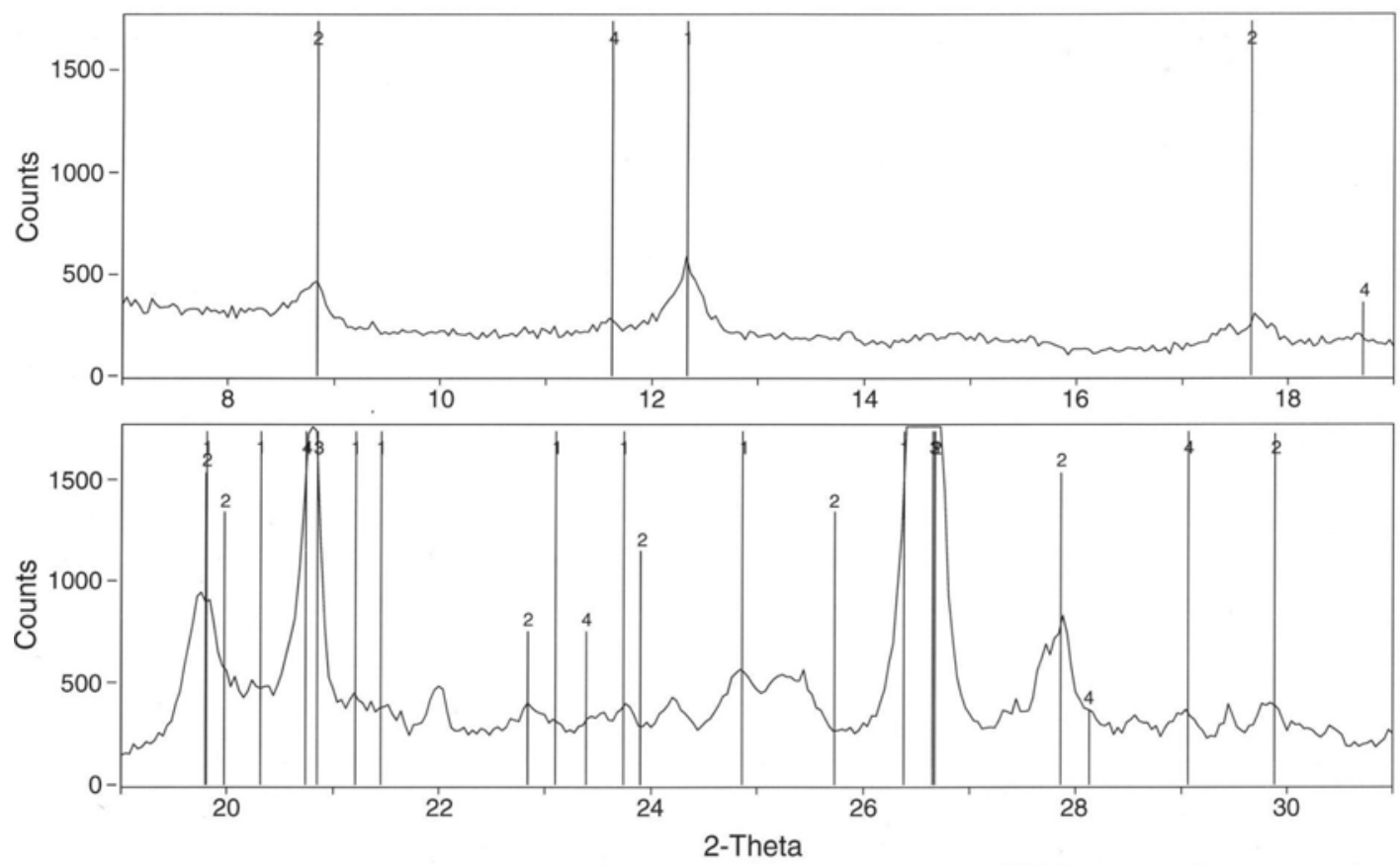

1> 14-0164: Kaolinite-IIT1AIRG - Al2Si2O5(OH)4

2> 26-0911: Illite-IIT2M\#1/RG - (K,H3O)AI2Si3AIO10(OH) 3> 33-1161: Quartz, syn - SiO2 4> 21-0816: Gypsum - CaSO4!2H2O

Figure 5.1 XRD pattern for soil H1A (numbers identify peaks of selected minerals)

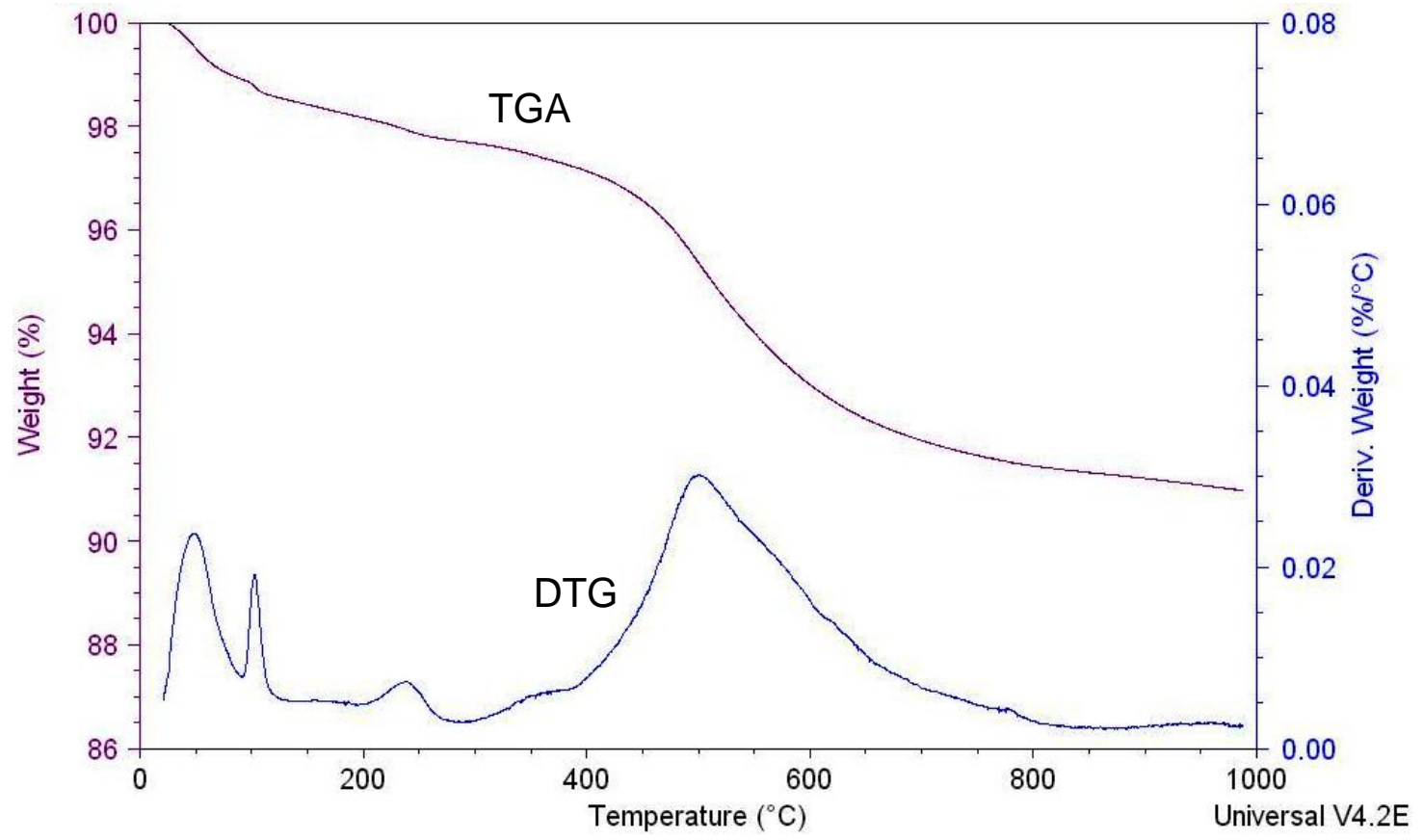

Figure 5.2 TGA plot with DTG data for soil H1A 
The TGA data and the associated peaks in the first Derivative ThermoGravimetric (DTG) curve show weight loss in correspondence to approximately the following temperatures: $\sim 55^{\circ} \mathrm{C}, 100^{\circ} \mathrm{C}, 240^{\circ} \mathrm{C}, 500^{\circ} \mathrm{C}$. The conspicuous peaks at about $55^{\circ} \mathrm{C}$ and $100^{\circ} \mathrm{C}$ may be explained by the loss of hygroscopic moisture from illite. Most clay micas including illite, often referred to as 'hydrated mica', show the loss of hygroscopic moisture in the $50-250^{\circ} \mathrm{C}$ range, with peaks in the $100-125^{\circ} \mathrm{C}$ range (Mitchell, 1993; de Araújo et al. 2004). For example, experiments with dolomite have shown that ground dolomite releases adsorbed water at about $60^{\circ} \mathrm{C}$. Hydrous ferric oxide also shows the first peak of release of water centering about $60^{\circ} \mathrm{C}$ (Bonen 2008).

The peak at about $240^{\circ} \mathrm{C}$ could correspond to the decomposition of ammonium sulfate $\left(\left(\mathrm{NH}_{4}\right)_{2} \mathrm{SO}_{4}\right)$, which might come from the surrounding area of coal mine spoils. Ammonium sulfate is decomposed into ammonia $\left(2 \mathrm{NH}_{3}\right)$ and sulfuric acid $\left(\mathrm{H}_{2} \mathrm{SO}_{4}\right)$ at $235-280^{\circ} \mathrm{C}$ (Apte et al. 1988). Finally, the peak around $500^{\circ} \mathrm{C}$ should correspond to the dehydroxylation of kaolinite and related minerals such as dickite and nacrite. For kaolinite, the main endothermic peak associated with dehydroxylation typically occurs in the $500-600^{\circ} \mathrm{C}$ range (Yeskis et al. 1985; Summer, 2000).

B. IC

Additional sulfate content determinations on the soil samples used for the swelling tests (see chapter 3 for measurements performed in preliminary stages of this research) were conducted in conjunction with the mineralogical analyses. The sulfate content of the soil was determined following two independent procedures: a gravimetric method which involved filtration with deionized water or a $0.05 \mathrm{~N} \mathrm{HCl}$ solution followed by titration with barium, and a second method which involved first filtration using either 
deionized water or a $0.05 \mathrm{~N} \mathrm{HCl}$ solution, then measurement of sulfate using IC analysis. Table 5.1 summarizes the values of the sulfate contents determined using these two methods. The data show significant differences measured with the two methods, and scatter between the results on different samples of the same soil. Note that previous measurements using the gravimetric method (see chapter 3) showed sulfate contents of about $13,000 \mathrm{mg} / \mathrm{kg}$.

These differences remain unexplained at this time. While efforts were made to homogenize the soil prior to forming two subsamples it is possible that the differences between sample (1) and (2) in Table 5.1 reflect the variability of the natural soil. Note also that, given that gypsum peaks can be seen in the XRD spectrum, it appears that the gravimetric results are too low. The same conclusion applies to the first IC result.

Table 5.1 Summary of soil sulfate content measurements

\begin{tabular}{|c||c|c|}
\hline Sample name & $\begin{array}{c}\mathrm{SO}_{4} / \text { soil } \\
(\mathrm{mg} / \mathrm{kg}, \mathrm{GV})\end{array}$ & $\begin{array}{c}\mathrm{SO}_{4} / \mathrm{soil} \\
(\mathrm{mg} / \mathrm{kg}, \mathrm{IC})\end{array}$ \\
\hline \hline $\mathrm{H} 1 \mathrm{~A}+\mathrm{D} / \mathrm{I} \mathrm{H}_{2} \mathrm{O}(1)$ & 5172.7 & 6957.9 \\
\hline $\mathrm{H} 1 \mathrm{~A}+\mathrm{HCl}(1)$ & 2197.3 & 16284.2 \\
\hline $\mathrm{H} 1 \mathrm{~A}+\mathrm{D} / \mathrm{I} \mathrm{H}_{2} \mathrm{O}(2)$ & - & 26360.8 \\
\hline $\mathrm{H} 1 \mathrm{~A}+\mathrm{HCl}(2)$ & - & 29057.6 \\
\hline
\end{tabular}

Note: GV = gravimetric method, IC = leaching method using IC analysis

$\mathrm{D} / \mathrm{I} \mathrm{H}_{2} \mathrm{O}=$ deionized water solution, $\mathrm{HCl}=0.05 \mathrm{~N} \mathrm{HCl}$ solution, (1) or (2) $=1$ st or 2 nd measurement with same soil, but different sample 


\subsubsection{Stabilizers Alone}

XRD and TGA tests were also performed on the hydrated lime, the analytical lime, the quick lime, and the cement (XRD only) alone. The results of these tests are presented in Figures 5.3 and 5.4 (hydrated lime, HL), Figures 5.5 and 5.6 (analytical lime, AL), Figure 5.7 and 5.8 (quick lime, QL), and Figure 5.9 (Portland cement, PC).
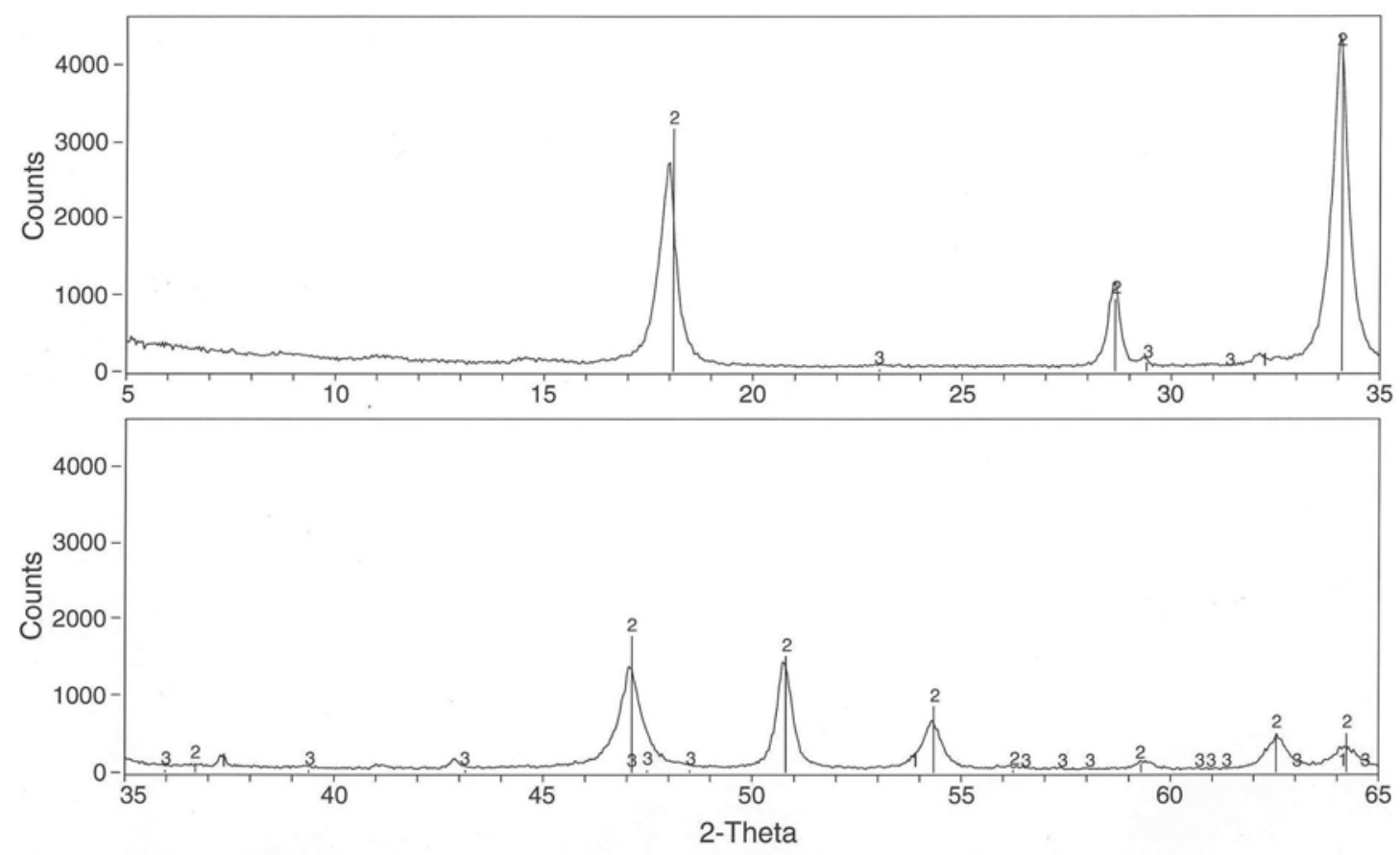

1> 37-1497: Lime, syn - CaO

3> 05-0586: Calcite, syn - $\mathrm{CaCO} 3$

2> 04-0733: Portlandite, syn - $\mathrm{Ca}(\mathrm{OH}) 2$

Figure 5.3 XRD pattern for hydrated lime (HL)(numbers identify peaks of selected minerals)

The XRD spectrum shown in Figure 5.3 indicates that, as expected, the main component of hydrated lime is calcium hydroxide $\left(\mathrm{Ca}(\mathrm{OH})_{2}\right)$. This is supported by the TGA data, which show the greatest mass loss around $450^{\circ} \mathrm{C}$, the temperature at which 
calcium hydroxide decomposes. Note that Figure 5.4 also shows some (much smaller) weight loss at around $600^{\circ} \mathrm{C}$. This should be due to the species of calcium carbonate formed due to carbonation.

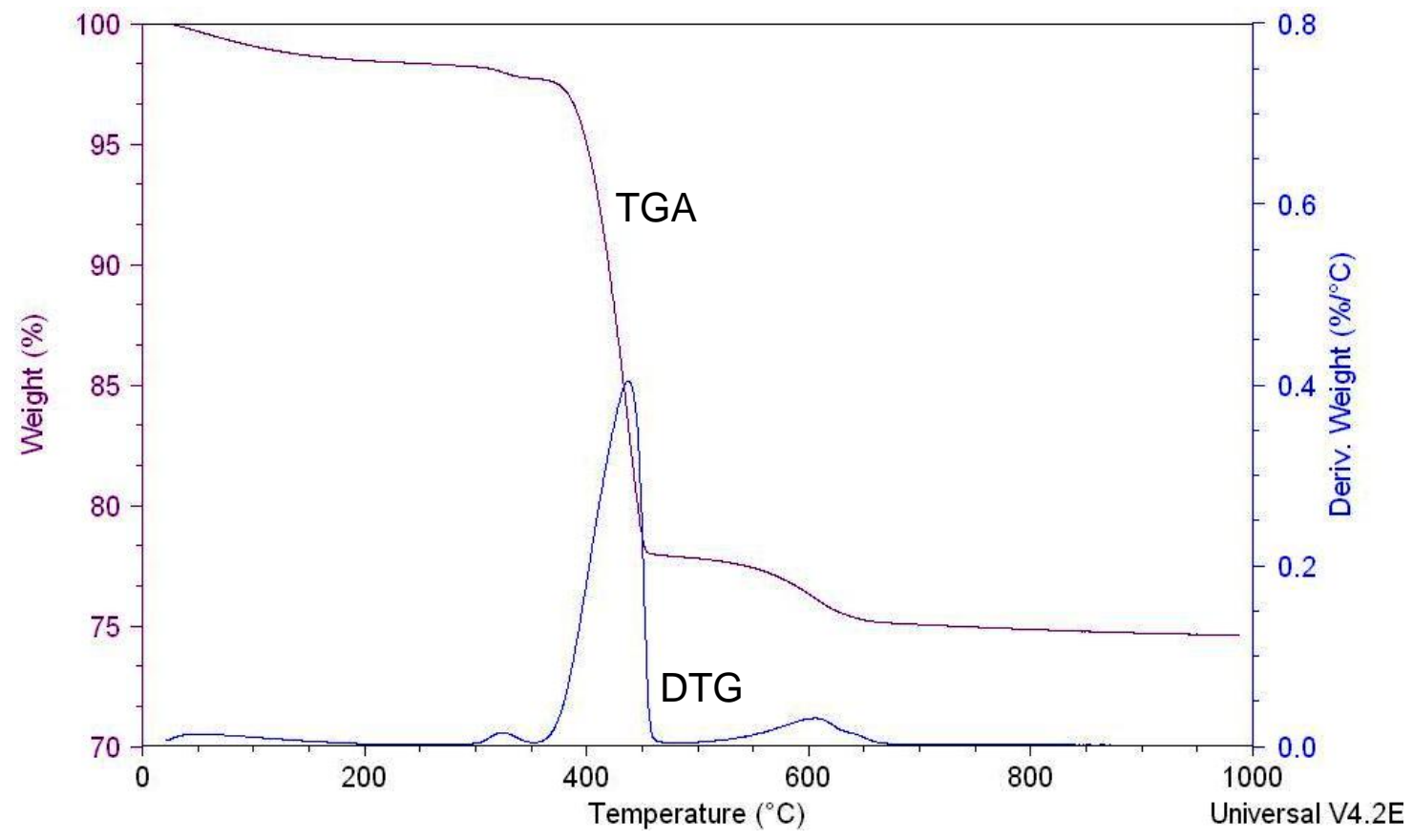

Figure 5.4 TGA plot with DTG data for hydrated lime (HL)

The XRD spectra shown in Figure 5.5 and Figure 5.7 indicate that the main component of analytical and quick lime is calcium oxide ( $\mathrm{CaO}$ ), although the peaks of calcite and portlandite (calcium hydroxide) can also be identified. The TGA and DTG data support only the presence of calcium hydroxide and calcite (the mass losses at around $450^{\circ} \mathrm{C}$ and $600^{\circ} \mathrm{C}$ correspond to the decomposition of these two minerals), since decomposition of calcium oxide occurs at temperatures greater than $1000^{\circ} \mathrm{C}$, i.e. beyond the maximum temperature reached in the TGA tests performed here. Note from the XRD 
and TGA results that the amount of calcite is very small since all the stabilizers were stored in air-tight containers which were flushed with nitrogen gas whenever the container was opened in order to avoid hydration or carbonation.
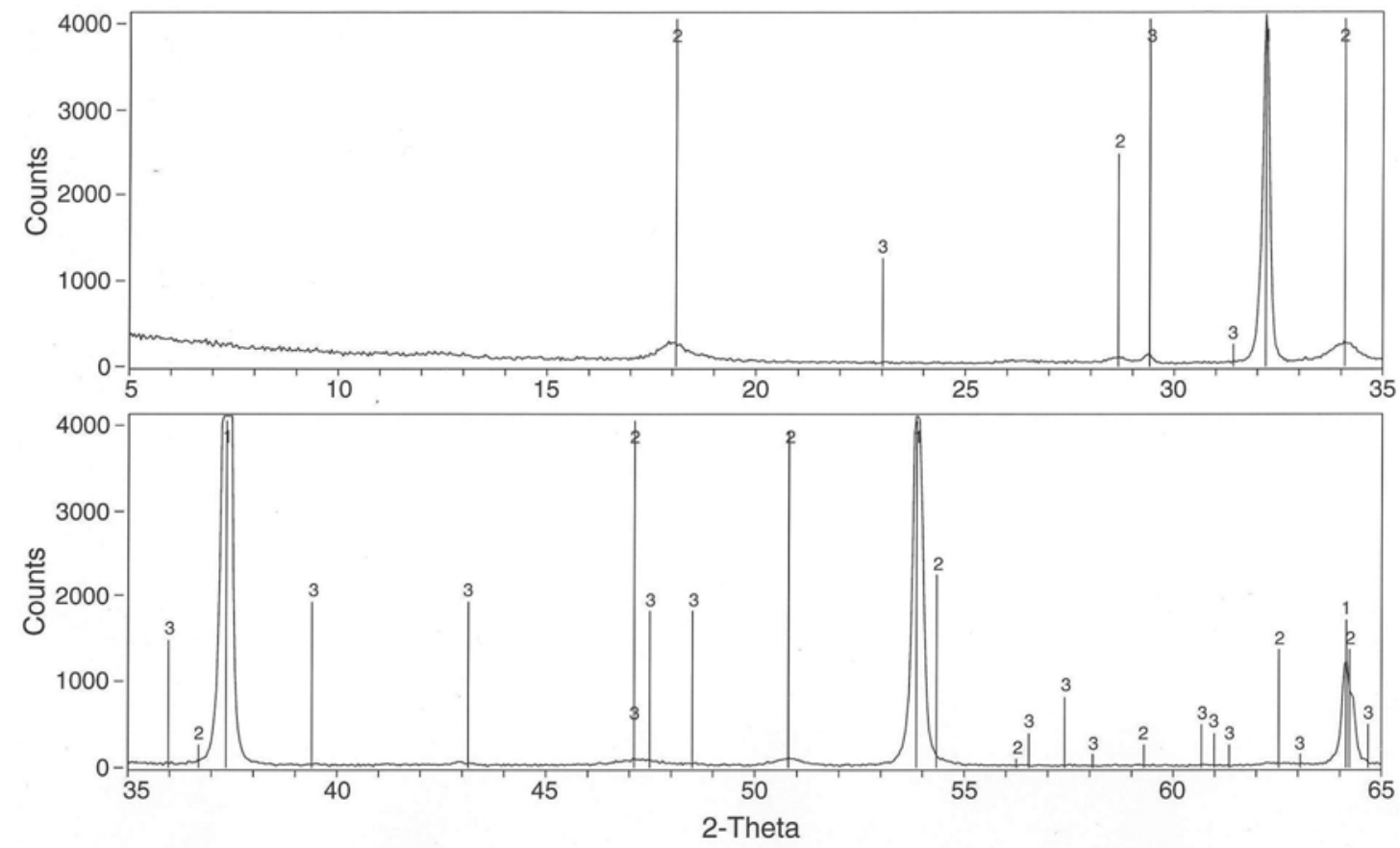

1> 37-1497: Lime, syn - CaO

2> 04-0733: Portlandite, syn - $\mathrm{Ca}(\mathrm{OH}) 2$

3> 05-0586: Calcite, syn - CaCO3

Figure 5.5 XRD pattern for analytical lime (AL) (numbers identify peaks of selected minerals) 


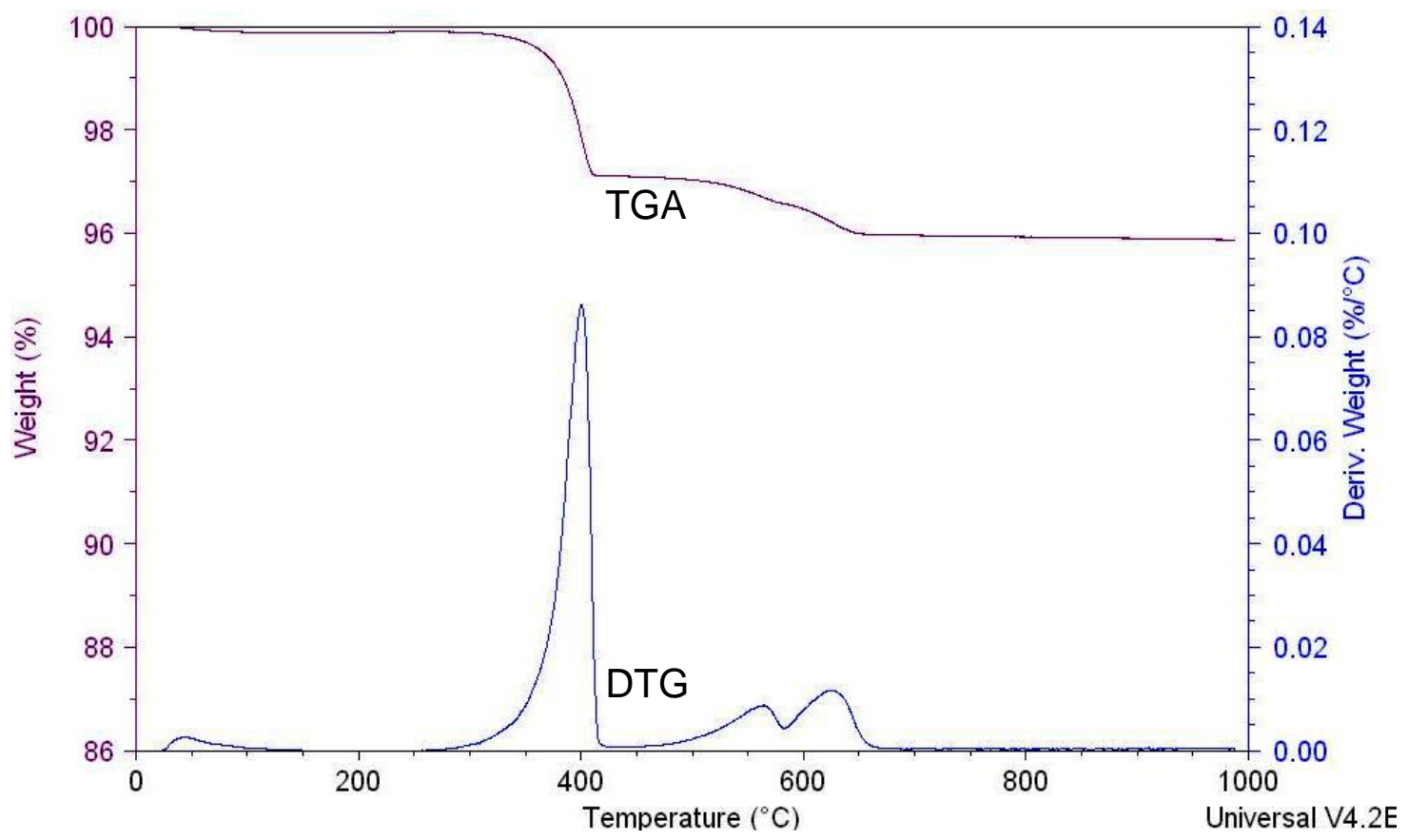

Figure 5.6 TGA plot with DTG data for analytical lime (AL)
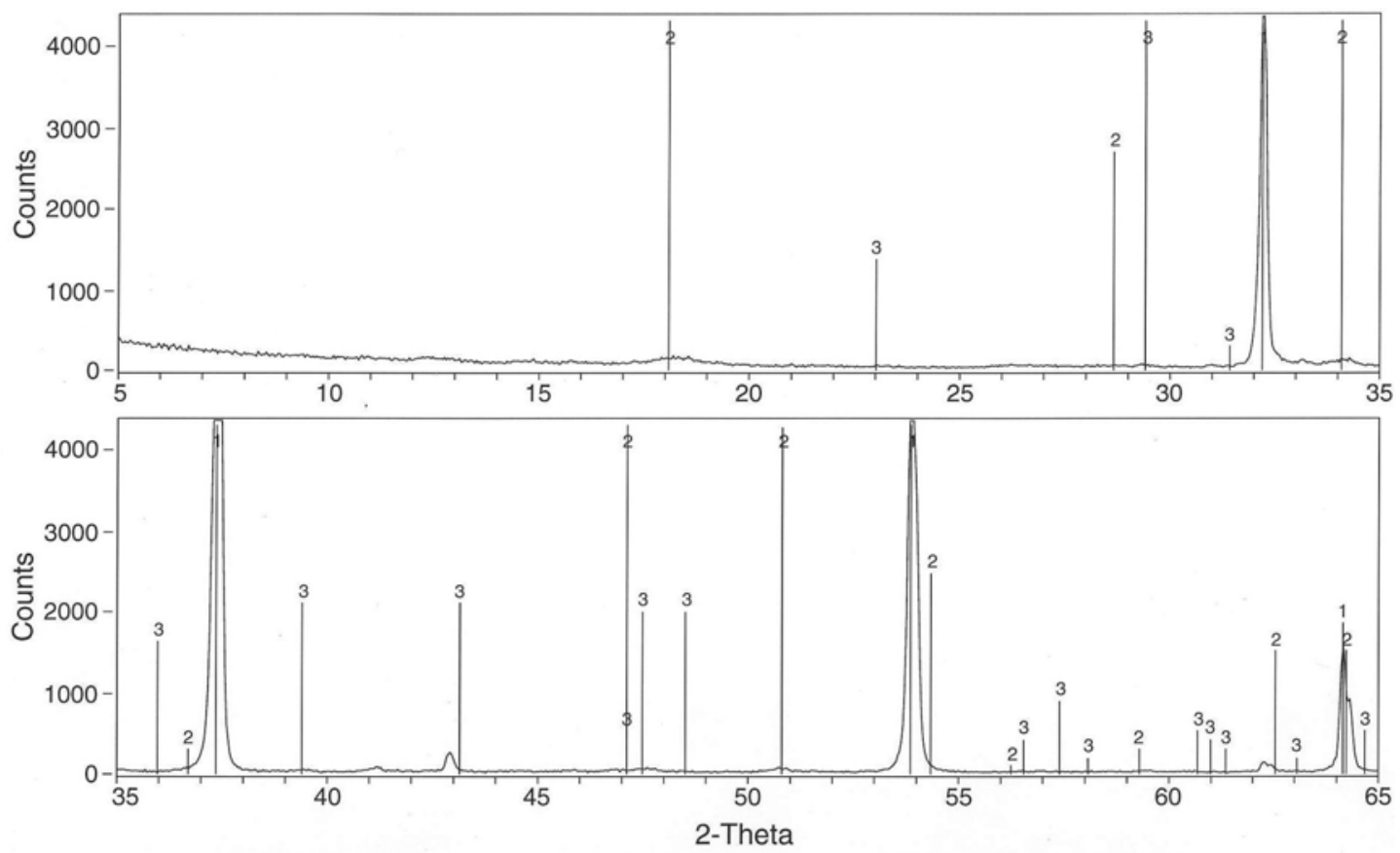

1> 37-1497: Lime, syn - CaO

2> 04-0733: Portlandite, syn - $\mathrm{Ca}(\mathrm{OH}) 2$

3> 05-0586: Calcite, syn - CaCO3

Figure 5.7 XRD pattern for quick lime (QL) (numbers identify peaks of selected minerals) 


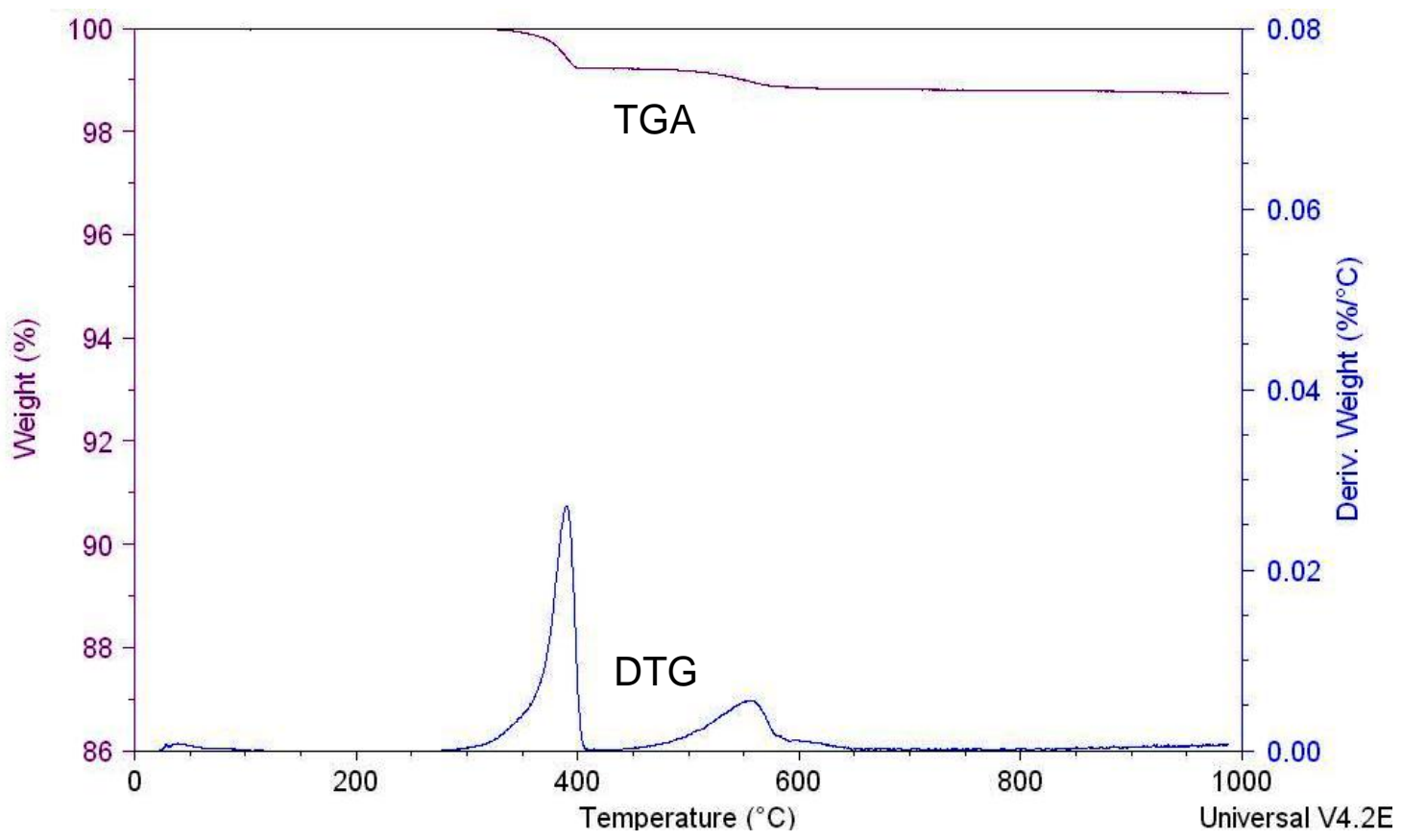

Figure 5.8 TGA plot with DTG data for quick lime (QL)
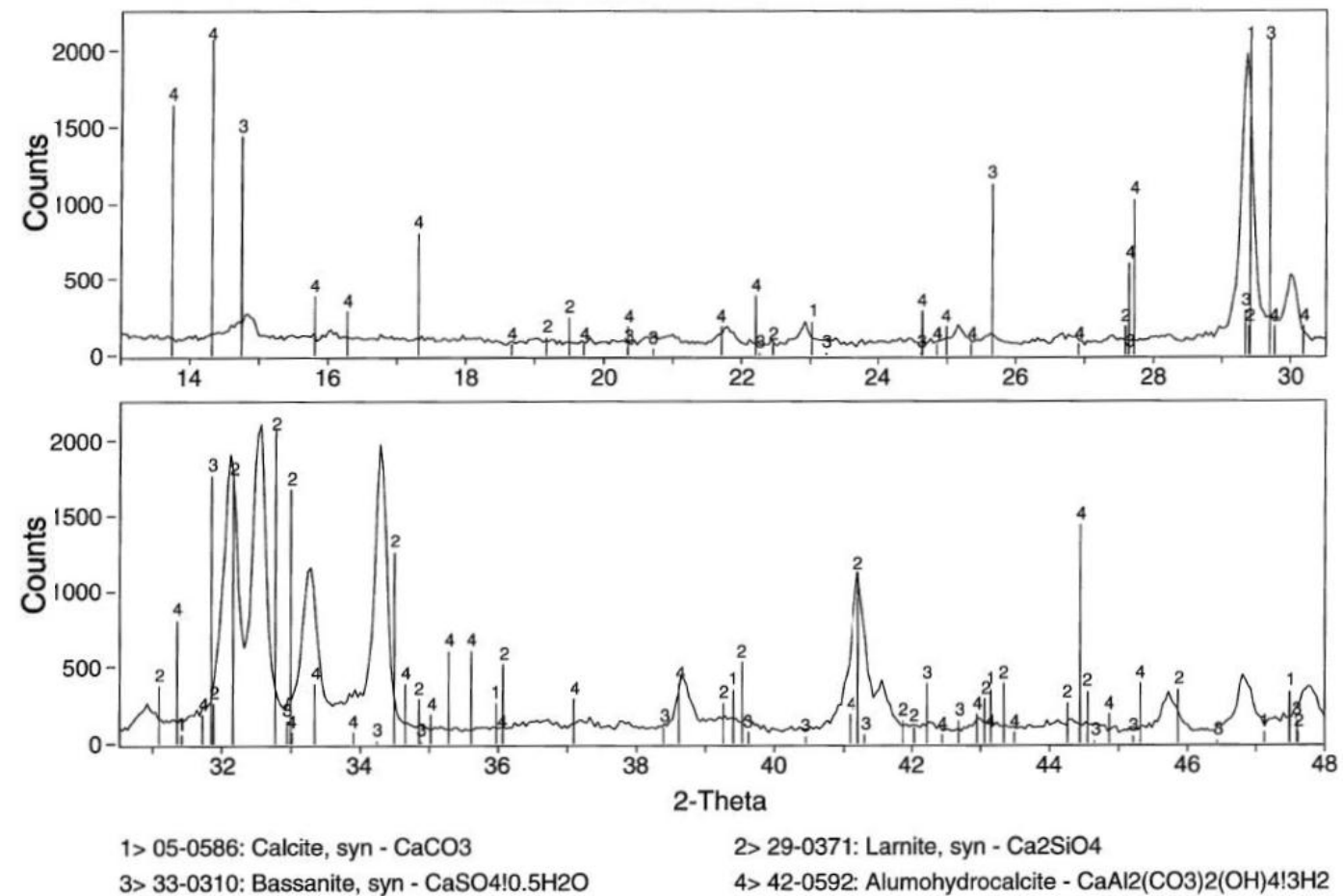

Figure 5.9 XRD pattern for Portland cement (PC) (numbers identify peaks of selected minerals) 
Figure 5.9 presents the XRD spectrum for Portland cement. The peaks corresponding to the following compounds can be identified: calcite (calcium carbonate, $\mathrm{CaCO}_{3}$ ), larnite (beta polymorph of calcium silicate, $\mathrm{Ca}_{2} \mathrm{SiO}_{4}$ ), bassanite (calcium sulfate hemihydrate, $\left.2 \mathrm{CaSO}_{4} \cdot \mathrm{H}_{2} \mathrm{O}\right)$, and alumohydrocalcite $\left(\mathrm{CaAl}_{2}\left(\mathrm{CO}_{3}\right)_{2}(\mathrm{OH})_{4} \cdot 3\left(\mathrm{H}_{2} \mathrm{O}\right)\right)$ (Highway research board 1972).

Figure 5.10 summarizes the XRD patterns for all the stabilizers It shows that all stabilizers are pure materials.
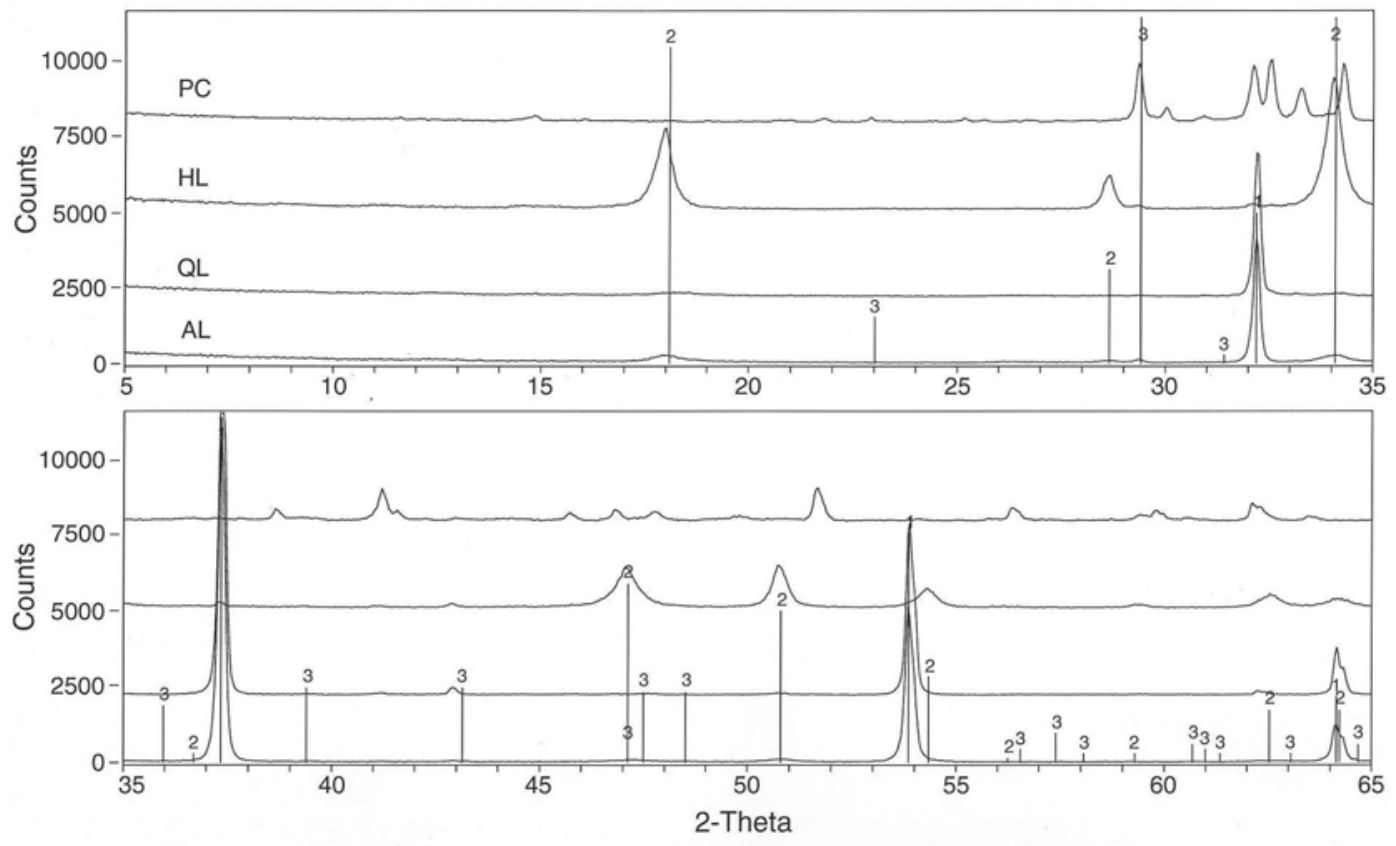

1> 37-1497: Lime, syn - CaO

2> 04-0733: Portlandite, syn - $\mathrm{Ca}(\mathrm{OH}) 2$

3> 05-0586: Calcite, syn - $\mathrm{CaCO} 3$

Figure 5.10 XRD patterns for all stabilizers only (numbers identify peaks of selected minerals) 


\subsubsection{Soil Stabilizer Mixtures}

\subsubsection{Soil mixed with hydrated lime (HL)}

As discussed in Chapter 4, the dosage of hydrated lime was varied over a significant range: $1.5,3,5,7$, and $9 \%$, with the highest swelling observed for the soil treated with 3\% hydrated lime (see Table 4.8). XRD and TGA results for specimens treated with these percentages of HL are presented in Figures $5.12-5.13$ (1.5\%HL), Figures 5.14 - 5.15 (3\% HL), Figures 5.16 - 5.17 (5\% HL), Figure 5.18 - 5.19 (7\% HL), and Figure $5.20-5.21(9 \%$ HL). The data from all the XRD and TGA tests performed are summarized in Tables 5.2 and 5.3, respectively. All these data were obtained testing the specimens on which the swelling strains presented in Table 4.7 were measured.

Given that previous studies on sulfate induced heave have identified ettringite as being responsible for the swelling, this mineral is the focus of the chemical and mineralogical analyses presented in this chapter.

In XRD spectra, ettringite is mainly identified by peaks at $2 \theta \sim 9.1^{\circ}, 15.8^{\circ}, 18.9^{\circ}$ and $22.9^{\circ}$. These peaks are found in the XRD patterns of all mixtures with hydrated lime. For these mixtures, the main peaks for ettringite become increasingly clear as the amount of hydrated lime increases from 1.5 to $9 \%$. Note that the peaks are difficult to detect in the 1.5 and $3 \%$ hydrated lime mixtures. In particular, the peak at about $9.1^{\circ}$ is not found. This appears to be due to the rapid crystallization process of ettringite (Bonen 2008).

The presence of ettringite, which has a decomposition temperature of $55^{\circ} \mathrm{C}$, is also detected through thermal gravimetric analysis (note the peak in the DTG in 
correspondence to this temperature). Note that weight loss in correspondence to $55^{\circ} \mathrm{C}$ was observed also in the natural soil (see Figure 5.2), not as a result of the presence of ettringite, but due to the loss of hygroscopic moisture. This loss is expected to partially "mask" the ettringite loss in the soil-stabilizer mixtures. Table 5.5 which summarizes the TGA data shows that for hydrated lime dosages of 5\%-9\% the weight loss in correspondence to $55^{\circ} \mathrm{C}$ (as measured by the peak of the DTG curve) exceeds that measured on the soil alone $\left(0.058-0.08 \% /{ }^{\circ} \mathrm{C}\right.$ for $5 \%-9 \% \mathrm{HL}$ versus $0.023 \% /{ }^{\circ} \mathrm{C}$ for the soil alone). This confirms the formation of ettringite in these mixtures. For $1.5 \%$ and $3 \%$ HL, consistent with the XRD data, the TGA results are less clear, as the weight loss at $55^{\circ} \mathrm{C}$ is close to the values measured on the natural soil (see DTG peaks of 0.02$0.025 \% /{ }^{\circ} \mathrm{C}$ versus $0.023 \% /{ }^{\circ} \mathrm{C}$ for the soil alone).

Calcium hydroxide (which has its main peaks at $2 \theta \sim 18.1^{\circ}$ and $34.1^{\circ}$ ) could not be identified in any of the XRD spectra (see also Table 5.4). Calcium hydroxide is decomposed at around $470-600^{\circ} \mathrm{C}$. Hence, the small peak in this temperature range observed for the 1.5, 3 and 5\% hydrated lime mixtures could be an indication of the presence of small amounts of $\mathrm{Ca}(\mathrm{OH})_{2}$. Note that the peak in the DTG curve corresponding to the loss of calcium hydroxide occurs near that corresponding to the burning of the clay minerals $\left(\sim 500^{\circ} \mathrm{C}\right)$, which is observed in all samples.

In addition to the various minerals present in the natural soil (see Figure 5.1), the XRD spectra for the $7 \%$ and $9 \%$ hydrated lime mixtures also indicate the presence of calcium carbonate (main peak at $2 \theta \sim 29.4^{\circ}$ ). In the spectra obtained for the other mixtures the calcium carbonate peaks were either hard to identify or could not be observed. However, as summarized in Table 5.5, the TGA results indicate that some 
calcium carbonate was present in all soil stabilizer mixtures. This is most likely a result of the exposure to air of the specimens prior to testing, which leads to carbonation of the sample. Note that the cases in which calcium carbonate is not seen in the XRD patterns correspond to the mixtures with the smallest weight loss at the temperature for calcium carbonate measured in the TGA tests. Specifically, when the derivative of the total weight with regard to temperature is higher than $0.02\left(\% /{ }^{\circ} \mathrm{C}\right)$, the peaks for calcium carbonate are clearly distinguishable in the XRD patterns. The decomposition temperature of calcium carbonate falls within a fairly wide temperature range: 625 $900^{\circ} \mathrm{C}$. This temperature range reflects differences in the degree of crystallinity of the carbonate, as well as in the content of $\mathrm{Mg}$ and $\mathrm{Mn}$ that is incorporated in the calcium carbonate crystal (Bonen 2008). In many cases the DTG curve shows two peaks that are believed to correspond to the decomposition of different calcium carbonate species (e.g. for $7 \% \mathrm{HL}$ see weight loss at both $625^{\circ} \mathrm{C}$ and $750^{\circ} \mathrm{C}$ ).

An illustration of the variation of the decomposition temperature of calcium carbonate is presented in Figure 5.11. This figure presents TGA results for four samples: a sample of calcium carbonate, which shows weight loss at around $750^{\circ} \mathrm{C}$ and three samples of $\mathrm{Ca}(\mathrm{OH})_{2}$. The first sample of $\mathrm{Ca}(\mathrm{OH})_{2}$ was tested directly from the container (this TGA curve shows almost all the weight loss occurring at $\sim 430^{\circ} \mathrm{C}$ ); the other two were tested after being left for some time (17 hours and 5 days) exposed to air, and hence to carbonation. With carbonation weight loss is seen corresponding to the decomposition of the calcium carbonate formed. The temperature of decomposition of the calcium carbonate ranges from approximately $650^{\circ}$ to the $750^{\circ}$ (the value measured on the pure calcium carbonate). In particular, with an increase in the duration of the exposure to air, 
the temperature corresponding to the decomposition of the carbonate is increasingly shifted to the right (i.e. to higher T).

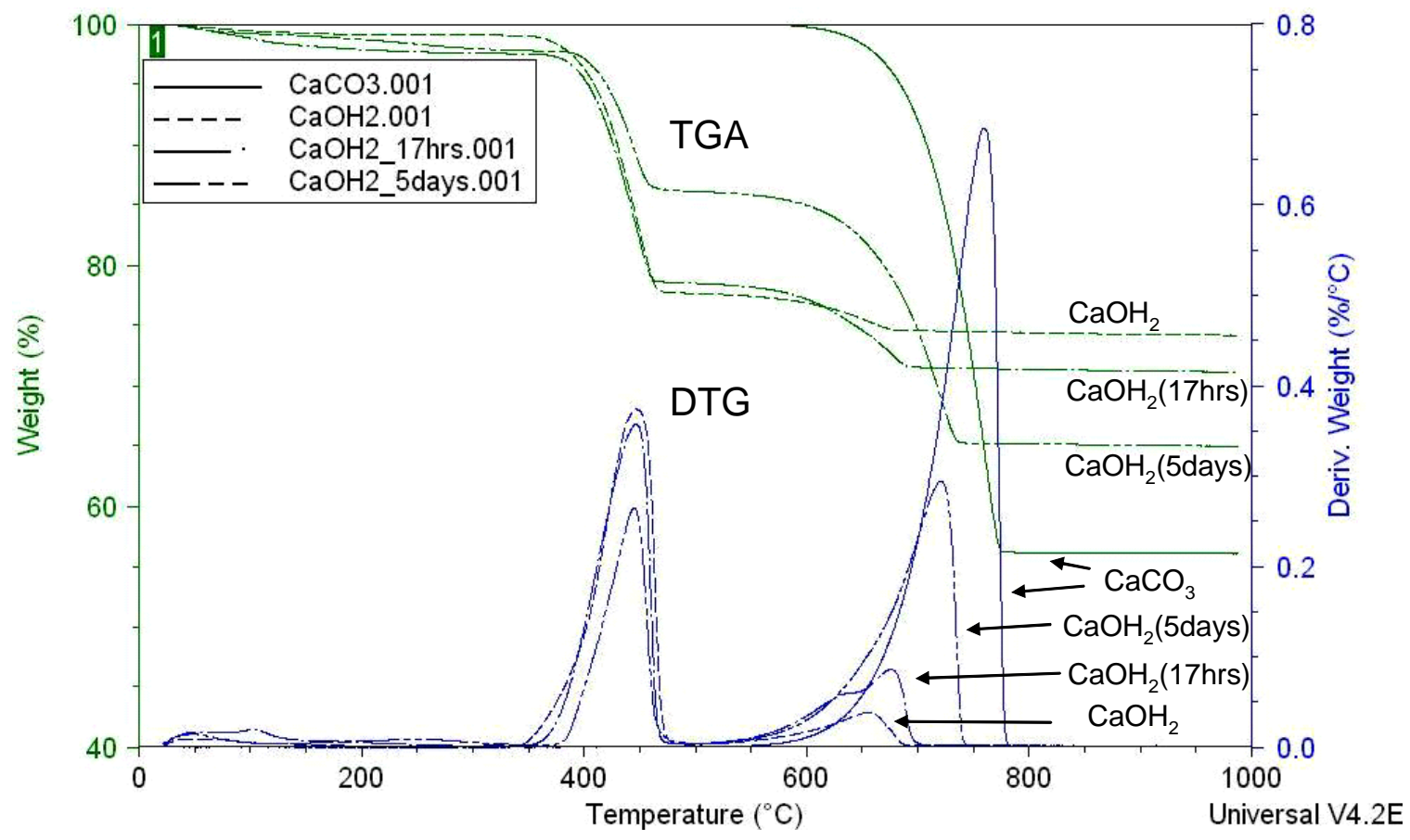

Figure 5.11 TGA plot illustrating the range of temperature at which calcium carbonate decomposes

Finally, as observed for the soil alone, the TGA data for the soil stabilizer mixtures show weight losses in correspondence to $100^{\circ} \mathrm{C}(1.5 \%$ and $3 \% \mathrm{HL}$ samples only) and $240^{\circ} \mathrm{C}$ (all samples). As discussed for the soil alone, the first weight loss is likely related to the loss of hygroscopic moisture of the micas present in the soil. Note that the magnitude of this weight loss is quite variable (see Table 5.5). The fact that this weight loss is not observed in the 5, 7 and $9 \%$ hydrated lime mixtures may be due to different degrees of drying of the samples prior to testing. 
The loss around $240^{\circ} \mathrm{C}$ appears consistent across all samples, including the soil alone. As stated above, it is hypothesized that the decomposition of ammonium sulfate (present in the soil) may be responsible for this mass loss.
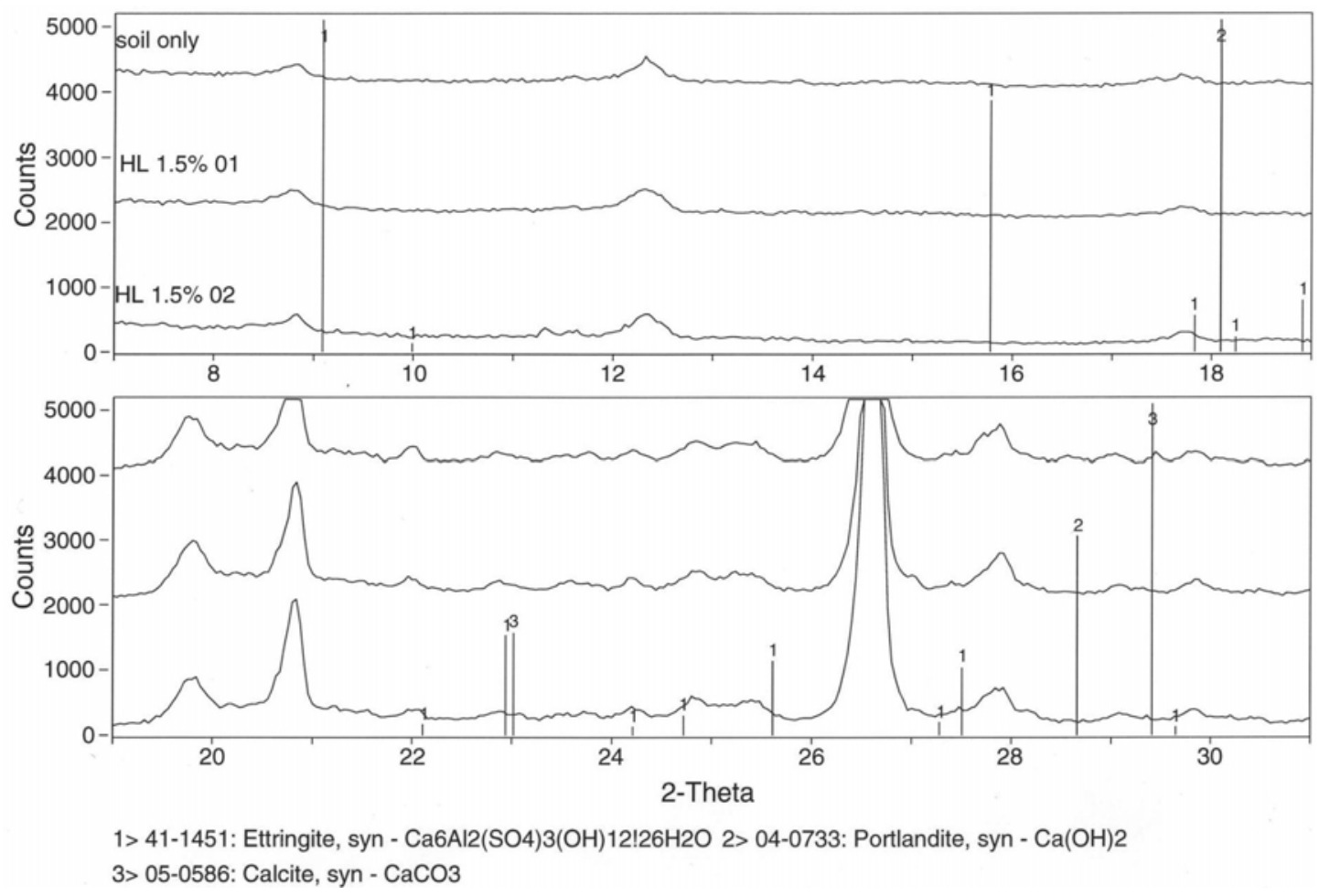

Figure 5.12 XRD pattern for H1A soil treated with $1.5 \%$ hydrated lime (numbers identify peaks of selected minerals) 


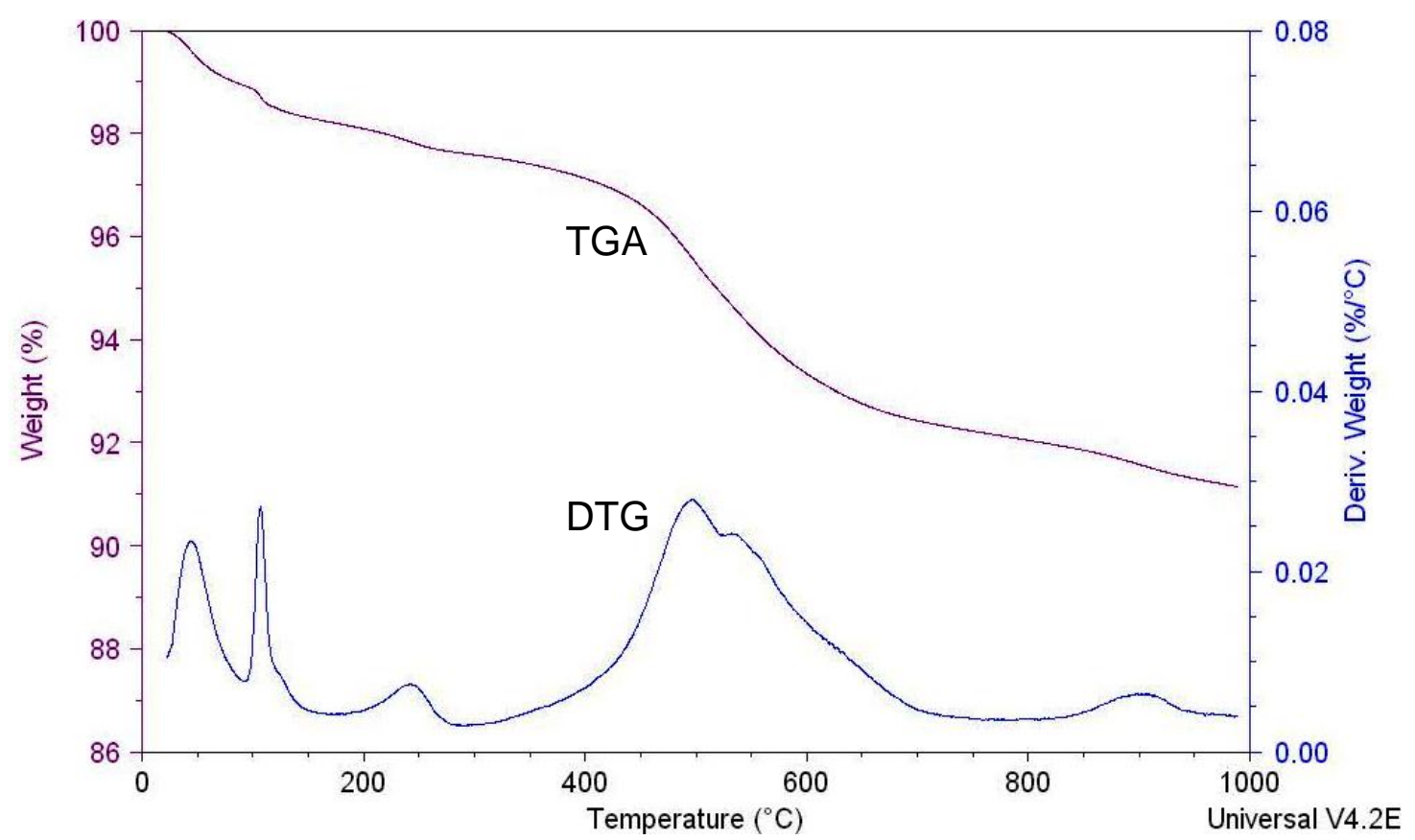

Figure 5.13 TGA plot with DTG data for H1A soil treated with 1.5\% hydrated lime
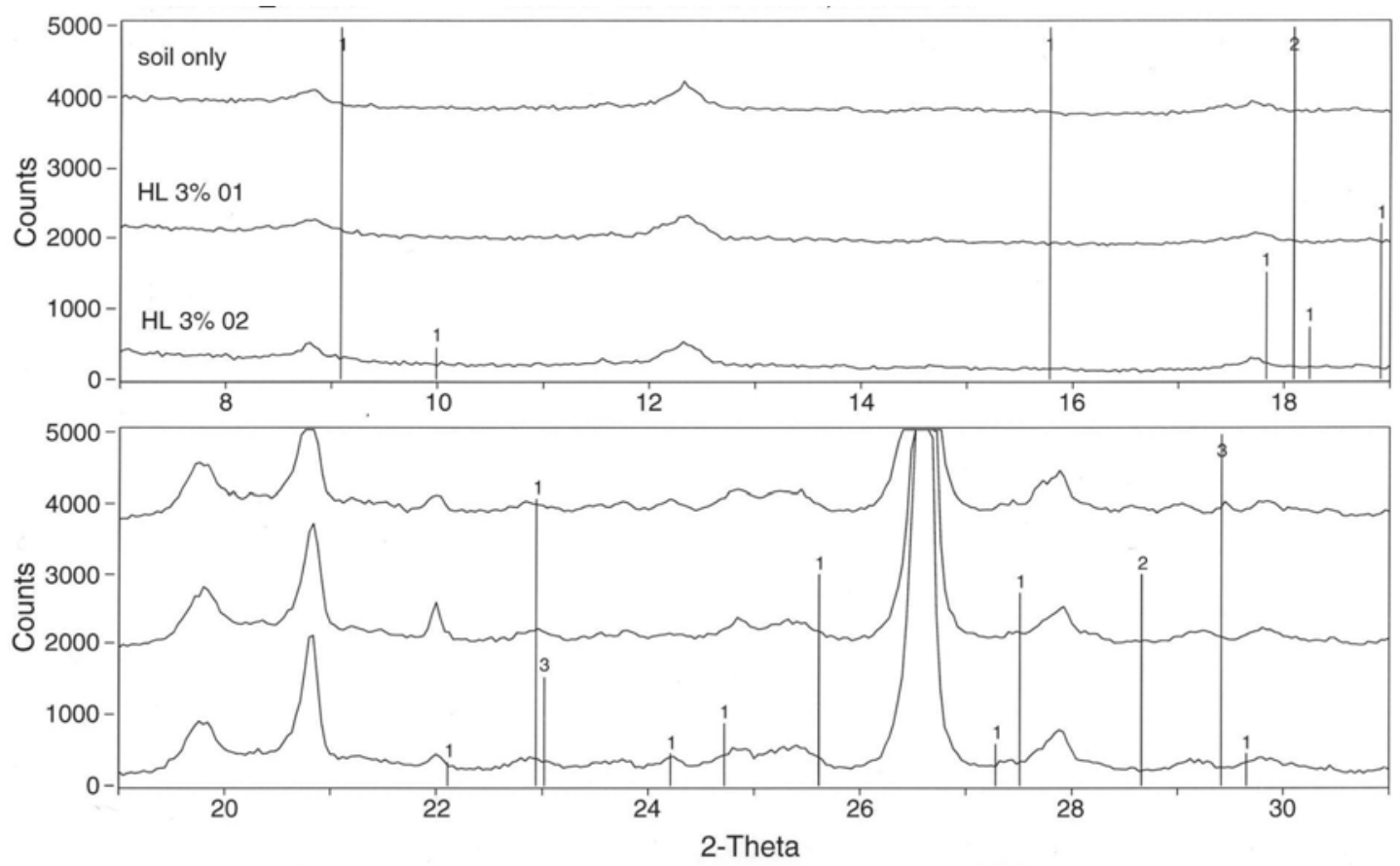

1> 41-1451: Ettringite, syn - Ca6Al2(SO4)3(OH)12!26H2O 2> 04-0733: Portlandite, syn - $\mathrm{Ca}(\mathrm{OH}) 2$ 3> 05-0586: Calcite, syn - $\mathrm{CaCO} 3$

Figure 5.14 XRD pattern for H1A soil treated with 3\% hydrated lime (numbers identify peaks of selected minerals) 


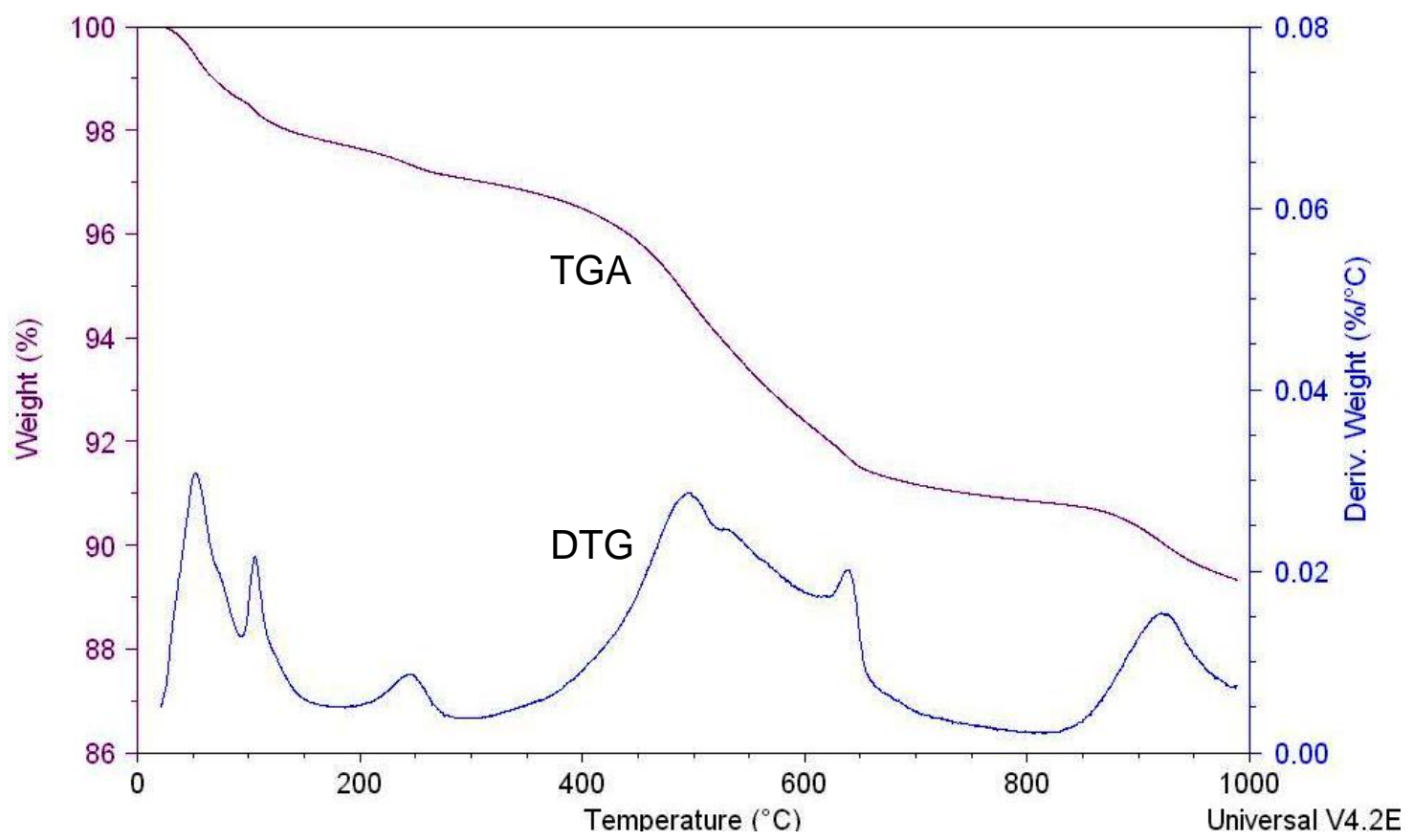

Figure 5.15 TGA plot with DTG data for H1A soil treated with 3\% hydrated lime
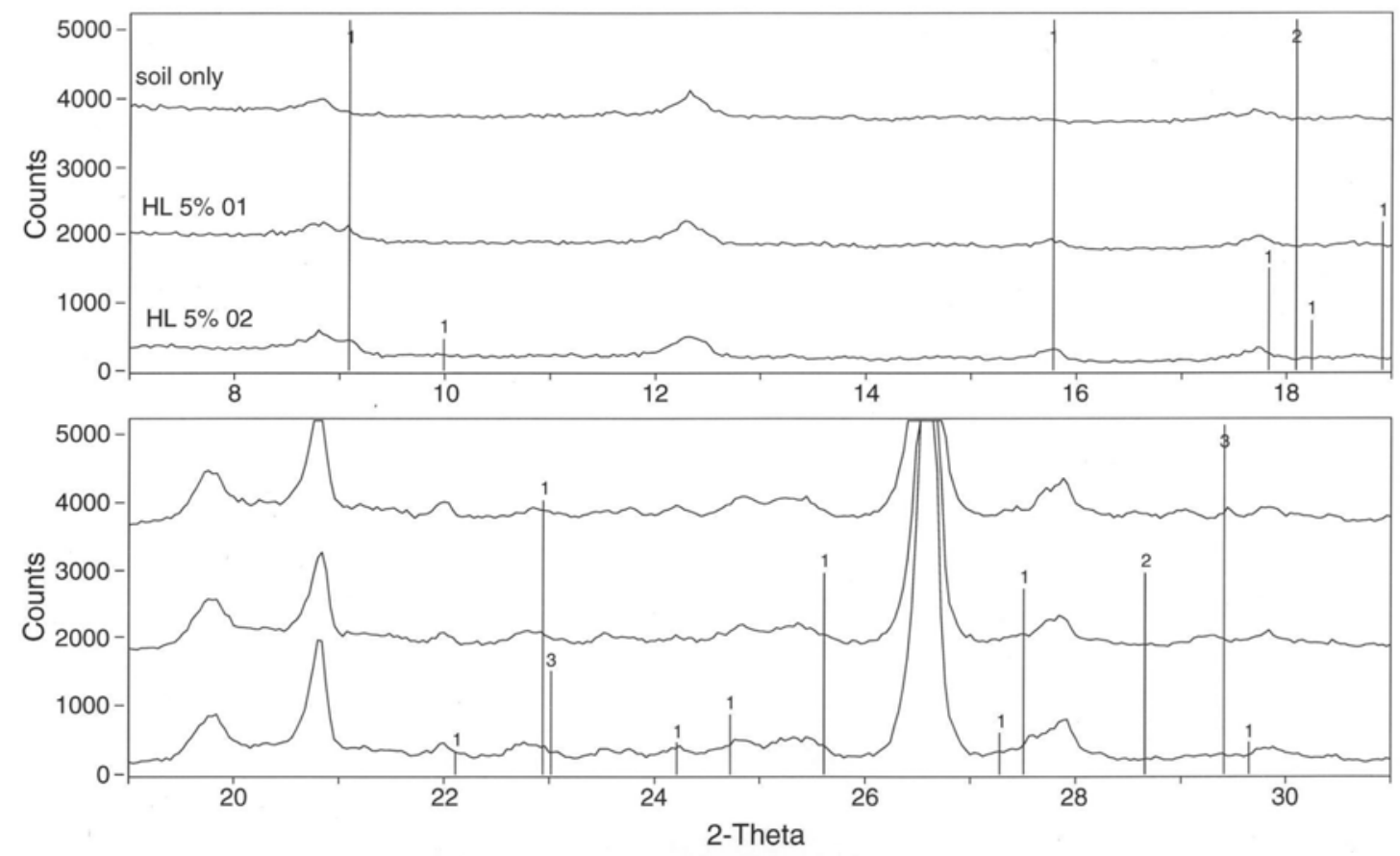

1> 41-1451: Ettringite, syn - Ca6Al2(SO4)3(OH)12!26H2O 2> 04-0733: Portlandite, syn - $\mathrm{Ca}(\mathrm{OH}) 2$ 3> 05-0586: Calcite, syn - CaCO3

Figure 5.16 XRD pattern for H1A soil treated with 5\% hydrated lime (numbers identify peaks of selected minerals) 


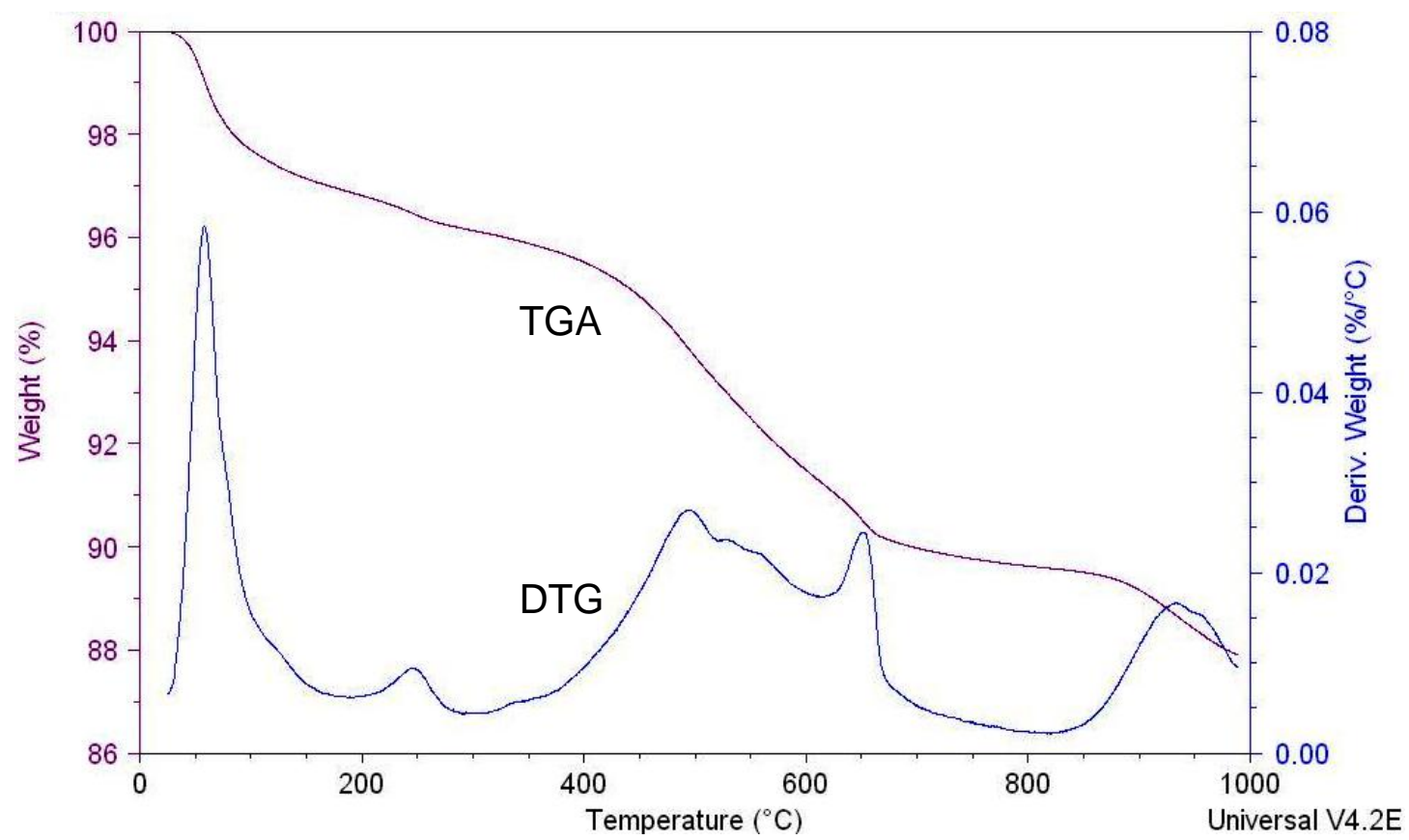

Figure 5.17 TGA plot with DTG data for H1A soil treated with 5\% hydrated lime
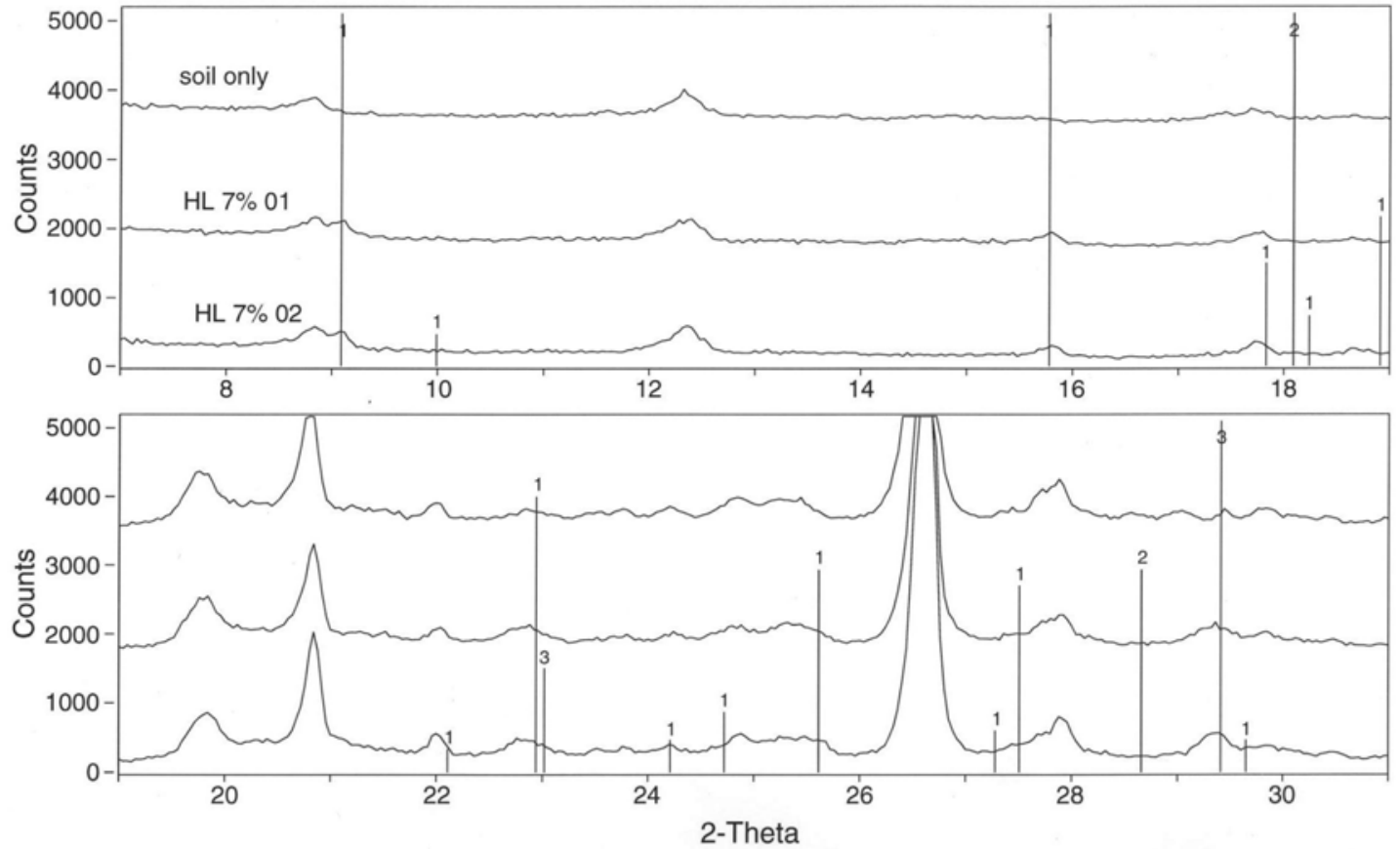

1> 41-1451: Ettringite, syn - Ca6Al2(SO4)3(OH)12!26H2O 2> 04-0733: Portlandite, syn - $\mathrm{Ca}(\mathrm{OH}) 2$ 3> 05-0586: Calcite, syn - $\mathrm{CaCO} 3$

Figure 5.18 XRD pattern for H1A soil treated with 7\% hydrated lime (numbers identify peaks of selected minerals) 


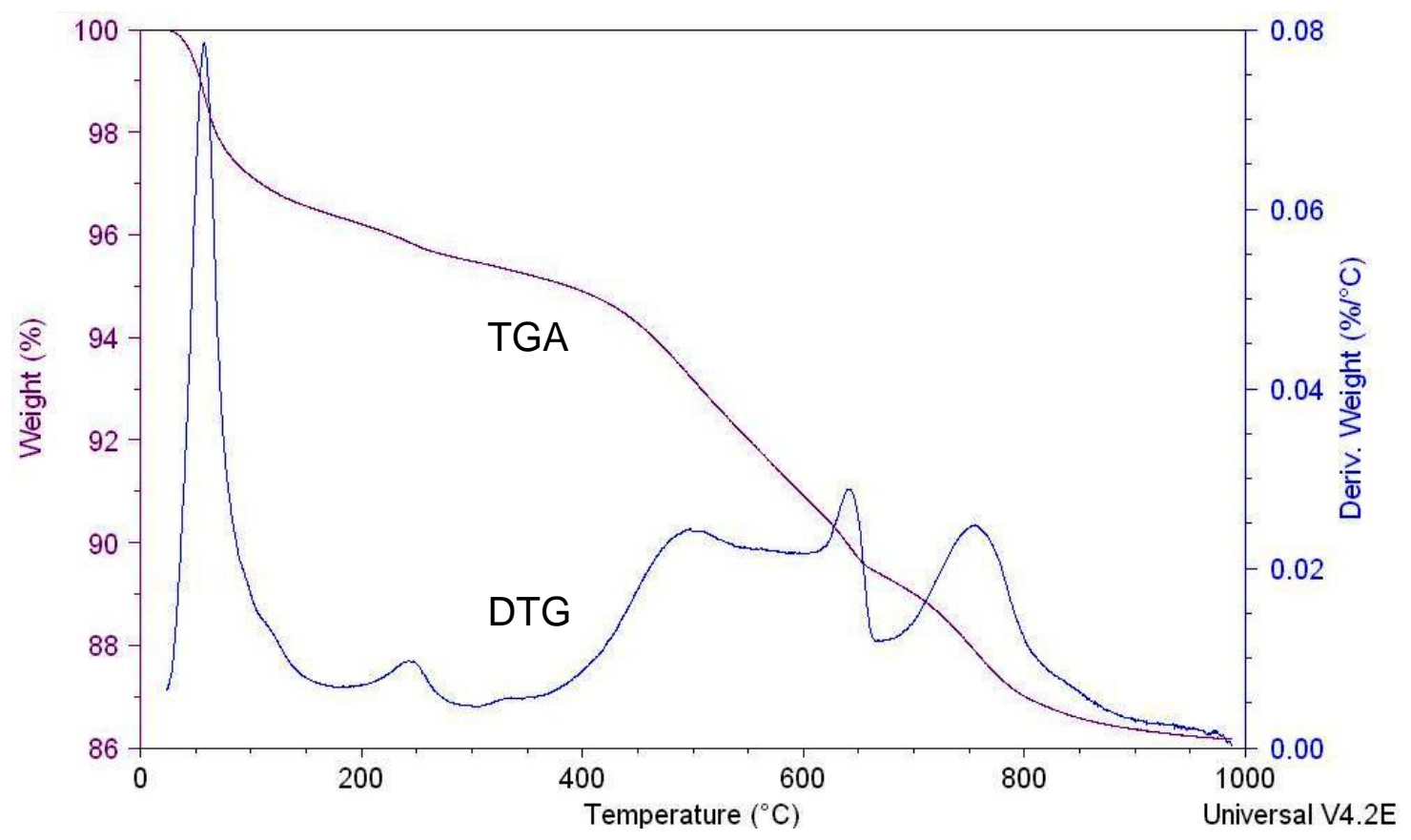

Figure 5.19 TGA plot with DTG data for H1A soil treated with 7\% hydrated lime
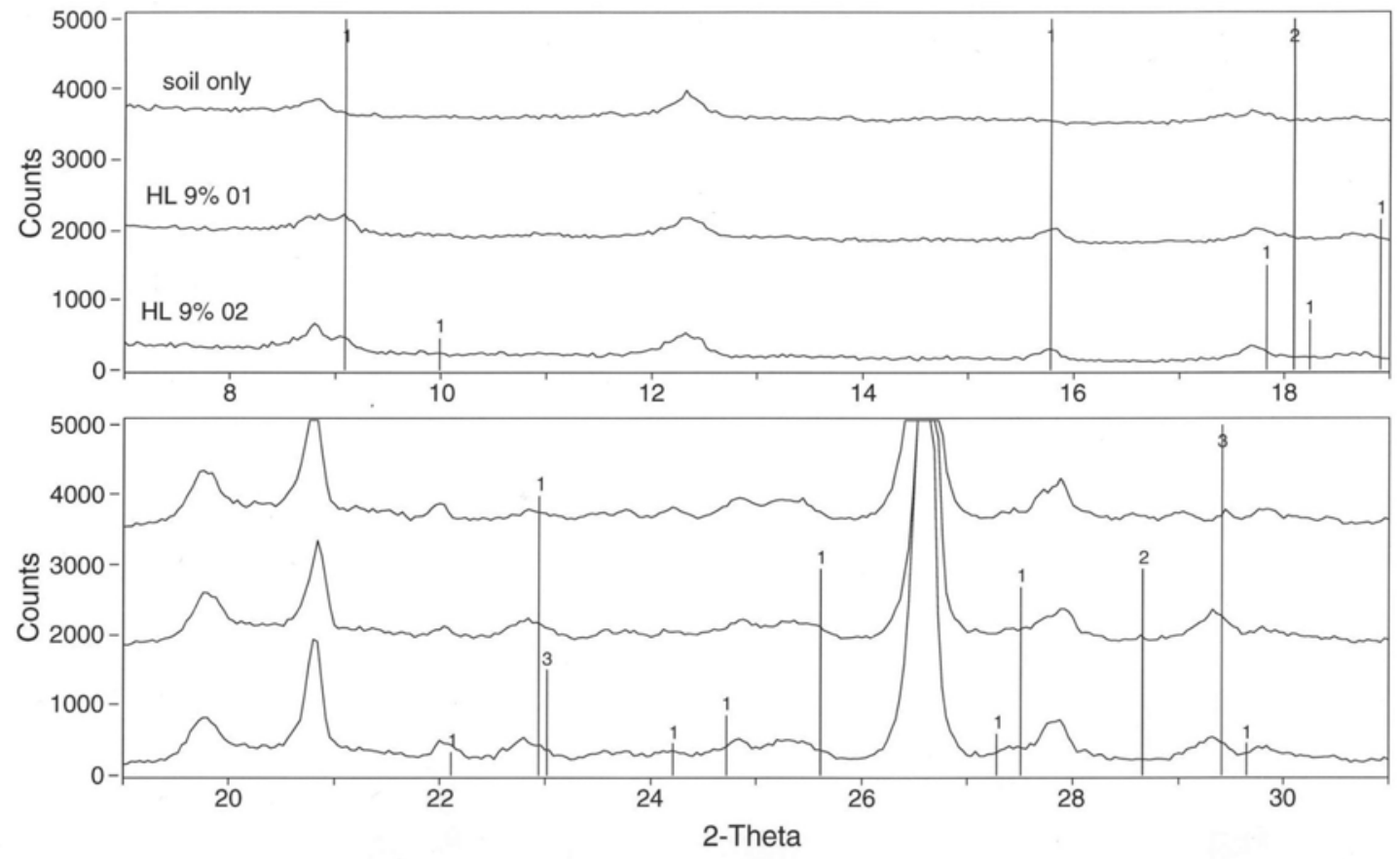

1> 41-1451: Ettringite, syn - Ca6Al2(SO4)3(OH)12!26H2O 2> 04-0733: Portlandite, syn - $\mathrm{Ca}(\mathrm{OH}) 2$ 3> 05-0586: Calcite, syn - CaCO3

Figure 5.20 XRD pattern for H1A soil treated with 9\% hydrated lime (numbers identify peaks of selected minerals) 


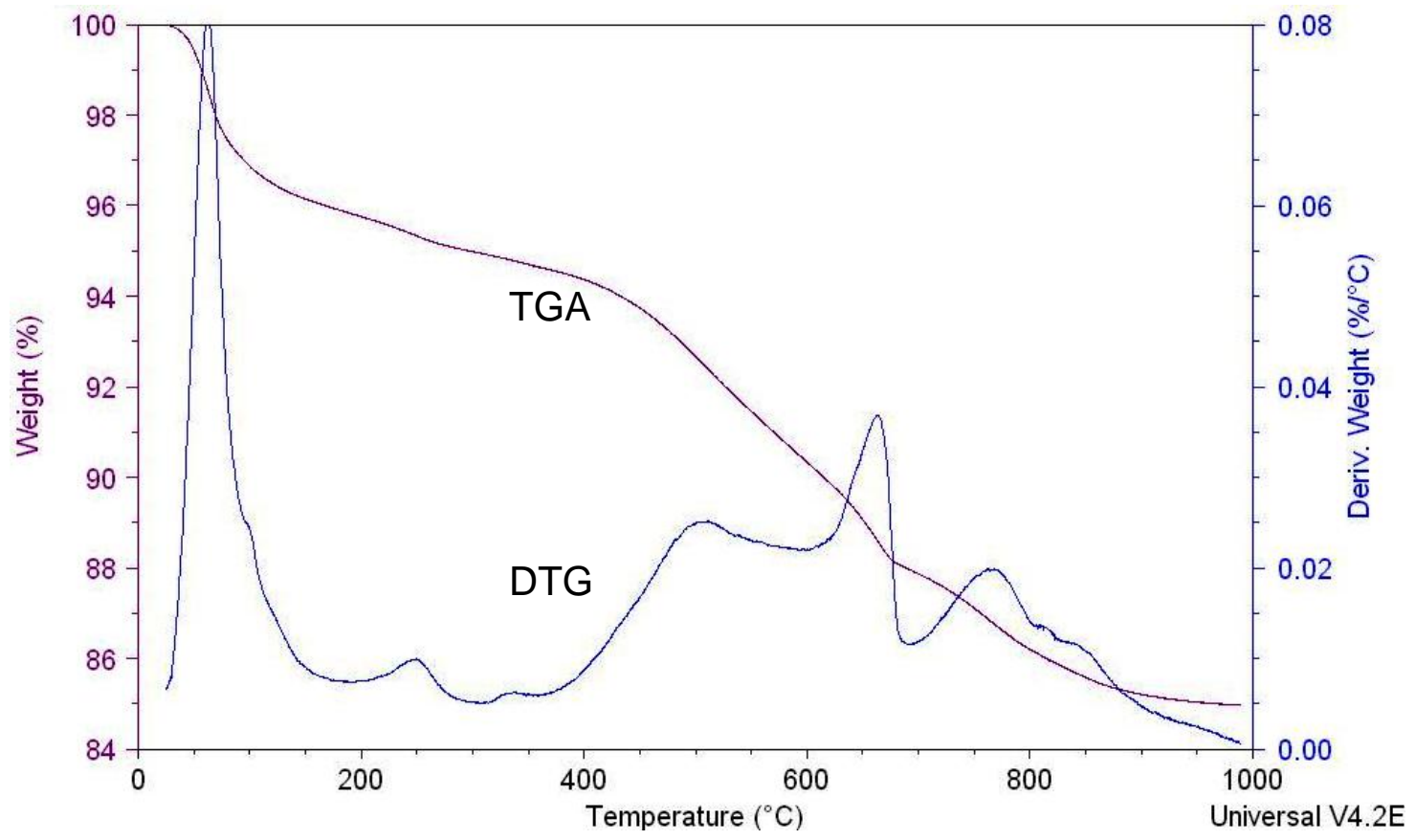

Figure 5.21 TGA plot with DTG data for H1A soil treated with 9\% hydrated lime

\subsubsection{Soil mixed with analytical lime (AL), quick lime (QL) and Portland cement (PC)}

The results for the XRD and TGA tests conducted on soil-stabilizer mixtures prepared with $3 \%$ and $7 \%$ analytical lime, quick lime and Portland cement are presented in Figures 5.22 - 5.25 (AL), Figures 5.26 - $5.29(\mathrm{QL})$, and Figures 5.30-5.33 (PC). The XRD spectra for soil stabilizer mixtures prepared with analytical lime, quick lime and Portland cement, all show the presence of the peaks of ettringite at $2 \theta \sim 9.1^{\circ}, 15.8^{\circ}, 18.9^{\circ}$ and $22.9^{\circ}$. Additionally, as the amount of stabilizer mixed with the soil increases, the peaks for ettringite become more easily distinguishable. The TGA results are generally consistent with this observation. For analytical lime and Portland cement increasing weight loss (reflected by a greater peak of the derivative curve) is observed at $55^{\circ} \mathrm{C}$ with increasing stabilizer dosage. 
The peaks of calcium hydroxide were not observed in any of the XRD spectra. However, the TGA data support the presence of calcium hydroxide in the mixtures with $3 \%$ analytical lime, $3 \%$ quick lime and 3 and $7 \%$ Portland cement. Note that, as discussed above, the peak in the DTG curve corresponding to the loss of calcium hydroxide occurs very close to the much larger one corresponding to the dehydration of the clay minerals $\left(\sim 500^{\circ} \mathrm{C}\right)$, which is observed in all samples.

The peaks for calcium carbonate were clearly identified in the XRD spectra for the mixtures with 3 and $7 \%$ analytical lime, and 7\% quick lime; however, in the other cases they were hard to identify. The TGA results indicate, instead, the presence of calcium carbonate in all soil stabilizer mixtures. As discussed above for the hydrated lime mixtures, the presence of calcium carbonate is the result of carbonation of the samples. Finally, as observed for the soil alone and the hydrated lime-soil mixtures, the TGA data show weight losses in correspondence to $100^{\circ} \mathrm{C}$ and $240^{\circ} \mathrm{C}$. As discussed above for the mixtures with hydrated lime, these weight losses correspond to the loss of hygroscopic moisture and the decomposition of ammonium sulfate, respectively. While the weight loss at $240^{\circ} \mathrm{C}$ appears consistent for all stabilizer mixtures (see Table 5.3), weight loss is observed only in the mixtures with $3 \%$ analytical lime and 3 and $7 \%$ Portland cement. This could reflect different degrees of drying of the samples. 

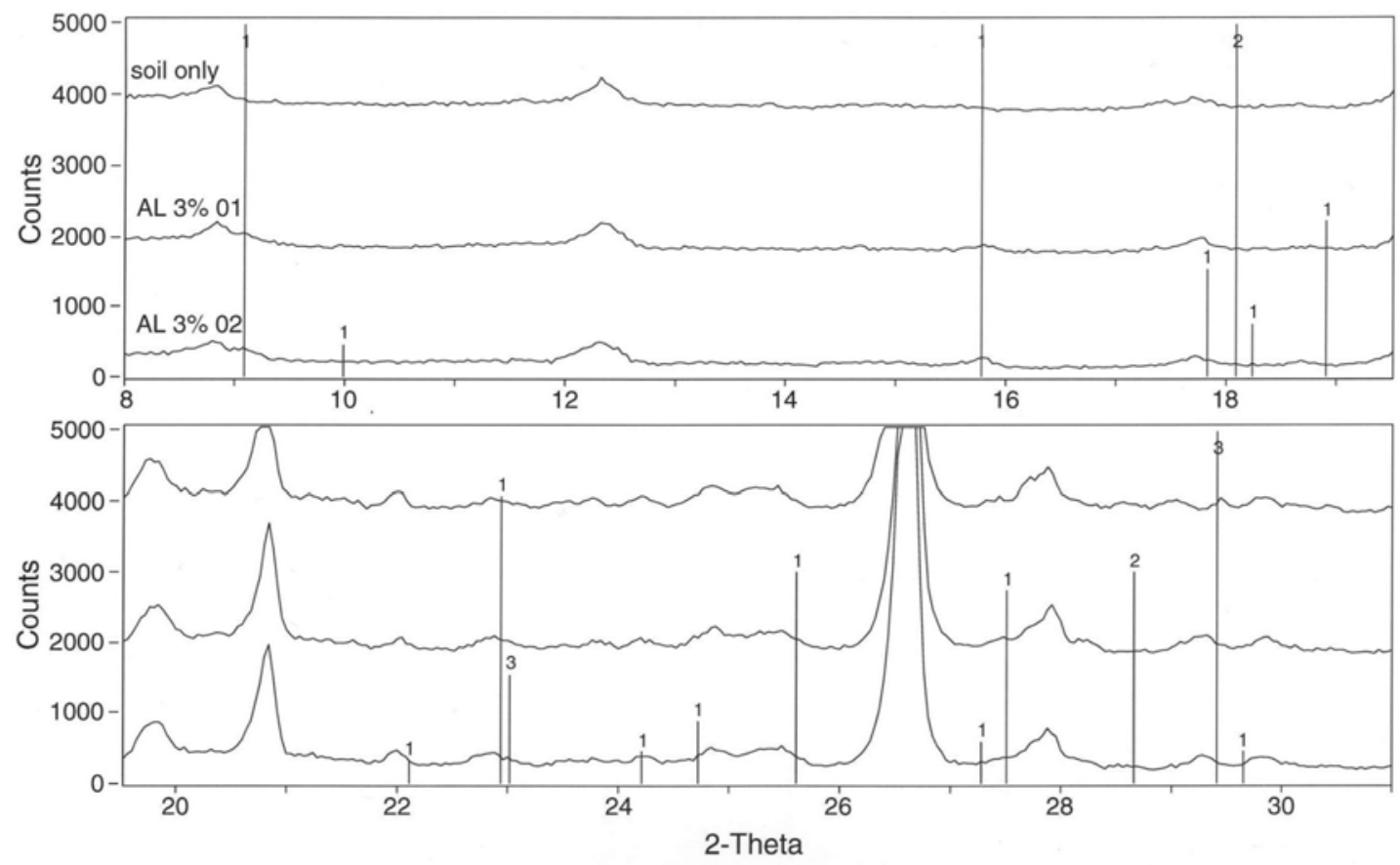

1> 41-1451: Ettringite, syn - Ca6Al2(SO4)3(OH)12!26H2O 2> 04-0733: Portlandite, syn - $\mathrm{Ca}(\mathrm{OH}) 2$ 3> 05-0586: Calcite, syn - $\mathrm{CaCO} 3$

Figure 5.22 XRD pattern for H1A soil treated with 3\% analytical lime (numbers identify peaks of selected minerals)

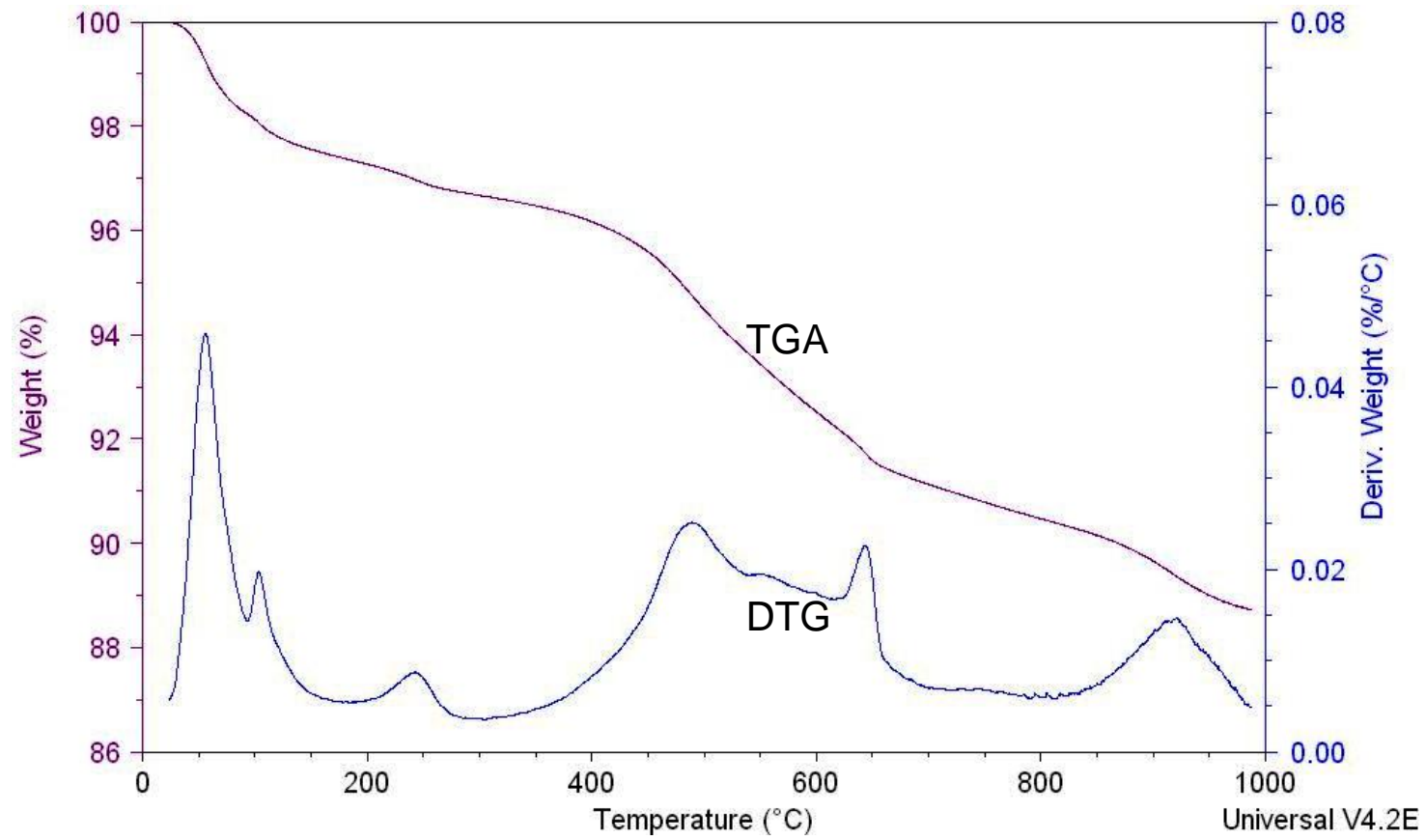

Figure 5.23 TGA plot with DTG data for H1A soil treated with 3\% analytical lime 

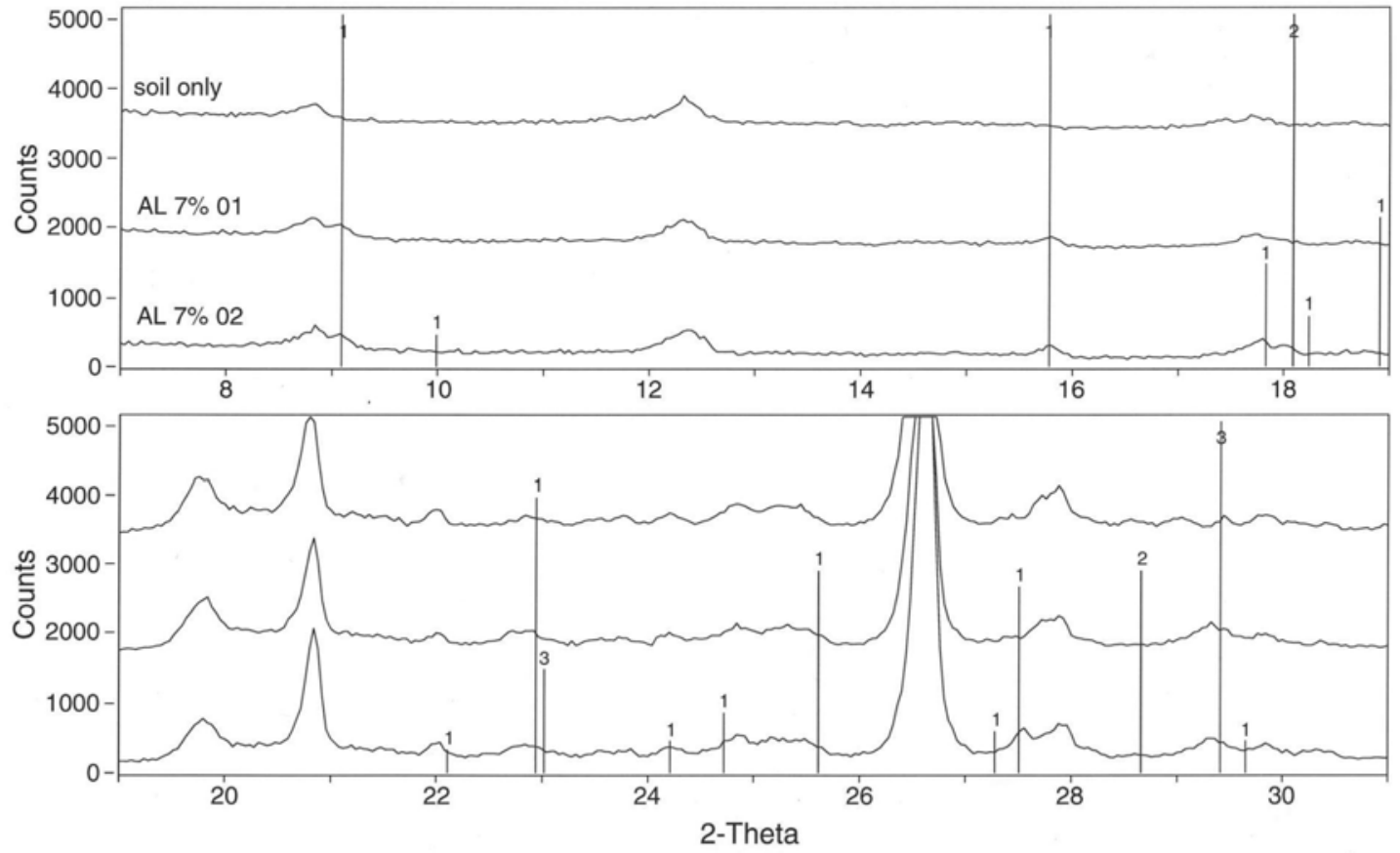

1> 41-1451: Ettringite, syn - Ca6Al2(SO4)3(OH)12!26 22 2> 04-0733: Portlandite, syn - $\mathrm{Ca}(\mathrm{OH}) 2$ 3> 05-0586: Calcite, syn - CaCO3

Figure 5.24 XRD pattern for H1A soil treated with 7\% analytical lime (numbers identify peaks of selected minerals)

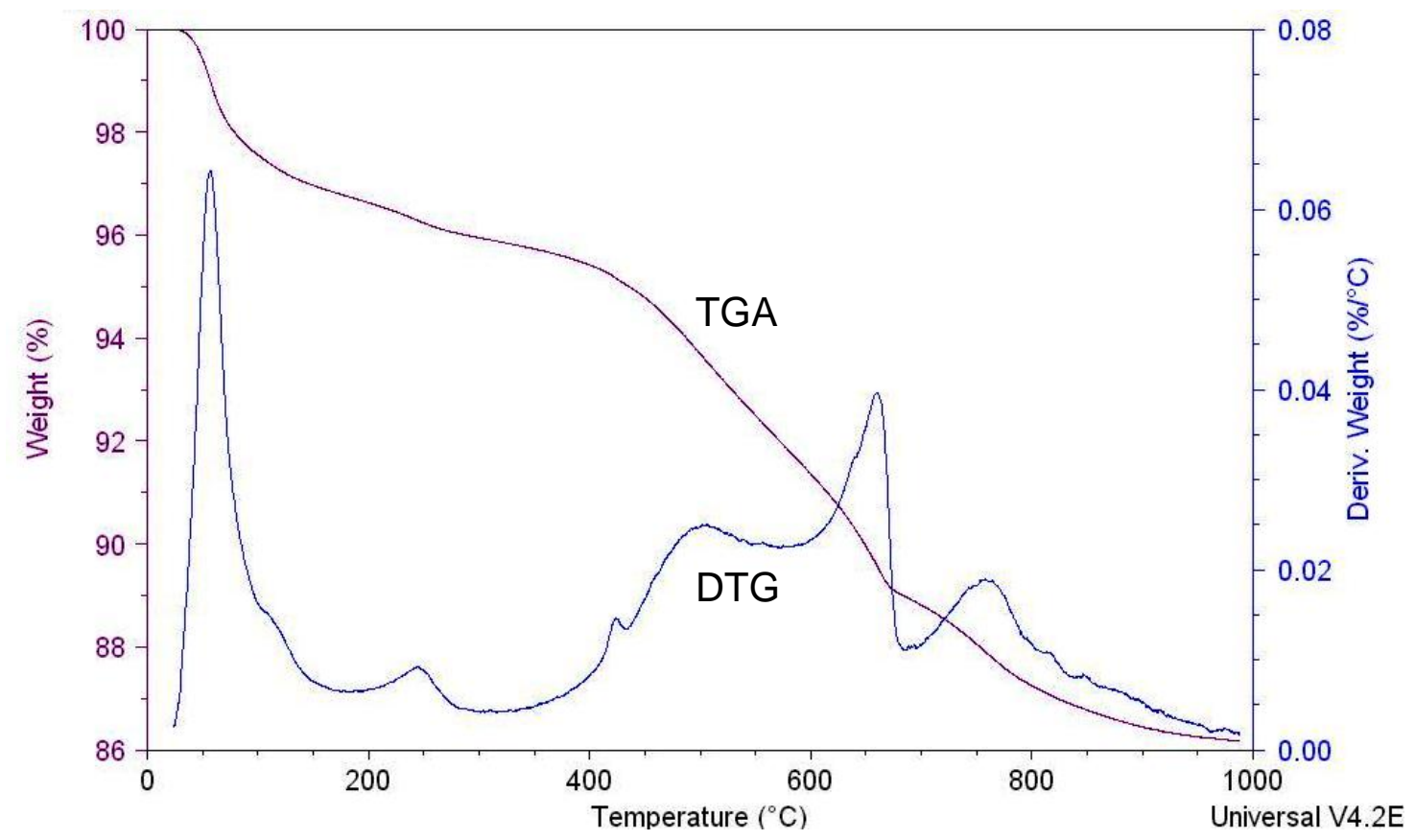

Figure 5.25 TGA plot with DTG data for H1A soil treated with 7\% analytical lime 

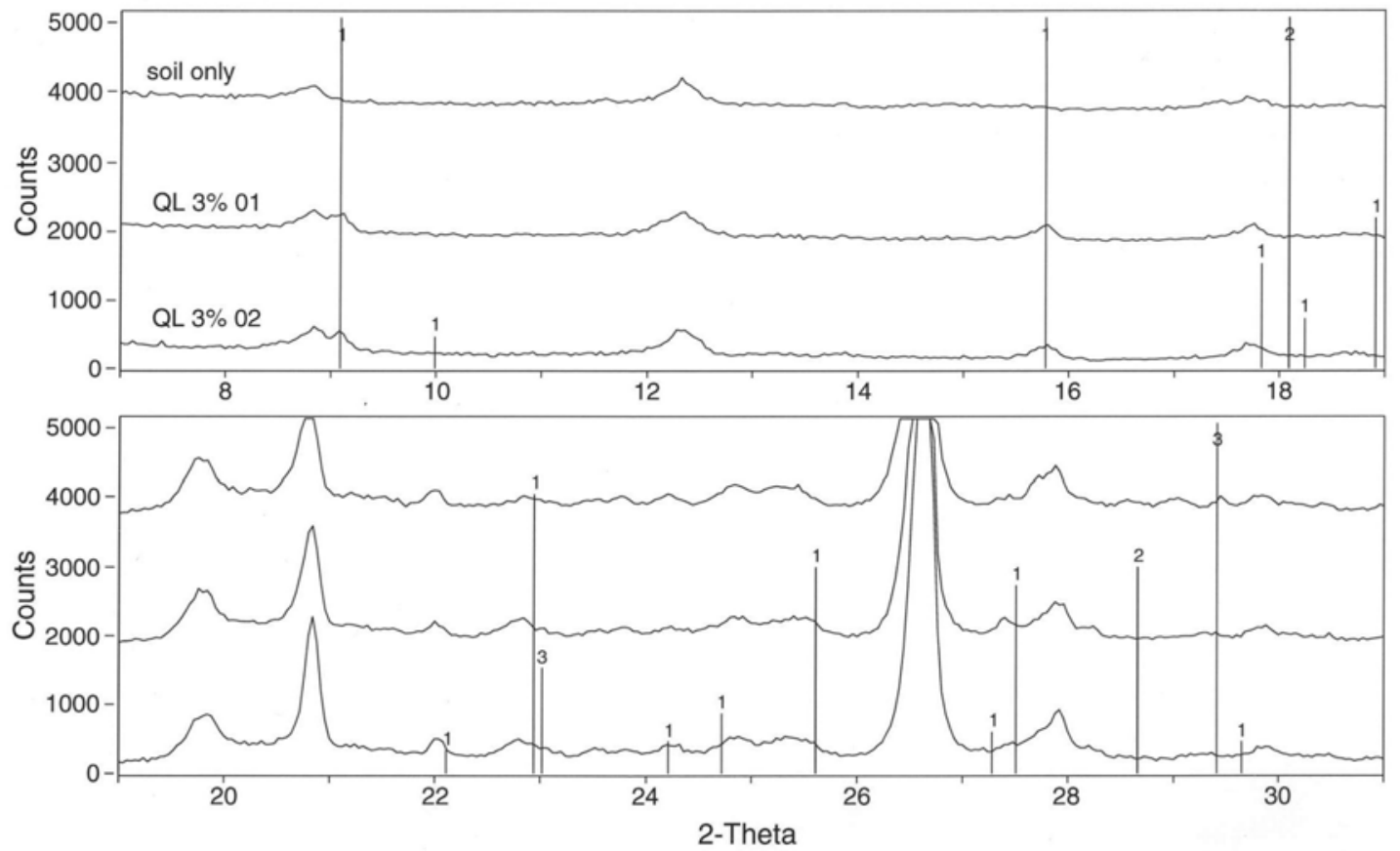

1> 41-1451: Ettringite, syn - Ca6Al2(SO4)3(OH)12!26H2O 2> 04-0733: Portlandite, syn - $\mathrm{Ca}(\mathrm{OH}) 2$ 3> 05-0586: Calcite, syn - $\mathrm{CaCO} 3$

Figure 5.26 XRD pattern for H1A soil treated with 3\% quick lime (numbers identify peaks of selected minerals)

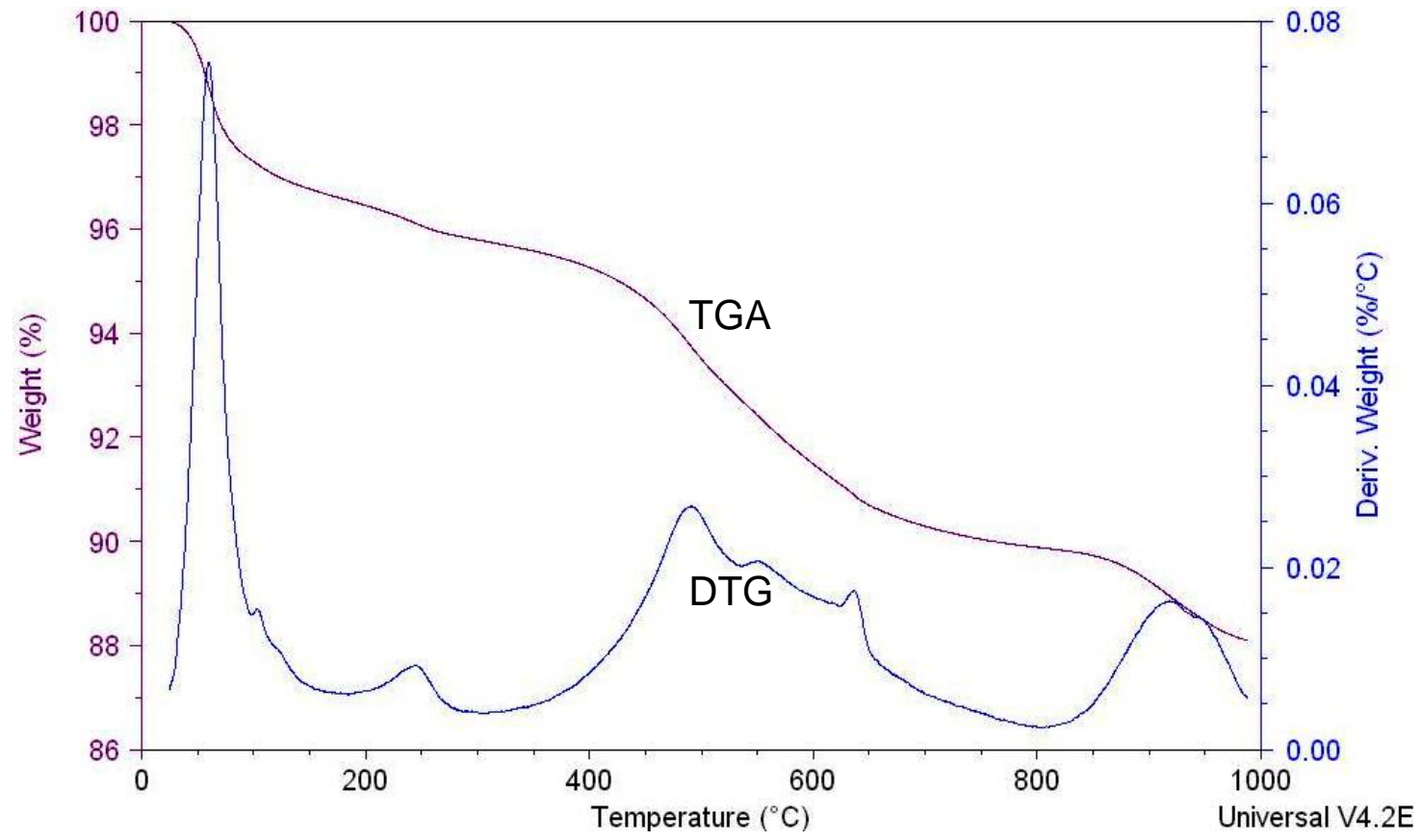

Figure 5.27 TGA plot with DTG data for H1A soil treated with 3\% quick lime 

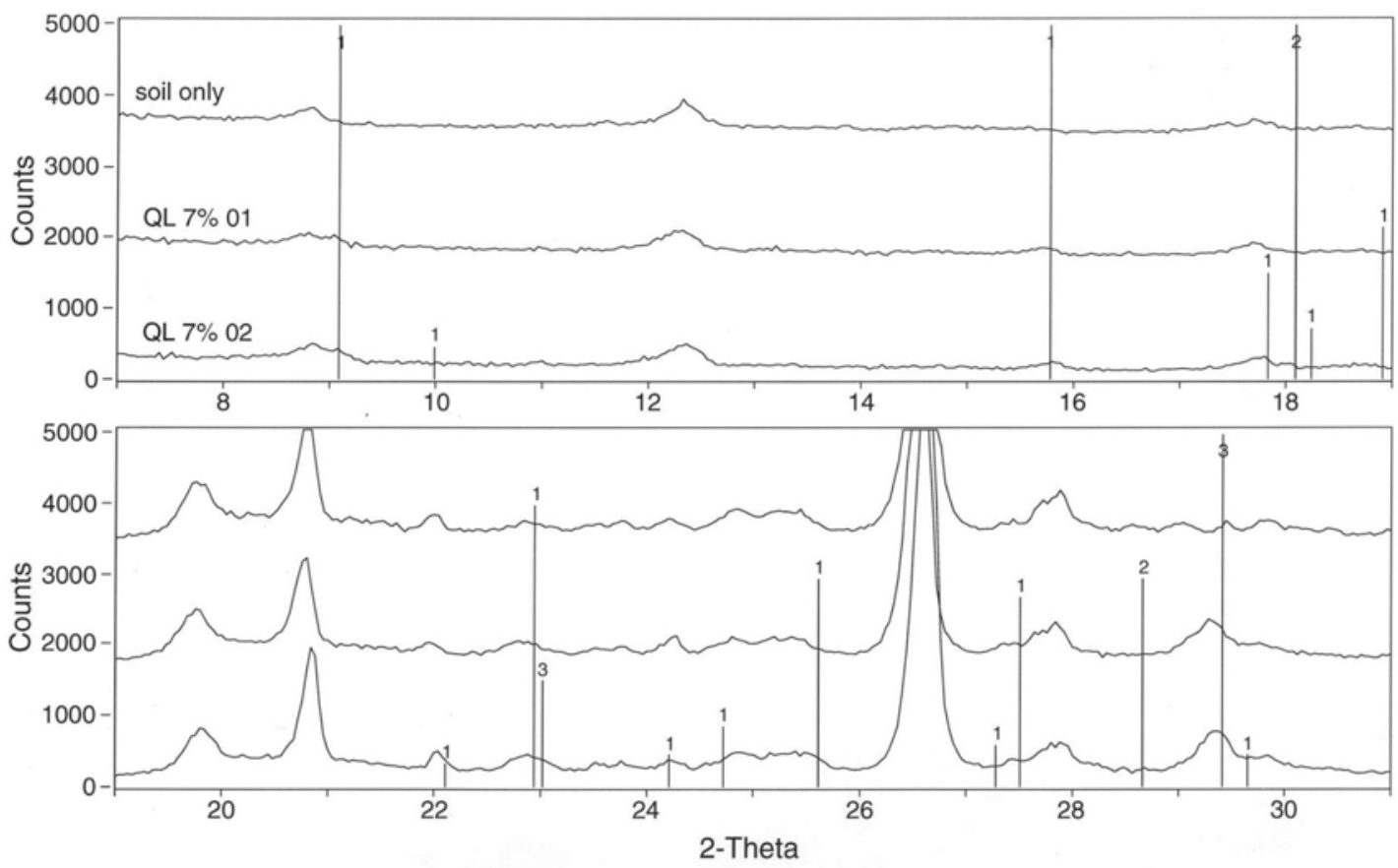

1> 41-1451: Ettringite, syn - Ca6Al2(SO4)3(OH)12!26 2 2 2> 04-0733: Portlandite, syn - $\mathrm{Ca}(\mathrm{OH}) 2$ 3> 05-0586: Calcite. svn - $\mathrm{CaCO} 3$

Figure 5.28 XRD pattern for H1A soil treated with 7\% quick lime (numbers identify peaks of selected minerals)

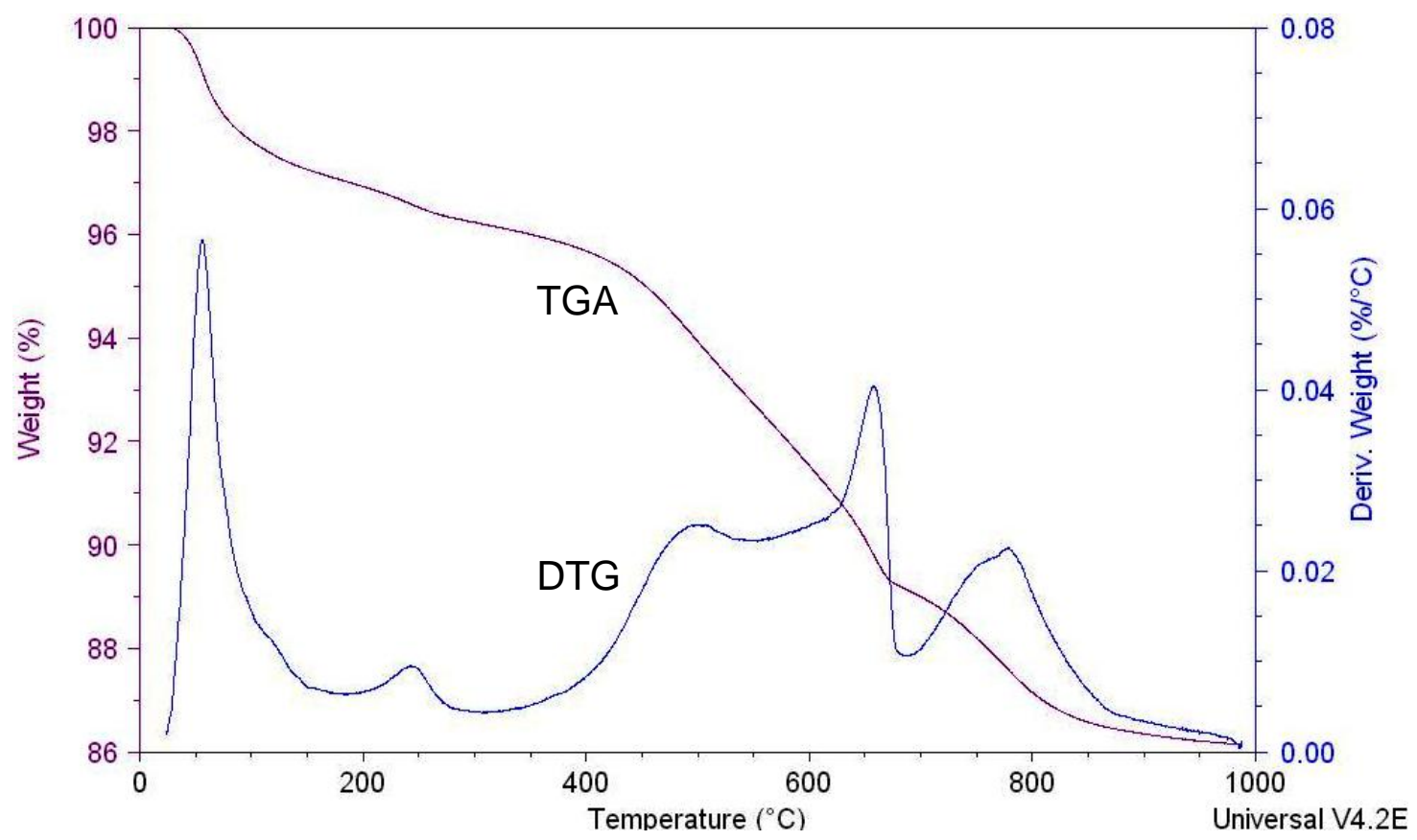

Figure 5.29 TGA plot with DTG data for H1A soil treated with 7\% quick lime 

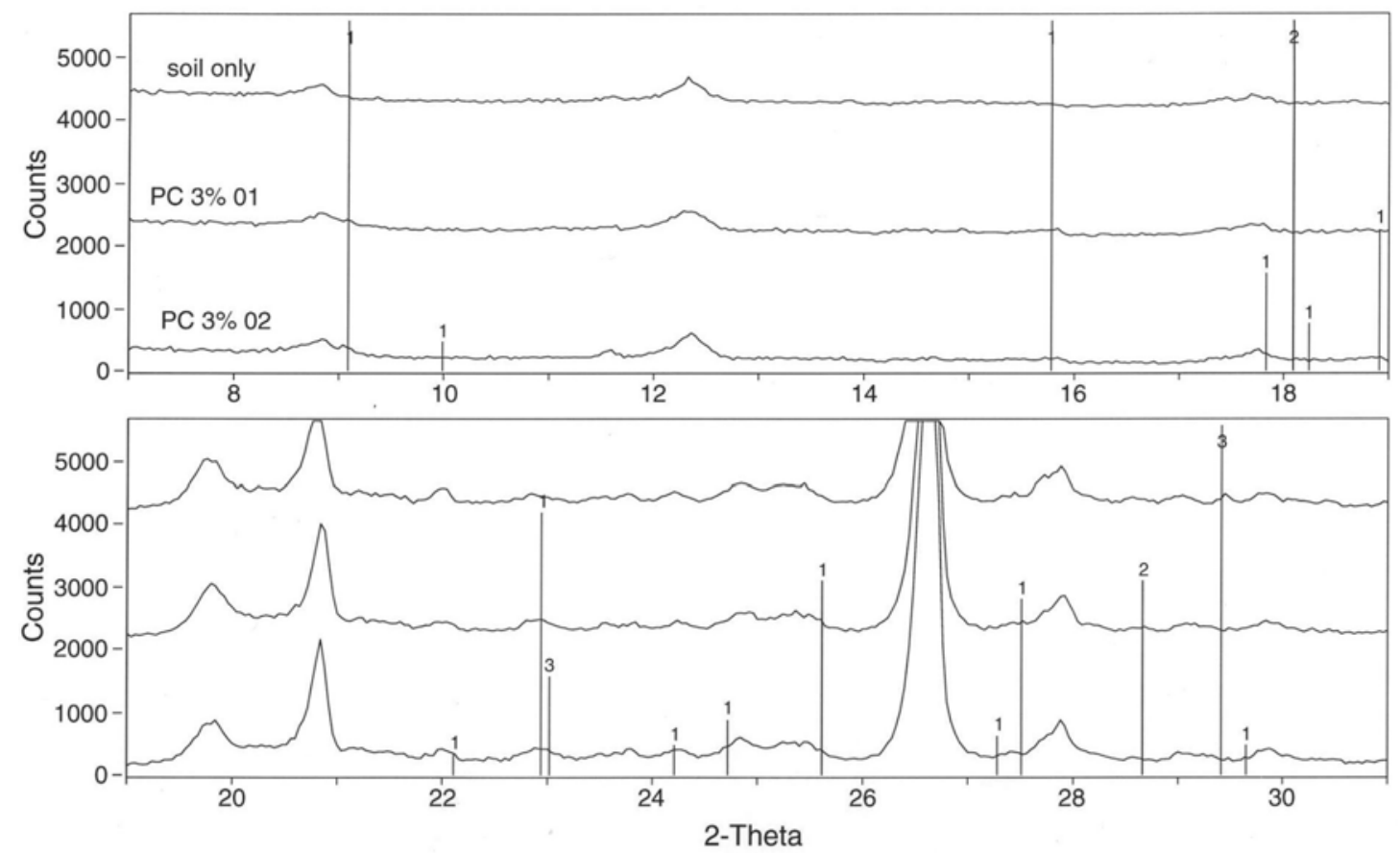

1> 41-1451: Ettringite, syn - Ca6Al2(SO4)3(OH)12!26H2O 2> 04-0733: Portlandite, syn - $\mathrm{Ca}(\mathrm{OH}) 2$ 3> 05-0586: Calcite, syn - $\mathrm{CaCO} 3$

Figure 5.30 XRD pattern for H1A soil treated with 3\% Portland cement (numbers identify peaks of selected minerals)

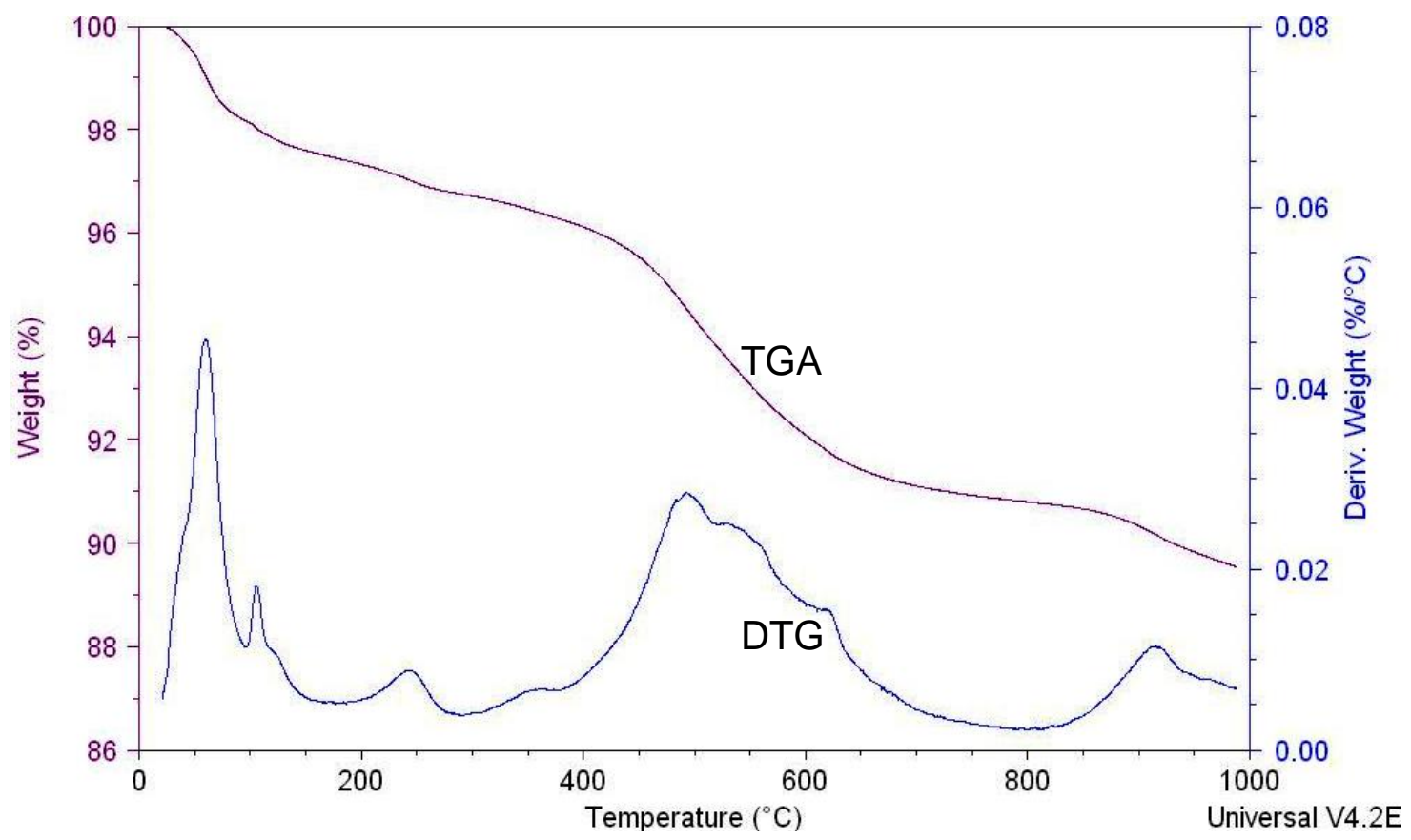

Figure 5.31 TGA plot with DTG data for H1A soil treated with 3\% Portland cement 

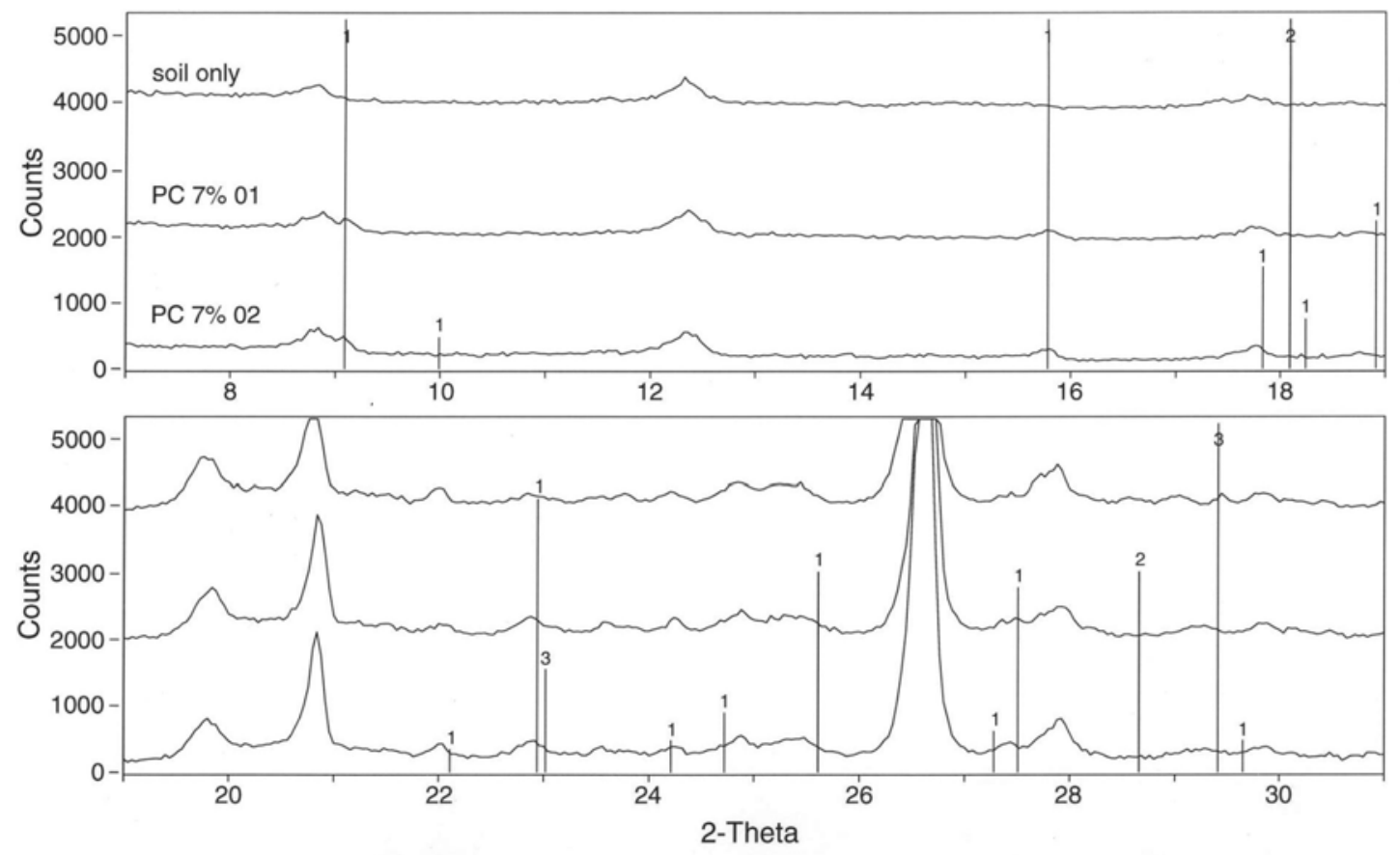

1> 41-1451: Ettringite, syn - Ca6Al2(SO4)3(OH)12!26H2O 2> 04-0733: Portlandite, syn - $\mathrm{Ca}(\mathrm{OH}) 2$ 3> 05-0586: Calcite, syn - $\mathrm{CaCO} 3$

Figure 5.32 XRD pattern for H1A soil treated with 7\% Portland cement (numbers identify peaks of selected minerals)

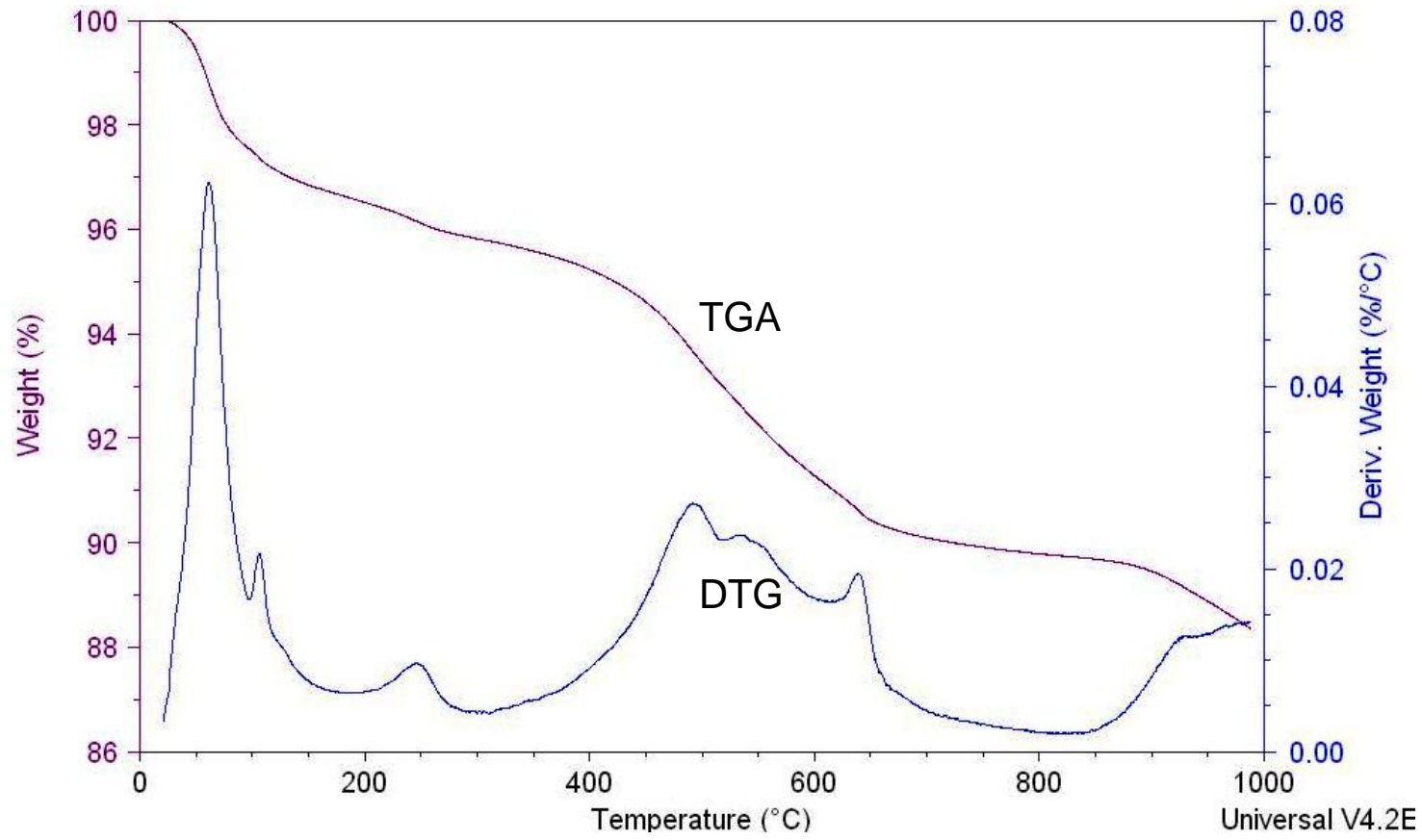

Figure 5.33 TGA plot with DTG data for H1A soil treated with 7\% Portland cement 
Table 5.2 Summary of XRD tests results

\begin{tabular}{|c|c|c|c||c|c|c|c|}
\hline Mixture & Ettringite & $\mathrm{Ca}(\mathrm{OH})_{2}$ & $\mathrm{CaCO}_{3}$ & Mixture & Ettringite & $\mathrm{Ca}(\mathrm{OH})_{2}$ & $\mathrm{CaCO}_{3}$ \\
\hline $\mathrm{HL} 1.5 \%$ & $\mathrm{Y}$ (small) & $\mathrm{N}$ & $\mathrm{N}$ & AL3\% & $\mathrm{Y}$ & $\mathrm{N}$ & $\mathrm{Y}$ \\
\hline $\mathrm{HL} 3 \%$ & $\mathrm{Y}$ (small) & $\mathrm{N}$ & $\mathrm{N}$ & AL7\% & $\mathrm{Y}$ & $\mathrm{N}$ & $\mathrm{Y}$ \\
\hline $\mathrm{HL} \%$ & $\mathrm{Y}$ & $\mathrm{N}$ & $\mathrm{N}$ & $\mathrm{QL3} \%$ & $\mathrm{Y}$ & $\mathrm{N}$ & $\mathrm{N}$ \\
\hline $\mathrm{HL7} \%$ & $\mathrm{Y}$ & $\mathrm{N}$ & $\mathrm{Y}$ & QL7\% & $\mathrm{Y}$ & $\mathrm{N}$ & $\mathrm{Y}$ \\
\hline $\mathrm{HL} \%$ & $\mathrm{Y}$ & $\mathrm{N}$ & $\mathrm{Y}$ & PC3\% & $\mathrm{Y}$ & $\mathrm{N}$ & $\mathrm{N}$ \\
\hline & & & & PC7\% & $\mathrm{Y}$ & $\mathrm{N}$ & $\mathrm{Y}$ \\
\hline
\end{tabular}

Note: $\mathrm{Y}=$ detected, $\mathrm{N}=$ not detected

main peaks for ettringite at $2 \theta \sim 9.1^{\circ}, 15.8^{\circ}, 18.9^{\circ}$, and $22.9^{\circ}$, calcium hydroxide at $2 \theta \sim 18.1^{\circ}$ and calcium carbonate at $2 \theta \sim 29.4^{\circ}$ 
Table 5.3 Summary of TGA tests results (Continued)

\begin{tabular}{|c||c|c|c|c|c|c|}
\hline Mixtures & $\begin{array}{c}\text { Hydrous } \\
\text { mica and } \\
\text { ettringite }\end{array}$ & $\begin{array}{c}\mathrm{dW} / \mathrm{dT} \\
\left(\% /{ }^{\circ} \mathrm{C}\right)\end{array}$ & $\begin{array}{c}\text { Hydrous } \\
\text { mica at } \\
100^{\circ} \mathrm{C}\end{array}$ & $\begin{array}{c}\mathrm{dW} / \mathrm{dT} \\
\left(\% /{ }^{\circ} \mathrm{C}\right)\end{array}$ & $\begin{array}{c}\left(\mathrm{NH}_{4}\right)_{2} \mathrm{~S} \\
\mathrm{O}_{4}\end{array}$ & $\begin{array}{c}\mathrm{dW} / \mathrm{dT} \\
\left(\% /{ }^{\circ} \mathrm{C}\right)\end{array}$ \\
\hline Soil only & mica only & 0.023 & $\mathrm{Y}$ & 0.02 & $\mathrm{Y}$ & 0.008 \\
\hline $\mathrm{HL} 1.5 \%$ & $\mathrm{Y}$ & 0.02 & $\mathrm{Y}$ & 0.024 & $\mathrm{Y}$ & 0.008 \\
\hline HL3\% & $\mathrm{Y}$ & 0.025 & $\mathrm{Y}$ & 0.033 & $\mathrm{Y}$ & 0.009 \\
\hline HL5\% & $\mathrm{Y}$ & 0.058 & $\mathrm{~N}$ & - & $\mathrm{Y}$ & 0.009 \\
\hline HL7\% & $\mathrm{Y}$ & 0.078 & $\mathrm{~N}$ & - & $\mathrm{Y}$ & 0.009 \\
\hline HL9\% & $\mathrm{Y}$ & 0.080 & $\mathrm{~N}$ & - & $\mathrm{Y}$ & 0.01 \\
\hline AL3\% & $\mathrm{Y}$ & 0.045 & $\mathrm{Y}$ & 0.02 & $\mathrm{Y}$ & 0.008 \\
\hline AL7\% & $\mathrm{Y}$ & 0.065 & $\mathrm{~N}$ & - & $\mathrm{Y}$ & 0.009 \\
\hline QL3\% & $\mathrm{Y}$ & 0.075 & $\mathrm{~N}$ & - & $\mathrm{Y}$ & 0.01 \\
\hline QL7\% & $\mathrm{Y}$ & 0.056 & $\mathrm{~N}$ & - & $\mathrm{Y}$ & 0.01 \\
\hline PC3\% & $\mathrm{Y}$ & 0.045 & $\mathrm{Y}$ & 0.017 & $\mathrm{Y}$ & 0.009 \\
\hline PC7\% & $\mathrm{Y}$ & 0.062 & $\mathrm{Y}$ & 0.02 & $\mathrm{Y}$ & 0.009 \\
\hline
\end{tabular}

Note: $\mathrm{Y}=$ peaks existing, $\mathrm{N}=$ no peaks existing

$\mathrm{dW} / \mathrm{dT}\left(\% /{ }^{\circ} \mathrm{C}\right)=$ derivative of total weight $(\%)$ with regard to temperature $\left({ }^{\circ} \mathrm{C}\right)$

Decomposition temperature

$\approx 55^{\circ} \mathrm{C}$ ettringite (plus contribution already present in natural soil)

$\approx 100^{\circ} \mathrm{C}$ hydrous mica (hygroscopic moisture)

$\approx 240^{\circ} \mathrm{C}$ ammonium sulfate 
Table 5.3 Summary of TGA test results

\begin{tabular}{|c|c|c|c|c|c|c|c|}
\hline Mixtures & Kaolinite & $\begin{array}{c}\mathrm{dW} / \mathrm{dT} \\
\left(\% /{ }^{\circ} \mathrm{C}\right)\end{array}$ & $\mathrm{Ca}(\mathrm{OH})_{2}$ & $\begin{array}{c}\mathrm{dW} / \mathrm{dT} \\
\left(\% /{ }^{\circ} \mathrm{C}\right)\end{array}$ & $\mathrm{CaCO}_{3}$ & $\begin{array}{c}\text { TW/al } \\
\left(\% /{ }^{\circ} \mathrm{C}\right)\end{array}$ & $\begin{array}{c}\text { Weight } \\
\text { Remaining } \\
(\%)\end{array}$ \\
\hline Soil only & $\mathrm{Y}$ & 0.03 & $\mathrm{~N}$ & - & $\mathrm{N}$ & - & 90.6 \\
\hline HL1.5\% & $\mathrm{Y}$ & 0.028 & $\mathrm{Y}$ & 0.023 & $\mathrm{Y}$ & 0.007 & 90.8 \\
\hline HL3\% & $\mathrm{Y}$ & 0.025 & $\mathrm{Y}$ & 0.023 & $\mathrm{Y}$ & 0.02 & 88.5 \\
\hline HL5\% & $\mathrm{Y}$ & 0.027 & $\mathrm{Y}$ & 0.02 & $\mathrm{Y}$ & 0.023 & 88 \\
\hline HL7\% & $\mathrm{Y}$ & 0.025 & $\mathrm{~N}$ & - & $\mathrm{Y}$ & 0.028 & 86.3 \\
\hline HL9\% & $\mathrm{Y}$ & 0.025 & $\mathrm{~N}$ & - & $\mathrm{Y}$ & 0.037 & 85.3 \\
\hline AL3\% & $\mathrm{Y}$ & 0.025 & $\mathrm{Y}$ & 0.02 & $\mathrm{Y}$ & 0.022 & 88.7 \\
\hline AL7\% & $\mathrm{Y}$ & 0.025 & $\mathrm{~N}$ & - & $\mathrm{Y}$ & 0.04 & 85.5 \\
\hline QL3\% & $\mathrm{Y}$ & 0.025 & $\mathrm{Y}$ & 0.02 & $\mathrm{Y}$ & 0.017 & 88 \\
\hline QL7\% & $\mathrm{Y}$ & 0.024 & $\mathrm{~N}$ & - & $\mathrm{Y}$ & 0.04 & 85 \\
\hline PC3\% & $\mathrm{Y}$ & 0.028 & $\mathrm{Y}$ & 0.023 & $\mathrm{Y}$ & 0.015 & 89.5 \\
\hline PC7\% & $\mathrm{Y}$ & 0.027 & $\mathrm{Y}$ & 0.023 & $\mathrm{Y}$ & 0.018 & 88.5 \\
\hline
\end{tabular}

Note: $\mathrm{Y}=$ peaks existing, $\mathrm{N}=$ no peaks existing

$\mathrm{dW} / \mathrm{dT}\left(\% /{ }^{\circ} \mathrm{C}\right)=$ derivative of total weight $(\%)$ with regard to temperature $\left({ }^{\circ} \mathrm{C}\right)$

Decomposition temperature

$\approx 500^{\circ} \mathrm{C}$ kaolinite (and related minerals)

$\approx 470-600^{\circ} \mathrm{C}$ calcium hydroxide

$\approx 625-900^{\circ} \mathrm{C}$ calcium carbonate, 2 peaks possible due to carbonation

(time-dependent behavior) 


\subsection{Data Analysis}

The previous section described the minerals that could be identified from the XRD and TGA analyses conducted on the soil-stabilizer mixtures at the end of the swelling stage (see summary of data in Tables 5.2 - 5.4). Of the minerals identified through these analyses, the only one that can be responsible for the measured swelling is ettringite. It was pointed out that peaks corresponding to ettringite could be clearly identified in most XRD spectra and in the TGA curves. In two cases $(1.5 \%$ and $3 \%$ hydrated lime mixtures) the presence of ettringite was less clear in both the XRD and TGA results.

To quantify the amount of ettringite present in each sample, the area under the derivative curve in correspondence to the peak at $55^{\circ} \mathrm{C}$ (corresponding to the decomposition of ettringite) can be calculated. See an example for the mixture with $3 \%$ hydrated lime in Figure 5.34.

This calculation was performed through the software of the TA Instrument used for the TGA analyses. Values of the mass of the sample lost during the first endotherm are summarized in Table 5.4 and expressed both in percentage and absolute terms.

It is of interest to relate the amount of ettringite (expressed as a percentage of the sample mass) to the nominal lime or cement contents. This is done in Figure 5.35 which shows that there is a general positive correlation between the total amount of calcium added and the area under the peak. 


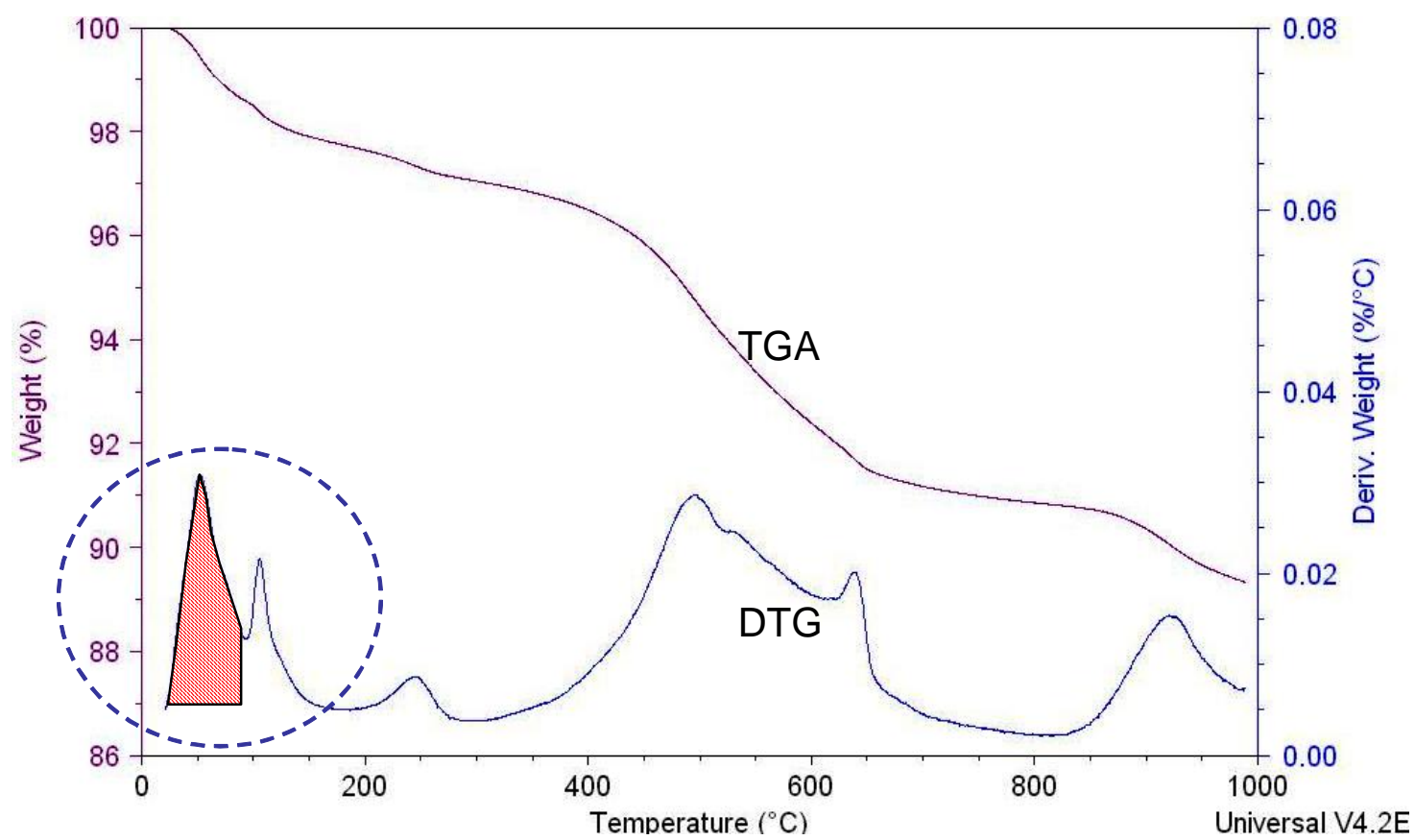

Figure 5.34 Area under the $55^{\circ} \mathrm{C}$ peak on the DTG curve (H1A soil treated with $3 \%$ hydrated lime)

Table 5.4 Area under the $55^{\circ} \mathrm{C}$ peak

\begin{tabular}{|c|c|c||c|c|c|}
\hline Mixtures & $\begin{array}{c}\text { Area } \\
\text { (weight, \%) }\end{array}$ & $\begin{array}{c}\text { Weight } \\
\text { loss (mg) }\end{array}$ & Mixtures & $\begin{array}{c}\text { Area } \\
\text { weight, } \\
\%)\end{array}$ & $\begin{array}{c}\text { Weight } \\
\text { loss (mg) }\end{array}$ \\
\hline \hline Soil only & 1.10 & 0.37 & AL3\% & 1.78 & 0.60 \\
\hline HL1.5\% & 0.94 & 0.29 & AL7\% & 2.35 & 0.69 \\
\hline HL3\% & 1.42 & 0.41 & QL3\% & 2.62 & 0.83 \\
\hline HL5\% & 2.21 & 0.65 & QL7\% & 2.10 & 0.65 \\
\hline HL7\% & 2.75 & 0.75 & PC3\% & 1.80 & 0.59 \\
\hline HL9\% & 2.99 & 0.67 & PC7\% & 2.40 & 0.77 \\
\hline
\end{tabular}

The interpretation is that the addition of lime (hydrated or quick lime) or Portland cement results in a formation of a hydrous phase that readily gives off hygroscopic 
moisture under $100^{\circ} \mathrm{C}$. According to the XRD analyses, the hydrous phase corresponds to ettringite. The fact that the temperature peak is generally increased with successive additions of calcium indicates that a poorly-crystallized ettringite is formed with low additions of calcium, i.e. 1.5 and $3 \%$ and thus, not all peaks of ettringite are present in the XRD diffractograms.

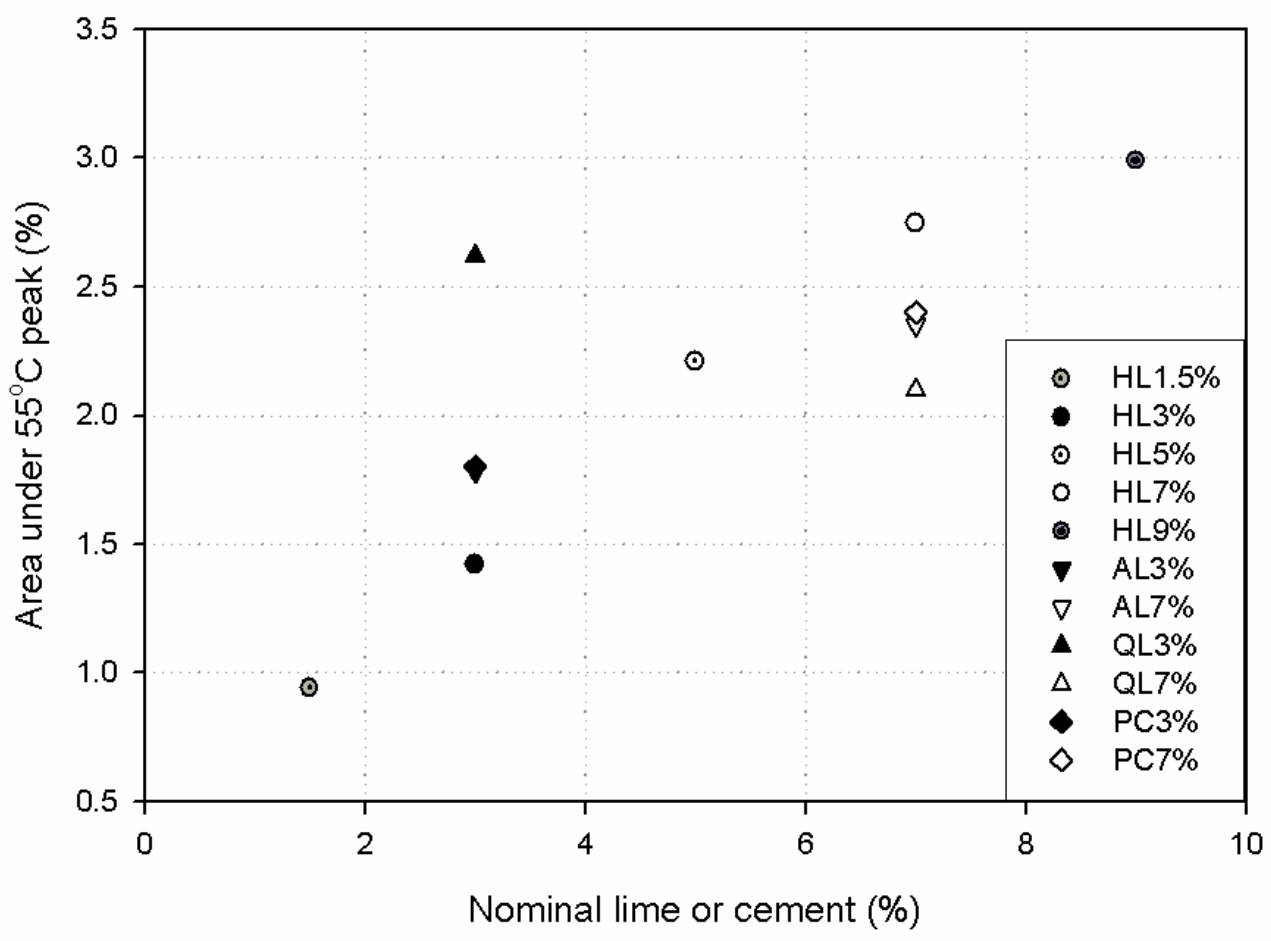

Figure 5.35 Plot of nominal lime or cement vs. area under $55^{\circ} \mathrm{C}$

Given that ettringite is considered responsible for the swelling, it is of interest to establish whether the amount of ettringite present (as measured by the values of the areas under the $55^{\circ} \mathrm{C}$ peak reported in Table 5.4) correlate with the strains measured in the swelling tests. Unfortunately, as shown in Figure 5.36, there is no clear correlation 
between these two quantities. In particular, the fact that the greatest swelling strain was consistently measured in the mixture with $3 \%$ hydrated lime remains unexplained.

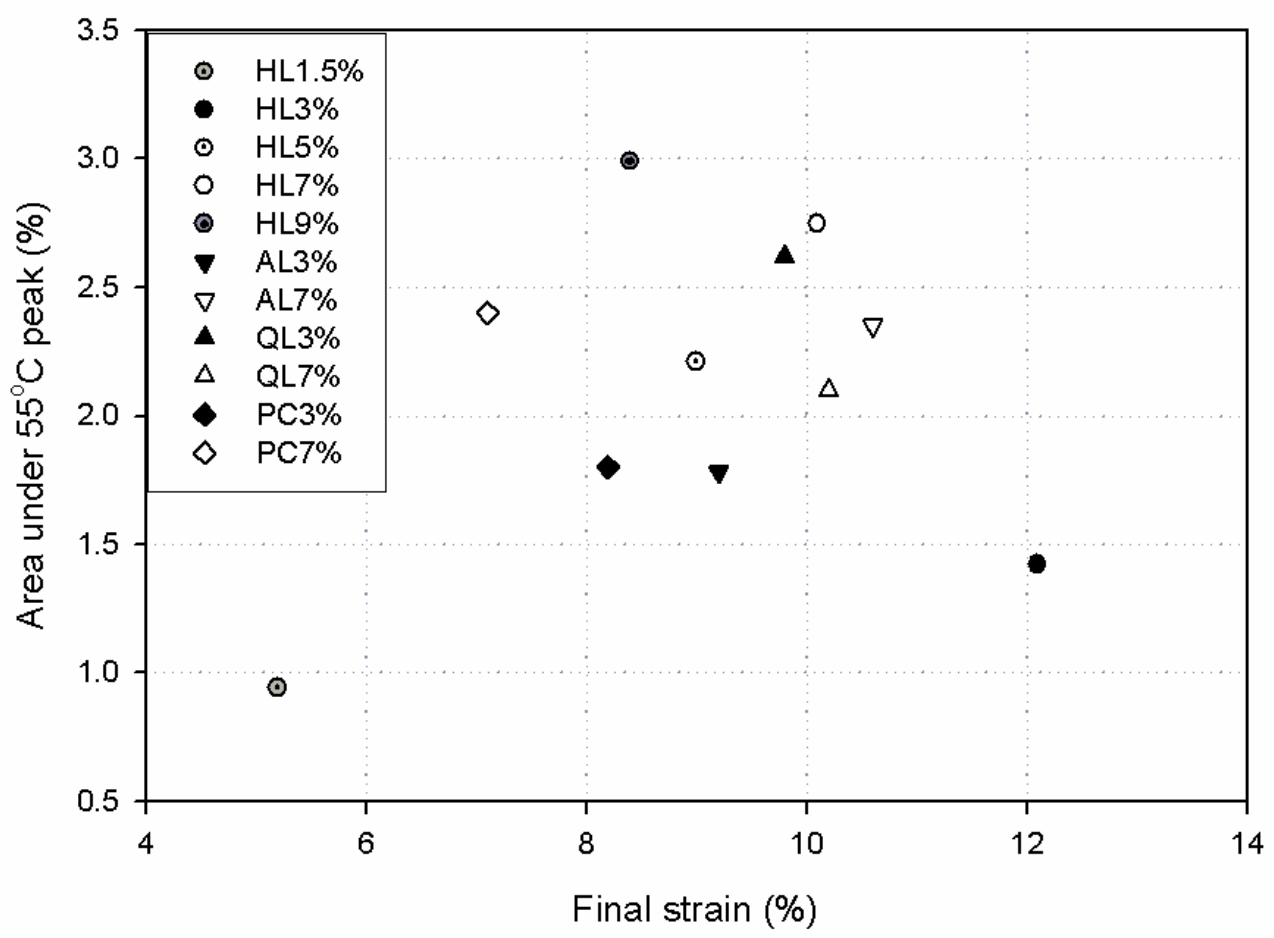

Figure 5.36 Plot of final swelling strain vs. area under $55^{\circ} \mathrm{C}$

\subsection{Summary}

This chapter presented the results of tests conducted to investigate the chemical and mineralogical characteristics of the soil-stabilizer mixtures at the end of the swelling phase with the goal of identifying the source of the swelling behavior. In particular, the results of $\mathrm{x}$-ray diffraction (XRD) and thermal gravimetric (TGA) analyses were reported for all soil stabilizer mixtures examined in this research. Data were also presented for the 
untreated soil and the stabilizers alone to be used as baseline results. Additional sulfate content data for the untreated soil were also presented.

The peaks present in the XRD spectra of the soil-stabilizer mixtures were identified. In addition to the minerals already present in the natural soil, the XRD analyses detected the presence of ettringite, calcium carbonate (resulting from carbonation of the sample prior to testing) and calcium hydroxide. Of these minerals only ettringite can be responsible for the observed swelling, Ettringite was clearly observed to be present in all the soil-stabilizer mixtures with the exception of those with $1.5 \%$ and $3 \%$ hydrated lime. For these samples the peaks of ettringite could not be clearly identified in the XRD spectra. It is hypothesized that a poorly-crystallized ettringite is formed with small addition of calcium, i.e. 1.5 and $3 \%$ and thus, not all peaks of ettringite are visible in the XRD diffractograms.

The TGA results for the soil stabilizer mixtures show that the main phases that release either water or $\mathrm{CO}_{2}$ are ettringite, illite, ammonium sulfate, calcium hydroxide, kaolinite, and calcium carbonate (listed according to the temperature at which weight loss takes place). Illite, ammonium sulfate and kaolinite are present also in the untreated soil. The weight loss that reflects the decomposition of ettringite occurs at about $55^{\circ} \mathrm{C}$. In correspondence to this temperature, clear peaks in the derivative of the mass loss curve were observed in all the mixtures, although some loss of the hygroscopic moisture also occurs around this temperature. Consistent with the XRD results the detection of ettringite from the TGA analyses was less clear in the case of the mixtures with $1.5 \%$ and $3 \%$ hydrated lime. 
The percentages of ettringite present in the various soil stabilizer mixtures were calculated from the area under the $55^{\circ} \mathrm{C}$ peak of the derivative of the mass loss curve obtained from the TGA test. A positive correlation was found between the total amount of calcium added and this area. No correlation, however, was found between the amount of ettringite, as measured by this area, and the final strain measured in the swelling tests. 


\section{CHAPTER 6. CONCLUSIONS AND RECOMMENDATIONS}

\subsection{Overview of Work}

The main objective of this research was to investigate the potential for "sulfateinduced heave" in coal mine spoils treated with calcium based stabilizers. There exist ample documentation in the literature of significant damage occurring as a result of this phenomenon particularly in the sulfate-rich soils present in the desert and semidesert southwestern United States. Extensive research conducted over the past 20 years indicates that the heave, which can lead to failure of the overlying pavement, is due to the formation of expansive minerals (ettringite and thaumasite) through the reaction of the sulfates and alumina present in the soil and the calcium coming from the stabilizers (e.g. lime and cement) used to improve the soil properties. Sulfate content, clay content, $\mathrm{pH}$, moisture, calcium content, and temperature are some of the factors that are known to affect the magnitude of the heave.

While the climatic conditions in Indiana are such that sulfates (which are highly soluble) are not commonly present in the soil, there exist, particularly in the southwestern counties of the State, areas where strip mining processes have left behind spoils which are likely to have high sulfate contents. Extensive development of the transportation infrastructure is expected in these regions in the coming years (e.g. I-69 construction and 
US 231 extension). This was the motivation for the research project funded through the Joint Transportation Research Program. This contains the main findings from this work. Several coal mine spoil samples from six different counties in Indiana were first obtained. Based on measurements of the sulfate content, one location, on the Hawthorn coal mine site in Sullivan County, was selected for additional sampling. Most subsequent investigations were conducted on spoil sampled from this site at a depth of $0.5-2 \mathrm{ft}$ (this sample is referred to throughout this as sample H1A), which had a sulfate content greater than $10,000 \mathrm{ppm}$, the critical threshold level above which significant swelling problems should be expected following treatment with calcium-based stabilizers (National Lime Association 2000).

Given the heterogeneous nature of the spoil samples and the presence of larger clods and aggregates, the spoil samples were homogenized in a large concrete mixer and went through a crushing and sieving process aimed at obtaining a subsample that could be compacted and tested in the laboratory. Through this screening process about $35-40 \%$ of the original sample was removed.

The experimental program conducted on the remaining spoil material both alone and after treatment with four different stabilizers included: $\mathrm{pH}$ tests, compaction tests, swelling tests, unconfined compression tests, as well as mineralogical/chemical tests.

The following calcium-based stabilizers were used: hydrated lime (i.e. $\mathrm{Ca}(\mathrm{OH})_{2}$ referred to as $\mathrm{HL}$ ), two types of quick lime (i.e. $\mathrm{CaO}$ : one industrial product referred to as QL, and one research grade analytical lime referred to as AL), and type I Portland cement (referred to as PC). These stabilizers are widely used in the state of Indiana. Dosages of $3 \%$ and $7 \%$ by mass of the dry soil were selected for all stabilizers (following $\mathrm{pH}$ fixation 
tests); for the hydrated lime additional tests were conducted with the following dosages: $1.5 \%, 5 \%$ and $9 \%$.

Compaction tests were conducted on all soil-stabilizer combinations using the Harvard miniature apparatus to determine the compaction curve and in particular the optimum water content. This apparatus was selected to minimize the amount of soil used and to accelerate the swelling process (controlled by the size of the specimen). Specimens compacted at optimum were then used for one-dimensional swelling tests using a simple custom built sand-bath setup. In this setup a 2.8 inch high and 1.3 inch diameter Harvard miniature specimen is housed in a cylindrical plastic mold and is surrounded by dense sand that is maintained saturated. In this manner access of water to the specimen is provided from all sides, while allowing deformation only in the vertical direction. A stainless steel top cap placed on top of the specimen provides the desired surcharge stress (for the majority of the tests a 0.3 psi surcharge stress was used). The vertical strains are measured through LVDTs connected to a data acquisition system and mounted on the side of a Plexiglas box in which the plastic cylindrical molds containing the specimens are positioned (the box can house eight cylinders). This box is maintained inside a Styrofoam environmental enclosure to limit temperature fluctuation over the measurement period, which was typically for one month.

At the end of the swelling tests, the pore fluid was extracted from the specimens for additional testing, while the solids were used to prepare samples for both x-ray diffraction (XRD) and thermal gravimetric analyses (TGA). These tests were conducted to investigate the mechanism responsible for the observed swelling. 
Swelling tests similar to those performed on the coal mine spoils were also performed on a local silty clay with negligible sulfate content, treated with quick lime to establish reference swelling behavior for a "non-problematic soil".

In addition to examining the effect of the various stabilizers on the swelling strains, the experimental program performed for this research also examined the role played by the surcharge stress, and explored the effectiveness of two mitigating techniques: pre-compaction mellowing and double lime treatment.

\subsection{Results and Conclusions}

The main conclusions that can be drawn from the swelling tests and chemical/mineralogical studies conducted on the coal mine spoil (H1A subsample)stabilizer mixtures investigated in this research can be summarized as follows:

- Sulfate induced swelling occurred in all soil-stabilizer mixtures. In all cases the final swelling strain (which ranged between 5.2\% and 12.1\%) exceeded the value measured on the untreated soil (equal to $4.3 \%$ ).

- These values of the strains are consistent with data for sulfate-rich soils treated with lime and cement presented in the literature (e.g. Puppala et al. 2005).

- Of all treated specimens those exhibiting the most significant swelling were those treated with $3 \%$ hydrated lime (swelling strain as large as $12.1 \%$ ), while the smallest swelling strains were measured for $1.5 \%$ hydrated lime (5.2\% strain) and Portland cement (7.1\% to $8.2 \%$ strain). 
- Tests, conducted by varying the dosage of hydrated lime over a significant range $(1.5 \%-9 \%)$, indicate an increase in the final swelling as the dosage of this stabilizer, is increased from $1.5 \%$ to $3 \%$ and a decrease of the strain with further addition of lime.

- The data for 3\% and 7\% Portland cement are consistent with those for the hydrated lime, i.e. greater swelling is observed with lower stabilizer addition. For the quick lime no significant difference is observed between the soil treated with 3\% and 7\% lime; while the results for the analytical lime show a slightly higher swelling for a dosage of $7 \%$.

- The development in time of the swelling is similar for all soil-stabilizer mixtures, and differed from that of the untreated soil. In the latter case, the final swelling strain is reached after less than 10 hours. For all soilstabilizer mixtures swelling is, instead, delayed, with approximately one month needed to reach the final swelling strain, and one week required for $50 \%$ of this strain to take place.

- In the soil-stabilizer mixtures, swelling can be attributed to the crystallization pressure that is exerted because of the formation of new phases as a result of one or more chemical reactions (see next point).

- XRD and TGA analyses confirm the presence of ettringite - an expansive mineral formed in presence of sulfate ions, alumina and calcium - in most of the soil-stabilizer mixtures. This is consistent with observations by other researchers for heave arising in other sulfate rich 
soils after treatment with lime and cement (in addition to ettringite, thaumasite has also been observed to form).

- The delay in the swelling observed in the treated specimens is thought to reflect the time required for the reaction to occur; the fact that initially the expansive reaction products can be accommodated inside the soil voids; and, finally, the fact that initially the expansive behavior may be compensated by the shrinkage that characterizes the setting phase.

- Further analysis of the TGA data indicates a correlation between the amount of ettringite detected (as measured by the area under the peak of the curve representing the first derivative with respect to temperature of the mass loss curve) and the amount of lime or cement added to the soil.

- No correlation, instead, could be established, between the amount of ettringite formed (and measured as above) and the strains measured in the swelling tests.

- In particular the fact that the greatest swelling strain was consistently measured in the mixture with $3 \%$ hydrated lime remains unexplained. In this case a minimal - if any - amount of ettringite was detected by both XRD and TGA. It is hypothesized that a poorly-crystallized ettringite is formed with low additions of calcium, i.e. 1.5 and $3 \%$ and thus, not all peaks of ettringite are visible in the XRD diffractograms. Such an observation has not been reported in the literature.

- The limited investigation of the role played by the surcharge stress $(0.3$ psi to $2.4 \mathrm{psi}$ ), conducted only for spoil treated with $3 \%$ hydrated lime, 
shows a decrease in the final swelling strain with increasing surcharge stress. This result is consistent with previous experiences reported in the literature. Note however, that for all surcharge stresses the final swelling strain exceeds the value measured on the untreated soil under the smallest surcharge.

- The tests conducted to investigate pre-compaction mellowing as a means to mitigate the effects of sulfate induced swelling indicate that this technique may prove effective provided that the mellowing period is sufficiently long. With 3\% and 7\% hydrated lime a mellowing period of 3 days and 2 days, respectively, was needed to produce final swelling strains comparable to those measured on the untreated soil.

- Unconfined compression tests indicate that as a result of mellowing the strength of the treated soil is partially compromised, although it continues to greatly exceed the value measured on the untreated soil.

- Double lime treatment was, instead, found to be ineffective as a mitigation technique. Tests conducted adding lime in two different stages $(3 \%$ and 4\%) separated by a mellowing period of 1 to 7 days indicated no significant reduction in the final swelling strain compared to the tests with single addition of $3 \%$ or $7 \%$ lime followed by a mellowing period (precompaction technique described above). This is likely due to the very high sulfate content of the spoil used in this research.

In conclusion, the results summarized above suggest that sulfate induced heave may be a concern in coal mine spoils. The great heterogeneity and variability of these 
materials indicate, however, that the lessons learned for the particular spoils examined in this research may not be directly extrapolated to all other coal mine spoils, which should, instead be evaluated on a case by case basis. Note for example, that most of the spoil sample examined in the preliminary stages of this work showed negligible sulfate contents. The methods described in this can be used for such an investigation.

\subsection{Recommendations}

This investigated sulfate induced heave in coal mine spoils treated with calcium based stabilizers by examining the swelling behavior of one particular spoil sample after treatment with both lime and cement.

While much has been learned as a result of this study, some aspects of the observed behavior remain unexplained and several issues must be addressed to improve the understanding of this phenomenon, as well as to extend the results to broader conditions. In light of this, recommendations for future work can be summarized as follows:

1. Further investigate in the laboratory the behavior of the Hawthorn mine spoil treated with small amounts of hydrated lime to assess whether swelling is indeed caused by the formation of a poorly-crystallized ettringite or whether one or more other minerals are responsible for the observed behavior. Microstructural tests, such as Scanning Electron Microscopy (SEM), might prove useful for such an investigation. 
2. Extend the research performed to include thermodynamic geochemical modeling of the materials involved in this research for better establishing the conditions supporting the formation of ettringite.

3. Extend the work performed to other spoils sampled in other areas of Indiana.

4. Perform larger scale swelling tests (not done in this research due to the limited amount of soil available).

5. Perform a field scale experiment for comparison to laboratory data. The Hawthorn mine site where samples were obtained for this research would be an ideal location for such an experiment. The field test should involve continuous monitoring of the deformations and sampling for laboratory tests.

6. The research presented in this was performed using fairly traditional testing methods. There exist today experimental apparatuses for more advanced study of unsaturated systems such as the compacted soils and soil-stabilizer systems examined in this research. Future research could benefit from these methods. In particular, it is suggested that the behavior of the soil both alone and treated with the various stabilizers be investigated in terms of their Soil Water Characteristic Curve (SWCC). 


\section{LIST OF REFERENCES}

AASHTO (1999). "Standard method of test for determining water-soluble sulfate ion content in soil.” Designation T 290 - 95.

Apte, N.G., Kiran, E., and Chernosky, J.V. (1988). "Thermal decomposition of aluminium-bearing compounds.” J. Thermal Analysis, 34(4), 975-981.

ASTM C 150 (2007). "Standard specification for Portland cement."

ASTM D 4318 (2005). "Standard test methods for liquid limit, plastic limit, and plasticity index of soils."

ASTM D 4546 (2003). "Standard test methods for one-dimensional swell or settlement potential of cohesive soils."

ASTM D 4972 (2001). "Standard test methods for pH of soils."

ASTM D 6276 (1999). "Standard test methods for using pH to estimate the soil-lime proportion requirement for soil stabilization."

Bonen, D. (2008). Personal communications.

de Araújo, J.H., da Silva, N.F., Acchar, W., and Gomes, U.U. (2004). “Thermal decomposition of illite." Materials Research, 7(2), 359-361.

Dermatas, D. (1995). "Ettringite-induced swelling in soils: State-of-the-art." Appl. Mech. Rev., 48(10), 659-673.

Eades, J.L. and Grim, R.E. (1966). "A quick test to determine lime requirements for lime stabilization.” Highway Res. Rec., No. 139, 61-72.

Ferris, G.A., Eades, J.L., Graves, R.E., and McClellan, G.H. (1991). “Improved characteristics in sulfate soils treated with barium compounds before lime stabilization." Transp. Res. Rec., No. 1295, 45-51.

Harris, J.P., Sebesta, S., and Scullion, T. (2004). "Hydrated lime stabilization of sulfatebearing vertisols in Texas." Transp. Res. Rec., No. 1868, 31-39. 
Hawlader, B.C., Lee, Y.N., and Lo, K.Y. (2003). "Three-dimensional stress effects on time-dependent swelling behaviour of shaly rocks." Canadian Geotech. J., 40, 501-511.

Highway research board. (1972). "Guide to compounds of interest in cement and concrete research.” Highway Research Board Special Report, No.127, 1-53.

Holtz, R.D. and Kovacs, W.D. (1981) An introduction to geotechnical engineering, Prentice-Hall, Inc., Upper Saddle River, NJ.

Hunter, D. (1988). "Lime-induced heave in sulfate-bearing clay soils." J. Geotech. Eng., 114(2), 150-167.

Hunter, D. (1989). "The geochemistry of lime-induced heave in sulfate-bearing clay soils." PhD dissertation, University of Nevada, Reno, NV.

Kinuthia, J.M., Wild, S., and Jones, G.I. (1999). "Effects of monovalent and divalent metal sulphates on consistency and compaction of lime-stabilized kaolinite." Applied Clay Science, 14(1-3), 27-45.

Kota, P.B.V.S., Hazlett, D., and Perrin, L. (1996). "Sulfate-bearing soils: problems with calcium-based stabilizers." Transp. Res. Rec., No. 1546, 62-69.

Little, D.N., Herbert, B., and Kunagalli, S.N. (2005). "Ettringite formation in lime-treated soils: Establishing thermodynamic foundations for engineering practice." Transportation Research Board 2005 Annual Meeting, No. 05-2239, Washington, D.C.

Livneh, M. and Livneh, N.A. (2002). "The Israeli guide for calculating the surcharge pressure required for pavement structures laid on swelling clay soils." 4th Transportation Specially Conference of the Canadian Society for Civil Engineering, Montréal, Québec.

Mitchell, J.K. (1986). "Practical problems from surprising soil behavior." J. Geotech. Eng., 112(3), 259-289.

Mitchell, J.K. (1993). Fundamentals of soil behavior, 2nd edition, John Wiley and Sons.

Mitchell, J.K., and Dermatas, D. (1992). "Clay soil heave caused by lime-sulfate reactions." Innovations and Uses for Lime, ASTM STP 1135, D.D. Walker, Jr., T.B. Hardy, D.C. Hoffman, and D.D. Stanley, Eds., Philadelphia, 41-64.

National Lime Association (2000). Testing memorandum: Guidelines for stabilization of soils containing sulfates, Arlington, VA.

National Lime Association (2001). Using lime for soil stabilization and modification: A proven solution!, Arlington, VA. 
Odler, I. and Jawed, I. (1991). "Expansive reactions in concrete.” Materials Science of Concrete Vol.2, edited by Skalmy, J. and Mindess, S., The American Ceramic Society, Inc., Westerville, $\mathrm{OH}, 221-247$.

Perrin, L.L. (1992). "Expansion of lime treated clays containing sulfates." Proc. 7th int. conf. on expansive soils, Dallas, TX, Vol. 1, 409-414.

Petry, T.M. (1994). "Investigation, analyses and recommendation for resolution of sulfate induced heave on SH-161 in Irving, Texas." Texas Transportation Institute Research Study 7-1994.

Petry, T.M. and Little, D.N. (1992). "Update on sulfate-induced heave in treated clays: Problematic sulfate levels.” Transp. Res. Rec., No. 1362, 51-55.

Puppala, A.J., Griffin, J.A., Hoyos, L.R., and Chomtid, S. (2004). "Studies on sulfateresistant cement stabilization methods to address sulfate-induced soil heave." J. Geotech. Geoenviron. Eng., 130(4), 391-402.

Puppala, A.J., Intharasombat, N., and Vempati, R.K. (2005a). "Experimental studies on ettringite-induced heaving in soils.” J. Geotech. Geoenviron. Eng., 131(3), 325-337.

Puppala, A.J., Viyanant, C., Kruzic, A.P., and Perrin, L. (2002). "Evaluation of a modified soluble sulfate determination method for fine-grained cohesive soils." Geotech. Test. J., 25(1), 85-94.

Puppala, A.J., Wattanasanticharoen, E., Vempati, R., and Hoyos, L.R. (2005b). "Experimental studies to address volume change behaviors of chemically treated sulfate bearing soils." Final Research Report, National Science Foundation Project (Project No. 0100255).

Research Institute of Indiana Univerisity, http://igs.indiana.edu/Geology/maps/coal/cmis/ index.cfm

Robert, B.F. and Rhinehammer, T.B. (1953). "Rapid precipitaion of barium sulfate." Analytical Chemistry, 25(10), 1544-1548.

Rollings, R.S., Burkes, J.P., and Rollings, M.P. (1999). "Sulfate attack on cementstabilized sand.” J. Geotech. Geoenviron. Eng., 125(5), 364-372.

Sherwood, P.T. (1962). "Effect of sulfates on cement- and lime-stabilized soils." Highway Research Board Bulletin, 353, 98-107.

Solomon, W. (2003). Progress report. 
Summer, M.E. (2000). Handbook of soil science, CRC Press, Boca Raton, FL.

Wang, L. (2002). "Cementitious stabilization of soils in the presence of sulfate." $P h D$ dissertation, Louisiana State University, Baton Rouge, LA.

West, T.R. (1995). Geology applied to engineering, Prentice Hall, Inc., Englewood Cliffs, NJ.

Wikipedia-strip mining, http://en.wikipedia.org/wiki/Strip_mining\#Strip_mining

Wild, S. Kinuthia, J.M., Jones, G.I., and Higgins, D.D. (1998). "Effects of partial substitution of lime with ground granulated blast furnace slag (GGBS) on the strength properties of lime stabilized sulphate-bearing clay soils." Engineering Geology, 51, 3753.

Wild, S. Kinuthia, J.M., Jones, G.I., and Higgins, D.D. (1999). "Suppression of swelling associated with ettringite formation in lime stabilized sulphate bearing clay soils by partial substitution of lime with ground granulated blast furnace slag (GGBS)." Engineering Geology, 51, 257-277.

Wild, S., Kinuthia, J.M., Robinson, R.B., and Humphreys, I. (1996). "Effects of ground granulated blast furnace slag (GGBS) on the strength and swelling properties of limestabilized kaolinite in the presence of sulphates." Clay Minerals, 31, 423-433.

Wilson, S.D. (1970). "Suggested method of test for moisture-density relations of soils using Harvard compaction apparatus." ASTM special technical publication 479, 101-103.

Yeskis, D., van Groos, A.F.K., and Guggenheim, S. (1985). "The dehydroxylation of kaolinite." American Minerologist, 70, 159-164. 


\section{Appendix A. ION CHROMATOGRAPHY AND INDUCTIVELY COUPLED PLASMA TESTS WITH SOIL STABILIZER MIXTURES}

Charge balance calculations based on the results of IC and ICP analysis are performed on hydrated lime mixtures. $[\mathrm{OH}]^{-}$ion concentrations are converted from $\mathrm{pH}$ measurement and $\left[\mathrm{SO}_{4}\right]^{2-}$ and $\mathrm{Cl}^{-}$ion concentrations are directly obtained from IC analysis. $\mathrm{Na}^{+}, \mathrm{K}^{+}, \mathrm{Ca}^{2+}, \mathrm{Al}^{3+}, \mathrm{Si}^{4+}$ and $\mathrm{S}$ ion concentrations are directly obtained from ICP analysis. Finally, charge balance with equivalent concentration of $\left[\mathrm{SO}_{4}\right]^{2-}$, which is converted from the concentration of $S$ using formula weight, and charge balance with $\left[\mathrm{SO}_{4}\right]^{2-}$ from IC analysis are summarized and compared in Table A.1.

Table A.1 Charge balances from IC and ICP for hydrated lime mixtures

\begin{tabular}{|c|c|c|c|c|c|}
\hline Mixtures & $\mathrm{pH}$ & $\mathrm{pOH}$ & $\begin{array}{c}{[\mathrm{OH}]^{-}} \\
{[\mathrm{mmol}]}\end{array}$ & $\begin{array}{c}\sum\left[\mathrm{SO}_{4}\right]^{2-} \\
{[\mathrm{mmol}]}\end{array}$ & $\begin{array}{c}\sum\left[\mathrm{SO}_{4}\right]_{\text {equiv }}^{2-} \\
{[\mathrm{mmol}]}\end{array}$ \\
\hline $\mathrm{HL} 1.5 \%$ & 9.06 & 4.95 & 0.21 & -20.09 & 3.61 \\
\hline $\mathrm{HL} \% \%$ & 8.88 & 5.12 & 0.10 & -14.11 & 2.25 \\
\hline $\mathrm{HL} \%$ & 9.09 & 4.91 & 0.34 & 14.83 & 14.09 \\
\hline HL7\% & 10.40 & 3.60 & 7.76 & 43.39 & 42.44 \\
\hline HL9\% & 9.21 & 4.79 & 0.63 & 35.84 & 34.40 \\
\hline
\end{tabular}

Note: $\sum\left[\mathrm{SO}_{4}\right]^{2-}=$ charge balance with $\left[\mathrm{SO}_{4}\right]^{2-}$ from IC analysis

$$
\sum\left[\mathrm{SO}_{4}\right]^{2-}=\text { charge balance with equivalent concentration of }\left[\mathrm{SO}_{4}\right]^{2-} \text { from }
$$

ICP analysis 
Charge balance calculations for the analytical lime, quick lime and Portland cement mixtures are performed based on the results of IC and ICP analysis. As mentioned above, charge balance with equivalent concentration of $\left[\mathrm{SO}_{4}\right]^{2-}$ from ICP analysis and charge balance with $\left[\mathrm{SO}_{4}\right]^{2-}$ from IC analysis are summarized and compared in Table A.2.

Table A.2 Charge balances from IC and ICP for analytical lime, quick lime and Portland cement mixtures

\begin{tabular}{|c|c|c|c|c|c|}
\hline Mixtures & $\mathrm{pH}$ & $\mathrm{pOH}$ & $\begin{array}{c}{[\mathrm{OH}]^{-}} \\
{[\mathrm{mmol}]}\end{array}$ & $\begin{array}{c}\sum\left[\mathrm{SO}_{4}\right]^{2-} \\
{[\mathrm{mmol}]}\end{array}$ & $\begin{array}{c}\sum\left[\mathrm{SO}_{4}\right]_{\text {equiv }}^{2-} \\
{[\mathrm{mmol}]}\end{array}$ \\
\hline \hline $\mathrm{AL3} \%$ & 9.26 & 4.74 & 0.41 & 8.66 & 4.48 \\
\hline $\mathrm{AL7 \%}$ & 10.25 & 3.76 & 5.66 & 53.79 & 51.62 \\
\hline $\mathrm{QL} 3 \%$ & 9.14 & 4.86 & 0.26 & 6.48 & 2.33 \\
\hline $\mathrm{QL} 7 \%$ & 10.95 & 3.05 & 18.09 & 17.39 & 16.78 \\
\hline $\mathrm{PC} \% \%$ & 8.95 & 5.05 & 0.19 & -1.05 & -3.56 \\
\hline PC7\% & 9.22 & 4.79 & 1.09 & 9.70 & -0.19 \\
\hline
\end{tabular}

Note: $\sum\left[\mathrm{SO}_{4}\right]^{2-}=$ charge balance with $\left[\mathrm{SO}_{4}\right]^{2-}$ from IC analysis

$$
\sum\left[\mathrm{SO}_{4}\right]^{2-}=\text { charge balance with equivalent concentration of }\left[\mathrm{SO}_{4}\right]^{2-} \text { from }
$$

ICP analysis 